\title{
Ultraschnelle, lichtinduzierte Primärprozesse im elektronisch angeregten Zustand des Grün Fluoreszierenden Proteins (GFP)
}

\author{
Dissertation \\ zur Erlangung des Doktorgrades \\ der Mathematisch-Naturwissenschaftlichen Fakultäten \\ der Georg-August-Universität zu Göttingen
}

vorgelegt von

Kathrin Winkler

aus Greifswald

Göttingen 2002 
D7

Referent: Prof. Dr. J. Troe

Korreferent: Prof. Dr. J. Schroeder

Tag der mündlichen Prüfung: 24.01.2003 


\section{Inhaltsverzeichnis}

$\begin{array}{ll}\text { Zusammenfassung } & 1\end{array}$

1 Einleitung 3

2 Stand der Forschung $\quad 7$

2.1 Struktur des GFP . . . . . . . . . . . . . . . . . . 7

2.2 Spektrale Eigenschaften des GFP . . . . . . . . . . . . . 9

2.2.1 Absorptions- und Emissionsverhalten . . . . . . . . . 9

2.2.2 Formen des GFP-Chromophors . . . . . . . . . . . . 10

2.3 Energieschema und Protonentransfer . . . . . . . . . . . . . 11

2.3.1 Zeitaufgelöste Fluoreszenzexperimente . . . . . . . . . . . 11

2.3.2 Frequenzaufgelöste Lochbrennspektroskopie . . . . . . . . 13

2.4 Protonentransfer und Struktur . . . . . . . . . . . . . . . . . 15

2.5 Dynamik im angeregten Zustand des GFP . . . . . . . . . . . . . 18

2.6 Theoretische Arbeiten . . . . . . . . . . . . . . . . . 22

3 Experimentelle Techniken 25

3.1 Lasersystem . . . . . . . . . . . . . . . . . . . 25

3.2 Optischer Parametrischer Verstärker . . . . . . . . . . . . . 29

3.3 Pump-Probe Absorptionsspektroskopie . . . . . . . . . . . . . . 35

3.3.1 Experimentelle Vorstudien . . . . . . . . . . . . . 35

3.3.2 Experimenteller Aufbau ............... . 37

3.3.3 Experimente zur Berechnung der Anisotropie . . . . . . . . 50

3.4 Differentielle Transmissionsspektren . . . . . . . . . . . . 51

3.5 Fluoreszenzkonversionsspektroskopie ............ . . 52

3.6 Zeitkorreliertes Einzelphotonenzählen . . . . . . . . . . . . 52

3.7 Absorptions- und Fluoreszenzspektren ... . . . . . . . . . . 54

3.8 Gewinnung des GFP . . . . . . . . . . . . . . . 55

4 Ergebnisse $\quad 57$

4.1 Zeitaufgelöste Pump-Probe-Signale . . . . . . . . . . . . . 57

4.2 Differentielle Transmissionsspektren . . . . . . . . . . . . . . 62

4.3 Zeitkorreliertes Einzelphotonenzählen . . . . . . . . . . 66 
4.4 Temperaturabhängige Messungen . . . . . . . . . . . . . . 68

4.5 Messungen der Schwingungsdynamik des GFP . . . . . . . . . . . 71

4.6 Messungen der Anisotropie . . . . . . . . . . . . . . . . . . . 73

4.7 Photokonversionsstudien . . . . . . . . . . . . . . . . 84

4.8 Pumpleistungsabhängigkeit . . . . . . . . . . . . . . . . 88

5 Diskussion $\quad 89$

5.1 Energetische Einordung der Ergebnisse . . . . . . . . . . . . . 89

5.2 Dynamisches Modell . . . . . . . . . . . . . . . . . . . 97

5.2.1 2-Niveau-Interkonversionsmodell . . . . . . . . . . . 97

5.2.2 Erweitertes dynamisches Modell . . . . . . . . . . . . . 101

5.2 .3 Dynamische Simulationen . . . . . . . . . . . . . 106

5.2.4 Vibrationsdynamiken in Proteinumgebungen . . . . . . . 114

6 Ausblick 117

6.1 Anisotropie ... . . . . . . . . . . . . . 117

6.2 Temperaturabhängigkeit . . . . . . . . . . . . . . . . . . 123

6.3 Photokonversion . . . . . . . . . . . . . . . . . 124

6.4 Multiexponentielle Dynamik . . . . . . . . . . . . . . . . . 125

6.5 Energietransfer . . . . . . . . . . . . . . . . . 125

$\begin{array}{ll}\text { Literaturverzeichnis } & 127\end{array}$

$\begin{array}{ll}\text { Abbildungsverzeichnis } & 137\end{array}$

$\begin{array}{ll}\text { Tabellenverzeichnis } & 141\end{array}$ 


\section{Zusammenfassung}

In der vorliegenden Arbeit werden Untersuchungen zu den photophysikalischen Prozessen des Grün Fluoreszierenden Proteins (GFP) vorgestellt, das aufgrund seiner langen Strahlungslebensdauer, seiner hohen Fluoreszenzquantenausbeute, sowie seiner großen Stabilität gegenüber Änderungen der Temperatur und der chemischen Umgebung als molekularbiologische Fluoreszenzsonde zahlreiche Anwendungen findet. Ziel der vorliegenden Arbeit ist es, ein tieferes Verständnis der ultraschnellen Primärprozesse im angeregten Zustand des GFP zu erlangen, um so seine Fluoreszenzeigenschaften erklären zu können. Dabei dient das GFP, dessen Chromophor in das Proteingerüst eingebettet und fester natürlicher Bestandteil des Proteins ist, als Modellsystem für das Studium der Dynamik eines Chromophors in einer Proteinumgebung. Derartige Untersuchungen sind interessant, weil über den Chromophor Rückschlüsse auf Proteindynamiken gezogen werden können.

Für diese Untersuchungen wurden zeit- und frequenzaufgelöste PumpProbe-Experimente durchgeführt, in denen die dynamischen Prozesse im angeregten Zustand des GFP innerhalb der ersten $100 \mathrm{ps}$ und eines weiten Spektralbereiches von 470 bis $730 \mathrm{~nm}$ mit einer Zeitauflösung von bis zu $60 \mathrm{fs}$ beobachtet wurden. Mit Hilfe von fluoreszenzspektroskopischen Untersuchungen, wie Fluoreszenzkonversions- und Einzelphotonenzählexperimenten (TCSPC), wurden das zeitliche Beobachtungsfenster bis etwa $50 \mathrm{~ns}$ ausgedehnt und die experimentellen Ergebnisse vervollständigt.

Diese Untersuchungen offenbaren nach Anregung mit ultraviolettem Licht einen relativ langsamen Protonentransfer auf einer Zeitskala von $10 \mathrm{ps}$ zwischen Chromophor, Aminosäureresten und Wassermolekülen innerhalb des GFP-Gerüsts. Es zeigt sich, dass zu frühen Zeiten (bis ca. 40 ps) eine starke Korrelation der Populationen der Reaktanden- und Produktzustände vorherrscht, die nach etwa $100 \mathrm{ps}$ infolge strahlungsloser Desaktivierung aufgehoben wird. Im zeitlichen Beobachtungsfenster bis in den Nanosekundenbereich wird ein multiexponentielles Zeitverhalten der Kinetiken beobachtet. 
Ein verallgemeinertes photophysikalisches Modell wird erarbeitet, welches eine Vielzahl experimenteller Befunde aus dieser und früheren Arbeiten quantitativ erklärt. Im Mittelpunkt dieses Modells stehen nichtreaktive Schwingungsrelaxationen des Chromophors, die mit dem elementaren Protonentransfer auf einer Zeitskala von ca. 20 ps konkurrieren. Darüberhinaus berücksichtigt das Modell einen strahlungslosen Desaktivierungskanal für den angeregten Zustand, der vermutlich über Torsionsbewegungen im Chromophor durch innere Konversion zurück in den Grundzustand führt ${ }^{1}$.

Das aufgestellte Modell erklärt die multiexponentielle Kinetik des Protonentransfers, den Isotopeneffekt, die Fluoreszenzkinetiken, sowie die Fluoreszenzquantenausbeute von etwa $85 \%$. Die hervorragende Übereinstimmung zwischen der Vielzahl experimenteller Ergebnisse und dem Modell belegt die Annahme, dass der Protonentransfer von nicht-reaktivem inter- und intramolekularen Schwingungsenergietransfer sowie innerer Konversion begleitet wird. Die hier vorgestellten dynamischen Prozesse im GFP haben Modellcharakter für ultraschnelle, lichtinduzierte Primärprozesse in Proteinen. 


\section{Kapitel 1}

\section{Einleitung}

Grün Fluoreszierende Proteine (GFP) können in einer Vielzahl biolumineszenter Coelenterata (Hohltiere) innerhalb des Stammes der Nesseltiere (Hydrozoa/Anthrazoa) gefunden werden ${ }^{2}$. Sie wurden erstmals von Shimomura und Mitarbeitern bei der Untersuchung der Biolumineszenz der Qualle Aequorea aequorea entdeckt ${ }^{3,4}$. Die schirmartig erscheinende Qualle besitzt an ihrem Rand Organe, die aus mehr als 120 kleinen Körnchen bestehen und das charakteristische grüne Licht emittieren (Abbildung 1.1). Eine hypsochrome Verschiebung der Emission nach Extraktion des Proteins wies darauf hin, dass für das Auftreten einer grünen Fluoreszenz mehr als nur ein Protein verantwortlich sein muss. Aus der Qualle Aequorea aequorea konnten schließlich das Protein Aequorin und ein weiteres, das Grün Fluoreszierende Protein (GFP) extrahiert werden. Beide Proteine können unter natürlichen Bedingungen nur als gemeinsamer Komplex die für das GFP charakteristische grüne Fluoreszenz erzeugen. ${ }^{1}$

Alle natürlich vorkommenden Grün Fluoreszierenden Proteine emittieren Licht in einem Wellenlängenbereich von $490-520 \mathrm{~nm}$. Die meisten weisen ein Emissionsmaximum bei $508-509 \mathrm{~nm}$ auf. Die Absorptionsmaxima der jeweiligen Spezies variieren jedoch stärker $(395-498 \mathrm{~nm})^{2}$. Das einzige im ultravioletten Spektralbereich $\left(\lambda_{\max }=398 \mathrm{~nm}\right)$ absorbierende, natürlich vorkommende GFP ist das der Qualle Aequorea Victoria ${ }^{7}$. Dieses kann durch Klonierung und Expression in größeren Mengen hergestellt werden ${ }^{8,9}$ und ist daher das Grün Fluoreszierende Protein, welches bisher am detailliertesten untersucht wurde.

\footnotetext{
${ }^{1}$ Der Mechanismus, der zur Erzeugung der grünen Fluoreszenz führt, sollte dabei über den Energietransfer von Aequorin auf GFP stattfinden. Nach Ward und Mitarbeitern wird die Biolumineszenz des Aequorins, die ein Maximum bei $460 \mathrm{~nm}$ hat und einen weiten Spektralbereich einschließt (bis über $600 \mathrm{~nm}$ ), vom GFP absorbiert, das dann die dazu relativ schmalbandige grüne Fluoreszenz emittiert ${ }^{5,6}$. Konzentrationsabhängige Studien haben jedoch gezeigt, dass der Energietransfer über Emission und Absorption von Strahlung nur bei sehr hohen Konzentrationen effizient ist, die jedoch in der Qualle nicht vorliegen können. Daher gewinnt der strahlungslose Energietransfer (Förster-Energietransfer) nach derzeitigen Vorstellungen mehr Bedeutung, was unter anderem auf die experimentelle Voraussage eines effizienteren Energietransfers bei Verringerung der Distanz zwischen Donor und Akzeptor basiert ${ }^{7}$.
} 


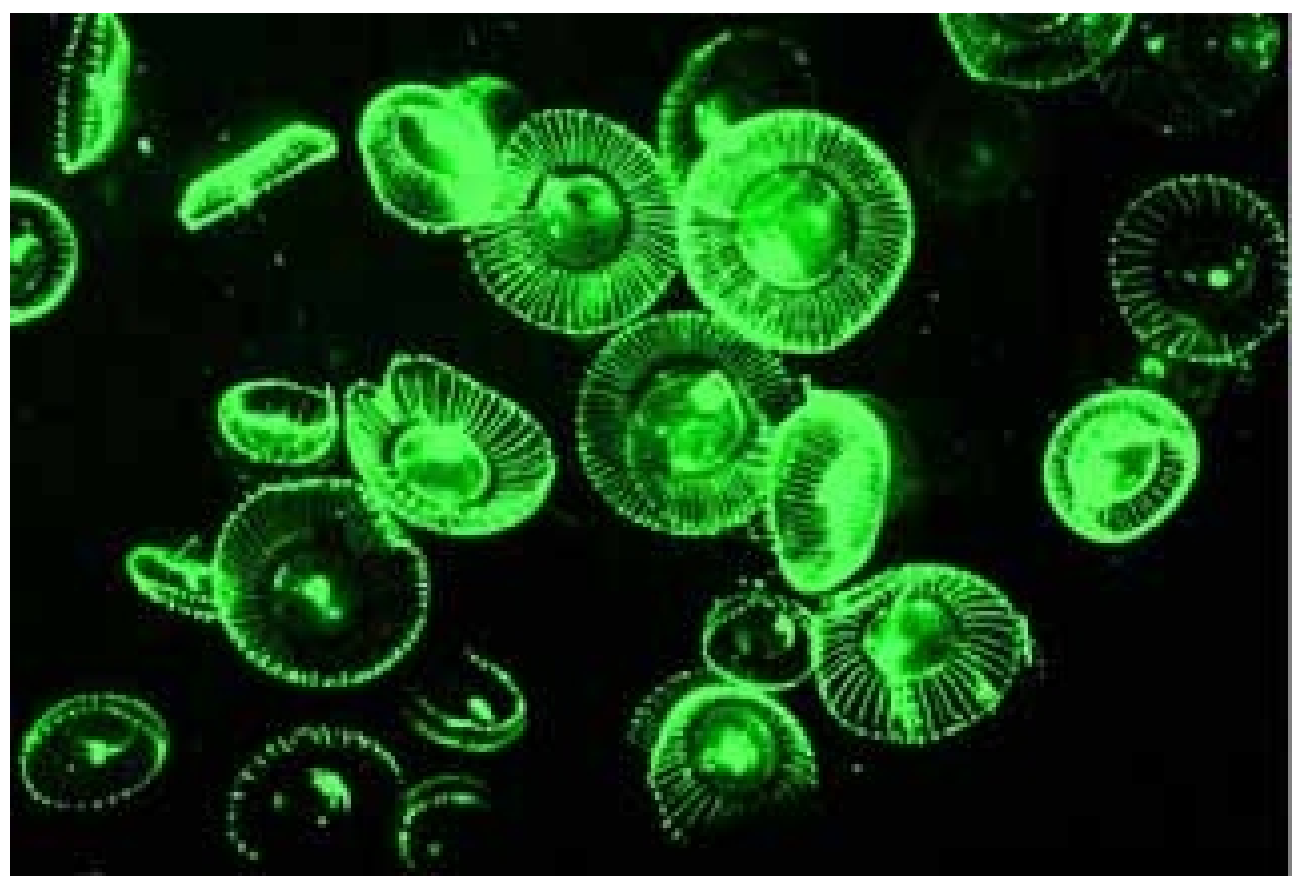

Abbildung 1.1: Qualle Aequorea aequorea nach Shimomura et al. ${ }^{2}$

Aufgrund seiner Struktur ${ }^{10,11}$ ist das GFP gegenüber der Veränderung chemischer und physikalischer Bedingungen im Vergleich zu anderen Proteinen relativ stabil und weist deshalb ohne Beteiligung von Kofaktoren ausgezeichnete Fluoreszenzeigenschaften auf. Aus diesem Grund ist es für vielfältige Applikationen interessant. So kann die Expression von Genen mit GFP als Marker beobachtet ${ }^{9}$, sowie die Proteinlokalisierung in lebenden Zellen verfolgt werden ${ }^{12}$. Desweiteren dient GFP und seine Mutanten, die sich unter anderem bezüglich ihres Absorptions- und Emissionsverhaltens voneinander unterscheiden, als Fluorophore für strukturbiologische Untersuchungen z. B. an DNA oder Proteinen mit Hilfe von Fluoreszenz-Resonanz-Energie-Transfers (FRET) zwischen GFP-Paaren ${ }^{12,13}$. Über die Effizienz des FRET können beispielsweise Protein-Proteinwechselwirkungen in vivo und in vitro studiert werden $^{14,15,16,17,18,19,20}$. Belmont konnte die Untersuchung von Chromosomdynamiken mit GFP demonstrieren ${ }^{21}$. Desweiteren können Proteindynamiken über das Photoausbleichen des GFP und die Beobachtung der Wiederkehr der Fluoreszenz untersucht werden ${ }^{22,23,24}$. GFP kann auch als Metallionen-spezifische Sonde verwendet werden. Die Komplexierung der Metallionen mit GFP führt dabei zur Fluoreszenzlöschung des GFP (quenching) ${ }^{25,26}$. Kürzlich haben Cinelli et al. gezeigt, dass eine Mutante des GFP als optisch kontrollierbares Element in der Bioelektronik unter Ausnutzung unterschiedlicher Emissionseigenschaften bei Anregung mit verschiedenen Energien eingesetzt werden kann $^{27}$. 
Dieser exemplarische Einblick in die Anwendungsmöglichkeiten des GFP zeigt, wie vielfältig sein Einsatz und wie groß seine Bedeutung in Biologie, Chemie, Physik und Medizin ist. Eine gezielte Anwendung dieses Proteins erfordert jedoch das detaillierte Verständnis seiner photophysikalischen Eigenschaften.

Mit strukturanalytischen Methoden konnte eine zylinderförmige Struktur des GFP nachgewiesen werden, in dessem Inneren ein Chromophor über kovalente und Wasserstoffbrückenbindungen an das Proteinrückgrat gebunden ist ${ }^{10,11}$. Der Einschluss des Chromophors in diesen Zylinder $(\beta$-can) ist für das charakteristische Absorptions- und Emissionsverhalten des Proteins verantwortlich. Umfangreiche Absorptions- und Emissionsspektroskopische Studien ${ }^{28,29,30,5}$ unter Veränderung der chemischen und physikalischen Bedingungen des gelösten GFP führten dabei zu der Erkenntnis, dass mindestens zwei Formen des GFP-Chromophors im thermodynamischen Gleichgewicht stehen, die sich bezüglich ihres Protonierungsgrades und ihrer Struktur unterscheiden. Studien des Emissionsverhaltens des GFP wiesen schließlich auf einen Protonentransfer im elektronisch angeregten Zustand hin. Erste zeitaufgelöste Methoden konnten die Zeitskala des Protonentransfers festlegen und zudem eine differenziertere Vorstellung der energetischen Struktur des Chromophors im GFP entwickeln ${ }^{31,32}$. Demnach existieren drei unterschiedliche Konformere des Chromophors sowohl im elektronischen Grundzustand als auch im elektronisch angeregten Zustand ${ }^{33}$. Diese Konformere entsprechen der neutralen Form des Chromophors, der anionischen sowie einer intermediären Form. Letztere korrespondiert einer strukturell nicht-relaxierten anionischen Konformation. Nach diesem Modell findet der Protonentransfer im elektronisch angeregten Zustand zwischen der neutralen Form und der Intermediärform statt. Strukturelle Studien liefern Modelle $^{34,35}$, nach denen der Protonentransfer zwischen Chromophor, Proteinrückgrat und inneren Wassermolekülen erfolgt. Aus verschiedenen zeitaufgelösten, spektroskopischen Untersuchungen ${ }^{31,32,36,37,38,39,40,41,42,43,44,45}$ konnten Einsichten in die Kinetik des Protonentransfers gewonnen werden. Dabei wiesen einige dieser Studien darauf hin, dass die Kinetik des Protonentransfers ein starkes multiexponentielles Verhalten aufweist. Strahlungslose Desaktivierung über innere Konversion kann dabei ebenfalls eine Rolle spielen, wie aus Untersuchungen verschiedener Mutanten des GFP sowie theoretischen Berechnungen von Modellchromophoren hervorging $46,47,48,49,50$.

Trotz einer Vielzahl zeit- und frequenzaufgelöster experimenteller Studien, sowie theoretischer Untersuchungen ${ }^{51,52,53,54,55}$, fehlt derzeit ein detailliertes Verständnis der Dynamik im angeregten Zustand des GFP. Dies umfasst die Mechanismen und Zeitskalen des Protonentransfers und der ihn begleitenden Prozesse. Im speziellen sollen die Ursachen für die in verschiedenen Arbeiten beobachtete multiexponentielle Kinetik aufgeklärt werden ${ }^{32,56,31,36}$. Für ein umfassendes Verständnis dieses höchst komplexen Proteins ist die genaue zeitliche und spektrale Charakterisierung der Vorgänge im angeregten Zu- 
stand notwendig. In dieser Arbeit werden dazu zeit- und frequenzaufgelöste Pump-Probe-Experimente sowie fluoreszenzspektroskopische Untersuchungen auf Zeitskalen von wenigen 10 fs bis zu mehreren Nanosekunden vorgestellt. Diese sollen dazu beitragen, ein Verständnis für die ultraschnellen, lichtinduzierten Primärprozesse im angeregten Zustand des GFP zu entwickeln.

In Kapitel 2 wird ein detaillierter Überblick über die Ergebnisse früherer Untersuchungen zum GFP gegeben. Darin werden die Struktur des GFP und die entwickelten energetischen Modelle eingeführt. Desweiteren wird hier eine strukturelle Vorstellung des Protonentransfers vermittelt, sowie auf verschiedene dynamische Prozesse im angeregten Zustand des GFP eingegangen. In Kapitel 3 werden die experimentellen Techniken erklärt. Diese umfassen das verwendete Kurzpulslasersystem, den optischen parametrischen Verstärker und die Entwicklung eines Pump-Probe-Experimentes, das die flexible Messung von zeit- und frequenzaufgelösten Experimenten erlaubt. Dabei wird im speziellen auf die Verbesserung des Signal-Rausch-Verhältnisses durch Implementierung von Referenzund rapid-scan-Technik eingegangen. In Kapitel 4 sind die wichtigsten zeit- und frequenzaufgelösten Ergebnisse dargestellt, mit denen ein in Kapitel 5 beschriebenes erweitertes dynamisches Modell entwickelt wird. Dies bildet den Kernpunkt dieser Arbeit. Darüberhinaus wird in Kapitel 4 ausführlich auf das Anisotropieverhalten des GFP und die Empfindlichkeit der Dynamik gegenüber Photokonversion eingegangen. Die Arbeit schließt mit Kapitel 6, in dem das Anisotropieverhalten detailliert diskutiert wird und ein Ausblick auf zukünftige Studien am GFP gegeben wird. 


\section{Kapitel 2}

\section{Stand der Forschung}

\subsection{Struktur des GFP}

Das Grün Fluoreszierende Protein (GFP) besteht aus 238 Aminosäuren, die zu $11 \beta$-Faltblättern, einer $\alpha$-Helix sowie kürzeren $\alpha$-helikalen Segmenten miteinander verknüpft sind ${ }^{14}$. Diese Strukturelemente sind, wie in Abbildung 2.1 gezeigt, so angeordnet, dass die $\beta$-Faltblätter einen Zylinder bilden $(\beta$-can), in dessen Inneres die $\alpha$-Helix zeigt. Dieser Zylinder besitzt eine so hohe Symmetrie, dass sich Wassermoleküle außerhalb des Zylinders zu Strängen (stripes) anordnen $^{57}$. Im Zentrum des Zylinders befindet sich der Chromophor des GFP, 4-(p-Hydroxybenzyliden)-imidazolin-5-on, der am Ende der $\alpha$-Helix angebracht ist.

Das Grün Fluoreszierende Protein kristallisiert nicht als Monomer sondern als Dimer. Die Kontaktflächen des Dimers bestehen aus hydrophoben Seitenketten und einer Vielzahl hydrophiler Seitenketten. Der kleinere hydrophobe Teil vermittelt vermutlich die Assoziation des GFP mit Aequorin in der Meeresqualle Aequorea Victoria ${ }^{57}$. Auch in wässriger Lösung wird Dimerisierung beobachtet, die Dissoziationskonstante beträgt etwa $100 \mu \mathrm{M}^{57,14}$.

Die Kristallstruktur des GFP wurde unabhängig von Yang et al. ${ }^{11}$ und Ormö et al. ${ }^{10} 1996$ gelöst und verfeinert. Jedes zylindrische Monomer hat danach einen Durchmesser von $30 \AA$ und eine Länge von $40 \AA$. Nach massenspektrometrischen Studien hat das GFP-Monomer eine molare Masse von $26836.1 \mathrm{~g} / \mathrm{mol}^{11}$.

Der Chromophor, 4-(p-Hydroxybenzyliden)-imidazolin-5-on, ist in Abbildung 2.2 gezeigt. Er wird autokatalytisch durch oxidative Zyklisierung der drei Aminosäuren Serin 65, Tyrosin 66 und Glycin 67 der GFP-Aminosäuresequenz gebildet $^{14}$. Ohne auf diese Reaktion einzugehen, führt sie zu der Ausbildung eines $\pi$-Elektronen-Systems, das über den gesamten Chromophor delokalisiert ist. Hervorzuheben ist die azide Hydroxybenzylidengruppe. Spektrophotometrische Titration des GFP ergab einen $p K_{a}$-Wert in Guanidin- $\mathrm{HCl}$ von $8.1^{6}$. 


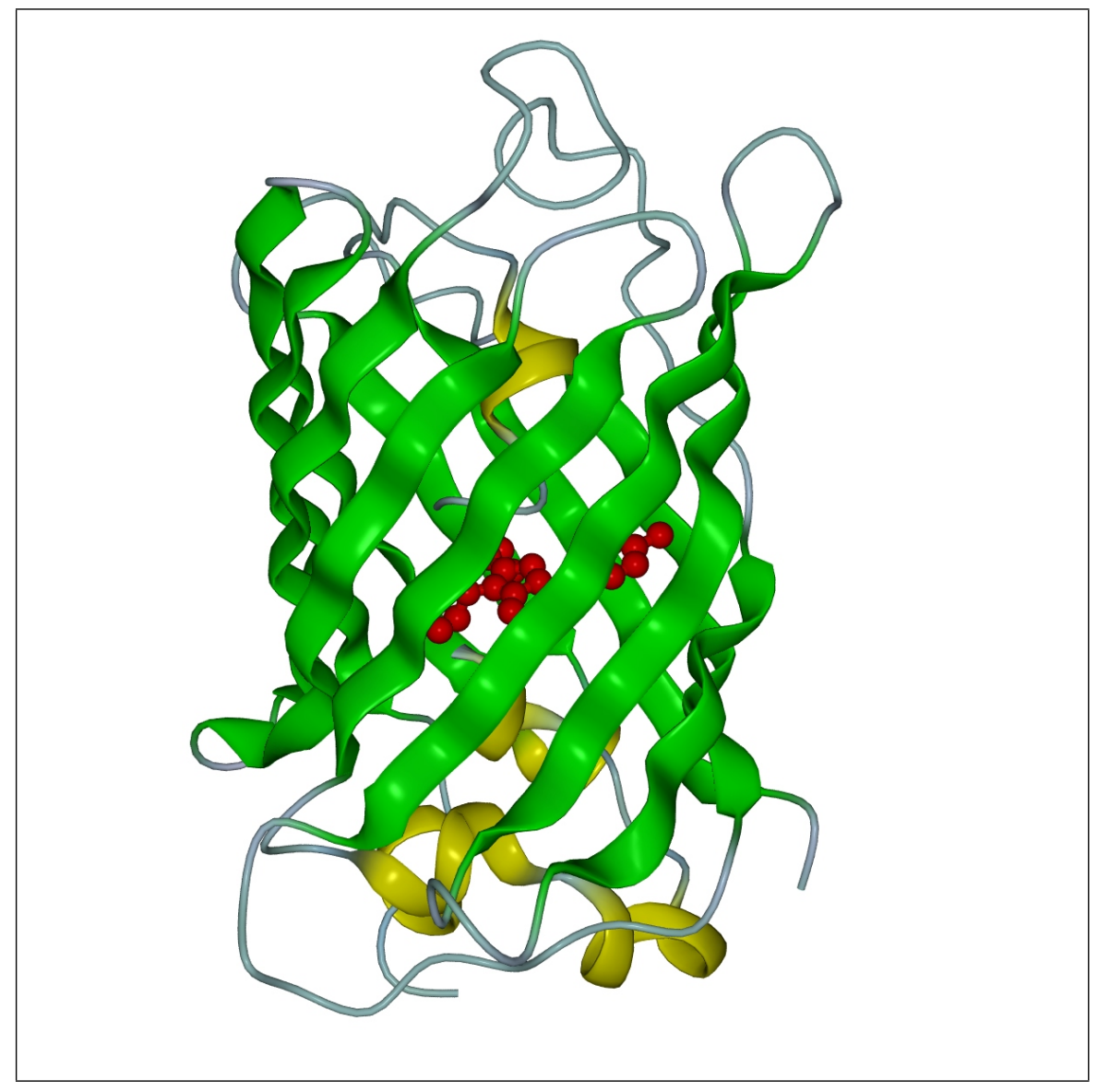

Abbildung 2.1: Kristallstruktur des GFP nach 11,58

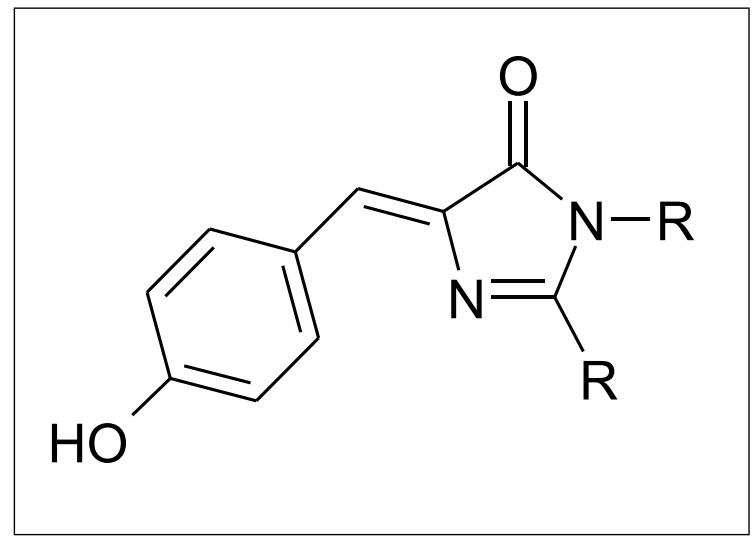

Abbildung 2.2: Chromophor des GFP

Die nähere Umgebung des Chromophors im Protein (Abstand weniger als $5 \AA$ ) ist von geladenen Aminosäureresten und Wasser geprägt. Diese sind so angeordnet, dass sich ein weit verzweigtes Wasserstoffbrückennetzwerk zwischen Chromophor 
und Aminosäureresten bzw. Chromophor und Wassermolekülen ausbildet. Seine weitere Umgebung (Abstand größer als $10 \AA$ ) ist sowohl durch apolare als auch durch polare Aminosäurereste gekennzeichnet. Die Gesamtstruktur des Proteins schirmt den in seinem Zentrum eingebetteten Chromophor von äußeren Einflüssen ab, die seine photchemischen und photophysikalischen Eigenschaften beeinflussen könnten. So wird verhindert, dass reaktive Moleküle zum Chromophor diffundieren und dass seine Fluoreszenz durch Stoßdesaktivierung unterdrückt wird (collisional quenching).

\subsection{Spektrale Eigenschaften des GFP}

\subsubsection{Absorptions- und Emissionsverhalten}

Das Absoptionsspektrum des GFP in wässriger Phosphatpufferlösung $(p H=7)$ zeigt im sichtbaren und ultravioletten Spektralbereich drei Absorptionsbanden (Abbildung 2.3). Die Banden mit Maxima bei $\lambda=398 \mathrm{~nm}$ und $\lambda=478 \mathrm{~nm}$ werden von elektronischen Resonanzen des Chromophors hervorgerufen. Die Absorptionsbande bei $\lambda=278 \mathrm{~nm}$ entspricht einer Überlagerung der Absorptionen von aromatischen Aminosäuren des GFP, wie Phenylalanin, Tyrosin und Tryptophan $^{32}$. Der Extinktionskoeffizient der Bande bei $\lambda=398 \mathrm{~nm}$ beträgt $\varepsilon \approx 30000 \mathrm{l} / \mathrm{mol} \mathrm{cm}$, während der der niederenergetischen Bande $(\lambda=478 \mathrm{~nm})$ $\varepsilon \approx 7000 \mathrm{l} / \mathrm{mol} \mathrm{cm} \mathrm{beträgt}{ }^{11}$.

Ein Fluoreszenzspektrum des GFP ist in Abbildung 2.3 als graue Kurve dargestellt. Es wurde bei einer Anregungswellenlänge von $\lambda_{\text {exc }}=400 \mathrm{~nm}$ aufgenommen. Das Emissionsmaximum liegt bei $\lambda=508 \mathrm{~nm}$ und weist eine Schulter um $\lambda=545 \mathrm{~nm}$ auf. Im Bereich um $450 \mathrm{~nm}$ erscheint außerdem eine äußerst kleine Schulter, die nur bei 20-facher Vergrößerung des Fluoreszenzspektrums in Abbildung 2.3 sichtbar wird.

Wird im Bereich der niederenergetischen Bande $\left(\lambda_{\mathrm{exc}}=478 \mathrm{~nm}\right)$ angeregt, verschiebt sich das Fluoreszenzmaximum um etwa $4 \mathrm{~nm}$ zu kürzeren Wellenlängen $\left(\lambda_{\max }=504 \mathrm{~nm}\right)$. Außerdem ist das Emissionsspektrum breiter als bei Anregung mit $\lambda_{\text {exc }}=400 \mathrm{~nm}$. 


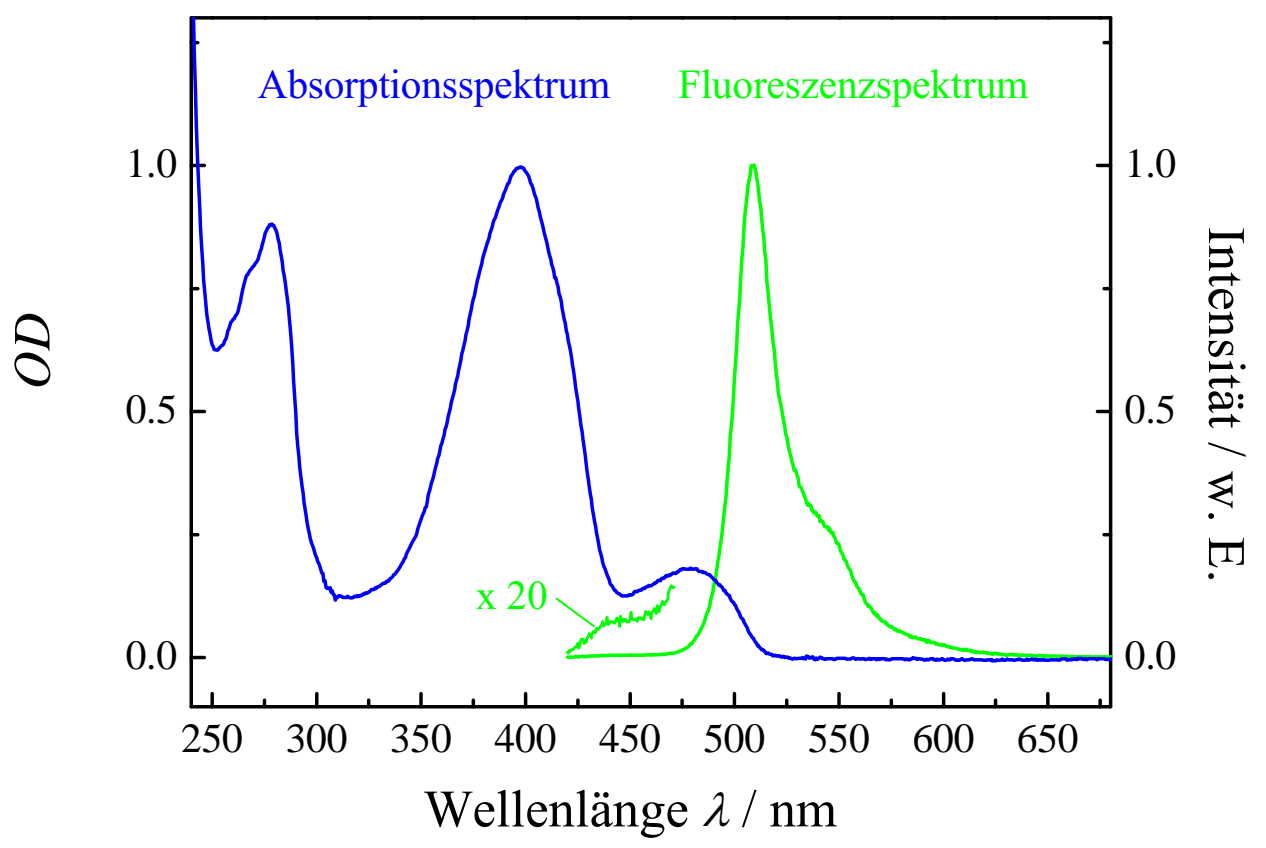

Abbildung 2.3: Absorptions- und Fluoreszenzspektrum $\left(\lambda_{\mathrm{exc}}=400 \mathrm{~nm}\right)$ von GFP, das in einer wässrigen Phosphatpufferlösung mit $p H=7$ gelöst ist. Gezeigt ist auch die Schulter des Fluoreszenzspektrums bei $450 \mathrm{~nm}$ als 20 -fache Vergrößerung.

\subsubsection{Formen des GFP-Chromophors}

Das Grün Fluoreszierende Protein zeichnet sich nicht nur durch seine hohe Fluoreszenzquantenausbeute (85-100\% je nach Anregungswellenlänge) aus, sondern auch durch seine Stabilität gegenüber Variation der Temperatur, des pH-Wertes (etwa 4-10) oder der Ionenstärke des Lösungsmittels. GFP in wässriger Lösung denaturiert in einem Temperaturintervall von $1-65^{\circ} \mathrm{C}$ nicht. Erst bei einer Temperatur von $78^{\circ} \mathrm{C}$ ist die Fluoreszenz auf die Hälfte ihrer ursprünglichen Intensität gesunken ${ }^{28}$. Allerdings ändert sich das Absorptionsspektrum: Mit höherer Temperatur steigt die Absorption der Bande bei $\lambda=478 \mathrm{~nm}$, während die bei $\lambda=400 \mathrm{~nm}$ gleichzeitig sinkt. Bei etwa $\lambda=430 \mathrm{~nm}$ erscheint im temperaturabhängigen Absorptionsspektrum ein isosbestischer Punkt ${ }^{28}$. Ähnliches wird bei Veränderung des pH-Wertes oder der Ionenstärke beobachtet. Mit kleinerem pH-Wert oder höherer Ionenstärke wächst die Absorption der Bande bei $\lambda=400 \mathrm{~nm}$, während sie bei $\lambda=478 \mathrm{~nm}$ fällt. Auch in diesem Falle tritt ein isosbestischer Punkt bei $430 \mathrm{~nm}$ auf ${ }^{28}$. 
Diese Experimente zeigen, dass der Chromophor in zwei verschiedenen Formen vorkommt, die sich bezüglich ihres Protonierungsgrades unterscheiden und miteinander im Gleichgewicht stehen ${ }^{28}$. Die Existenz eines isosbestischen Punktes im Absorptionsspektrum des GFP beweist diesen Schluss. Wegen der beschriebenen Abhängigkeit des Spektrums vom pH-Wert der Lösung entspricht die höherenergetische Bande der Absorption einer neutralen Form (A) des Chromophors, während die niederenergetische Bande eine anionische (B) repräsentiert.

In diesem Zusammenhang fällt auf, dass sich die beiden Emissionsspektren, die bei Anregung in der höher- und niederenergetischen Absorptionsbande aufgenommen werden, wie in Abschnitt 2.2.1 beschrieben, nur geringfügig voneinander unterscheiden. Das Fluoreszenzmaximum bei Anregung von A ist um etwa $100 \mathrm{~nm}$ relativ zur Absorptionsbande von A verschoben, während die Emission bei Anregung von B lediglich um $25 \mathrm{~nm}$ bezüglich des B-Absorptionsmaximums versetzt ist. Die relativ große Stokes-Verschiebung der Fluoreszenz bei A-Anregung im Vergleich zu der bei B-Anregung wurde in früheren Arbeiten als Indiz dafür genommen, dass erstere nicht aus $\mathrm{A}^{*}$ (erster elektronisch angeregter Zustand), sondern aus dem angeregten Zustand $\mathrm{B}^{*}$ der anionischen Form resultiert. Voraussetzung dafür ist ein Protonentransfer zwischen $A^{*}$ und $B^{*}$. Diese Annahme wird durch Photokonversionsstudien unterstützt. Sie haben gezeigt, dass die Absorptionsbande der neutralen Form A bei Bestrahlung des GFP mit ultraviolettem Licht $(\lambda=400 \mathrm{~nm})$ sinkt, während die Absorption der niederenergetischen Bande (anionische Form B) steigt. Offen bleibt jedoch die Frage, warum sich die Emissionsspektren je nach Anregungswellenlänge geringfügig unterscheiden.

\subsection{Energieschema und Protonentransfer}

\subsubsection{Zeitaufgelöste Fluoreszenzexperimente}

Zeitaufgelöste Experimente können in der Beantwortung der im vorherigen Abschnitt aufgeworfenen Frage, warum sich die Emissionsspektren bei Anregung der neutralen oder anionischen Form um $4 \mathrm{~nm}$ unterscheiden, sehr nützlich sein. So wurden unabhängig voneinander zeitaufgelöste, fluoreszenzspektroskopische Untersuchungen von Chattoraj et al. ${ }^{31}$ und Lossau et al..$^{32}$ durchgeführt. In diesen Experimenten wurde jeweils in den beiden Absorptionsbanden des GFP-Chromophors angeregt und die Kinetik der Fluoreszenz bei verschiedenen Wellenlängen aufgezeichnet. Die Fluoreszenzkonversionsexperimente von Chattoraj et al. ${ }^{31}$ hatten dabei die höhere Zeitauflösung (FWHM (Kreuzkorrelation $)=160 \mathrm{fs}$ ) und lieferten daher zuverlässigere Daten bezüglich ultraschneller Dynamiken, die der Emission eines Photons vorgelagert sind. Es wurden folgende Phänomene beobachtet: Unmittelbar nach Anregung der neutralen Form A bei $\lambda=400 \mathrm{~nm}$ (Abbildung 2.4), erscheint eine Emission um $\lambda=460 \mathrm{~nm}$. Diese 
klingt innerhalb von 80 ps auf 1/10 des Signalmaximums ab. Wird im Maximum des stationären Emissionsspektrums bei $508 \mathrm{~nm}$ detektiert, so wächst das Emissionssignal auf einer Zeitskala von mehreren zehn Pikosekunden langsam an und klingt innerhalb des Detektionsfensters von 120 ps nicht ab. Wird nun lediglich die Anregungswellenlänge auf $\lambda=478 \mathrm{~nm}$ geändert, d. h. die anionische Form B angeregt (Abbildung 2.4), so erscheint dieses Signal deutlich schneller als zuvor. Bei Wiederholung dieser Experimente mit deuterierten GFP-Lösungen, wird ausschließlich bei den ersten beiden Experimenten ein Isotopeneffekt festgestellt. Das heißt, das Zeitverhalten bei Anregung der neutralen Form $\left(\lambda_{\text {exc }}=400 \mathrm{~nm}\right)$ verlangsamt sich, während die Kinetik bei Anregung der anionischen Form $\left(\lambda_{\text {exc }}=478 \mathrm{~nm}\right)$ keine Veränderung bei Deuterierung zeigt.

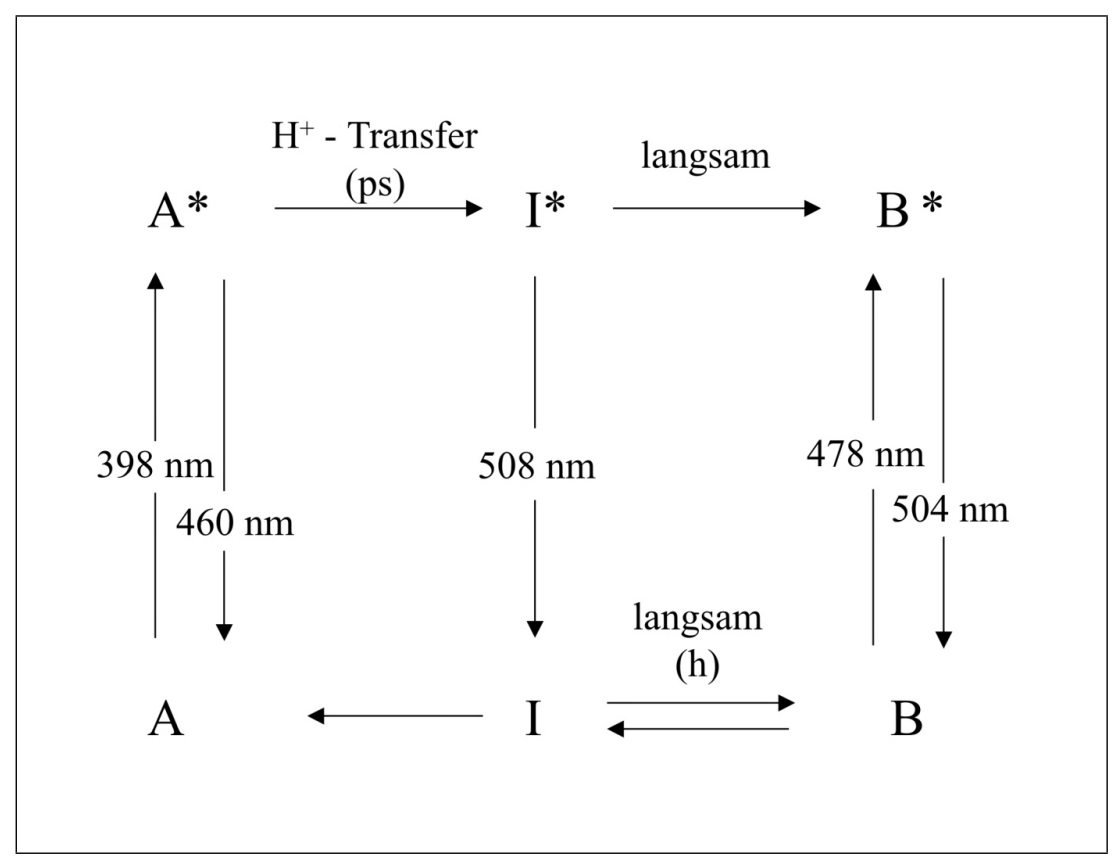

Abbildung 2.4: Energieniveauschema nach Chattoraj et al. ${ }^{31}$

Die aus Anregung der neutralen Form des Chromophors resultierenden Kinetiken, sind daher mit einem Protonentransfer im angeregten Zustand verbunden. Diese Reaktion und anschließende Emission einer anionischen Form ist im Vergleich zur Photokonversion von der neutralen Form A in die anionische Form B sehr schnell ${ }^{31}$. Chattoraj et al. schlossen hieraus, dass die Emission, die bei Anregung der höherenergetischen Bande $\left(\lambda_{\text {exc }}=400 \mathrm{~nm}\right)$ detektiert wird, nicht aus der anionischen Form B, sondern aus einem angeregten Intermediärzustand I* erfolgt $^{31}$. Abbildung 2.4 zeigt das angenommene Energieniveauschema. Die Wellenlängen entsprechen dabei den Maxima der in der vorliegenden Arbeit beobachteten stationären Absorptions- und Emissionsspektren bei Zimmertemperatur (siehe Abschnitt 2.2.1, mit Ausnahme der Emission aus A*). Die Emission bei 
$\lambda=460 \mathrm{~nm}$ entspricht demnach der Emission aus dem angeregten Zustand $\mathrm{A}^{*}$ der neutralen Form, während die Emission bei $\lambda=508 \mathrm{~nm}$ aus dem durch Protonentransfer populierten angeregten Intermediärzustand I* erfolgt. Der Intermediärzustand wird als strukturell nicht-äquilibrierte anionische Form betrachtet, d. h. die Elektronenkonfiguration entspricht der anionischen Form B, während sie strukturell der neutralen Form A ähnelt. Lossau et al. ${ }^{32}$ kamen innerhalb ihrer kinetischen Studien zu einem ähnlichen Energieniveauschema, allerdings schließt diese Arbeit die irreversible Photokonversion zur Ausbildung einer weiteren Form $\mathrm{X}$ ein $\left(\right.$ siehe $\left.^{32}\right)$.

Untersuchungen der Temperaturabhängigkeit des pumpinduzierten Signals bei $460 \mathrm{~nm}$ zeigen $^{31}$, dass das Abklingverhalten der Emission aus der neutralen Form bei $\lambda=460 \mathrm{~nm}$ mit sinkender Temperatur langsamer wird. Bei $85 \mathrm{~K}$ wird in dem beobachteten Zeitfenster von etwa 30 ps kein Abklingen, sondern ein Ansteigen der Emission beobachtet. Daraus wurde geschlossen, dass zwischen den angeregten Zuständen $\mathrm{A}^{*}$ und I* eine Barriere vorliegen sollte ${ }^{31}$.

\subsubsection{Frequenzaufgelöste Lochbrennspektroskopie}

Spektrale Lochbrennexperimente von Creemers et al. ${ }^{33}$ lieferten einen weiteren Beleg für das in Abbildung 2.4 dargestellte Schema. In dieser Arbeit wurde der Intermediärzustand nachgewiesen, die vibronische Struktur der Grundund angeregten Zustände analysiert und die elektronischen 0-0-Übergänge der drei Spezies bestimmt. Für den Nachweis einer dritten Form I* wurden zunächst sowohl die neutrale Form A als auch die anionische Form B mit Laserlicht bei einer Probentemperatur von $T=1.6 \mathrm{~K}$ illuminiert und so spektral ausgeblichen. In beiden Fällen erschien nach dem Ausbleichen der Absorptionsbande der jeweiligen Form (A oder B) bei etwa 490-495 nm ein lokales Maximum. Wurde jede dieser Proben mit einer Wellenlänge von $495 \mathrm{~nm}$ angeregt, konnte ein Emissionsspektrum detektiert werden, das quantitativ mit dem übereinstimmte, das bei Anregung mit $400 \mathrm{~nm}$-Laserlicht erhalten wird. Die nach dem Ausbleichen beider Banden (A oder B) enstehende neue Form ist daher mit derjenigen identisch, die nach A-Anregung emittiert. Diese wurde von Chattoraj et al. mit I* bezeichnet. Obwohl ein Ausbleichen von B zur Bildung des Grundzustandes von I führt, kann eine Emission aus I* nicht detektiert werden. Dieser Befund deutet an, dass B* strahlungslos nach I zerfallen kann. Ausgehend von $\mathrm{A}^{*}$ verläuft dagegen die Konversion zu I über dessen angeregten Zustand I*33.

Des Weiteren wurden in Lochbrennexperimenten die 0-0-Übergänge aller Spezies zu $\lambda\left(\mathrm{A}_{0-0}\right)=434 \mathrm{~nm}, \lambda\left(B_{0-0}\right)=477 \mathrm{~nm}$ und $\lambda\left(\mathrm{I}_{0-0}\right)=495 \mathrm{~nm}$ bestimmt. Durch Vergleich von Emissions- und Anregungsspektren bei $1.6 \mathrm{~K}$ in Abhängigkeit der Anregungswellenlänge bzw. Detektionswellenlänge konnten die Schwingungsfeinstrukturen der einzelnen Spezies nachgewiesen werden. Creemers et al. leiteten aus ihren Ergebnissen das in Abbildung 2.5 dargestellte Ener- 
gieniveauschema ab. Darin sind die Grund- und angeregten Zustände der drei Formen A, I und B gezeigt sowie deren 0-0-Übergänge und die entsprechenden Schwingungszustände mit Energien in reziproken Zentimetern eingezeichnet.

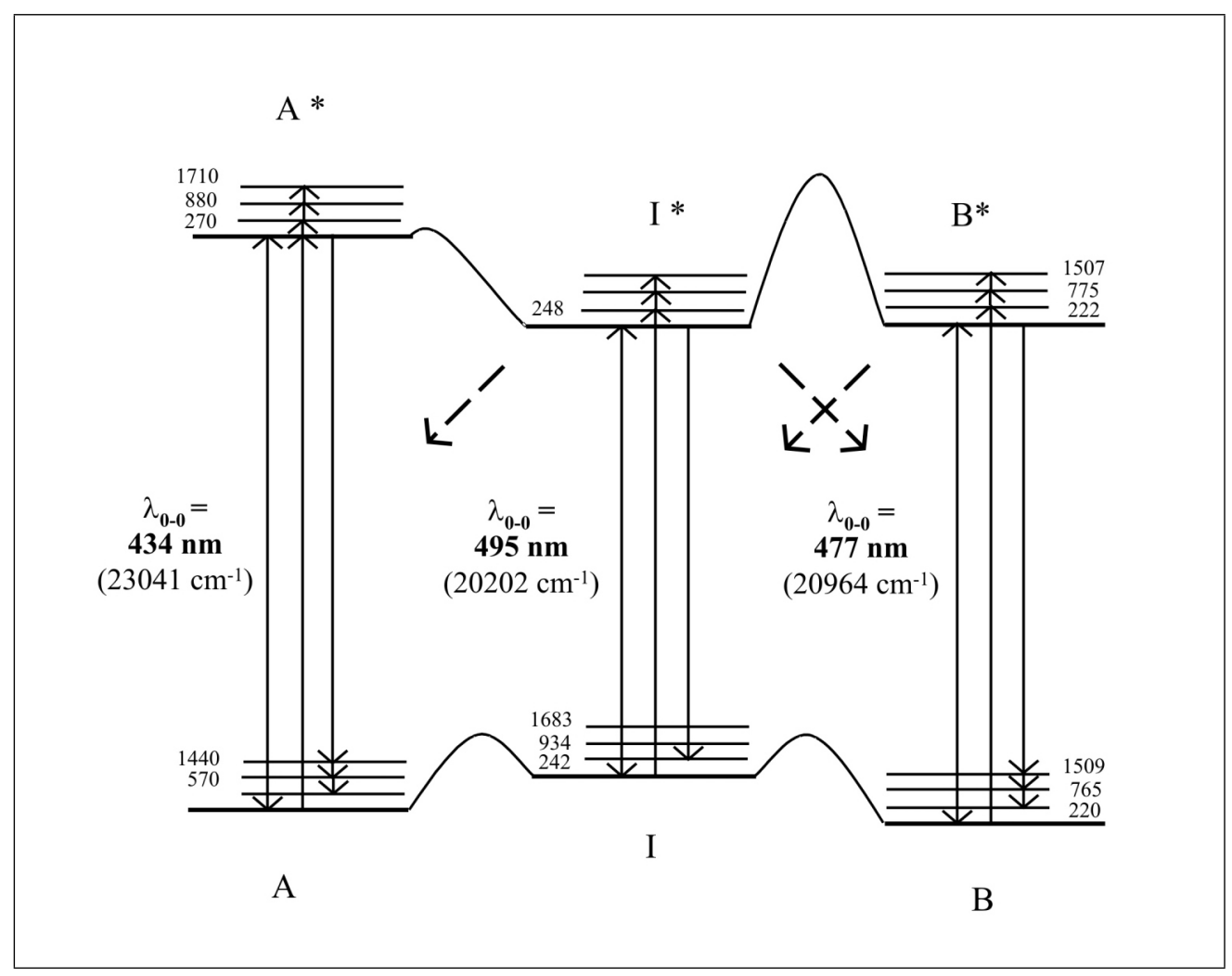

Abbildung 2.5: Energieniveauschema nach Creemers et al. ${ }^{33}$. Die Energiezustände der Schwingungsniveaus sind in reziproken Zentimetern angegeben.

Da der Intermediärzustand bei tiefen Temperaturen $T=1.6 \mathrm{~K}$ nicht und bei Zimmertemperatur nur wenig populiert ist, liegt der Grundzustand dieser Intermediärform energetisch höher als die Grundzustände von $A$ und $\mathrm{B}^{33}$. Um zu bestätigen, dass der Intermediat-Grundzustand I bei Zimmertemperatur tatsächlich populiert ist und dass die rote Flanke des Absoptionsspektrums in Abbildung 2.3 anteilig der I-Form entspricht, wurde bei $298 \mathrm{~K}$ mit Licht der Wellenlänge $495 \mathrm{~nm}$ angeregt. Es wurde ein Emissionsspektrum detektiert, das bei $508 \mathrm{~nm}$ maximal war und damit dem entsprach, das bei Anregung der neutralen Form A erhalten wurde ${ }^{33}$.

Da die Anregung der anionischen Form keine Emission aus I* bewirkt, kann von einer relativ grossen Barriere von mindestens $2000 \mathrm{~cm}^{-1}$ ausgegangen werden. Die Barrierenhöhen zwischen I und A bzw. I und B wurden von Creemers et al. zu einigen hundert reziproken Zentimetern abgeschätzt ${ }^{33}$. 


\subsection{Protonentransfer und Struktur}

Der Vergleich der durch Röntgendiffraktometrie gewonnenen Kristallstrukturen eines GFP Monomeren mit einer Mutante des GFPs (S65T) lieferte Brejc et al. ${ }^{59}$ das Fundament zur Entwicklung einer strukturellen Vorstellung des Protonentransfers im GFP.

Mutanten des GFP sind Proteine, bei denen oft in der Umgebung des Chromophors Aminosäurereste oder funktionelle Gruppen durch andere ersetzt sind. So weist die Mutante S65T an der 65. Stelle der Aminosäuresequenz des WildtypGFP (wt-GFP) kein Serin sondern Threonin auf. Dieser Unterschied führt dazu, dass S65T nur eine Absorptionsbande bei $489 \mathrm{~nm}$ besitzt und der Chromophor lediglich in der anionischen Form vorliegt ${ }^{10}$. Protonentransfer und Photokonversion werden auf diese Weise unterbunden, da das Wasserstoffbrückenbindungsnetzwerk zwischen Chromophor und Aminosäureresten sowie Wasser unterbrochen ist. Basierend auf dem Vergleich der Strukturen des wt-GFP und der S65T-Mutante wird in der Arbeit von Brejc et al. das duale Absorptionsverhalten und die Photoisomerisierung des wt-GFP diskutiert. Dabei bestimmt die röntgenstrukturanalytisch gemessene Wildtypstruktur des wt-GFP die Form des Chromophors, die bei $400 \mathrm{~nm}$ absorbiert (A). Die S65T-Struktur repräsentiert in dieser Arbeit die bei $477 \mathrm{~nm}$ absorbierende Form des Chromophors (B) im wt-GFP. Abbildung 2.6 zeigt die Strukturen der neutralen und anionischen Formen sowie die des Intermediärzustands. Die neutrale Form A zeichnet sich durch ein Wasserstoffbrückenbindungsnetzwerk zwischen Glutamat 222 (Glu222), dem Wassermolekül W22 und Serin 205 (Ser205) aus. Das Wassermolekül ist wiederum mit der Hydroxylgruppe des Chromophors (grün in Abbildung 2.6) über Wasserstoffbrückenbindungen verknüpft.

Die Transformation in die anionische Form verläuft über den hypothetischen Intermediärzustand I. Dieser Zustand ist durch den Protonentransfer (siehe Abbildung 2.6) auf das Glutamat charakterisiert. Das Proton wird dabei vom phenolischen Ende des Chromophors über Serin 205 und Wasser W22 auf das Glutamat übertragen und damit die Protonierungsgrade aller beteiligten funktionellen Gruppen verändert. Der Chromophor wird auf diese Weise an der Hydroxygruppe von Tyrosin 66 deprotoniert. Die Stabilisierung des ionisierten Zustands wird über W22 sowie die Histidin-148-Seitenkette (His148) über Wasserstoffbrückenbindungen zum Phenolat erreicht.

Weitere Stabilisierung des anionischen Zustands und die damit verbundene Ausbildung der anionischen Form B erfolgt über die Wasserstoffbrückenausbildung der Seitenkette des Threonin 203 (oberes Ender der Kette von Threonin 203 in Abbildung 2.6) zum Phenolatsauerstoff des Chromophors. Dadurch werden neue Wasserstoffbrückenbindungen geknüpft und alte gebrochen. Beispielsweise verschwindet die zwischen Serin 205 und Glutaminsäure 222, wodurch die Konformationsänderung der Hydroxylgruppe von der anti- zur energetisch günstigeren syn-Stellung stattfindet. Diese Konformationsänderung ist ein im 


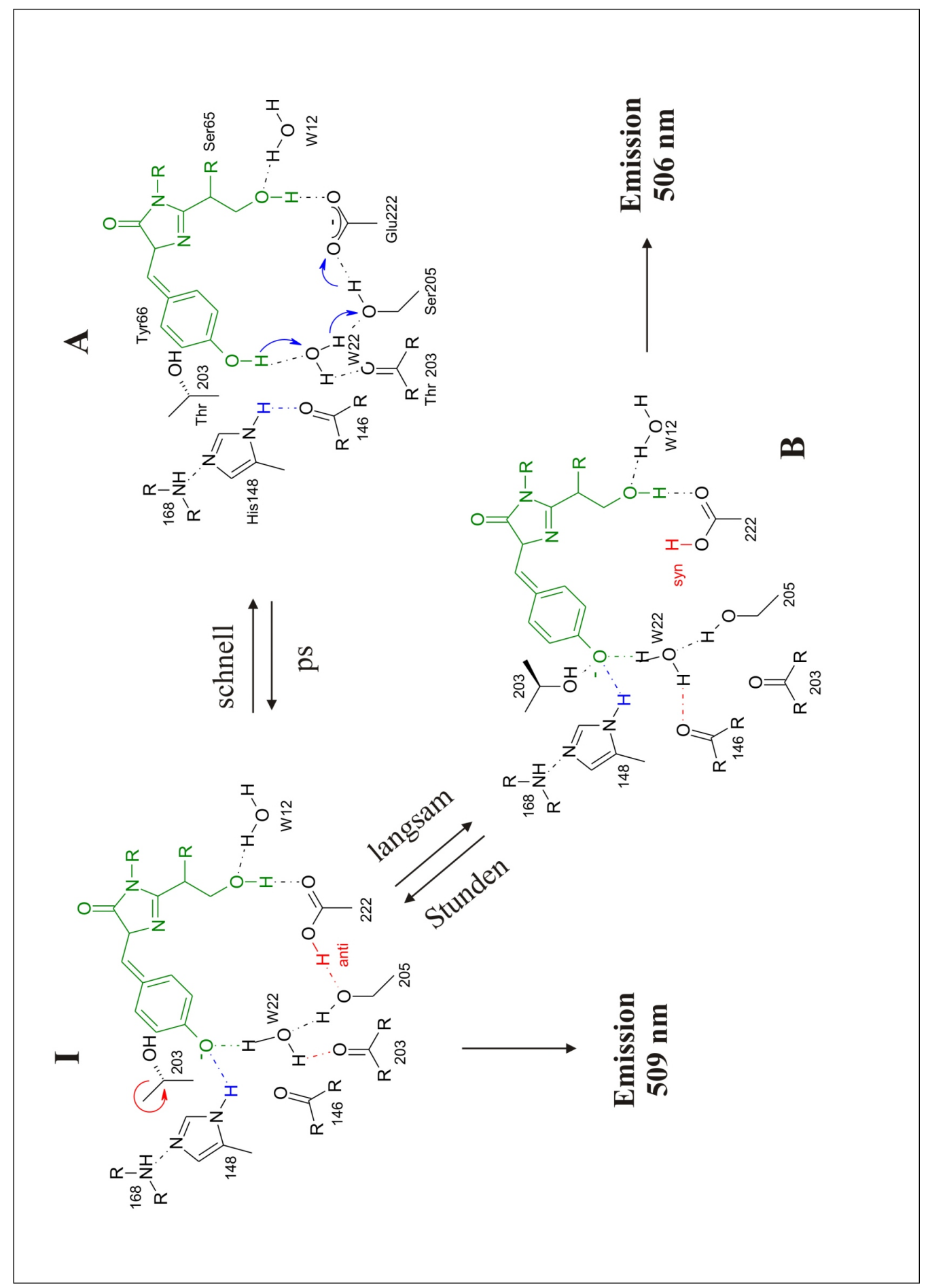

Abbildung 2.6: Prinzip des Protonentransfers nach kristallographischen Untersuchungen von Brejc et al. ${ }^{59}$. Die Emissionswellenlängen wurden dieser Arbeit entnommen. 
Vergleich zum Protonentransfer langsamer und wahrscheinlich weniger häufig stattfindender Prozess ${ }^{59}$.

Gemäß dieser Vorstellung ist ein ausgeprägtes Wasserstoffbrückennetzwerk für einen effizienten Protonentransfer von entscheidender Bedeutung. Eine Modifikation dieses Netzwerkes sollte die Dynamik des Protonentransfers ganz entscheidend beeinflussen. In der Tat beobachtet man für die Mutante S65T nur eine rotverschobene Absorptionsbande, die darauf hindeutet, dass der Chromophor nur in der anionischen Form vorliegen kann. Ein ProtonRücktransfer auf den Chromophor kann vermutlich nicht erfolgen, weil in S65T die Wasserstoffbrücke zwischen Glu 222 und Ser 205 fehlt. Nach Brejc et al. unterstützen diese Unterschiede die Bedeutung des Glutamats Glu 222 für den Protonentransfer und die Ausbildung der thermodynamisch stabilen anionischen Form des Chromophors im wt-GFP. Die im wt-GFP kristallographisch ermittelte Elektronendichteverteilung am Thr 203 legt den Schluss nahe, dass dieser Rest in zwei Konformationen existiert. Mit einer Wahrscheinlichkeit von $15 \%$ zeigt die Hydroxylgruppe in Richtung des Phenolatsauerstoffs des Chromophors unter Ausbildung einer Wasserstoffbrücke. Demgegenüber wendet sich der OH-Rest des Threonins mit 85\% Wahrscheinlichkeit vom Phenolat ab. Interessanterweise entspricht das Verhältnis der Konformerenwahrscheinlichkeit von 1:6 genau dem Verhältnis der Absorbanzen von anionischer und neutraler Form bei Zimmertemperatur ${ }^{59}$.

Van Thor et al. ${ }^{34}$ schlossen aus Photokonversionsstudien, dass das Glutamat 222 während des Protonentransfers nicht protoniert wird. Dies wird dadurch begründet, dass das FT-IR-Differenzspektrum nicht die Bande einer protonierten Glu-Carboxylgruppe zeigt. Stattdessen wird angenommen, dass das Glutamat 222 beim Protonentransfer nur kurzzeitig protoniert wird, das Wasserstoffbrückenbindungsnetzwerk jedoch prinzipiell erhalten bleibt. Das Proton wird über eine Kette von wasserstoffverbrückten Wassermolekülen von Glu 222 nur in die Volumenwasserphase geleitet. Fragwürdig bleibt jedoch, wie eine solche Vorstellung das energetische Modell aus den Abbildungen 2.4 und 2.5 sowie die beobachteten Dynamiken $^{31,32}$ erklären kann. Kürzlich untersuchten van Thor et al. die Photokonversion des GFP mittels massenspektrometrischen und ESR-Experimenten. Darüberhinaus wurde die Kristallstruktur des photokonvertierten GFP untersucht. Nach diesen Studien kommt es während der Photokonversion zur Decarboxylierung des Glutamats $222^{35}$. Dieses Ergebnis steht daher in starkem Widerspruch zu früheren Arbeiten von Breijc et al. ${ }^{59}$. 


\subsection{Dynamik im angeregten Zustand des GFP}

Die dynamischen Primärprozesse im elektronisch angeregten Zustand des GFP wurden bereits in Abschnitt 2.3.1 kurz beschrieben. Zeitaufgelöste fluoreszenzspektroskopische Experimente ${ }^{32,31}$ haben gezeigt, dass die Dynamik von der Anregungs- und Abfragewellenlänge abhängig ist. Die Ergebnisse von Chattoraj et al. und Lossau et al. deuten darauf hin, dass die Emission, die bei Anregung der neutralen Form detektiert wird, von zwei verschiedenen Zuständen ausgeht. Fluoreszenzlicht um $460 \mathrm{~nm}$ erfolgt aus $\mathrm{A}^{*}$ aus, während Licht längerer Wellenlängen in $\mathrm{I}^{*}$ ihren Ursprung hat. Das Abklingen der Emission bei $460 \mathrm{~nm}$ sowie der Fluoreszenzanstieg um $510 \mathrm{~nm}$ ist in beiden Fällen multiexponentiell. Wenn die anionische Form B angeregt wird, so beobachtet man ein ein innerhalb der Zeitauflösung instantanes Anstiegsverhalten der Emission bei $508 \mathrm{~nm}$, das von der Deuterierung des GFP unbeeinflusst bleibt ${ }^{31}$. Die Emissionen aus I* und $\mathrm{B}^{*}$ klingen auf einer Zeitskala von mehreren Nanosekunden monoexponentiell ab, während für die Fluoreszenz aus $A^{*}$ auf einer kürzeren Zeitskala multiexponentielles Verhalten beobachtet wird. Die Tabellen 2.1 und 2.2 zeigen die Anstiegs- und Abklingzeiten, die aus multiexponentiellen Anpassungen der Signale von Chattoraj ${ }^{31}$ et al. und Lossau et al. ${ }^{32}$ bei verschiedenen Anregungsund Abfragewellenlängen hervorgingen. Aufgeführt sind auch die Ergebnisse bei Deuterierung der Probelösung. Alle Daten wurden diesen Arbeiten entnommen.

Da die Signale bei Anregung mit Licht von $\lambda=400 \mathrm{~nm}$ einen Isotopeneffekt aufweisen, müssen die Zustände $\mathrm{A}^{*}$ und $\mathrm{I}^{*}$ von der Protonenbewegung direkt betroffen sein. Die Emission aus dem direkt angeregten anionischen Zustand $\mathrm{B}^{*}$ ist demgegenüber nicht von der Deuterierung beeinflusst und wird daher nicht mit dem Protonentransfer verbunden. Das multiexponentielle Verhalten der Emissionen aus $\mathrm{A}^{*}$ und $\mathrm{I}^{*}$ wird von Lossau et al. ${ }^{32}$ durch strukturelle Heterogenitäten erklärt. Demnach liegt eine strukturell statistische Verteilung von Wasserstoffbrückennetzwerken vor, in dem der Chromophor eingebettet ist $^{32}$. Da nun jede Struktur zu einem etwas anderen zeitlichen Verhalten des Protonentransfers führt, kann die experimentell beobachtete Kinetik nicht mehr monoexponentiell sein. Lossau et al. beobachteten, dass die Emission aus A* multiexponentiell bleibt, wenn eine Mutante des GFP untersucht wird, bei der der Protonentransfer unterbunden ist. Diese Beobachtung wird mit der strukturellen Reorganisation des Chromophors erklärt und mit einer starken Änderung des Dipolmomentes von A im wt-GFP belegt. Von Chattoraj et al. wurde dies zu $\Delta \mu=20 \mathrm{D}$ bestimmt $^{31}$.

Die Fragestellung, inwiefern strukturelle Reorganisationen bei der Dynamik im angeregten Zustand des GFP eine Rolle spielen, wurde von Kummer et al. ${ }^{36}$ eingehender untersucht. Die Autoren dieser Arbeit untersuchten durch Vergleich von Absorptions- und Anregungsspektren verschiedene Mutanten bezüglich ihrer Fluoreszenzquantenausbeute, sowie die Kinetik ihrer Emission. Während die Fluoreszenzquantenausbeute der neutralen Form beim wt-GFP 85 - 90 \% beträgt, 
kann sie bei verschiedenen Mutanten auf bis zu $10 \%$ (Mutante RST203Y) sinken. Diese geringe Quantenausbeute einer Spezies lässt zusätzliche strahlungslose Desaktivierungsprozesse wie die innere Konversion (IC) vermuten ${ }^{36}$. Die Studie zeigt weiterhin, dass die Fluoreszenzquantenausbeute der Mutante RST203Y bei niedrigen Temperaturen steigt. Desweiteren wird ein deutlich schnelleres Abklingverhalten der Emission von $A^{*}$ dieser Mutante beobachtet (mittlere Abklingzeit von $\mathrm{A}^{*} 10 \mathrm{ps}$ ) als beim wt-GFP (mittlere Abklingzeit von $\left.\mathrm{A}^{*} 150 \mathrm{ps}\right)^{32,36}$. Bei einer Temperatur von $80 \mathrm{~K}$ wird jedoch eine mittlere Abklingzeit von $300 \mathrm{ps}$ bei der Mutante RST203Y erreicht. Diese temperaturabhängigen Phänomene sprechen dafür, dass innere Konversion umso effizienter und schneller stattfindet, je mehr Konformationsfreiheit der Chromophors besitzt. Diese Erkenntnis führte zu der Annahme, dass im angeregten Zustand eine Torsionsbewegung um die Einfachbindung, die die beiden Ringe des Chromophors verbindet (Abbildung 2.2) stattfindet, die von der inneren Konversion in den Grundzustand gefolgt ist. Dies wurde durch den Vergleich des Chromophors mit ähnlichen Molekülen, wie Stilben, photoactive yellow protein (PYP) oder Rhodopsin, unterstützt. Bei tiefen Temperaturen ist nach Kummer et al. ${ }^{36}$ diese Torsionsbewegung eingefroren. Auch die innere Konversion sollte von strukturellen Heterogenitäten abhängig sein und ist daher durch eine nichtexponentielle Kinetik charakterisiert ${ }^{36}$.

\begin{tabular}{|c|c|c|c|c|}
\hline & Anregung/nm & Emission/nm & Amplitude $A_{i}$ & $\tau_{i} / \mathrm{ps}$ \\
\hline \multirow{6}{*}{ 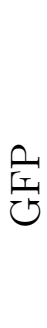 } & & & 0.5 & 3.6 \\
\hline & 398 & 460 & 0.4 & 12.0 \\
\hline & & & 0.1 & 120.0 \\
\hline & 398 & 508 & -0.24 & 2.2 \\
\hline & & & -0.43 & 8.1 \\
\hline & 478 & 508 & -0.06 & 1.9 \\
\hline \multirow{5}{*}{$\stackrel{\ominus}{\stackrel{1}{\prime \prime}}$} & 398 & 460 & 0.46 & 22.0 \\
\hline & & & 0.54 & 116.0 \\
\hline & 398 & 508 & -0.16 & 8.2 \\
\hline & & & -0.49 & 46.0 \\
\hline & 478 & 508 & -0.07 & 1.9 \\
\hline
\end{tabular}

Tabelle 2.1: Zeitkonstanten aus exponentiellen Anpassungen $(F(t)=$ $\left.\sum_{i} A_{i} e^{-t / \tau_{i}}\right)$ an die Fluoreszenzsignale aus Arbeiten von Chattoraj et al. ${ }^{31}$ bei Zimmertemperatur. Deuterierte GFP-Lösungen werden mit GFP-D bezeichnet. Negative Amplituden $A_{i}$ implizieren ein Anstiegsverhalten der Emissionen. 


\begin{tabular}{|c|c|c|c|c|}
\hline & Anregung/nm & Emission/nm & Amplitude $A_{i}$ & $\tau_{i} / \mathrm{ps}$ \\
\hline \multirow{7}{*}{$\frac{\rho}{\widetilde{T}}$} & & & 0.76 & 6.1 \\
\hline & 400 & 450 & 0.15 & 29 \\
\hline & & & 0.09 & 227 \\
\hline & & & -1.14 & 2.8 \\
\hline & 400 & 530 & -0.22 & 20 \\
\hline & & & 1 & 3300 \\
\hline & 462 & 530 & -1 & 3300 \\
\hline \multirow{7}{*}{$\stackrel{\hat{C}^{\prime}}{\vec{J}}$} & & & 0.32 & 8.7 \\
\hline & 400 & 450 & 0.45 & 48 \\
\hline & & & 0.23 & 195 \\
\hline & & & -0.30 & 48 \\
\hline & 400 & 530 & -0.37 & 1160 \\
\hline & & & 1 & 3300 \\
\hline & 462 & 530 & 1 & 3300 \\
\hline
\end{tabular}

Tabelle 2.2: Zeitkonstanten aus exponentiellen Anpassungen $(F(t)=$ $\left.\sum_{i} A_{i} e^{-t / \tau_{i}}\right)$ an die Fluoreszenzsignale aus Arbeiten von Lossau et al bei $295 \mathrm{~K}^{32}$. Deuterierte GFP-Lösungen werden mit GFP-D bezeichnet.

Viskositätsabhängige Messungen der Fluoreszenz eines Modellchromophors (Ethyl 4-(4-Hydroxyphenyl)methylidene-2-methyl-5-oxo-1-imidazolacetat, Abbildung 2.7) in verschiedenen Lösungsmitteln zeigen, dass innere Konversion des Chromophors im GFP tatsächlich von Bedeutung ist ${ }^{39}$.

Der Modellchromophor zeigt in Glycerol eine nur äußerst schwache Fluoreszenz. In Ethanol oder Ethylenglycol erscheint im Emissionsspektrum sogar nur noch Raman-Streuung ${ }^{39}$. Erst wenn das Lösungsmittel bis unter den Glasübergang abgekühlt wird, entwickelt sich eine intensive Fluoreszenz. Die Fluoreszenzabklingkurven weisen in allen Lösungsmitteln bis auf Glycerolglas ein multiexponentielles Verhalten auf, sowie eine ausgeprägte Abhängigkeit von der Nachweiswellenlänge. Die Ähnlichkeit zwischen den Zerfallszeiten der Emission des Modellchromophors in Ethanol mit den Zeiten der Wiederbevölkerung des Grundzustands (Einfarben-Pump-Probe-Absorptionsexperiment) wurde als Indiz dafür genommen, dass die innere Konversion der entscheidene Mechanismus für die Fluoreszenzabklingdynamik ist ${ }^{36}$. Die Strahlungslebensdauer wächst mit der Viskosität von Subpikosekunden (z. B. Ethanol) bis 30 ps in Glycerol und $2.1 \mathrm{~ns}$ in Glycerolglas. Diese Ergebnisse werden so verstanden, dass der strahlungslose Zerfallskanal an eine Bewegung des Chromophors mit großer Amplitude gekoppelt ist, die von der Lösungsmittelviskosität abhängig ist. Im Gegensatz zum GFP weisen sowohl die neutrale als auch die anionische Form 


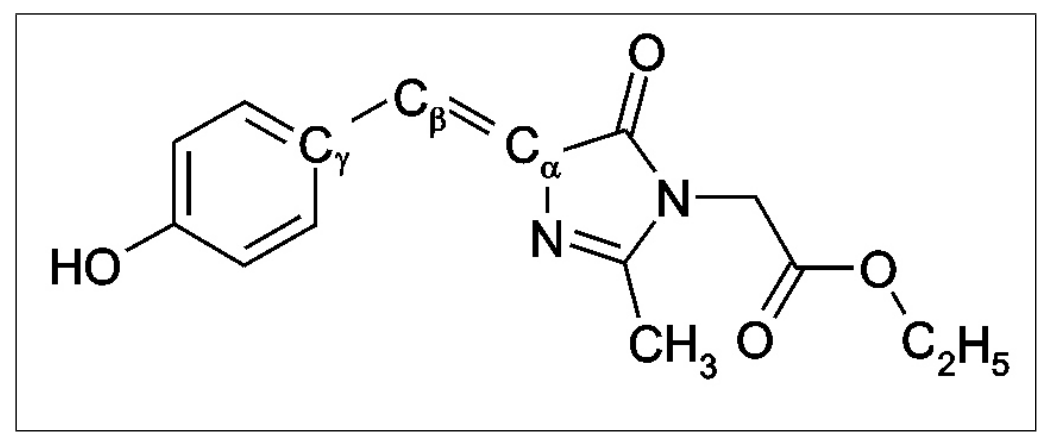

Abbildung 2.7: Modellchromophor aus Kummer et al. ${ }^{39}$

des Modellchromophors Strahlungslebensdauern von sehr ähnlicher Größenordnung auf (diese liegen auf einer Pikosekundenzeitskala). Das heißt, auch die Fluoreszenz der anionischen Form ist nun gelöscht - innere Konversion scheint auch für die anionische Form im Modellchromophor möglich zu werden ${ }^{39}$. Die Tatsache, dass die anionische Form im Protein keiner inneren Konversion unterliegt, die des Modellchromophors jedoch durchaus, wird mit der erhöhten sterischen Hinderung der Rotation um $C_{\beta}-C_{\alpha}$ (Abbildung 2.7) infolge der rigiden Proteinumgebung erklärt. Da der Imidazolonring des Chromophors an das Proteinrückgrat gebunden ist, wird die relativ starke Bewegung um $C_{\beta}-C_{\alpha}$ unterdrückt. Die Bewegung um $C_{\beta}-C_{\gamma}$ wird weniger durch die Proteinstruktur gehindert sein, da der Phenylring nur um seine eigene Achse rotieren muss und auch nur über Wasserstoffbrückenbindungen mit dem Protein verknüpft ist ${ }^{39}$.

Für die innere Konversion, d. h. die Rotation bzw. Torsionsbewegung des Chromophors im GFP, sind sowohl Packungsdichte des Chromophors innerhalb des Proteins als auch die Struktur der Wasserstoffbrückenbindungen um die Phenolgruppe des Chromophors von Bedeutung. Kummer et al..$^{38}$ haben kürzlich die Emissionsdynamik von zwei GFP-Mutanten untersucht, in denen der Protonentransfer offensichtlich unterbunden ist. Aus temperaturabhängigen Messungen der Fluoreszenzdynamik wird geschlossen, dass die strukturelle Anordnung der Wasserstoffbrückenbindungen um die rotierende Gruppe des Chromophors (Phenylgruppe im wt-GFP) entscheidender ist, als die Packungsdichte um den Chromophor. Ist beispielsweise eine Wasserstoffbrücke zwischen Chromophor (Phenylgruppe im wt-GFP) und einem Wassermolekül parallel zur Rotationsachse gerichtet, wie das im Wildtyp-GFP der Fall ist, so ist die innere Konversion gegenüber einer nichtparallelen Ausrichtung favorisiert ${ }^{38}$. 


\subsection{Theoretische Arbeiten}

Quantenchemische Berechnungen ${ }^{46}$ der elektronischen Resonanzen eines Modellchromophors des GFP (Abbildung 2.8) dienten der Zuordnung der experimentell ermittelten Absorptionen zu verschiedenen Chromophors. Entgegen der bislang

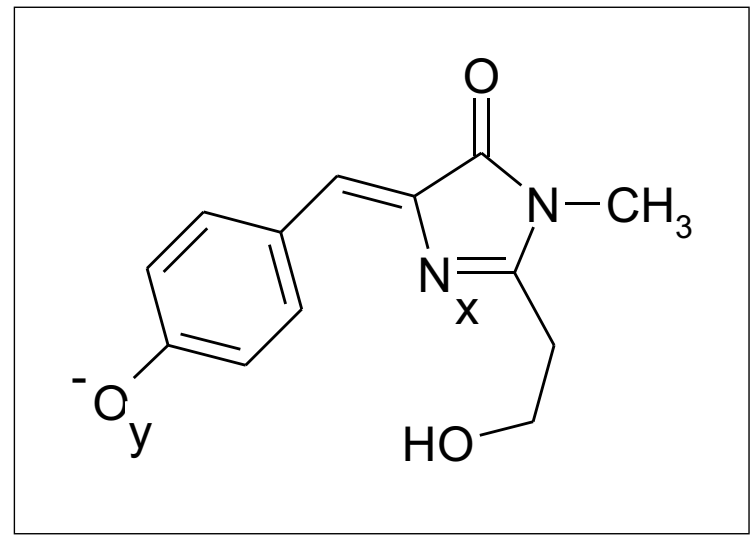

Abbildung 2.8: Anionischer Modelchromophor für die theoretischen Berechnungen von Voityuk et al. ${ }^{46,47}$

vertretenen Annahme, dass der Chromophor in neutraler und anionischer Form vorkommt ${ }^{28}$, zeigten diese Berechnungen, dass die Absorptionsbande bei $398 \mathrm{~nm}$ durch eine kationische Form $\left(\left[\mathrm{HO}_{\mathrm{y}} \ldots \mathrm{N}_{\mathrm{x}} \mathrm{H}\right]^{+}\right)$und die bei $478 \mathrm{~nm}$ durch ein Zwitterion $\left(\mathrm{O}_{\mathrm{y}}^{-} \ldots \mathrm{HN}_{\mathrm{x}}^{+}\right)$hervorgerufen wird. Diese Berechnungen zeigten weiterhin, dass Protonentransfer zwischen Chromophor und Umgebung zu signifikanten Veränderungen der Resonanzenergien des Chromophors führt. Der heterozyklische Stickstoff ist nach Voityuk et al. ${ }^{47}$ sowohl im Grund- als auch im angeregten Zustand protoniert. Im angeregten Zustand ist die Protonenaffinität jedoch reduziert, so dass es zum Protonentransfer kommt und die vorherrschende Form im angeregten Zustand die zwitterionische ist, aus der Emission erfolgt.

In einer weiteren theoretischen Studie widmenten sich Voityuk et al. ${ }^{48}$ der Frage, in welcher Form des Chromophors und in welchem elektronischen Zustand Rotationen bzw. Torsionen um die entsprechenden Bindungen $(\gamma, \beta$ in Abbildung 2.9) energetisch möglich sind. Es wurde der gleiche Modellchromophor aus Abbildung 2.8 verwendet. Vier mögliche Protonierungsvarianten wurden dabei betrachtet: $\left[\mathrm{O}_{\mathrm{y}} \ldots \mathrm{N}_{\mathrm{x}}\right]^{-},\left[\mathrm{HO}_{\mathrm{y}} \ldots \mathrm{N}_{\mathrm{x}}\right],\left[\mathrm{O}_{\mathrm{y}}^{-} \ldots \mathrm{N}_{\mathrm{x}} \mathrm{H}^{+}\right],\left[\mathrm{HO}_{\mathrm{y}} \ldots \mathrm{N}_{\mathrm{x}} \mathrm{H}\right]^{+}$. Energieprofile des elektronischen Grundzustands und des ersten angeregten Zustands wurden für alle vier Spezies in Abhängigkeit der Diederwinkel $\gamma$ (Twistbewegung um $C_{\gamma}-C_{\beta}$ ) und $\beta$ (Twistbewegung um $C_{\beta}-C_{\alpha}$ ) berechnet (vgl. Abbildung 2.9).

Zusammenfassend zeigen diese Berechnungen, dass innere Konversion vom ersten angeregten Zustand $S_{1}$ zum Grundzustand $S_{0}$ mit größter Wahrscheinlich- 


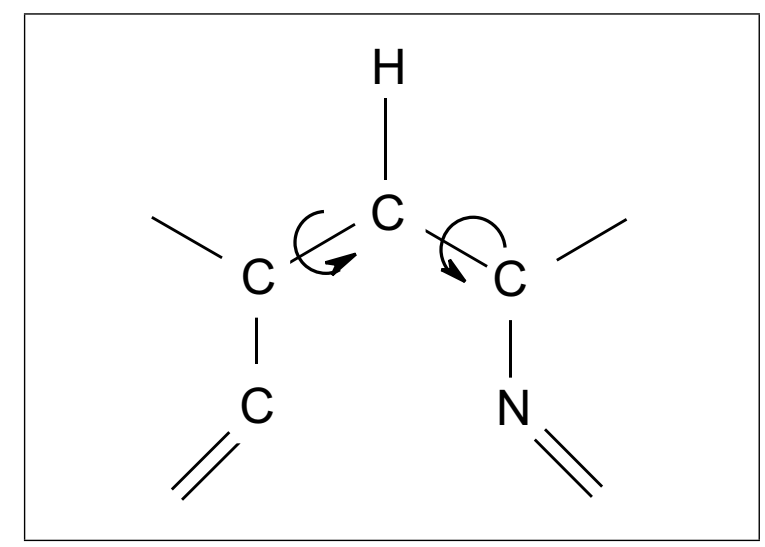

Abbildung 2.9: Schema der Chromophorgeometrie mit Rotationswinkeln aus Voityuk et al. ${ }^{48}$

keit aus der kationischen Form $\left[\mathrm{HO}_{\mathrm{y}} \ldots \mathrm{N}_{\mathrm{x}} \mathrm{H}\right]^{+}$erfolgt und zwar als Twistbewegung um $C_{\beta}-C_{\alpha}$ (Winkel $\beta$ in Abbildung 2.9). Das Energieprofil in Abhängigkeit der Diederwinkel $\gamma$ und $\beta$ weist im ersten angeregten Zustand zwei Minima bei $90^{\circ}$ und $270^{\circ}$ auf. Im Grundzustand befinden sich demgegenüber bei den gleichen Winkeln Maxima. Minima und Maxima sind nur durch eine geringe Energielücke voneinander getrennt, wodurch innere Konversion begünstigt wird ${ }^{48}$. Die Geschwindigkeitskonstante für innere Konversion fällt exponentiell mit abnehmender Energiedifferenz zwischen angeregtem und Grundzustand ${ }^{60,61,62}$. Nach Anregung der planaren Konformation des Chromophors erfolgt eine schnelle intramolekulare Twistbewegung um $C_{\beta}-C_{\alpha}$ in Richtung des Minimums von $S_{1}$. Dort erfolgt die strahlungslose Desaktivierung mit nicht-adiabatischem Übergang zu $S_{0}$. Werden diese Ergebnisse auf den Chromophor im GFP übertragen, so kann eine schnelle innere Konversion nur dann verhindert werden, wenn diese Bewegung eingeschränkt ist. Die Hinderung einer solchen Bewegung des Chromophors im GFP stellt sicher, dass die Lebensdauer des $\mathrm{S}_{1}$-Zustands im Kation ausreichend lang ist, um den Protonentransfer im GFP zu ermöglichen. Innere Konversion ist nach diesen Berechnungen auch im Anion möglich, jedoch sind die Energieunterschiede zwischen Grund- und angeregtem Zustand für Bewegungen um $C_{\beta}-C_{\alpha}$ und $C_{\gamma}-C_{\beta}$ deutlich größer als im Falle des Kations. Die intramolekulare Rotation um $C_{\gamma}-C_{\beta}$ in der neutralen Form $\left[\mathrm{HO}_{\mathrm{y}} \ldots \mathrm{N}_{\mathrm{x}}\right]$, im Zwitterion $\left[\mathrm{O}_{\mathrm{y}}^{-} \mathrm{N}_{\mathrm{x}} \mathrm{H}^{+}\right]$und im Kation $\left[\mathrm{HO}_{\mathrm{y}} \ldots \mathrm{N}_{\mathrm{x}} \mathrm{H}\right]^{+}$führt zu Konformationen, die für die innere Konversion irrelevant sind.

Die Betrachtungen des gesamten Kapitels lassen auf die Komlexität der Dynamik im angeregten Zustand des GFP schließen. Die Kinetik des Protonentransfers und der inneren Konversion spielen hierbei eine große Rolle und erfordern weitere gezielte Untersuchungen. In den vorherigen Abschnitten zeigte sich auch, dass die Ursache der multiexponentiellen Kinetiken stärker beleuchtet werden muss. 



\section{Kapitel 3}

\section{Experimentelle Techniken}

Die Charakterisierung der ultraschnellen Dynamik im angeregten Zustand des GFP wurde unter Kombination von zeit- und frequenzaufgelösten experimentellen Methoden vorgenommen. Dazu wurden femtosekundenzeitaufgelöste PumpProbe-Messungen zur Beobachtung des Zeitverlaufs der pumpinduzierten Transmissionsänderung durchgeführt, sowie zeitabhängige transiente Spektren aufgenommen. Darüberhinaus wurden Fluoreszenzkonversionsexperimente sowie zeitkorrelierte Einzelphotonenzählexperimente (TCSPC-Time-Correlated Single Photon Counting) durchgeführt. Die zeit- und frequenzaufgelösten Pump-ProbeMessungen, die den Hauptteil der Experimente bilden, sind mit dem im Folgenden beschriebenen Lasersystem ausgeführt worden.

\subsection{Lasersystem}

Die femtosekundenzeitaufgelösten Pump-Probe-Experimente wurden mit Hilfe eines kommerziellen Titan-Saphir Lasersystems mit regenerativen Verstärker durchgeführt (Coherent). Es besteht aus einem Argon-Ionenlaser als Pumpquelle, einem Titan-Saphir Oszillator, einem Pulsstrecker, einem regenerativen Verstärker, einem Pulskompressor, sowie einem optischen parametrischen Verstärker. Die Funktionsweise dieses Lasersystems soll im folgenden kurz beschrieben werden. Es wurde bereits sehr ausführlich in früheren Arbeiten diskutiert ${ }^{63,64,65,66}$.

Der Argon-Ionenlaser (Coherent INNOVA Sabre) emittiert Licht mehrerer Wellenlängen, wobei die den Laserresonator abschließenden dielektrischen Spiegel den spektralen Bereich auf 454.5 - $514.5 \mathrm{~nm}$ begrenzen. Er liefert eine Leistung von $21 \mathrm{~W}$, von denen $7 \mathrm{~W}$ zum Pumpen des Oszillators und $14 \mathrm{~W}$ für den Betrieb des regenerativen Verstärkers verwendet werden ${ }^{67}$.

\section{Oszillator}

Der Oszillator (Coherent Mira Seed, Abbildung 3.1, ${ }^{65}$ ) besitzt als laseraktives Medium einen mit Titan-Ionen dotierten Saphir-Kristall Ti: $\mathrm{Al}_{2} \mathrm{O}_{3}$ (Ti:Saphir), 
das sich nicht nur durch sein äußerst breites Absorptionsspektrum bei einer Mittenwellenlänge von $500 \mathrm{~nm}$ auszeichnet, sondern vor allem ein breites Emissionsspektrum besitzt, wodurch sich das spektral sehr ausgedehnte Verstärkungsprofil des Ti:Saphirs von etwa $680 \mathrm{~nm}$ bis $1000 \mathrm{~nm}$ erklärt. Der Ti:Saphir-Oszillator gehört zum konzentrisch gefalteten Resonatortyp, bei dem einerseits Pump- und Lasermode im aktiven Medium koaxial fokussiert werden und andererseits der im Kristall entstehende Astigmatismus des Laserstrahls kompensiert wird. Im Oszillator befindet sich weiterhin ein Prismenpaar zur Kompensation der Gruppengeschwindigkeitsdispersion, die durch verschiedene optische Elemente, wie dem Ti:Saphir-Kristall und den Prismen selbst, hervorgerufen wird. Die Erzeugung kurzer Pulse in einem Ti:Saphir-Oszillator erfolgt über passive Modenkopplung, die auch als Kerr-Lens-Modelocking bezeichnet wird. Modenkopplung beschreibt die Ausbildung einer festen Phasenbeziehung aller Resonatormoden zueinander innerhalb des Verstärkungsprofils. Die dem Kerr-Lens-Modelocking zugrunde liegenden physikalischen Phänomene sind die Ausbildung einer Kerr-Linse und die damit verbundene räumliche Selbstfokussierung des Strahls, sowie die Selbstphasenmodulation. Beide Effekte sind direkte Folge der intensitätsabhängigen, nichtlinearen Änderung des Brechungsindexes des Ti:Saphir-Kristalls.

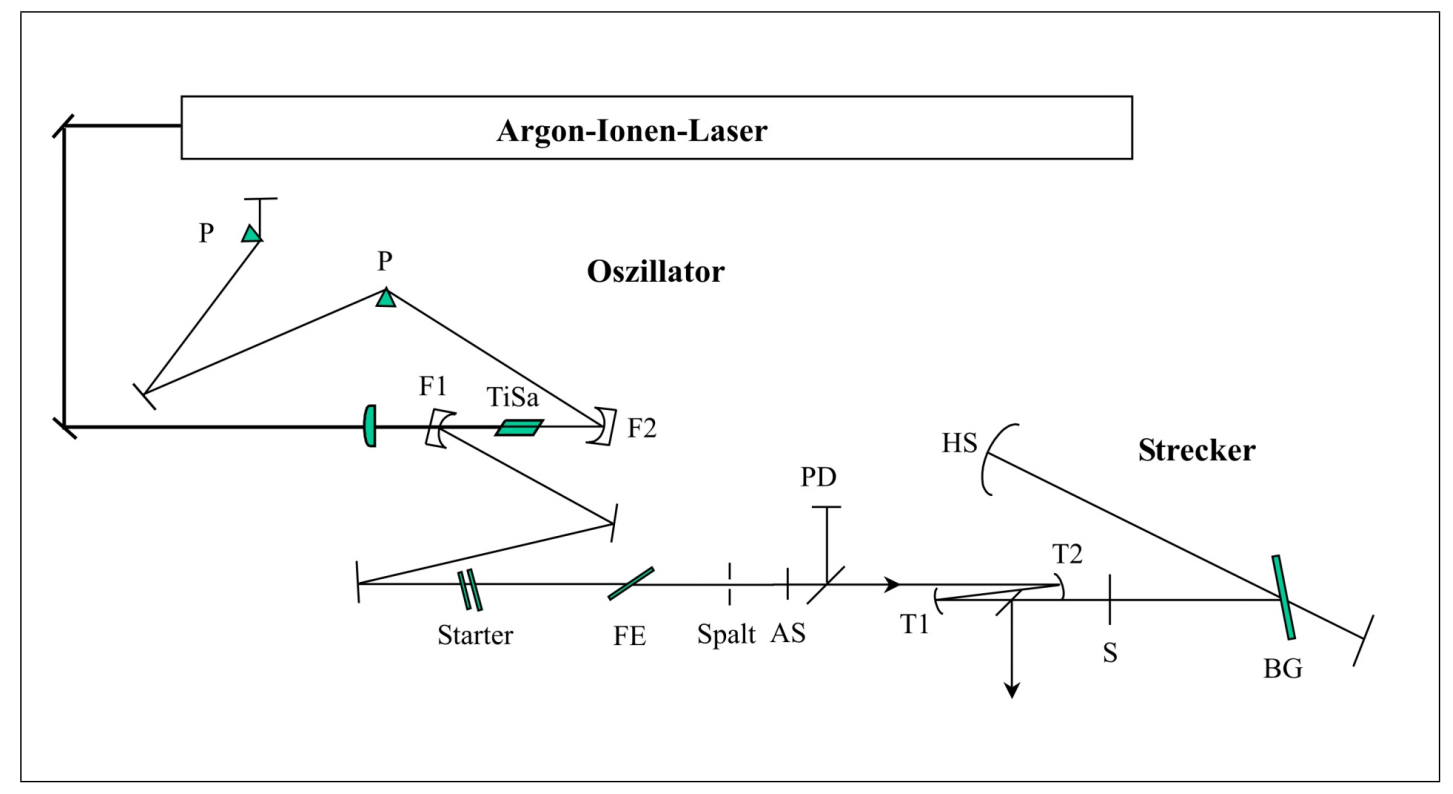

Abbildung 3.1: Ti:Saphir Oszillator und Strecker; F1,F2-Faltspiegel, FEfrequenzselektives Element, AS-Auskoppelspiegel, T1/T2-Teleskopspiegel, $\mathrm{BG}$ - Beugungsgitter, HS - Hohlspiegel, PD-Photodiode, S-Spiegel, $\mathrm{P}$ - Prisma. 
Die Selbstfokussierung bewirkt die Verkleinerung des Strahls unter Zunahme der Lichtintensität in seinem Zentrum. Die Selbstphasenmodulation beschreibt die zeitliche Änderung der Pulsform, die durch die intensitätsabhängige Änderung der optischen Weglänge im Kristall infolge der Nichtlinearität des Brechungsindexes hervorgerufen wird. Durch die Selbstphasenmodulation wird eine Frequenzverbreiterung des Pulses erzeugt, was seine zeitliche Verkürzung zur Folge hat. Der Beginn des Kerr-Lens-Modelocking wird durch eine Störung initiiert, durch die einige Moden miteinander koppeln und schließlich alle anderen mitreißen. Dies wird im Abbildung 3.1 vorgestellten Ti:Saphir-Oszillator von einem Starter unterstützt, der die Länge des Resonators periodisch ändert und auf diese Weise die Modenkopplung auslöst. Das Kerr-Lens-Modelocking wird weiterhin durch eine harte Apertur in Form eines variablen Schlitzes vor den Auskoppelspiegel begünstigt, welcher die $c w$-Mode gegenüber der im gepulsten Betrieb diskriminiert. Im Oszillator befindet sich außerdem ein doppelbrechender Quarzkristall, der als frequenzselektives Element fungiert (birefringent filter) und auf diese Weise den Oszillator über einen Bereich von 780 bis $840 \mathrm{~nm}$ durchstimmen lässt.

Der Coherent Mira Seed liefert bei einer Wellenlänge von $800 \mathrm{~nm}$ und einer Repetitionsrate von $76 \mathrm{MHz}$ Pulse mit einer Leistung von $650 \mathrm{~mW}$. Die Kürze der Pulse kann bis zu 20 fs betragen, was einer spektralen Breite von etwa $50 \mathrm{~nm}$ entspricht.

\section{Strecker}

Für nichtlineare, optische Prozesse, wie die Erzeugung der zweiten Harmonischen oder optische parametrische Verstärkung, werden Pulse benötigt, die eine weit höhere Energie besitzen als die im Oszillator erzeugten. Bevor jedoch eine Verstärkung der Pulsenergien erfolgen kann, ist es notwendig, die Pulse vorher zeitlich zu strecken, da die Verstärkung ultrakurzer Pulse schnell zu extremen Spitzenintensitäten führen kann. Dadurch würden einerseits optische Elemente zerstört und andererseits das räumliche und zeitliche Profil des Pulses nichtlinear verzerrt werden. Für die Streckung der Pulse, die auf einer linearen, reversiblen Methode beruhen muss, werden die dispersiven Eigenschaften von Gittern ausgenutzt. Um einen Puls zeitlich zu strecken, muss er ein Medium passieren, das eine positive Gruppengeschwindigkeitsdispersion besitzt. Da Gitter eine negative Gruppengeschwindigkeitsdispersion aufweisen, muss eine Methode gefunden werden, diese umzukehren. Im vorgestellten Lasersystem ist dies durch den Einbau eines reflektierenden Teleskops in den Strahlengang des Streckers realisiert (Abbildung 3.1). Der im Oszillator erzeugte Pulse durchläuft nun mehrfach die Kombination aus Beugungsgitter und Teleskop, so dass er einen positiven linearen chirp erfährt (chirp - zeitliche Streckung des Pulses) und er somit um einen Faktor von etwa 1000 verlängert wird ${ }^{64}$. 


\section{Regenerativer Verstärker (RegA)}

Da die zu verstärkenden Pulse einen chirp aufweisen, wird die Verstärkungsmethode auch als chirped pulse amplification bezeichnet. Das Verstärkungsmedium Ti:Saphir gehört zu den Materialien, die für die Verstärkung kurzer Pulse hervorragend geeignet sind. Sein Verstärkungsquerschnitt von $\sigma_{g}=2.7 \cdot 10^{-19} \mathrm{~cm}^{2}$, sein Sättigungsfluss von $J_{\text {sat }}=0.9 \mathrm{~J} / \mathrm{cm}^{2}$, seine Verstärkungsbandbreite von etwa $230 \mathrm{~nm}$, die lange Lebensdauer des angeregten Niveaus von $\tau=2.5 \mu$ s und seine hohe Zerstörungsschwelle sind notwendige Bedingungen für eine optimale Verstärkung kurzer Pulse ${ }^{64}$. Der in dieser Arbeit benutzte regenerative Verstärker (Coherent RegA Model 9000, Abbildung 3.264) lässt sich im Wesentlichen in zwei Bereiche einteilen: dem Ti:Saphir-Verstärkungsmedium, dessen Aufbau dem eines Laseroszillators gleicht, und dem akustisch-optischen cavity dumper.

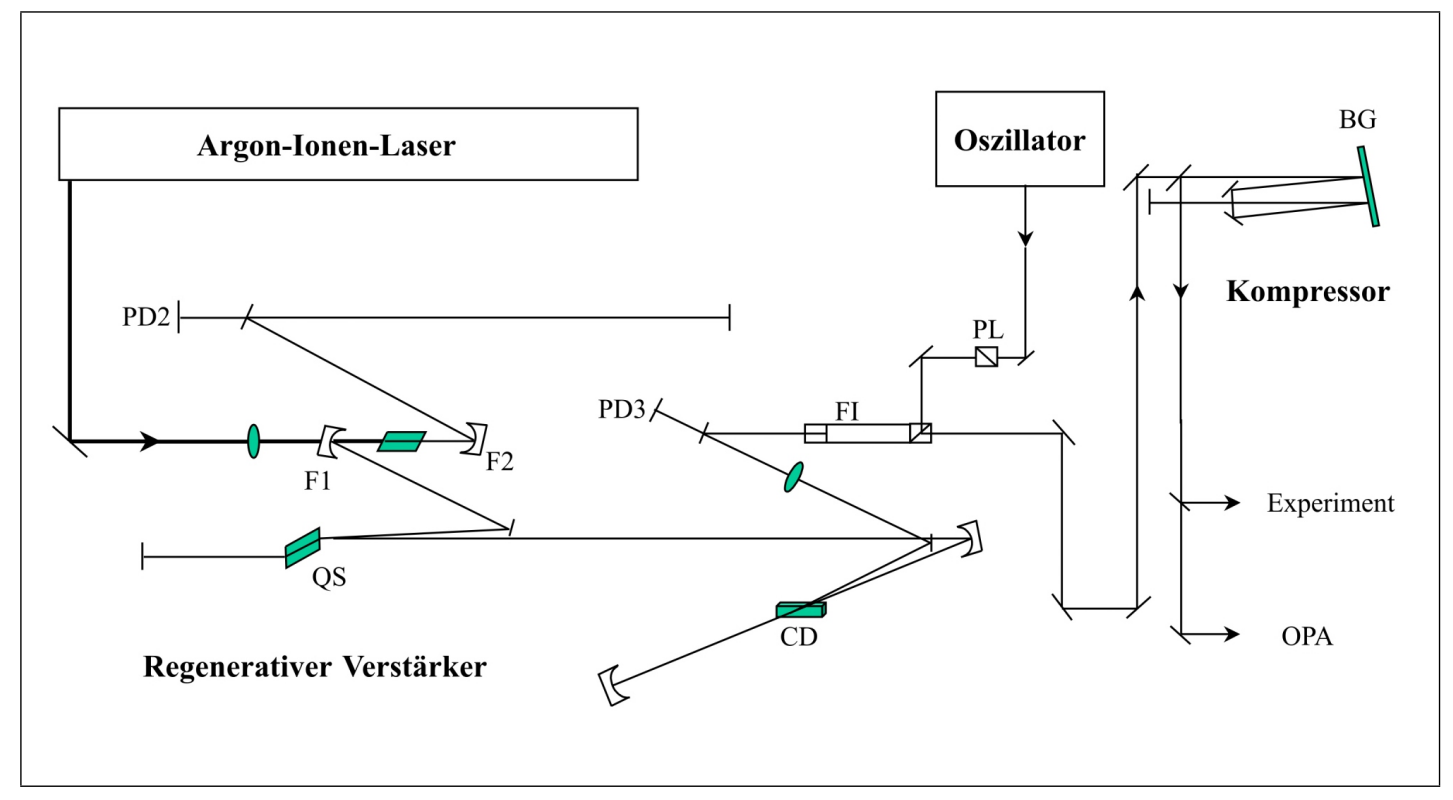

Abbildung 3.2: Regenerativer Verstärker und Kompressor; F1/F2-Faltspiegel, QS - Q-switch, PL - Polarisator, FI - Faraday Isolator, CD - cavity dumper, BG2Beugungsgitter, PD2/3-Photodioden, OPA - Optischer Parametrischer Verstärker

Wie bereits oben erwähnt, wird das Verstärkungsmedium von einem Argon-Ionenlaser mit einer Leistung von $14 \mathrm{~W}$ gepumpt. Der Resonator des Verstärkers besitzt die gleiche Länge wie der Laseroszillator, wodurch eine optimale Synchronisation von ein- und ausgekoppelten Puls mit dem ankommenden Oszillatorpulszug gewährleistet ist. Im Resonator befindet sich des Weiteren ein akustisch-optischer Q-switch, der einerseits den Populationsabbau des angeregten Niveaus vor Einkopplung des zu verstärkenden Pulses verhindert und andererseits eine hohe normale Dispersion aufweist, wodurch eine weitere 
Verlängerung des Pulses erfolgt.

Die Einkopplung des im Oszillator generierten Pulszugs erfolgt zunächst über einen Polarisator und Faradayisolator, welcher polarisationsabhängig für Licht in den Verstärker durchlässig, aber für Licht aus ihm heraus in Richtung des Oszillators undurchlässig ist. Dadurch werden Reflexionen zurück in den Oszillator verhindert werden. Der Lichtstrahl wird dann auf den cavity dumper gelenkt, der die photodiodenkontrollierte Ein- und Auskopplung der einzelnen Pulse steuert. Sobald ein $R F$-Puls ( $R F$-radio frequency) von einer Steuerungseinheit an den cavity dumper übertragen wird, erfolgt die partielle Reflektion des einzukoppelnden Lichtstrahls, so dass dieser Teil in den Verstärkungsresonator eintreten kann. Der Q-switch ist elektronisch mit dem cavity dumper synchronisiert, so dass er sich kurze Zeit nach dem $R F$-Puls ausschaltet und so den Verstärkungsvorgang im Resonator ermöglicht. Nach etwa 24 Umläufen ist der Puls ausreichend verstärkt und es erfolgt ein zweiter $R F$-Puls an den cavity dumper, was zur Auskopplung des verstärkten Pulses führt.

\section{Kompressor}

Nach Durchlaufen des regenerativen Verstärkers haben die Pulse eine weitere zeitliche Streckung erfahren, die nicht lediglich auf die lineare Gruppengeschwindigkeitsdispersion, sondern auch auf Dispersionen höherer Ordnung zurückzuführen ist. Der Kompressor (Abbildung 3.2) muss daher sowohl Dispersion zweiter als auch dritter Ordnung kompensieren ${ }^{64}$. Im Gegensatz zu Prismendispersionskompensationsstrecken, die lediglich die lineare Dispersion wieder rückgängig machen, können Beugungsgitter auch die Dispersion dritter Ordnung kompensieren. Der z-förmige Kompressor besteht daher aus einem goldbeschichteten Beugungsgitter und mehreren planparallelen Spiegeln, welche der Puls mehrfach passiert.

Nach diesem Prinzip werden bei $800 \mathrm{~nm}$ und einer Repetitionsrate von $250 \mathrm{kHz}$ Pulse bei einer Leistung von etwa $1.4 \mathrm{~W}$ erzeugt, die eine Halbwertsbreite (FWHM) von etwa $30 \mathrm{fs}$ besitzen.

\subsection{Optischer Parametrischer Verstärker}

Zur Verwendung ultrakurzer Lichtpulse im Wellenlängenbereich von etwa 470 bis $750 \mathrm{~nm}$ wurde in dieser Arbeit ein optischer, parametrischer Verstärker aufgebaut. Optische parametrische Verstärkung findet statt, wenn hohe Lichtintensitäten auf ein optisch nichtlineares Medium treffen, beispielsweise ein dielektrischer Kristall. Im Gegensatz zur linearen Polarisation, die bei Wechselwirkung eines elektromagnetischen Feldes mit einem Dielektrikum erzeugt wird, gewinnen bei Vergrößerung der Lichtintensitäten nichtlineare Anteile immer stärkere Bedeutung. Die Gesamtpolarisation, die als Potenzreihenentwicklung in Abhängigkeit 
der elektrischen Feldstärke E dargestellt werden kann, beinhaltet nun quadratische, kubische und höhere Terme, wobei $\chi^{(\mathrm{n})}$ die Suszeptibilitäten n-ter Ordnung sind:

$$
P(t)=\epsilon_{0}\left[\chi^{(1)} \cdot E(t)+\chi^{(2)} \cdot E^{2}(t)+\chi^{(3)} \cdot E^{3}(t)+\cdots\right] .
$$

Während bei nichtlinearen Prozessen in isotropen Medien (Flüssigkeiten, zentrosymmetrische Kristalle usw.) der quadratische Term aus Symmetriegründen wegfällt, basieren nichtlineare Prozesse in anisotropen Medien hauptsächlich auf diesem Teil der Polarisation. Im Fall der Frequenzverdopplung (SHG - Second Harmonic Generation) entspricht der nichtlineare (quadratische) Term der Polarisation einer Welle, die die doppelte Frequenz von der eingestrahlten Welle besitzt. Im Photonenbild entstehen aus zwei Photonen niedriger Energie ein Photon mit der doppelten Energie. Bei der optischen, parametrischen Verstärkung wird eine Welle in einen anisotropen Kristall eingestrahlt, wobei zwei neue Wellen verschiedener Frequenzen entstehen. Die resultierende Polarisation kann nach Shen ${ }^{68}$ durch:

$$
\begin{aligned}
P(k, \omega)= & \chi^{(1)}(k, \omega) \cdot E(k, \omega)+ \\
& \chi^{(2)}\left(k_{2}=k_{3}-k_{1}, \omega_{2}=\omega_{3}-\omega_{1}\right) \cdot E\left(k_{3}, \omega_{3}\right) E\left(k_{1}, \omega_{1}\right) .
\end{aligned}
$$

wiedergegeben werden. $k_{3}$ und $\omega_{3}$ entsprechen hierbei dem Wellenvektor bzw. der Frequenz der eingestrahlten Welle und $k_{1}, \omega_{1}$ sowie $k_{2}, \omega_{2}$ diesen Parametern der resultierenden Wellen. Bei der optischen, parametrischen Verstärkung beschreiben $\omega_{2}$ die Frequenz der Signalwelle, $\omega_{3}$ die der Pumpwelle und $\omega_{1}$ die der sogenannten Idlerwelle. Bei allen nichtlinearen Prozessen gelten Energie- und Impulserhaltung, das heißt im Falle der optischen parametrischen Verstärkung:

$$
\begin{aligned}
& \omega_{\text {pump }}=\omega_{\text {signal }}+\omega_{\text {idler }} \\
& k_{\text {pump }}=k_{\text {signal }}+k_{\text {idler }} .
\end{aligned}
$$

Da der Ausbreitungsvektor $k$ einer Welle eine Funktion des frequenzabhängigen Brechungsindexes $n(\omega)$ ist, kann der Impulserhaltungssatz 3.3 als eine Phasenanpassungsbedingung formuliert werden. Im kollinearen Fall gilt:

$$
\begin{aligned}
\omega_{\text {pump }} \cdot n\left(\omega_{\text {pump }}\right) & =\omega_{\text {signal }} \cdot n\left(\omega_{\text {signal }}\right)+\omega_{\text {idler }} \cdot n\left(\omega_{\text {idler }}\right) \\
\operatorname{mit} \quad k & =\omega \cdot \frac{n(\omega)}{c_{0}} .
\end{aligned}
$$

Nur dann, wenn die Phasenanpassungsbedingung erfüllt ist, d. h. wenn die Grundwelle dieselbe Phasengeschwindigkeit $\left(v_{P h}=\omega / k\right)$ wie die erzeugten Oberwellen hat, kann es zu einer Addition von den mikroskopischen Anteilen, die 
von den Dipolen im Kristall ausgehen, zu einer makroskopischen Welle kommen, so dass optische parametrische Verstärkung stattfindet. Grundlage für die Phasenanpassung ist ein doppelbrechender Kristall, in dem der Brechungsindex sowohl von der Polarisation als auch vom Einfallswinkel abhängt. In einem optisch einachsigen Kristall (z. B. $\beta$-Bariumborat, BBO), in dem der Brechungsindex einer Frequenz entlang dieser Achse unabhängig von der Polarisation ist, kann nun optische parametrische Verstärkung stattfinden. Dabei ist die Pumpwelle außerordentlich (a) und Signal- und Idlerwelle ordentlich (o) polarisiert (Typ I):

$$
k_{\text {pump }}^{a}=k_{\text {signal }}^{o}+k_{\text {idler }}^{o} .
$$

Diese Phasenanpassung kann nur bei einer bestimmten Einstrahlrichtung relativ zur optischen Achse erfüllt werden. Da die Einstrahlrichtung bevorzugt senkrecht zur Kristalloberfläche erfolgen soll, ist der Kristall bereits in einem Winkel $\Theta$ relativ zur optischen Achse geschnitten.

Zur Erhöhung der Effizienz wird bei der optischen parametrischen Verstärkung der Pumpwelle eine so genannte Seedwelle (Seedpuls) überlagert. Dieser Seedpuls ist ein Weißlichtkontinuum, in dem alle zu verstärkenden spektralen Komponenten der Signalwelle bereits vorhanden sind.

Der Aufbau des optischen, parametrischen Verstärkers ist in Abbildung 3.3 schematisch gezeigt. Es handelt sich hierbei um eine kollinearen OPA, d. h. der Pumpstrahl wird kollinear mit dem Strahl eines Weißlichtkontinuums - dem SeedStrahl - überlagert und so in den Kristall fokussiert. Der nichtkollineare Aufbau (NOPA-non-collinear optical parametric amplifier), wie er oft mit verstärkten Ti:Saphir-Lasersystemen mit einer Repetitionsrate von $1 \mathrm{kHz}$ durchgeführt wird, ist mit dem vorgestellten Lasersystem schwer realisierbar, da die Pulsenergien ca. 250 mal geringer als die der $1 \mathrm{kHz}$ Systeme sind, wodurch die Justage aufgrund des fehlenden Superfluoreszenzringes sehr schwierig wird. Andererseits sind die Pulse, die zum Pumpen eines NOPAs primär verwendet werden um eine Größenordnung (etwa $200 \mathrm{fs}$ ) länger als die des in dieser Arbeit verwendeten. Da die Pulsdauer und die Bandbreite im Fourier-Limit umgekehrt proportional sind, wird es mit kürzeren Pulsen immer schwieriger, den Gruppengeschwindigkeitsversatz zwischen Signal- und Idlerwelle zu kompensieren. Diese Kompensation ist eine wesentliche Grundlage für das Funktionieren eines NOPAs.

Die Mittenwellenlänge des Pumppulses beträgt $400 \mathrm{~nm}$ und wird durch Frequenzverdopplung von $500 \mathrm{~mW}$ des im Lasersystem erzeugten Lichtes von $800 \mathrm{~nm}$ in einem BBO-Kristall $\left(\theta=29.2^{\circ}, d=0.5 \mathrm{~mm}\right)$ generiert. Die Leistung des $400 \mathrm{~nm}$ Lichtes betrug direkt nach Frequenzverdopplung etwa $100 \mathrm{~mW}$. Das Weißlichtkontinuum wird erzeugt, wenn Licht von $800 \mathrm{~nm}(150 \mathrm{~mW})$ durch eine Linse $(f=30 \mathrm{~mm})$ in ein Saphirsubstrat von $3 \mathrm{~mm}$ Dicke fokussiert wird. Das Weißlichtkontinuum (Seedpuls) durchläuft eine Verzögerungsbühne (Bühne 1) und wird 


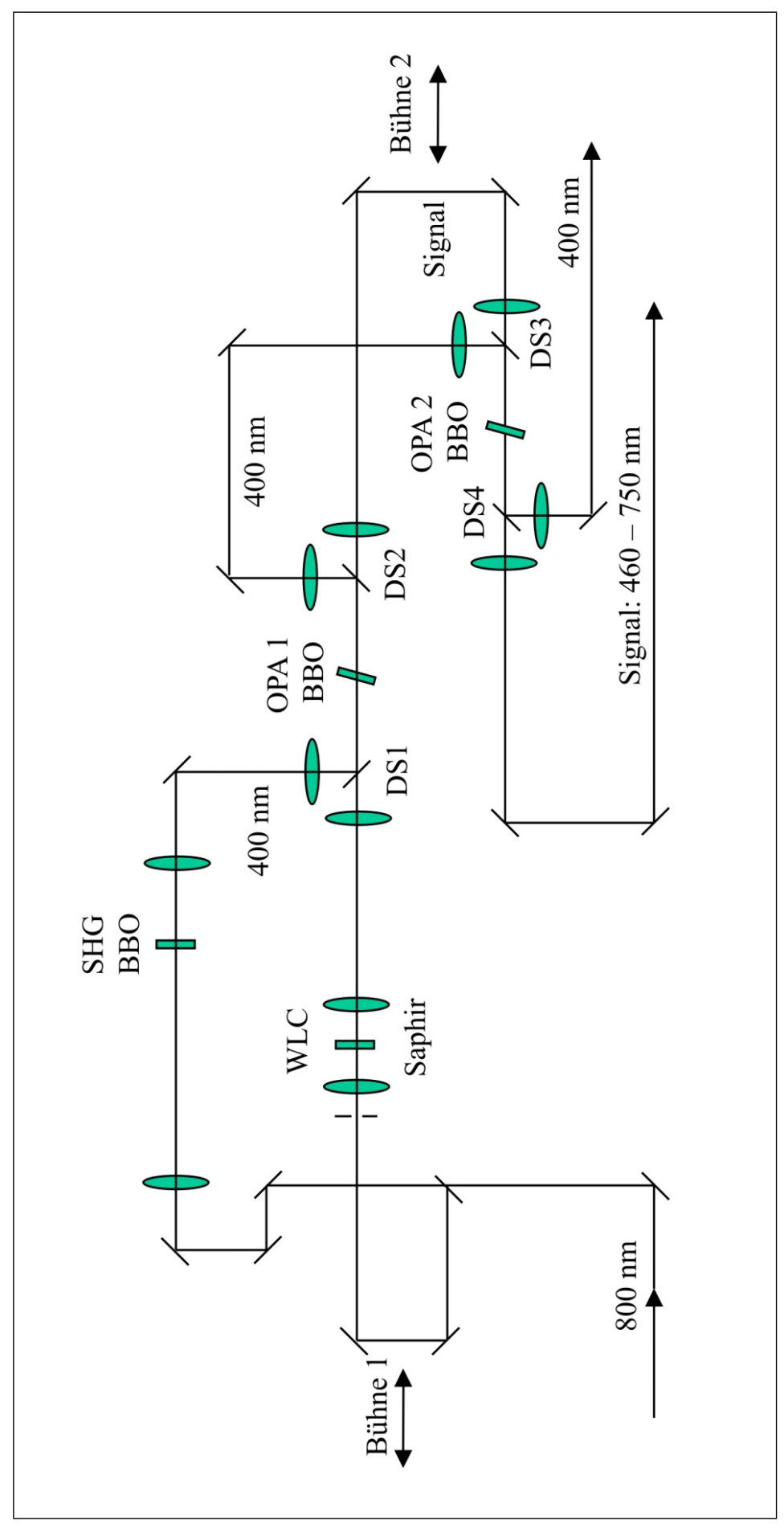

Abbildung 3.3: Optischer Parametrischer Verstärker; WLC - Weißlichtkontinuum, SHG/BBO-BBO-Kristall zur Verdopplung, DS-dielektrische Spiegel, OPA/BBO - BBO-Kristall zur optischen parametrischen Verstärkung 
mit dem Pumppuls über den dielektrischen Spiegel DS1 im Kristall überlagert. Die Fokussier- und Kollimationslinsen des Seed- und des Pumppulses besitzen alle eine Brennweite von $110 \mathrm{~mm}$ bzw. $100 \mathrm{~mm}$. Alle Linsen sind über Verschiebebühnen in ihrer Position variabel, so dass eine optimale Fokussierung beider Strahlen bezüglich der Kristallposition unabhängig voneinander erfolgen kann. Um eine ausreichende Konversionseffizienz zu erhalten, werden BBO-Kristalle mit einer Dicke von $0.5 \mathrm{~mm}$ bei einem Schnittwinkel von $32^{\circ}$ verwendet (BBO-Kristall, Typ I). Nach dem ersten Verstärkungsprozess werden Signal- und Pumpwelle durch einen dielektrischen Spiegel voneinander getrennt und nach der zweiten Verzögerungsstrecke (Bühne 2), die die Signalwelle durchläuft, wieder räumlich und zeitlich überlagert. In der zweiten Verstärkungsstufe wird das erzeugte Signal um einen Faktor 10 verstärkt, so dass die Leistung der Pulse nach Durchgang durch den zweistufigen OPA etwa $40 \mathrm{~mW}$ beträgt, was einer Effizienz von etwa $30 \%$ entspricht.

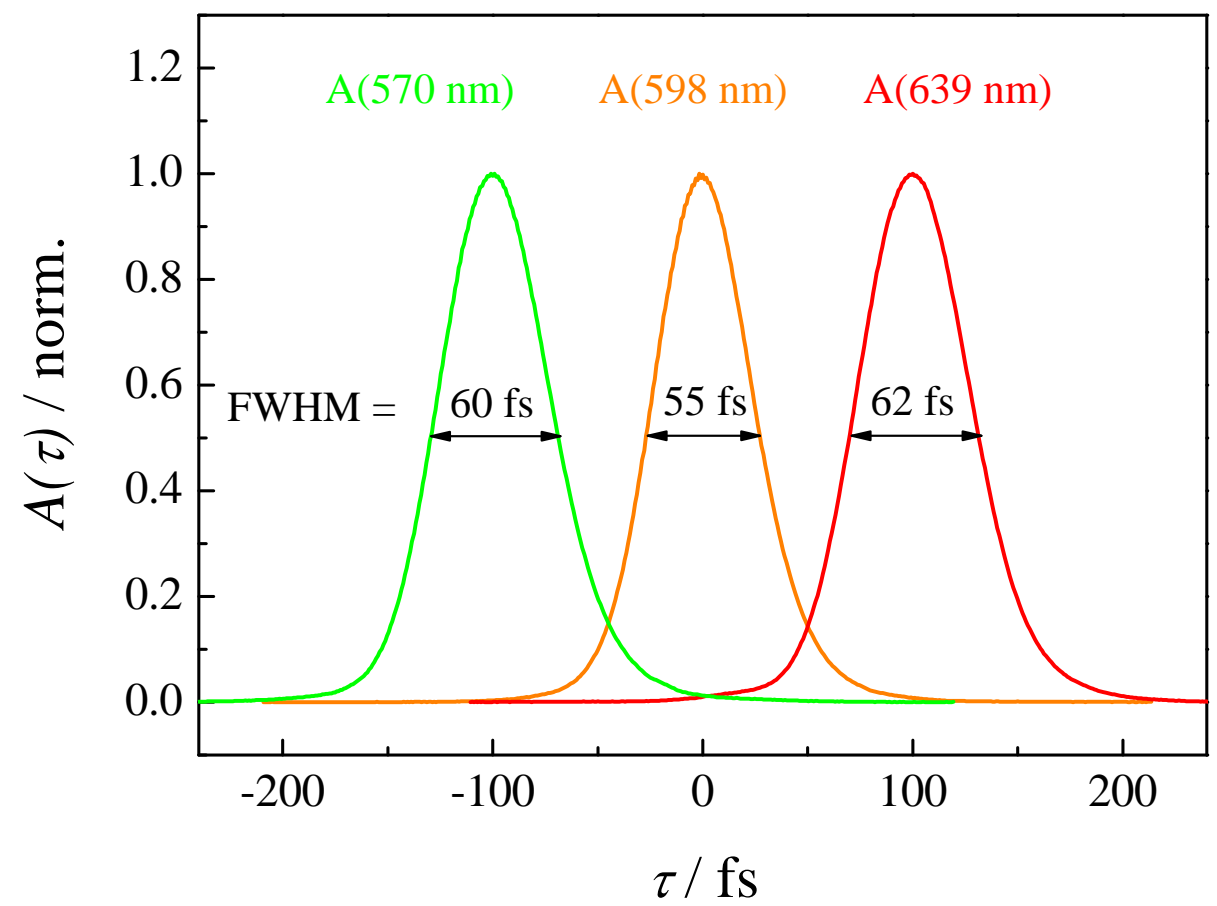

Abbildung 3.4: Autokorrelationen der im OPA generierten und verstärkten Femtosekundenpulse einiger ausgewählter Wellenlängen. Zur Übersichtlichkeit wurden die Autokorrelationen verschoben. 
Die Charakterisierung der Pulse bezüglich ihrer Länge wurde über die Messung der Intensitätsautokorrelationsfunktion ${ }^{68}$ mittels eines dafür aufgebauten Autokorrelators vorgenommen:

$$
A(\tau)=\int_{-\infty}^{+\infty} I(t) \cdot I(t+\tau) d t
$$

Über einen spektralen Bereich von 470 bis $700 \mathrm{~nm}$ liefert der optische parametrische Verstärker Pulse mit einer Halbwertsbreite von 35 bis $40 \mathrm{fs}$, wenn von gaußförmigen Pulsprofilen ausgegangen wird. Die Autokorrelationen des im OPA erzeugten Lichtes sind für einige ausgewählte Wellenlängen in Abbildung 3.4 dargestellt.

Die Spektren der Pulse wurden mit einem Spektrometer (IST-REES E 2000) für verschiedene Mittenwellenlängen aufgenommen. Sie sind in Abbildung 3.5 abgebildet können näherungsweise durch ein Gauß-Profil beschrieben werden. Die Halbwertsbreiten betragen je nach Wellenlänge 8 bis $17 \mathrm{~nm}$, einem bandbreitenlimitierten Puls entsprechend.

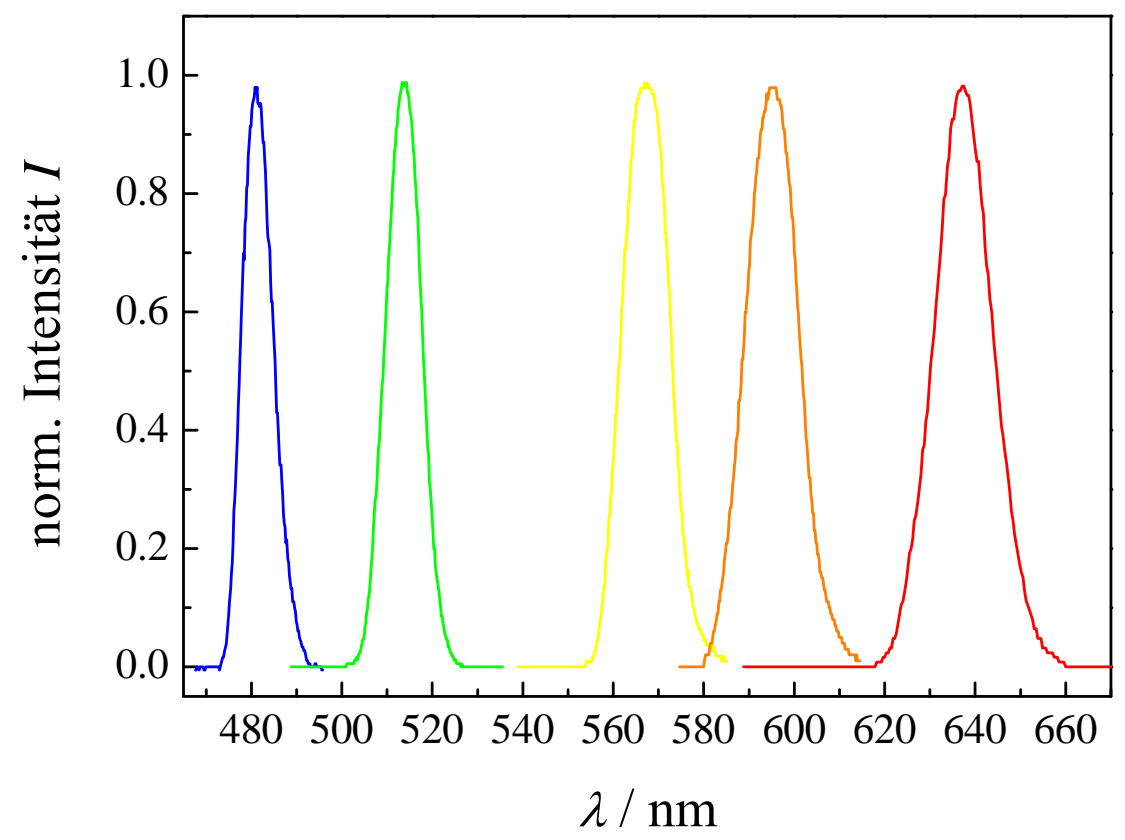

Abbildung 3.5: Spektren der im OPA generierten und verstärkten Femtosekundenpulse 


\subsection{Pump-Probe Absorptionsspektroskopie}

Das Ziel der Kurzzeitspektroskopie ist die Quantifizierung der systemeigenen Dynamik auf einer Femtosekundenzeitskala. Das zu untersuchende System wird dabei durch einen Anregungspuls (Pumppuls) aus seinem Gleichgewichtszustand gebracht und die Relaxation in diesen zurück oder einen neuen mit einem Nachweispuls (Probepuls) abgefragt.

Bei der hier eingesetzten zeitaufgelösten Pump-Probe Absorptionsspektroskopie wird der Chromophor mit einem Femtosekundenpuls elektronisch angeregt. Die Relaxation kann entweder in den Gleichgewichtszustand durch Fluoreszenz oder innere Konversion erfolgen oder in einen neuen Gleichgewichtszustand übergehen, als Folge photochemischer Umsetzungen, wie Protonentransfer, Isomerisierungen oder ähnlichen Prozessen. Ein zweiter leistungsschwächerer Puls, der zu dem Pumppuls zeitlich verzögert ist, wird als Probepuls verwendet, der die Antwort des Systems über dessen Transmissionseigenschaften nachweist. Dabei können entweder die transiente Absorption in einen höheren angeregten Zustand oder die stimulierte Emission in den oder einen anderen Grundzustand beobachtet werden, sofern die Nachweiswellenlänge in einem spektralen Bereich liegt, der der Energiedifferenz der betreffenden Zustände entspricht. Dieses Verhalten wird im Experiment als pumpinduzierte Änderung der Intensität des Probelichtes beobachtet. Ihre Dynamik wird durch die zeitliche Verzögerung von Pumpzu Probepuls aufgenommen. Die physikalische Größe ist die Relaxationszeit $T_{1}$ des angeregten Zustands. Wird als Nachweispuls ein breitbandiges Spektrum verwendet, so können zeitaufgelöste transiente Spektren (Differentielle Transmissionsspektren) aufgenommen werden.

\subsubsection{Experimentelle Vorstudien}

Da Experimente zur transienten Absorption bzw. stimulierten Emission von GFP nur von Lossau et al. ${ }^{32}$ bei lediglich zwei Probewellenlängen durchgeführt wurden und das Verhalten des GFP nach elektronischer Anregung daher nur sehr lückenhaft charakterisiert war, erfolgten zum Abtasten des Spektralbereichs vorab Messungen mit dem folgenden einfachen experimentellen Aufbau. Der Pumppuls bei einer Wellenlänge von $400 \mathrm{~nm}$ konnte durch Erzeugung der zweiten Harmonischen in einem BBO-Kristall $\left(d=0.5 \mathrm{~mm}, \theta=29.2^{\circ}\right)$ erhalten werden. Zur Kompensation der positiven Gruppengeschwindigkeitsdispersion wurde er über eine Prismenkombination, wie in Abbildung 3.6 gezeigt, geleitet. Um minimale Verluste beim Durchlaufen der Prismenkombination zu erreichen, musste die Polarisationsebene des s-polarisierten Pumpstrahls mit einer Kombination aus einem Polarisator und einem $\lambda / 2$-Plättchen um $90^{\circ}$ gedreht werden, damit im Brewsterwinkel für minimale Reflektion für p-polarisiertes Licht gearbeitet werden konnte. Diese Kombination kann darüberhinaus zum Einstellen der Pumpleistung genutzt werden. Der Pumpstrahl passierte dann eine mit einer 
Frequenz von $10 \mathrm{~Hz}$ periodisch bewegte optische Verzögerungsstrecke, mit der die Verzögerung zwischen Pump- und Probepuls variiert wurde. Als Probepuls diente das Weißlichtkontinuum aus dem optischen, parametrischen Verstärker. Pump- und Probepulse wurden über je eine Quarzlinse mit einer Brennweite von $150 \mathrm{~mm}$ fokussiert und im Fokus zur Überlappung gebracht. Die GFP-Probe wurde in diesem Testexperiment mit etwa $10 \mathrm{~mW}$ des $400 \mathrm{~nm}$-Lichtes elektronisch angeregt. Die Dynamik im angeregten Zustand wurde mit einem Probepuls, der eine Leistung von etwa $0.5 \mathrm{~mW}$ hatte, abgefragt. Die Wellenlängenselektion des Probelichtes erfolgte über Interferenzfilter, die vor einem Photomultiplier angebracht wurden.

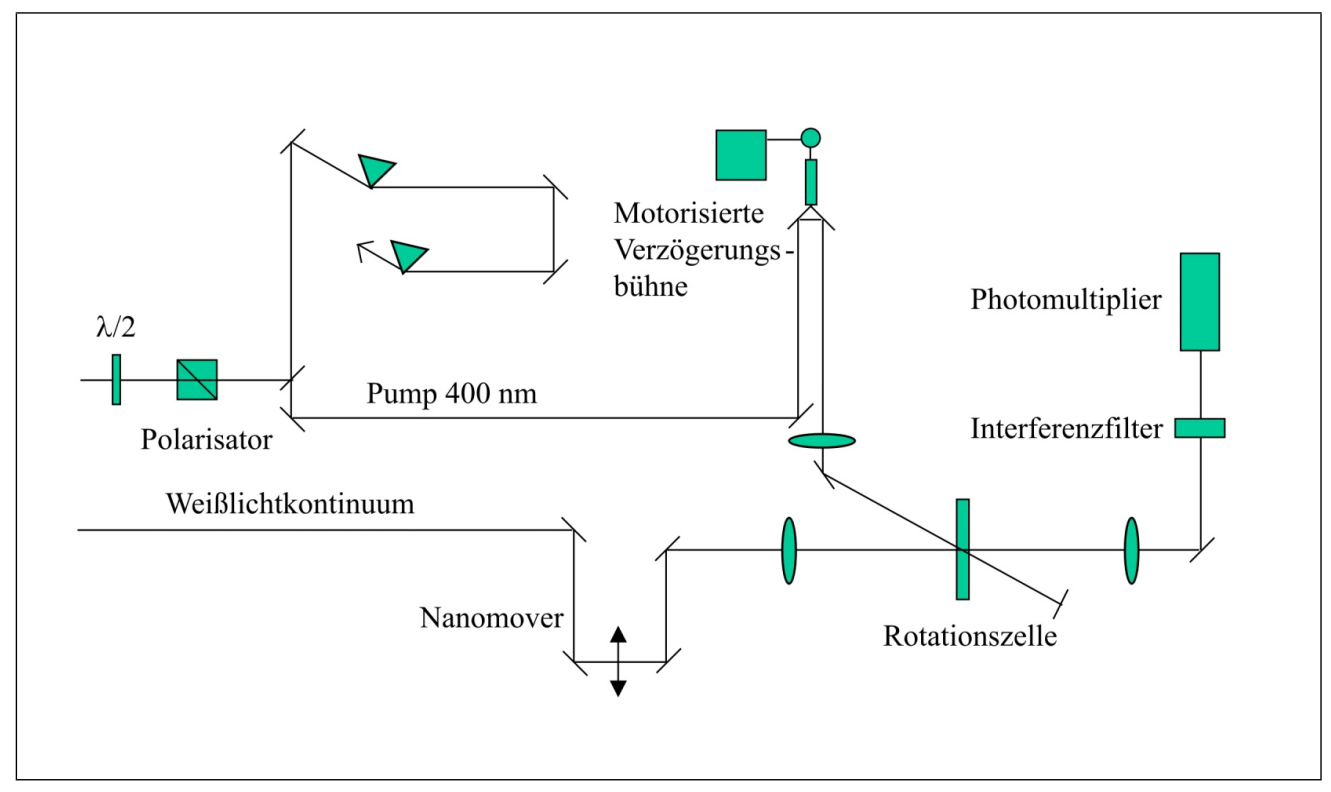

Abbildung 3.6: Vorexperimenteller Aufbau

Obwohl ein Pump-Probe-Experiment, in dem ein Weißlichtkontinuum als Probepuls verwendet wird, in seiner Durchführung sehr einfach zu realisieren ist, hat es zwei Nachteile: zum einen ist die Zeitaufösung in einem solchen Experiment geringer als bei Verwendung kurzer Pulse mit definierter Mittenwellenlänge. Zum anderen hat die Verwendung eines Interferenzfilters bzw. im allgemeinen eines frequenzselektiven Elementes vor dem Detektor eine sogenannte Kreuzphasenmodulation am zeitlichen Nullpunkt zur Folge, welche auf dem Signal erscheint ${ }^{69}$. In Abbildung 3.7 ist ein Pump-Probe-Absorptionssignal von 1,8-Dihydroxyanthrachinon abgebildet, das am Nullpunkt die Kreuzphasenmodulation (starke Intensitätsänderung in Abbildung 3.7) aufweist. Die zeitlich aufgelösten Schwingungskohärenzen (schwache Intensitätsänderungen in 3.7) bei kleinen Verzögerungszeitpunkten $(0.5-2 \mathrm{ps})$ werden von diesem Artefakt überlagert. 
Bei der Kreuzphasenmodulation wird die Phase moduliert und damit die Frequenz des Lichtes verändert, wodurch sich die Lichtintensität, die den Detektor erreicht, je nach Verzögerungszeitpunkt zwischen Pump- und Probepuls ändert. Die Auswertung eines solchen Signals ist schwierig, da die Bestimmung des exakten zeitlichen Nullpunktes erschwert ist und gegebenenfalls Schwingungskohärenzen von dem Artefakt der Kreuzphasenmodulation überlagert werden. Das Weißlichtkontinuum als Nachweiswellenlänge wurde daher durch im optischen parametrischen Verstärker erzeugte Pulse ersetzt.

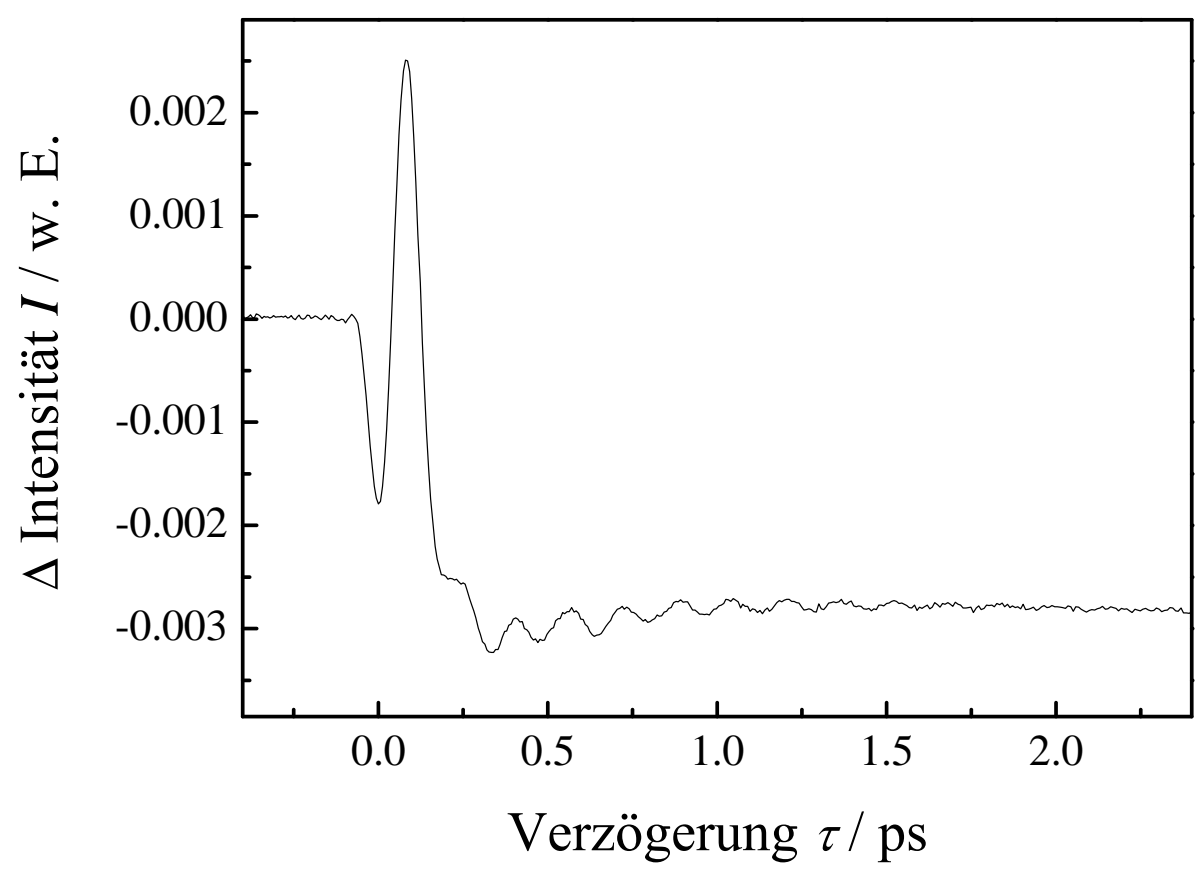

Abbildung 3.7: Pump-Probe-Absorptionssignal von 1,8-Dihydroxyanthrachinon mit Kreuzphasenmodulation am Nullpunkt

\subsubsection{Experimenteller Aufbau}

Das Grün Fluoreszierende Protein hat die Eigenschaft, bei Bestrahlung mit UVLicht zu photokonvertieren, d. h. die optische Dichte der höherenergetischen Absorptionsbande bei $400 \mathrm{~nm}$ nimmt ab, während die der niederenergetischen Bande bei $478 \mathrm{~nm}$ zunimmt. Hinzu kommt die Eigenschaft, dass sich GFP wie die meisten Proteine bei Bestrahlung mit Licht sehr hoher Intensität zersetzen. Die 
Untersuchung des Grün Fluoreszierenden Proteins erforderte daher die Entwicklung von Methoden zur Optimierung des Signal-Rausch-Verhältnisses sowie die Verbesserung der Zellen und der Zellhalterung.

\section{Zelle und Zellhalterung}

Die optimale Methode, eine Flüssigkeit mit Kurzpulstechniken zur beispielsweise transienten Absorption spektroskopisch zu untersuchen, ist der Einsatz eines Jets. Ein Jet besteht aus einer Düse, die über Schläuche mit einem Flüssigkeitsreservoir und einer Pumpe verbunden ist, die die Flüssigkeit mit einer Geschwindigkeit von etwa $5 \mathrm{~m} / \mathrm{s}$ durch die Düse presst. Die Benutzung eines Jets hat den Vorteil, dass im Gegensatz zu einer Küvette keine Glasflächen vorhanden sind, in denen ungewollte Signalbeiträge möglich wären. Außerdem bieten Glasflächen Möglichkeiten zur Ablagerung von Schmutzpartikeln, wodurch verstärktes Rauschen entsteht. Zudem hat der Jet den Vorteil, dass er über ein umfangreiches Flüssigkeitsreservoir verfügt, wodurch die Gesamtlösung länger unzersetzt bleibt. Das GFP kann nicht in einem Jet untersucht werden, da es extrem zeit- und arbeitsaufwendig wäre, etwa $100 \mathrm{ml} \mathrm{GFP} \mathrm{-} \mathrm{die} \mathrm{für} \mathrm{einen} \mathrm{Jet}$ mindestens notwendig wären - mit ausreichender optischer Dichte von etwa 0.3 (etwa $c=3.3 \cdot 10^{-4} \mathrm{~mol} / \mathrm{l}$ ) herzustellen. Darüberhinaus weisen Jets mit relativ zähen Lösungen (z. B. Ethylenglykol) bessere Flusseigenschaften als mit weniger zähen auf, d.h. es werden weniger Turbulenzen mit zähen Lösungen erwartet. Da das GFP vorzugsweise in einer weniger zähen, wässrigen Pufferlösung untersucht wird, ist ein Jet auch aus diesem Grund für die folgenden Experimente ungeeignet. In dieser Arbeit wurde ausschließlich eine Küvette in einer Rotationsvorrichtung verwendet. Die Rotation der Probelösung ist wichtig, um thermische Effekte wie die Aufheizung oder die Ausbildung einer thermischen Linse zu vermeiden. Um thermische Effekte zu verhindern, ist es wünschenswert, dass alle Laserpulse, die mit einer Repetitionsrate von $250 \mathrm{kHz}$ die Lösung erreichen, ein neues Probevolumen treffen. In Abbildung 3.8 ist die Zellhalterung mit der Rotationsvorrichtung abgebildet.

Die Zelle besteht aus einem Boden und einem Deckel aus Quarzglas, zur Abdichtung wird zwischen beiden Teilen ein Teflonring angebracht. Die Glasküvette wird in die Zellhalterung mit Teflon- und Gummiring eingesetzt und schließlich in eine Rotationsvorrichtung eingebracht. Diese besteht aus einem Motor (Faulhaber DC-Motor, 90 W), an dessen Achse ein Zahnrad montiert ist, welches über einen Zahnriemen die Kraft auf das mit dem Lager verbundene Zahnrad überträgt, in dem die Zellhalterung befestigt ist. Das Lager dieser Rotationszelle ist ein System aus zwei gegeneinander befestigten Kugellagern, wobei eines der beiden Kugellager das andere seitlich stabilisiert. Die Verwendung einer Rotationsvorrichtung mit nur einem Lager ist in diesem Falle nicht ausreichend, da es infolge der sehr hohen Umdrehungsgeschwindigkeit 


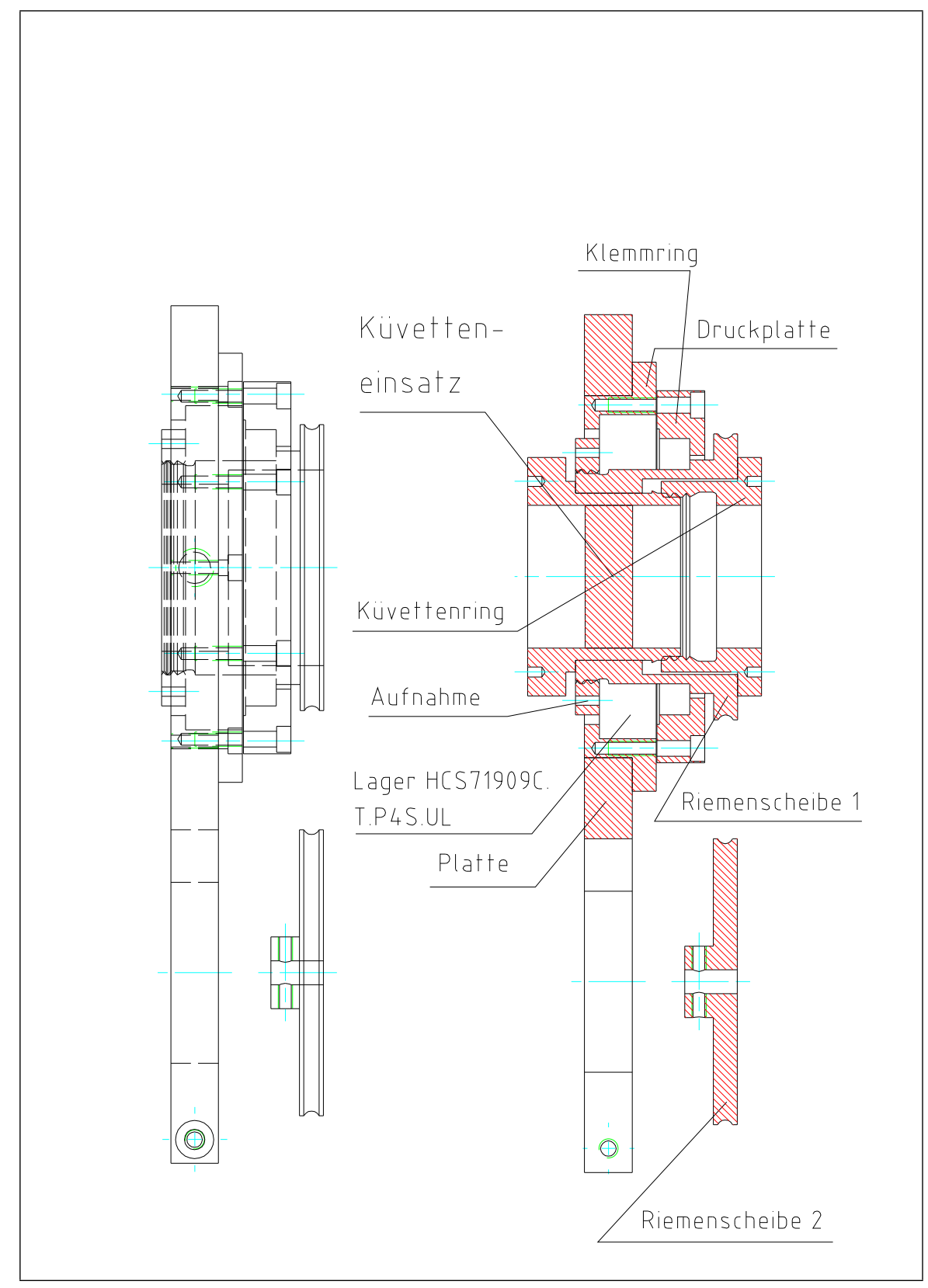

Abbildung 3.8: Zellhalterung mit Kugellager

von 6000 Umdrehungen pro Minute $(100 \mathrm{~Hz})$ und der relativ hohen Masse der Zellhalterung eine zur Rotationsrichtung seitliche Kraft erfährt, wodurch es binnen kürzester Zeit zerstört würde. Dies konnte durch die Verbesserung mit dem doppelten Kugellagersystem verhindert werden.

Problematisch für die Spektroskopie von Substanzen, die sich in der Rotationszelle befinden, ist die hohe Repetitionsrate des Lasers von $250 \mathrm{kHz}$. Soll ge- 
währleistet werden, dass jeder Puls ein neues Probevolumen trifft, so muss eine Rotationsgeschwindigkeit von 24000 upm erreicht werden, wenn angenommen wird, dass der Fokus nur $100 \mu \mathrm{m}$ groß ist und das Licht auf einer Bahn läuft, die einem Radius von $1 \mathrm{~cm}$ entspricht. Dies war unter den gegebenen experimentellen Bedingungen nicht möglich, da die Umdrehungszahl kleiner Motoren begrenzt ist und das Getriebe bei noch höheren Drehgeschwindigkeiten innerhalb kürzester Zeit zerstört würde. Die Experimente wurden daher bei einer Geschwindigkeit von 6000 upm durchgeführt. Messungen unter Variation der Umdrehungszahl (1000 - 6000 upm) haben gezeigt, dass sich das entsprechende Signal bezüglich seiner Intensität und seines Zeitverhaltens nicht ändert. Da es bei einer so hohen Rotationsgeschwindigkeit zu Frequenzübertragungen über den Tisch auf das Lasersystem kommt, musste die Rotationsvorrichtung vom Lasertisch entkoppelt werden. Dies wurde in einfacher Weise durch Installation eines weiteren Tisches, der nicht mit dem eigentlichen Lasertisch verbunden war, erreicht.

\section{Detektion}

Durch die Wahl der Detektion in den zeitaufgelösten Pump-Probe-Messungen konnte eine deutliche Verbesserung des Signal-Rausch-Verhältnisses erzielt werden. Bei den Vorexperimenten diente zur Detektion ein Photomultiplier (1 P 28 Hamamatsu), bei dem nur 7 von 10 Dynoden zur Verstärkung genutzt wurden und den ein Netzteil mit einer Spannung von $700 \mathrm{~V}$ versorgte. Der Einsatz von Photomultipliern ist notwendig, wenn die Signale sehr schwach sind. Sie haben jedoch den Nachteil, dass sie im Vergleich zu Photodioden ein relativ großes Rauschen aufweisen, das unter anderem davon resultiert, dass jede Dynode einen wesentlichen Rauschbeitrag liefert. Da bei den in dieser Arbeit vorgestellten Experimenten genügend Lichtintensität vorhanden war, wurde nach den Vorexperimenten auf Photomultiplier verzichtet und stattdessen batteriebetriebene Photodioden verwendet. Bei den Photodioden handelte es sich um StandardSiliziumphotodioden (SD 200-13-23-042, Silicon Detector Corporation) mit einer Fläche von $5 \times 5 \mathrm{~mm}^{2}$ und einer Anstiegszeit von $50 \mathrm{~ns}$ (bei $50 \Omega$ ).

Der Einsatz von Photodioden brachte eine enorme Verbesserung des SignalRausch-Verhältnisses um einen Faktor von mindestens 10, wie Abbildung 3.10 zeigt.

\section{Referenztechnik}

Die Photokonversionseigenschaft des GFP und seine Zersetzungstendenz erlauben es nicht, das Probevolumen mit hoher Leistung anzuregen. Um mit einer Probe längere Zeit arbeiten und reproduzierbare Messungen erhalten zu können, darf die Pumpleistung nicht größer als maximal $2 \mathrm{~mW}$ sein. Die pumpinduzierten Änderungen der Probelichtintensität sind aufgrund dessen klein, so dass umso mehr Bemühungen angestellt werden müssen, um ein gutes 
Signal-Rausch-Verhältnis zu erzielen.

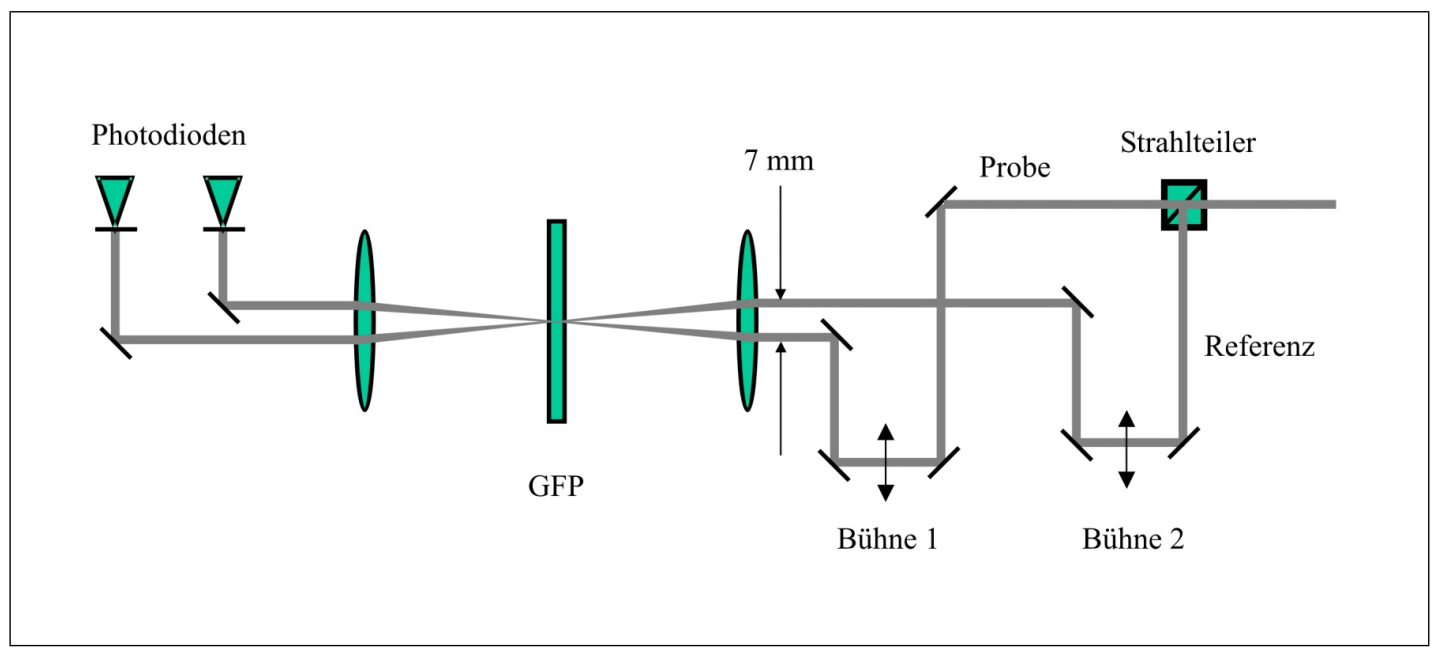

Abbildung 3.9: Referenztechnik

Große Probleme bereitete die Unterdrückung des Laserrauschens, d.h. der Intensitätsfluktuationen des Lasers, sowie des Rauschens, das durch die Rotation der Zelle erzeugt wurde - einerseits infolge räumlicher Ablenkung des Probestrahls, andererseits durch Reflexe an der Rotationsküvette und an den Linsen. Dies konnte zum einen durch das Schleifen der Zellfenster unterdrückt werden, so dass sie eine Planparallelität mit weitaus höherer Genauigkeit erhielten und die Ablenkung des Lichtstrahls bei Rotation der Zelle minimiert wurde. Zum anderen wurde der Probestrahl mit einem 50-prozentigem Strahlteilerwürfel geteilt, wovon ein Teil als Probe (über die Bühne 1 in Abbildung 3.9 gelenkt) und der andere als Referenz (über Bühne 2 geleitet) verwendet wurde. Beide Strahlen liegen parallel zueinander mit einem Abstand von $7 \mathrm{~mm}$ auf der Fokussierlinse und werden in der Probelösung überlagert. Der Referenzpuls erreichte die Probelösung zeitlich vor dem Pump- und Probepuls und lieferte daher keinen Signalbeitrag. Da der Referenzstrahl dasselbe Probevolumen trifft wie der Probestrahl, detektiert er all diejenigen Störungen, die durch das Laserrauschen sowie Partikel oder Fluktuationen im Probevolumen entstehen. Bei Differenzbildung der beiden Strahlen verschwinden diese Beiträge größtenteils. Diese Technik führte zu einer deutlichen Verbesserung des Signal-Rausch-Verhältnisses um einen Faktor zehn. Abbildung 3.10 zeigt ein Signal aus einer Messung ohne Referenztechnik und unter Verwendung eines Photomultipliers. Das obere Signal, das zur Übersichtlichkeit entlang der Ordinate verschoben wurde, resultiert aus einer Messung mit Referenztechnik und mit Photodioden.

Trotz dieser Verbesserung konnte Rauschen, das mit einer Frequenz von $100 \mathrm{~Hz}(6000 \mathrm{upm})$ starker Intensitätsänderung auf dem Signal erschien, auch 


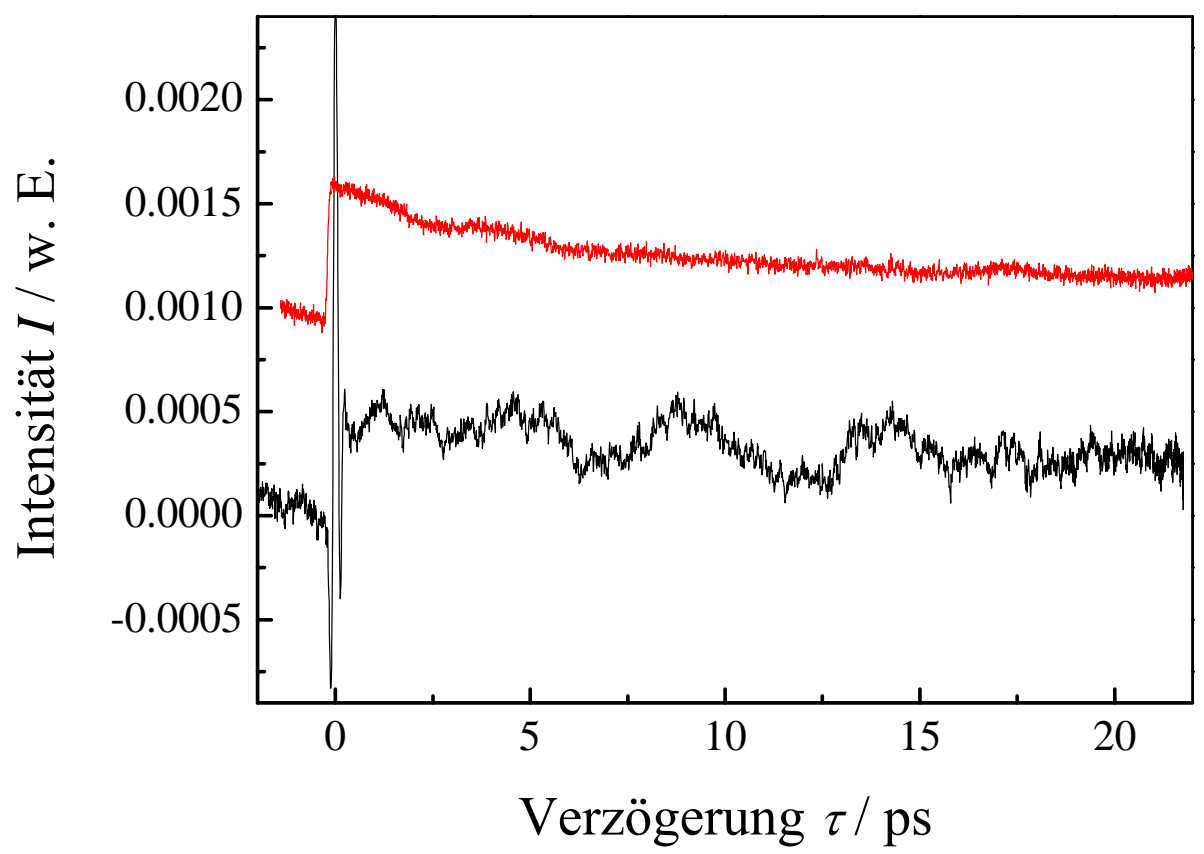

Abbildung 3.10: GFP-Pump-Probe-Signale; Unten: Signal aufgenommen ohne Referenz mit einem Photomultiplier; Oben: Signal aufgenommen mit Referenz mit zwei Photodioden, verschoben entlang der Ordinate; Hierbei ist zu beachten, dass das untere Signal unter Anregung mit etwa $10 \mathrm{~mW}$ Pumpleistung aufgenommen wurde, während das obere Signal mit maximal $1 \mathrm{~mW}$ angeregt wurde.

mit dieser Technik nicht unterdrückt werden. Dieses Rauschen hatte prinzipiell drei Ursachen: Erstens war die Planparallelität der Küvette noch nicht ausreichend, so dass der Strahl auf den Detektoren aufgrund der Ablenkung durch die Glasflächen wanderte. Außerdem konnte die gesamte Zellhalterung nicht so gefertigt werden, dass auch bei optimaler Planparallelität der Zelle, das Gesamtsystem (Zelle, Zellhalterung und Rotationsvorrichtung) ebenfalls optimal planparallel ist. Zweitens hat die eben beschriebene Anordnung der Referenztechnik (Abbildung 3.9) den Nachteil, dass Reflexe, die beispielsweise von der Kollimationslinse kommen, nicht in den eintreffenden Strahl zurücklaufen, sondern auf die Fokussierlinse versetzt treffen, dann wieder reflektiert werden und so auf die Detektoren treffen. Bei der Reflexion gehen sie wiederum durch die nicht perfekt planparallele Zelle und führen so zu einem Rauschen, das auf dem Signal periodisch mit einer Frequenz von $100 \mathrm{~Hz}$ erscheint. Die dritte Rauschursache sind Schmutzpartikel auf den Glasflächen bzw. in Bereichen 
der Lösung, in denen sich die beiden Strahlen räumlich noch nicht oder nur wenig treffen. Da Probe- und Referenzstrahlen in einem Winkel zueinander in die Zelle fokussiert werden, erfährt jeder eine Ablenkung und Streuung durch andere Schmutzpartikel. Streuungen, die so entstehen, können somit nicht kompensiert werden. Aus diesem Grund wurde die Referenztechnik aus Abbildung 3.9 verbessert, indem die beiden Strahlen nun nicht mehr unter einem Winkel in das Probevolumen treffen, sondern kollinear in die Probe fokussiert werden. Damit dies verwirklicht werden konnte, wurde die Polarisationsebene des Referenzstrahls um $90^{\circ}$ gedreht und ein Polarisationsstrahlteiler, wie in Abbildung 3.11 gezeigt, direkt vor der Kollimationslinse eingebaut.

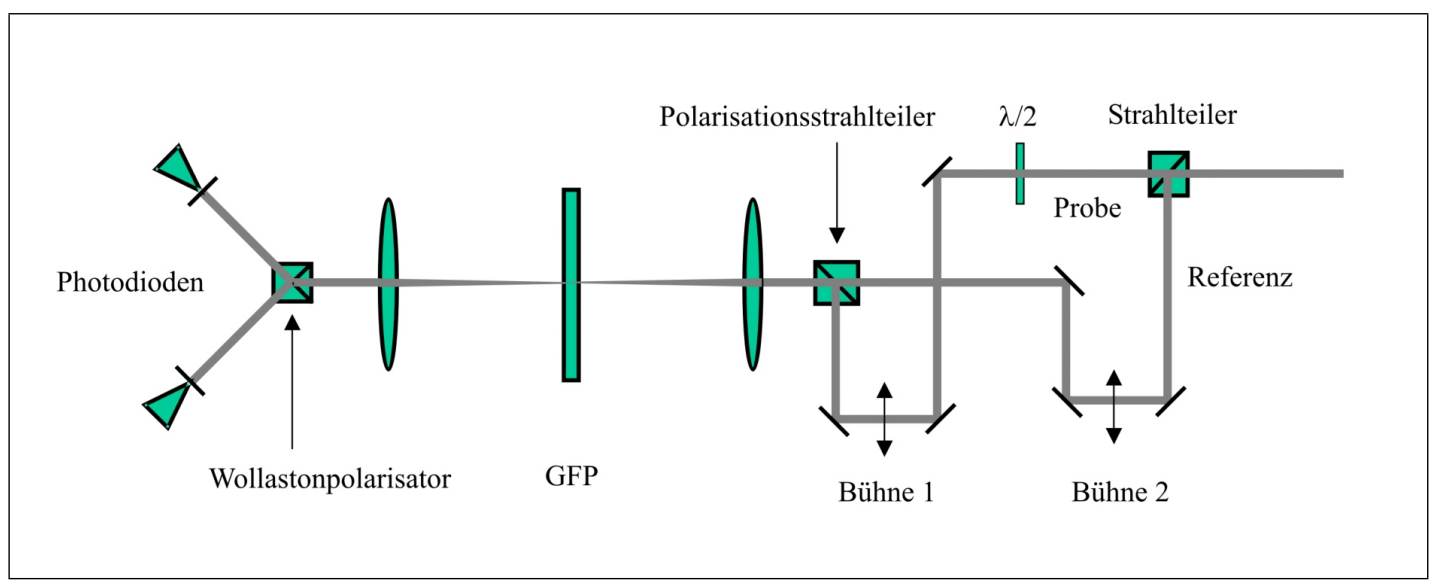

Abbildung 3.11: Verbesserte Referenztechnik

Der Strahl, der über Bühne 1 geleitet wird, erfährt vorher mit einer $\lambda / 2$ Platte eine Drehung um $90^{\circ}$, ist somit s-polarisiert und wird daher im Polarisationsstrahlteiler in einem Winkel von $90^{\circ}$ reflektiert, während der p-polarisierte Strahl (Bühne 2) den Polarisationsstrahlteiler passiert. Beide verlaufen nun perfekt kollinear, so dass beide das gleiche Rauschen detektieren. Probe und Referenz werden nach Passieren der Kollimationslinse durch einen Wollaston-Polarisator räumlich getrennt und treffen dann auf die beiden Detektoren. Die mit einer Frequenz von $100 \mathrm{~Hz}$ auftretenden periodischen Störungen konnten so unterdrückt werden, was zu einer weiteren Verbesserung des Signal-Rausch-Verhältnisses führte. Dies ist in Abbildung 3.12 demonstriert. Die Störungen, die von der Ablenkung der Strahlen infolge der Rotation der Zelle hervorgerufen werden, verschwinden bei Verwendung der Referenztechnik mit Polarisatoren vollständig. 


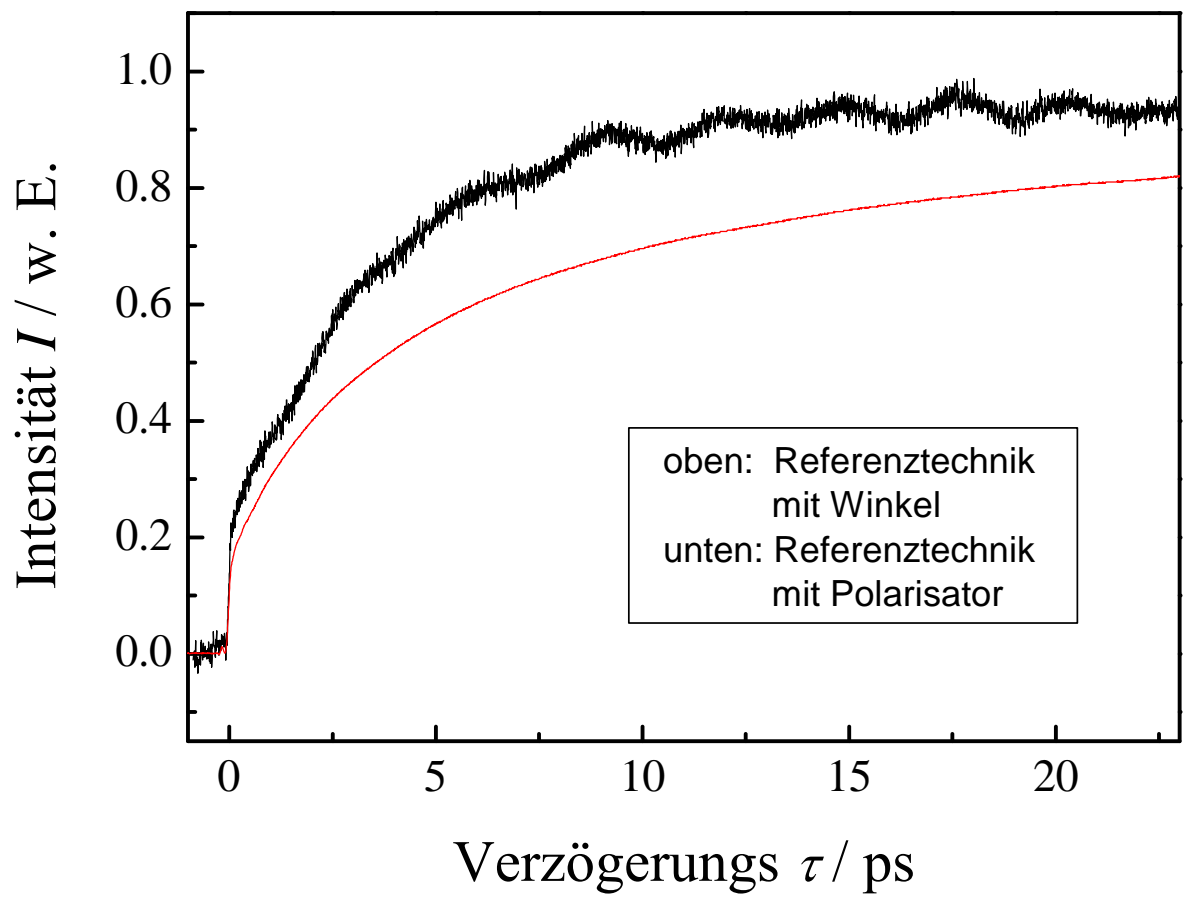

Abbildung 3.12: GFP-Pump-Probe-Signale, die mit verschiedenen Referenztechniken gemessen wurden

\section{Rapid-Scan Methode}

Die Schnelligkeit, ein Signal mit adäquatem Signal-Rausch-Verhältnis aufzunehmen, ist mit Blick auf die Photokonversionseigeschaften des GFP bei seiner spektroskopischen Untersuchungen von großer Bedeutung, da die Photokonversion die Veränderung des dynamischen Verhaltens der Signale zur Folge hat. Deshalb sollte die Mittelung so schnell wie möglich erfolgen. Aus diesem Grund wurde die rapid-scan-Technik eingesetzt. Diese Technik wurde bereits in Experimenten zur Untersuchung des optischen Kerr-Effektes von verschiedenen Flüssigkeiten erfolgreich angewandt ${ }^{70,71}$. Bei der konventionellen step-scan-Technik wird durch eine computergesteuerte optische Verzögerungsbühne (Nanomover), über den z. B. der Probestrahl geleitet wird, jeder einzelne Verzögerungszeitpunkt angefahren. Bei jedem dieser Punkte erfolgt die Mittelung mehrerer Einzelsignale. Diese Methode ist für Messungen am GFP ungeeignet, da die gesamte Messroutine, die aus Nanomoveransteuerung, Mittelung und Datenaquisition besteht, lange dauert. 
Bei der rapid-scan-Technik wird dieses Problem umgangen. Sie basiert auf der höherfrequenten Bewegung (z.B. $10 \mathrm{~Hz}$ ) zweier zur Tischfläche senkrecht stehender Federbleche, auf denen eine rechtwinklige Spiegelkombination montiert ist. Abbildung 3.13 zeigt diese Anordnung. Der zu verzögernde Strahl wird über die Spiegelkombination geleitet, die über die Federn nach vorn und hinten bewegt wird. Dies wird mit einem DC-Motor erreicht, auf dessen Achse ein exzentrisches Rad befestigt ist. Die Exzentrizität kann hierbei je nach gewünschter Gesamtverzögerungszeit $1 \mathrm{~mm}$ oder $2 \mathrm{~mm}$ betragen. Um die Gesamtverzögerungszeit noch zu vergrößern, wurde eine weiterer Reflektor fest installiert, der den Strahl nach oben und schließlich erhöht wieder zurück laufen lässt. Diese Doppelkombination ist auch deshalb vorteilhaft, weil der Strahl bei Bewegung der Federbleche nicht lediglich eine Vor- und Rückbewegung erfährt, sondern auch minimal nach unten abgelenkt wird. Dadurch würde der Strahl in Abhängigkeit der Pump-Probe-Verzögerung wandern, was zu periodischen Intensitätsänderungen des Signals führen kann (jittern). Die Gesamtverzögerungszeit beträgt bei Wahl eines $1 \mathrm{~mm}$-exzentrischen Rades in dieser Anordnung etwa 25 ps und bei einem $2 \mathrm{~mm}$-exzentrischen Rad das Doppelte. Die Frequenz mit der die Federbleche bewegt werden, kann variiert werden, in den hier vorgestellten Experimenten betrug die Frequenz jedoch immer $10 \mathrm{~Hz}$. Das Probelicht, dessen Intensität pumpinduziert verändert ist, trifft schließlich auf die Photodioden, deren Spannung auf ein digitales Oszilloskop (Tektronix TDS 540, 4 Kanäle) gegeben wird, in dem die einzelnen Messkurven gemittelt werden. Das Oszilloskop wird über eine Gabellichtschranke (siehe Abb. 3.13) mit der Frequenz des Motors getriggert. Die Position des Signals entlang der Zeitachse wird ebenfalls mit Hilfe der Lichtschranke festgelegt.

Die vorgestellte rapid-scan Technik ist hervorragend für das verwendete Lasersystem geeignet, da bei der Pulsrepetitionsrate des Lasers von $250 \mathrm{kHz}$ innerhalb eines scans mit einer Dauer von 0.1s 25000 Pulse für eine Verzögerungszeit von $25 \mathrm{ps}$ zur Verfügung stehen. Mit dieser Technik können im Zeitraum von einer Minute somit 600 Messkurven aufgenommen und gemittelt werden. Bei einer dreiminütigen Mittelung konnte ein Signal-Rausch-Verhältnis von mindestens 100:1 bis hin zu 1500:1 erreicht werden. Dies ist unter anderem darauf zurückzuführen, dass Langzeitrauschen bzw. Langzeitfluktuationen nicht mehr relevant sind. Beachtenswert ist die Anzahl der Messpunkte, die nun nicht mehr durch die Schrittweite des Nanomovers festgelegt ist, sondern ausschließlich durch die sampling-Rate des Oszilloskops bestimmt ist. Das Oszilloskop hat eine sampling-Rate von 1GS/s (GS-Gigasample) und ein vertikales Aufösungsvermögen von 8 bit bei jedem scan. In allen Messungen wurden 5000 Punkte pro scan aufgenommen. Das entspricht bei einem Gesamtdelay von 25 ps einem Punktabstand von etwa 6 fs. Die Realzeitachse und die Probelichtintensitäten wurden gleichzeitig im DC-Modus aufgenommen. Nach Beendigung der Mittelungen wurden die Daten über eine GPIB-Schnittstelle zu einem Rechner 


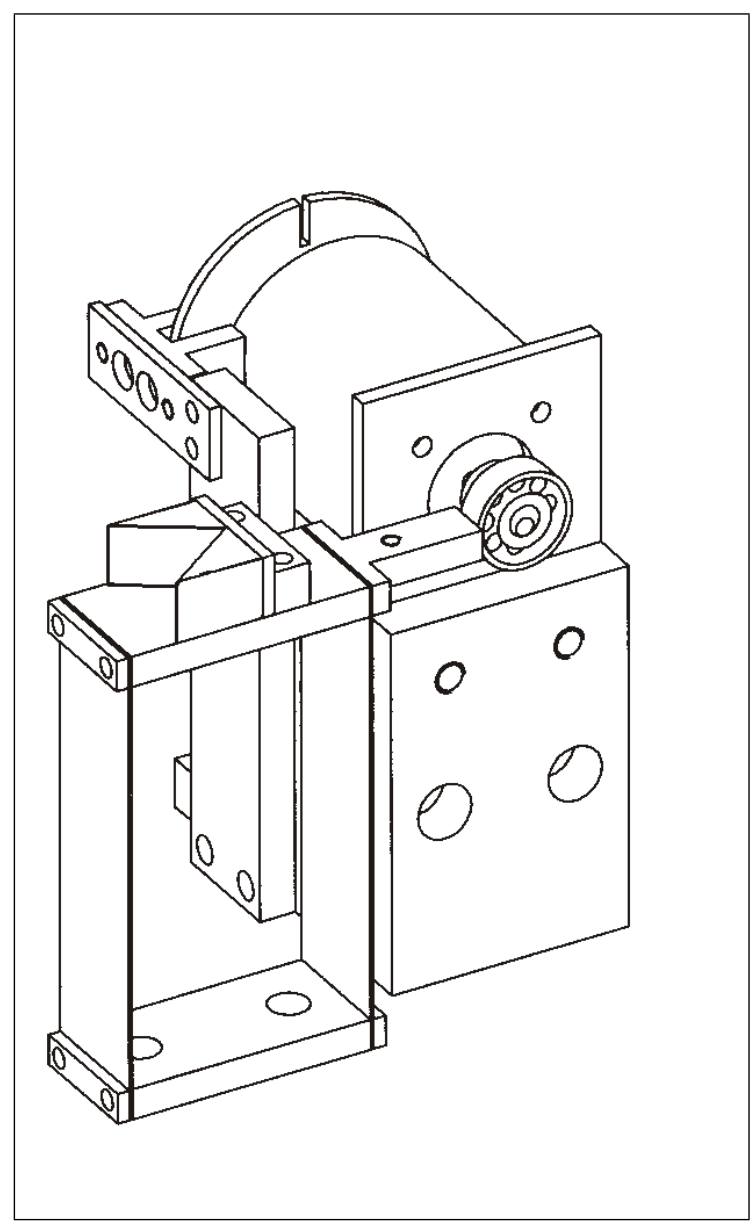

Abbildung 3.13: Rapid-Scan Vorrichtung

transferiert und in einem in HPVEE geschriebenen Programm weiterverarbeitet und gespeichert.

Da die Messdatenaufnahme in Realzeit erfolgt, d.h. die Abszisse entspricht der Zeit, die die Messung eines scans benötigt, und da die Bewegung der Spiegelkombination nicht linear ist, muss die Zeitachse geeicht werden. Dies geschieht über die Aufnahme einer Kreuzkorrelation zwischen Pump- und Probepuls unter Bewegung der Federbleche der rapid-scan Vorrichtung. Diese Kreuzkorrelation, die ein diskretes Maximum darstellt, wird über die schrittweise Bewegung der motorisierten optischen Verzögerungsbühne 1 in Abbildung 3.14 (Melles Griot, Nanomover) entlang der Abszisse des Oszilloskops verschoben. Indem nun die Position der Verzögerungsbühne mit der Position des Maximums entlang der Realzeitskala korreliert wird, ist es möglich eine Kalibration durchzuführen. Es muss weiterhin beachtet werden, dass infolge dieser Nichtlinearität die Punkte nicht gleichmäßig verteilt sind. Dies führt zu Problemen bei der Auswertung der 
Daten, wenn beispielsweise Fouriertransformationen mit Fast Fourier Transform Algorithmen durchgeführt werden sollen. Es ist daher notwendig, die Datenpunkte gleich zu verteilen.

\section{Experiment}

Unter Implementierung der Referenz- und der rapid-scan-Technik sowie der Verbesserung der Detektion konnte ein experimenteller Aufbau, wie er in Abb. 3.14 gezeigt ist, umgesetzt werden. Das Experiment wurde in einer Weise aufgebaut, dass sowohl die Anregungswellenlänge als auch die Abtastwellenlänge variiert werden konnte. Dementsprechend besteht das Experiment im Prinzip aus drei Strahlengängen: dem des Weißlichtkontinuums, dem des im OPA erzeugten Lichtes $(470-750 \mathrm{~nm})$ und dem der zweiten Harmonischen des Ti:Saphir Lasers $(400 \mathrm{~nm})$.

Das Weißlichkontinuum wird durch Fokussierung (Linse mit $f=30 \mathrm{~mm}$ ) von Licht einer Wellenlänge von $800 \mathrm{~nm}$ in ein $3 \mathrm{~mm}$ dickes Saphirsubstrat erzeugt. Zuvor wird die Gruppengeschwindigkeitsdispersion kompensiert, indem das Licht über eine Prismenstrecke geleitet wird. Kompensation der Gruppengeschwindigkeitsdispersion erfolgt auch bezüglich des $400 \mathrm{~nm}$-Lichtstrahls und des im OPA (OPA 9400, Coherent $^{72}$ ) generierten Lichtes, wie in Abbildung 3.14 gezeigt ist. Dienen das Weißlichtkontinuum oder das im OPA erzeugte Licht als Probepuls, wird es in einem Strahlteilerwürfel in gleiche Teile getrennt und als Probe- und Referenzlicht auf die jeweiligen Bühnen geleitet. Unterschiedlich polarisiert werden sie in einem Polarisationsstrahlteilerwürfel wieder vereint und über eine Quarzlinse $(f=150 \mathrm{~mm})$ in die Probelösung fokussiert. Der $400 \mathrm{~nm}$ Puls wird durch Frequenzverdopplung in einem $0.2 \mathrm{~mm}$ dicken BBO-Kristall $\left(\theta=29.2^{\circ}\right)$ erzeugt. Er ist parallel polarisiert und kann in seiner Leistung mit der Kombination aus $\lambda / 2-$ Platte und Polarisator variiert werden. Wird das Weißlichtkontinuum als Probelicht verwendet, muss das Licht vor der Detektion spektral ausgeschnitten werden. Dies wird erreicht, indem es einen Monochromator (The Optometrics Group, Mini-Chrom Monochromators, Spalt: $300 \mu \mathrm{m}, 1800$ Linien $/ \mathrm{mm}, \lambda($ blaze $)=250 \mathrm{~nm})$ passiert. Der Pumppuls wird über die rapid-scan Bühne geleitet und über eine Quarzlinse $(f=150 \mathrm{~mm})$ in die Probe fokussiert. Soll die Anregungswellenlänge variiert werden, wird Licht aus dem OPA als Fundamentale verwendet, über einen Klappspiegel auf die rapid-scan Bühne gelenkt und in einer optischen Anordnung bestehend aus Linsen mit einer Brennweite von $f=100 \mathrm{~mm}$ und einem BBO-Kristall $\left(\theta=31^{\circ}, d=1 \mathrm{~mm}\right)$ frequenzverdoppelt. Als Spiegel für die Wellenlängen $300-390 \mathrm{~nm}$ werden UV-Aluminiumspiegel verwendet, für eine Pumpwellenlänge von $400 \mathrm{~nm}$ können dielektrische Spiegel verwendet werden und für die Probewellenlängen (Weißlichkontinuum, OPA-Licht) werden Silberspiegel eingesetzt. 


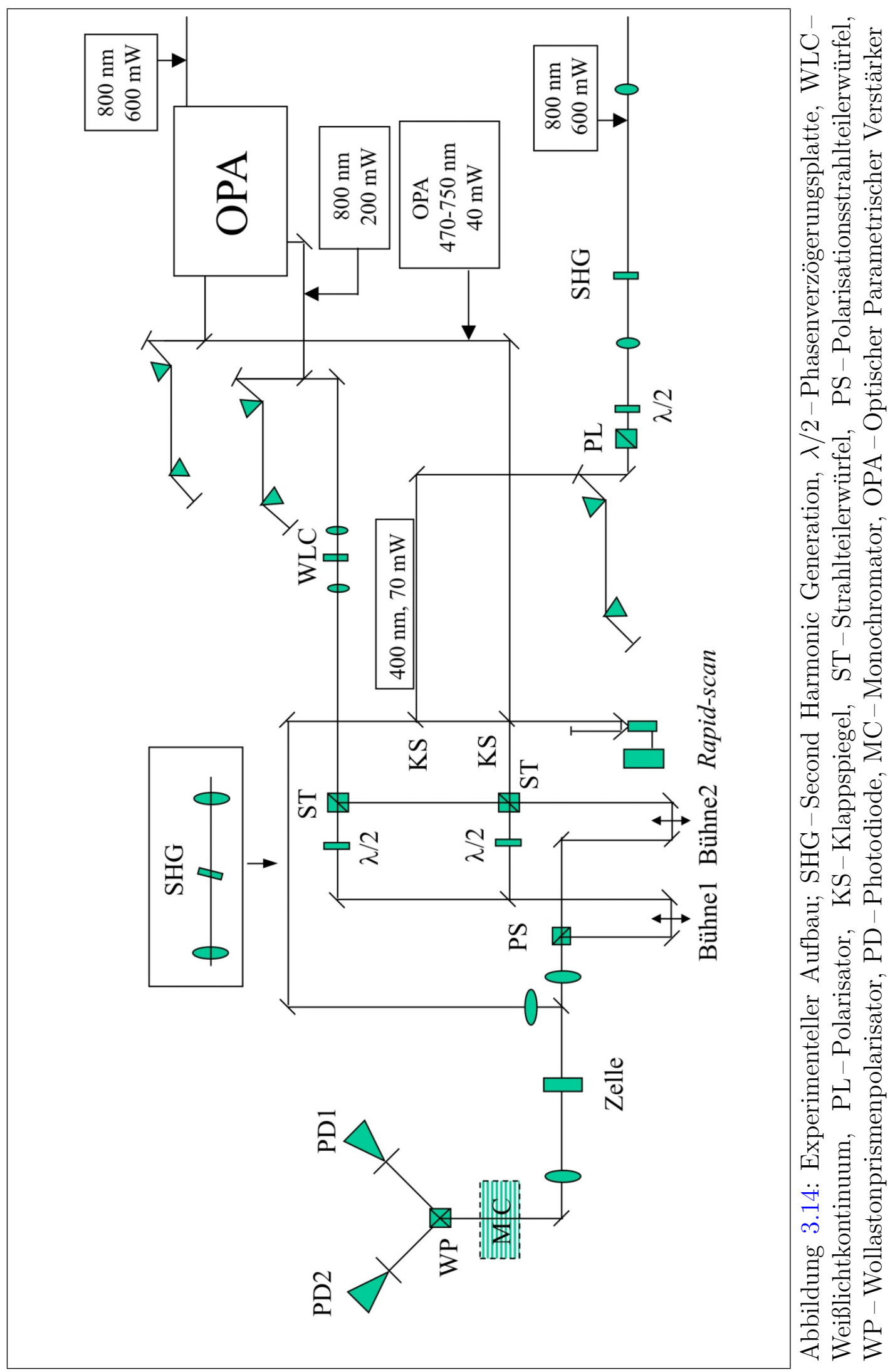




\section{Zeitauflösung}

Die beobachtete Änderung der Transmission $T(\tau)$, die durch den Pumppuls induziert wird, stellt sich als die Faltung von Geräteantwortfunktion $G(\tau)$ und der Kinetik $K(\tau)$ dar:

$$
T(\tau)=\int_{0}^{\tau} K(t) \cdot G(\tau-t) d t .
$$

In einem Pump-Probe-Experiment kann die Geräteantwortfunktion näherungsweise durch die Kreuzkorrelation von Pump- und Probepuls beschrieben werden. Sie wird durch nichtlineare optische Prozesse in einem anisotropen Kristall gemessen - in dieser Arbeit wurde dazu die Summenfrequenz aus Pumpund Probepuls in einem BBO-Kristall der Dicke $d=200 \mu \mathrm{m}$ erzeugt. Für die

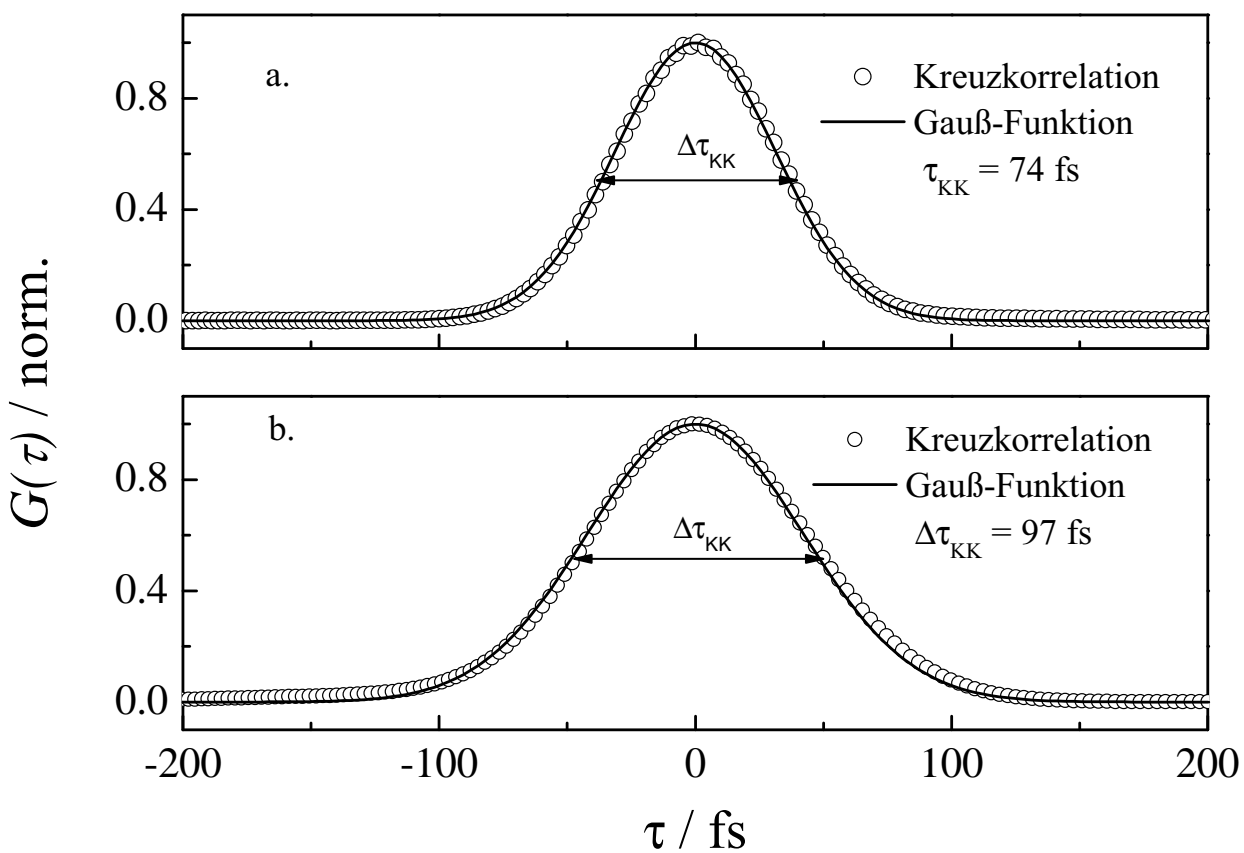

Abbildung 3.15: Kreuzkorrelation (Punkte) von Pulsen der Wellenlängen a. $400 \mathrm{~nm}$ und $600 \mathrm{~nm} ;$ b. $400 \mathrm{~nm}$ und Weißlichtkontinuum ( $700 \mathrm{~nm})$. Zusätzlich sind die jeweiligen Anpassungen mittels einer Gauß-Funktion dargestellt. 
Kreuzkorrelationsfunktion $G(\tau)$ gilt:

$$
G(\tau)=\int_{-\infty}^{\infty} I_{\text {pump }}(t) \cdot I_{\text {probe }}(\tau+t) d t
$$

Obwohl die Kreuzkorrelation ein relativ genaues Maß für die Geräteantwortfunktion ist, wird letztere zusätzlich von den dispersiven Eigenschaften des zu untersuchenden Mediums bestimmt, die sich von denen des Kristalls unterscheiden. Hinzu kommt der Unterschied bezüglich des Wechselwirkungsvolumens von Pump- und Probepuls zwischen Kristall und Medium. Die Schichtdicke der GFP-Lösungen betrug immer $d=1 \mathrm{~mm}$.

In Abbildung 3.15 ist jeweils eine Kreuzkorrelation zwischen einem $400 \mathrm{~nm}-$ Puls und einem im OPA generierten Puls sowie zwischen einem 400 nm-Puls und einer Wellenlänge des erzeugten Weißlichtkontinuums $(\lambda \approx 700 \mathrm{~nm})$ dargestellt. Beide Kreuzkorrelationen wurden mit einer Gauß-Verteilungsfunktion angepasst. Die Halbwertsbreiten der Pulse betragen $\tau=74$ fs, wenn die Kreuzkorrelation aus einem $400 \mathrm{~nm}$ Puls mit einem im OPA erzeugten Puls (a.) gemessen wird, sowie $\tau=97 \mathrm{fs}$ bei der Kreuzkorrelation von Pulsen der Wellenlänge von $400 \mathrm{~nm}$ mit einer aus dem Weißlichtkontinuum (b.).

\subsubsection{Experimente zur Berechnung der Anisotropie}

Um Informationen über die Rotationseigenschaften des Chromophors und des Grün Fluoreszierenden Proteins zu erhalten, wurde die zur Pumppolarisation parallelen und senkrechten Signalkomponenten gemessen und aus beiden die Anisotropie nach Gleichung 3.9 berechnet:

$$
r(t)=\frac{I_{\|}(t)-I_{\perp}(t)}{I_{\|}(t)+2 \cdot I_{\perp}(t)}
$$

Die Aufnahme von parallelem und senkrechtem Signal erfolgte zunächst gleichzeitig und später zur Verbesserung des Signal-Rausch-Verhältnisses in einem weiteren Experiment nacheinander. Der Pumpstrahl war bei diesen Messungen p-polarisiert. Als Probestrahl wurde der ursprünglich p-polarisierte Probestrahl mit einer $\lambda / 2$-Platte (für 200-1200 nm verwendbar) auf etwa $45^{\circ}$ gedreht - der Polarisationsstrahlteilerwürfel in Abbildung 3.14 musste für dieses Experiment durch einen Silberspiegel ersetzt werden. Der Wollastonpolarisator wurde so eingestellt, dass parallele und senkrechte Komponente relativ zur Polarisation des Pumpstrahls gemessen werden konnten. Die Intensitäten der parallelen und senkrechten Polarisation des Probelichtes ohne pumpinduziertes Signal ließen sich über die $\lambda / 2$-Platte aufeinander abstimmen. Da bei diesem Experiment ohne Referenztechnik gearbeitet werden musste, war das SignalRausch-Verhältnis im Vergleich zu den Messungen mit Referenztechnik um 
einen Faktor zehn schlechter. Aus diesem Grund wurden die beiden Polarisationen in einem weiteren Experiment nacheinander gemessen - mit Aufnahme des Referenzsignals. Der experimentelle Aufbau entsprach daher wieder dem aus Abbildung 3.14, mit dem einzigen Unterschied, dass hinter dem letzten Pumppolarisator ein $\lambda / 2-\mathrm{Plättchen} \mathrm{in} \mathrm{den} \mathrm{Strahlengang} \mathrm{eingebaut} \mathrm{wurde,} \mathrm{das} \mathrm{je}$ nach gewünschter Polarisation (parallel oder senkrecht) um $45^{\circ}$ gedreht wurde. Detektiert wurde daher immer die gleiche parallele Polarisation des Probelichtes unter Veränderung der Pumppolarisationsebene. Der Vergleich der berechneten Anisotropien aus beiden Methoden zeigt bezüglich der Amplitude und des Zeitverhaltens Übereinstimmung. Die Messungen weisen jedoch ein deutlich besseres Signal-Rausch-Verhältnis auf, wenn paralleles und senkrechtes Signal nacheinander gemessen wurde.

\subsection{Zeitabhängige Differentielle Transmissions- spektren}

Differentielle Transmissionsspektren wurden in einem Abtastbereich von 470$600 \mathrm{~nm}$ bei einer Pumpwellenlänge von $400 \mathrm{~nm}$ gemessen. Hierbei entsprach der experimentelle Aufbau im Prinzip dem in Abbildung 3.14 mit dem Weißlichkontinuum als Abtastpuls. Bei dem Experiment konnte jedoch im Unterschied zu den zeitaufgelösten Pump-Probe-Messungen nicht gleichzeitig Probe- und Referenzstrahl aufgenommen werden, da nur eine Diodenzeile vorhanden war. Das Licht wurde in einem Spektrometer (Bausch \& Lomb, Auflösung $4 \mathrm{~nm}$ ) in seine spektralen Komponenten zerlegt und auf eine Silizium-Photodiodenzeile (Hamamatsu S3901-512Q) abgebildet. Das Signal wurde an ein digitales Oszilloskop gegeben, in dem die Mittelung mehrerer Messkurven erfolgte. Eine computergesteuerte Verschiebebühne (Melles Griot, Nanomover, Bühne 1) ermöglichte die Verzögerung zwischen Pump- und Probepuls. Zur Berechnung der optischen Dichte $(\triangle O D$ entspricht der Differenz aus den optischen Dichten bei der Probenwellenlänge mit und ohne elektronische Anregung) wurde je einmal bei positiver und einmal bei negativer Pump-Probe-Verzögerung (Probepuls ist zeitlich vor dem Pumppuls) gemessen. Dies war notwendig, da die konventionelle Messtechnik, bei der ein Signal mit und eins ohne Pumppuls aufgenommen wird, die pumpinduzierten Störungen nicht kompensieren konnte. Die optische Dichte kann bei kleinen Änderungen der Probeintensität näherungsweise nach Gleichung 3.10 berechnet werden:

$$
\Delta O D=\frac{I-I_{0}}{I_{0}}
$$

Die Frequenzachse des mit der Diodenzeile aufgenommenen spektralen Ausschnitts wurde mit Interferenzfiltern kalibriert (Genauigkeit $\leq 2 \mathrm{~nm}$ ). 


\subsection{Fluoreszenzkonversionsspektroskopie}

In dieser Arbeit wurden Fluoreszenzkonversionsexperimente durchgeführt (siehe Abschnitt 4.6). Die Experimente basieren auf einem experimentellen Aufbau ${ }^{73}$ nach dem Konzept von Mahr et al. ${ }^{74}$. Diese Arbeiten wurden durchgeführt, um die Anisotropie der Fluoreszenz auf einer Pikosekundenzeitskala zu bestimmen. Die auf diese Weise gewonnenen Signale können keine Überlagerung von stimulierter Emission und transienter Absorption so wie im Pump-Probe-Experiment sein, sondern beruhen ausschließlich auf der Fluoreszenz aus den angeregten Zuständen.

Bei diesen Fluoreszenzkonversionsexperimenten wurde das GFP mit einem Pumppuls von etwa 150 fs Dauer bei einer Wellenlänge von $387.5 \mathrm{~nm}$ elektronisch angeregt. Die entstehende Fluoreszenz wird mit Parabolspiegeln eingefangen und in einen optisch nichtlinearen Kristall fokussiert. Ein zweiter Puls, der zum Pumppuls zeitlich verzögert ist, wird mit der Fluoreszenz im Kristall überlagert, in dem die Summenfrequenzerzeugung beider Wellen stattfindet. Dieser wird als Gatepuls bezeichnet, da er durch Variation der Verzögerungszeit relativ zur zeitabhängigen Fluoreszenz das Beobachtungsfenster festlegt. Auf diese Weise kann die gesamte Fluoreszenz mit einer Sub-Pikosekundenzeitauflösung abgetastet werden. Desweiteren bestimmt der Phasenanpassungswinkel des optischen Kristalls den spektralen Anteil der Fluoreszenz, der beim Mischprozess aufkonvertiert wird. Das aufkonvertierte Licht passiert schließlich einen Monochromator und wird über einen Photomultiplier detektiert. Über den Monochromator kann die spektrale Auflösung des Experimentes festgelegt werden.

Die Anisotropie wird gemessen, indem der Pumppuls einmal p-polarisiert und einmal s-polarisiert in die Lösung eingestrahlt wird. Die Summenfrequenzerzeugung erfolgt nach Typ I, d.h. nur gleiche Polarisationen bilden die Summenfrequenz. Da die Anregung einmal parallel und einmal senkrecht erfolgt, wird automatisch einmal die parallele und einmal die senkrechte Intensität der Fluoreszenz relativ zur Pumppolarisation gemessen. Aus diesen beiden Signalen kann nun die Anisotropie nach Gleichung 3.9 berechnet werden.

\subsection{Zeitkorreliertes Einzelphotonenzählen}

Fluoreszenzabklingkurven im Nanosekundenbereich wurden mittels Zeitkorreliertem Einzelphotonenzählen (TCSPC - Time-Correlated Single Photon Counting) aufgenommen. Der experimentelle Aufbau bestand dabei aus einem Ti:Saphir Oszillator, der mit einer Repetitionsrate von $76 \mathrm{MHz}$ Pulse mit einer Leistung von $300 \mathrm{~mW}$ lieferte ${ }^{75}$. Ein Diskriminator (constant fraction discriminator) und Teiler halbierte die Repetitionsrate auf $38 \mathrm{MHz}$. Mit einem Pulsselektor ( $p u l s e$ pi- 


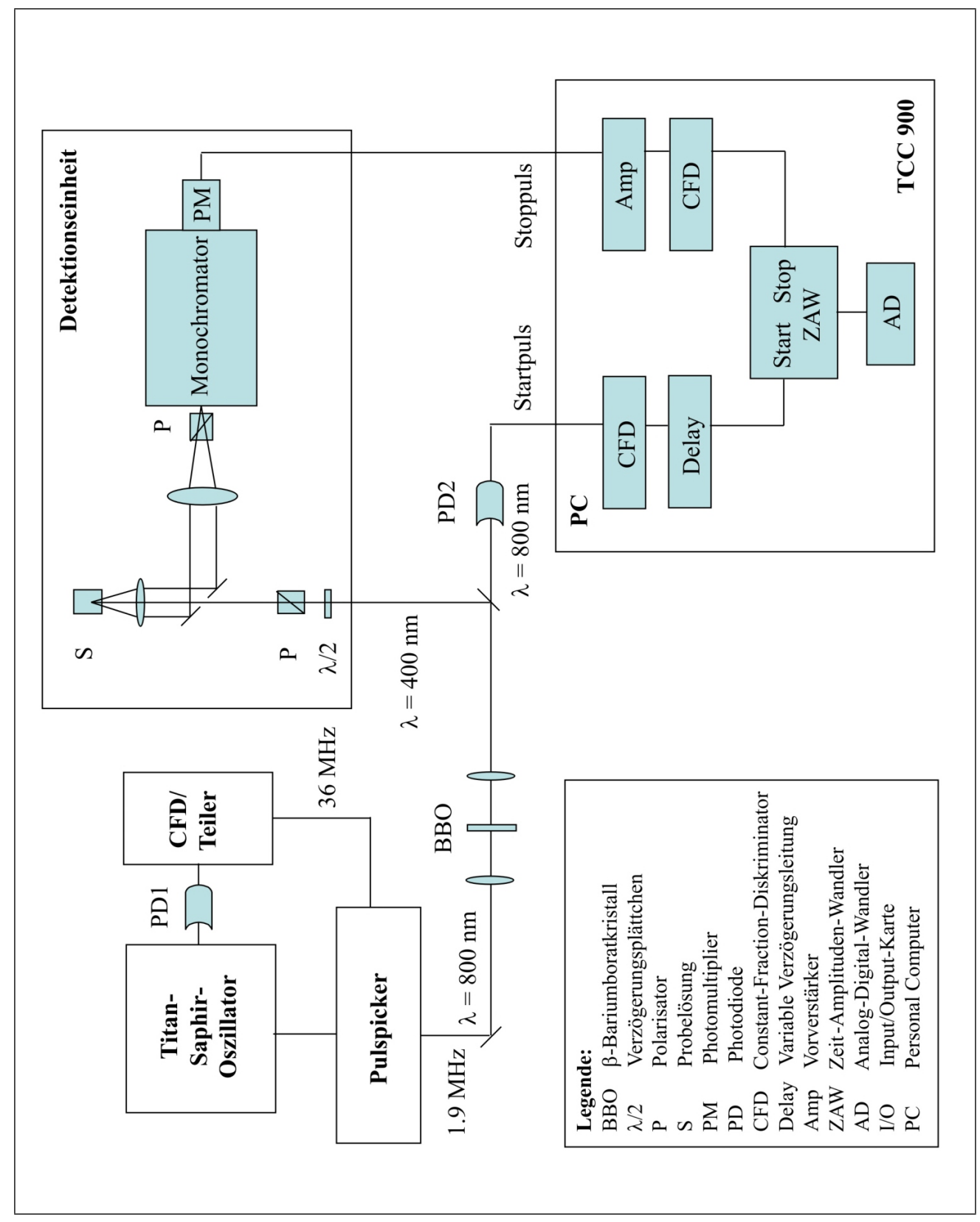

Abbildung 3.16: Schematische Darstellung des Einzelphotonenzählexperimentes mit der Detektionseinheit im oberen Kasten und der Steuerungseinheit im unteren.

cker), der aus einem akusto-optischen Modulator (cavity dumper, $\mathrm{SiO}_{2}$-Kristall) und einem Steuergerät besteht, wurde nun jeder 20-ste Puls ausgewählt (50\% Effizienz), so dass die Repetitionsrate des Lasers schließlich $1.9 \mathrm{MHz}$ betrug. Der frequenzverdoppelte Femtosekundenpuls mit einer Wellenlänge von $400 \mathrm{~nm}$ diente als Anregungspuls. Die in Rückwärtsrichtung abgestrahlte Fluoreszenz, 
wurde mit einem planparallelem Spiegel eingefangen und über eine Linse auf den Spalt eines Monochromators (Amko, Multimode) fokussiert (siehe Abbildung 3.16). Als Detektor am Ausgang des Monochromators diente ein Photomultiplier (Becker \& Hickl, PMH-100-1), der eine Antwortzeit von 150 ps hatte. Um sicherzustellen, dass nur Einzelphotonenereignisse stattfinden, wurde die Leistung des Anregungslichtes mit Neutralglasfiltern so abgeschwächt, dass Photonen mit einer maximalen Repetitionsrate von 19 bis $90 \mathrm{kHz}$ gezählt wurden (dies entspricht 1-5\% Ereignissen pro Sekunde relativ zu den Ereignissen pro Sekunde des Anregungslichtes - Einzelphotonenereignisse sind somit sichergestellt). Als

Steuerungseinheit des zeitkorrelierten Einzelphotonenzählexperimentes diente eine PC-Karte (TCC 900, Edinburgh Analytical Instruments), die im Wesentlichen aus einem Diskriminator (Constant Fraction Discriminator) für den Start- und Stoppuls besteht, aus einer Zeit-Amplituden-Umwandlungseinheit, einem Multi-Kanal-Analysator sowie der Software für die Datenaquisition und -verarbeitung. Abbildung 3.16 zeigt schematisch ein Einzelphotonenzählexperiment sowie das Prinzip der Steuerungseinheit (TCC 900). Der Startpuls erfolgt über Detektion eines Teils des Anregungslichtes (PD2 in Abbildung 3.16) und der Stoppuls wird durch die mit dem Photomultiplier nachgewiesene Fluoreszenz ausgelöst. Die Messroutine erfolgt im Umkehrmodus (reverse modus), d.h. erst wird der Stoppuls durch die Detektion der Fluoreszenz und dann relativ dazu der Startpuls gesetzt.

Fluoreszenzabklingkurven wurden bei $460 \mathrm{~nm}, 510 \mathrm{~nm}$ und $530 \mathrm{~nm}$ mit einer Polarisation von 54.7 (magischer Winkel) der Fluoresszenz relativ zur Pumppolarisation über einen Zeitbereich von 50 ns aufgenommen. Desweiteren wurde die Fluoreszenz parallel und senkrecht relativ zur Polarisation des Anregungspulses gemessen und aus diesen Signalen die Anisotropie nach Gleichung 3.9 berechnet.

\subsection{Absorptions- und Fluoreszenzspektren}

Stationäre Absorptionsspektren wurden mit einem Spektrometer (Schimadzu, UV 160) in einem Wellenlängenbereich von 200 bis $700 \mathrm{~nm}$ aufgezeichnet. Dabei musste vor und nach jedem Messtag jeweils ein Spektrum aufgezeichnet werden, um den Photokonversionszustand des GFP (vgl. Abschnitt 4.7) zu überprüfen (Verhältnis der optischen Dichten der Banden bei 400 und $478 \mathrm{~nm}$ ). Desweiteren wurde die Temperaturabhängigkeit der Absorption in einem Bereich von $5-55^{\circ} \mathrm{C}$ in einer temperierbaren Zelle gemessen.

Stationäre Emissionsspektren wurden mit einem Fluoreszenzspektrometer (Jobin Yvon, Fluorolog) detektiert. Dabei konnte die Anregungswellenlänge von 400 bis $470 \mathrm{~nm}$ variiert und die resultierenden Spektren in einem Bereich von 420-650 nm aufgezeichnet werden. 


\subsection{Gewinnung des GFP}

Die DNA-Kodierung für GFP wurde in das Plasmid pRSETa kloniert und in Escherichia Coli mit einer C-terminalen Histidinkette exprimiert ${ }^{76}$. Die Zellsuspension wurde zentrifugiert und der Überstand abgenommen und die feste Phase in Plastikbehältern tiefgefroren. $\mathrm{Zu}$ den tiefgefrorenen Zellen wurde eine Phosphatpuffer/Imidazollösung ( $500 \mathrm{mM} / 5 \mathrm{mM})$ gegeben, das ganze anschließend aufgetaut und eine zähe, homogene Suspension mechanisch hergestellt. Die Plastikbehälter wurden mehrmals in flüssigem Stickstoff schockgefroren, in einem $37^{\circ} \mathrm{C}$ warmen Wasserbad wieder aufgetaut und anschließend in einem Ultraschallbad zerkleinert. Das so freigesetzte Protein, das in der wässrigen Phase gelöst war, wurde durch Zentrifugieren von den Zellen abgetrennt.

Ein chelatisierender Nickelharz (Ni-NTA-Agarose, Qiagen, Hilden, Germany) wurde mit einer Phosphatpuffer/Imidazollösung (500 mM/250 mM und $500 \mathrm{mM} / 20 \mathrm{mM}$ ) gewaschen und der Überstand durch Zentrifugieren abgenommen. Die flüssige Proteinphase wurde mit dem Harz vereint und über Nacht bei $4{ }^{\circ} \mathrm{C}$ im Dunkeln bewegt. Die Harzsuspension wurde dreimal mit einer weniger konzentrierten Phosphatpuffer/Imidazollösung $(500 \mathrm{mM} / 5 \mathrm{mM})$ gewaschen und zentrifugiert. Die feste Harz/Proteinphase wurde auf eine mit Puffer/Imidazol (500 mM/5 mM) befüllte Säule gegeben, mit dem 500 mM/20 mM - Puffer gewaschen und das Protein von der Harzphase mit dem $500 \mathrm{mM} / 250 \mathrm{mM}$ - Puffer abgetrennt.

Für die Dialyse der Proteinlösung verwendete man einen Phosphatpuffer mit einem pH-Wert von $p H=7$ aus $10 \mathrm{mM} \mathrm{NaH} \mathrm{PO}_{4} / \mathrm{Na}_{2} \mathrm{HPO}_{4}$ und $100 \mathrm{mM} \mathrm{NaCl}$. Die GFP-Lösung wurde in Dialyseschläuche gegeben und vier Stunden mit einem Magnetrührer in der Pufferlösung bewegt. Danach wurde die Pufferlösung durch eine frische Lösung ausgetauscht und noch einmal über Nacht dialysiert. Die GFP-Lösung wurde in kleine Plastikbehälter gefüllt und die Absorption von jedem Röhrchen gemessen. Mit einer Vakuumzentrifuge wurde die GFP-Lösung eingetrocknet und schließlich bei $-25^{\circ} \mathrm{C}$ tiefgefroren. 



\section{Kapitel 4}

\section{Ergebnisse}

\subsection{Zeitaufgelöste Pump-Probe-Signale}

Zeitaufgelöste Pump-Probe-Transienten wurden in einem Nachweiswellenlängenbereich von 470 bis $730 \mathrm{~nm}$ nach Anregung mit einem Pumppuls der Wellenlänge $400 \mathrm{~nm}$ aufgenommen. Die Energie des Pumppulses betrug dabei etwa $5 \mathrm{~nJ}$, die der im optischen parametrischen Verstärker erzeugten Probepulse jeweils weniger

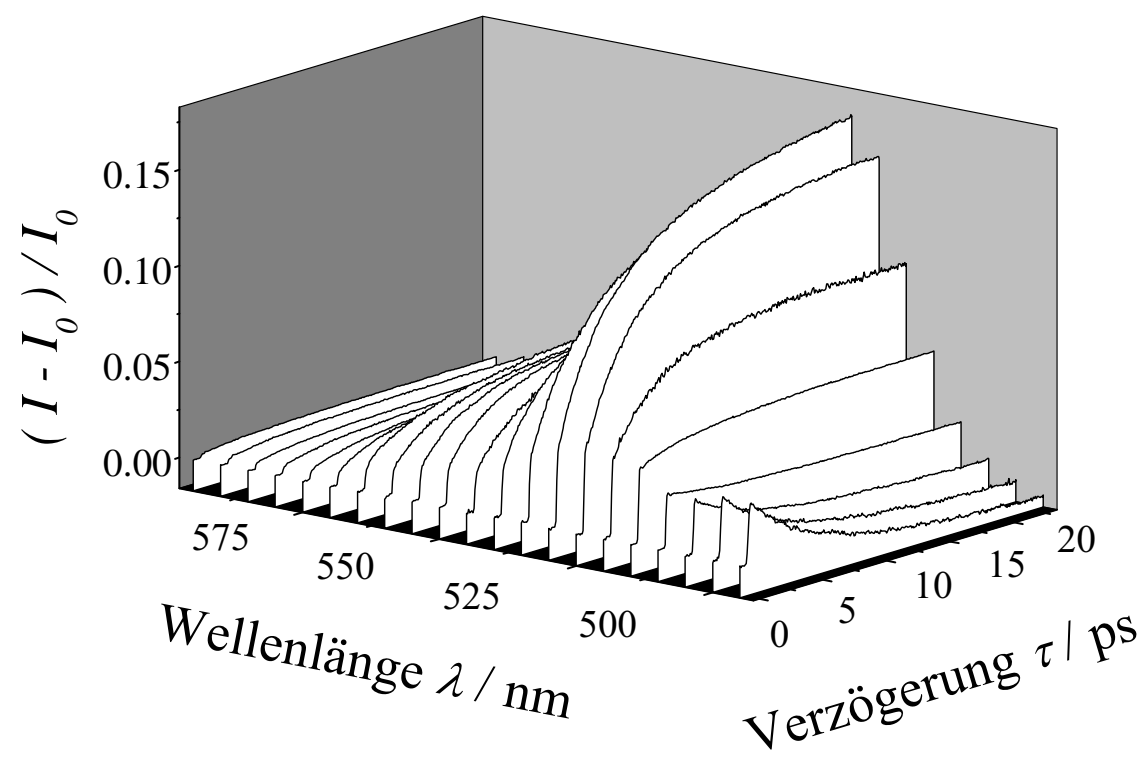

Abbildung 4.1: Zeitaufgelöste Pump-Probe-Signale im spektralen Bereich des stationären Emissionsspektrums bei Anregung mit Licht einer Wellenlänge von $400 \mathrm{~nm}$ in dreidimensionaler Darstellung 
als 1 nJ. Insgesamt wurden 36 Signale aufgezeichnet, die eine maximale PumpProbe-Verzögerungszeit von 25 ps hatten. Die Transienten von 475 bis $630 \mathrm{~nm}$ sind in den Abbildungen 4.1 und 4.2 in dreidimensionaler Form bzw. als Konturliniendiagramm dargestellt. Dabei wurde in den zeitaufgelösten Experimenten die Differenz aus Probestrahl- und Referenzstrahlintensität gemessen (siehe Kapitel 3.3). Da die Energien der Anregungs- und Abtastpulse zwischen den Einzelmessungen stark variierten, wurden die hier gezeigten Transienten bei $\tau=20 \mathrm{ps}$ auf die im Kapitel 4.2 dargestellten differentiellen Transmissionsspektren normiert, in denen $\left(I(t)-I_{0}\right) / I_{0}$ bestimmt wurde. Wie bereits in Abschnitt 3.4 beschrieben, gilt bei sehr kleinen Absorptionen die Beziehung $\left(I(t)-I_{0}\right) / I_{0}$ als Näherung für $\Delta O D(t)$, die wie Gleichung 4.1 definiert ist:

$$
\begin{aligned}
\Delta O D(t) & =O D_{\text {mitPump }}(t)-O D_{\text {ohnePump }}(t) \\
& =-\log \left(\frac{I(t)}{I_{0}}\right)_{\text {mitPump }}+\log \left(\frac{I(t)}{I_{0}}\right)_{\text {ohnePump }} .
\end{aligned}
$$

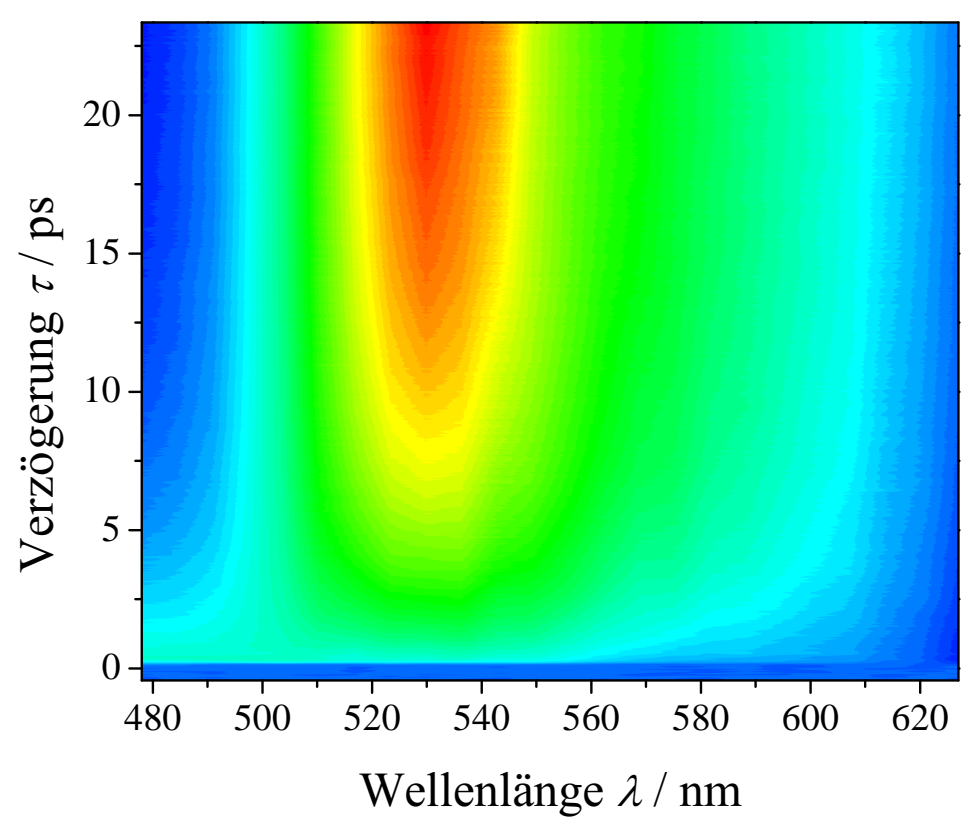

Abbildung 4.2: Zeitaufgelöste Pump-Probe-Signale im spektralen Bereich des stationären Emissionsspektrums bei Anregung mit Licht einer Wellenlänge von $400 \mathrm{~nm}$ als Konturdarstellung 


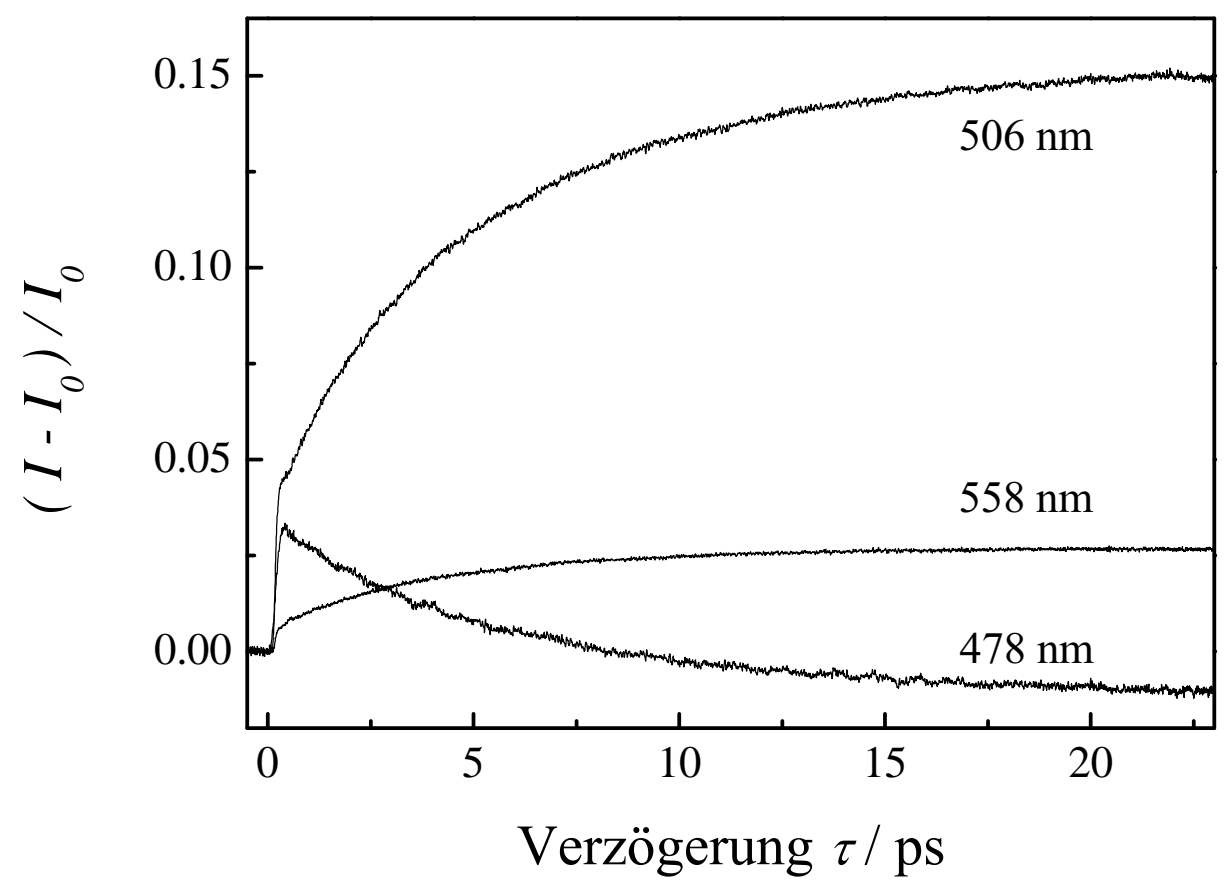

Abbildung 4.3: Repräsentative Transienten für den blauen Spektralbereich $(478 \mathrm{~nm})$, den Bereich in der Nähe des Maximums (506 nm) und den roten Spektralbereich $(576 \mathrm{~nm})$ innerhalb des stationären Emissionsspektrums des GFP.

Die Terme $O D_{\text {ohnePump }}(t)$ und $O D_{\text {mitPump }}(t)$ beschreiben die optische Dichte der Probe mit und ohne Anregungspuls.

Der Bereich von 470 bis $630 \mathrm{~nm}$ ist hauptsächlich durch stimulierte Emission gekennzeichnet, die bei etwa $508 \mathrm{~nm}$ maximal ist (siehe Abschnitt 4.2). Für diesen Bereich charakteristische Signale bei den Nachweiswellenlängen 478, 506 und $576 \mathrm{~nm}$ sind in Abbildung 4.3 zusammengefasst.

In einem Nachweiswellenlängenbereich von 496 bis $630 \mathrm{~nm}$ wächst die stimulierte Emission auf einer Zeitskala von etwa 20 ps multiexponentiell an. Der zeitliche Anstieg in diesem spektralen Bereich kann mit Zeitkonstanten von etwa 2 und 8 ps biexponentiell angepasst werden. Wie in Abbildung 4.4 dargestellt ist, erfolgt dieser relativ langsame Anstieg der Signale immer nach einem innerhalb der zeitlichen Auflösung des Experimentes instantan erscheinenden Signalbeitrag. 


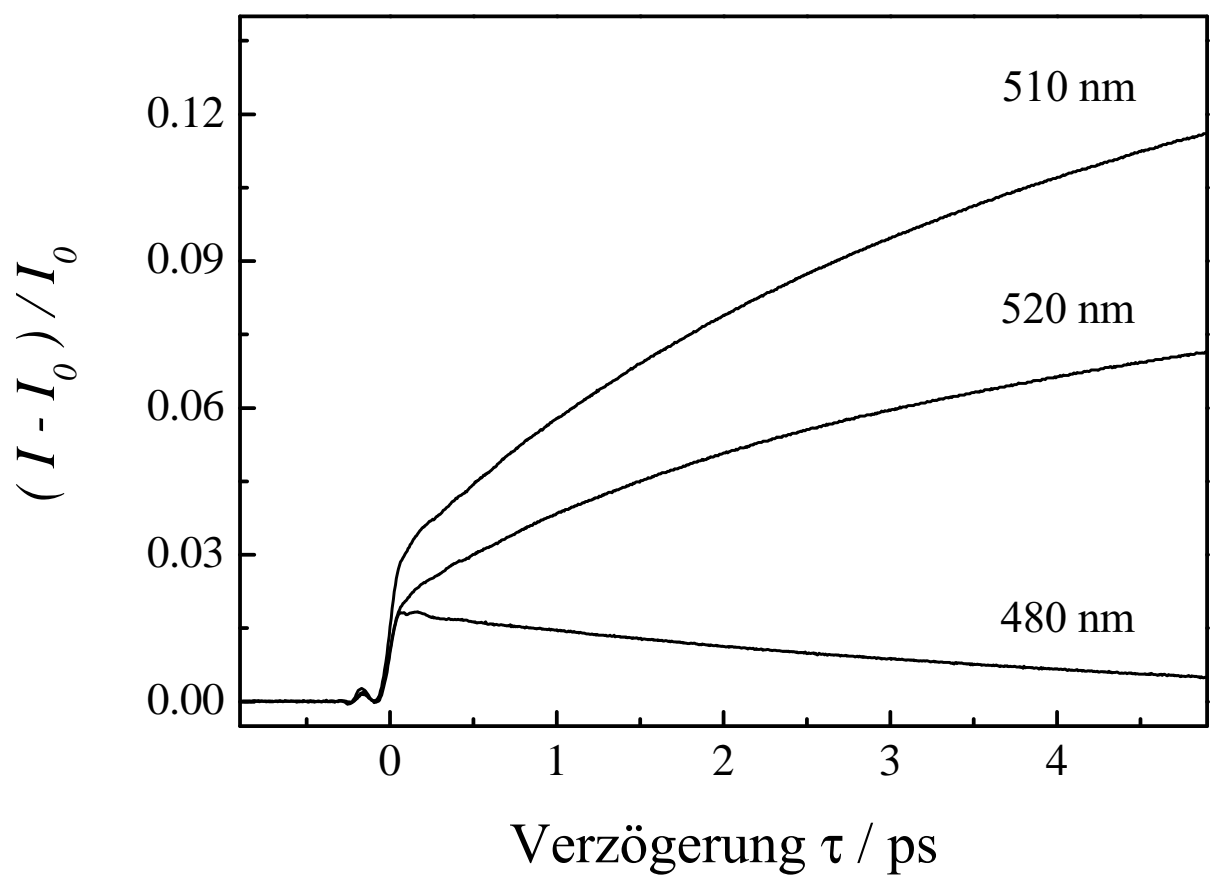

Abbildung 4.4: Verdeutlichung der innerhalb der experimentellen Zeitauflösung instantanen und der verzögerten stimulierten Emission bei verschiedenen Nachweiswellenlängen.

Für Nachweiswellenlängen, die kleiner als $496 \mathrm{~nm}$ sind, erscheint die stimulierte Emission ebenfalls innerhalb der Zeitauflösung des Experimentes instantan und klingt auf ähnlichen Zeitskalen ab (2 und 8 ps, siehe Abbildung 4.3). Wie Abbildung 4.5 veranschaulicht, verhalten sich die Signale bei 494 und $498 \mathrm{~nm}$ für Verzögerungszeiten $\tau$ größer als $500 \mathrm{fs}$ zueinander spiegelbildlich. Bei einer Nachweiswellenlänge von $496 \mathrm{~nm}$ ist die pumpinduzierte optische Dichte zeitlich konstant. Demzufolge entspricht $496 \mathrm{~nm}$ einer isosbestischen Wellenlänge der spektral-zeitlichen Entwicklung des GFP.

Für Nachweiswellenlängen unterhalb von $494 \mathrm{~nm}$ kann ein Vorzeichenwechsel des Signals beobachtet werden. Dieses Verhalten ist in Abbildung 4.3 (478 nm) verdeutlicht. In diesem Wellenlängenbereich können daher sowohl stimulierte Emission (bei frühen Verzögerungszeiten $\tau<5 \mathrm{ps}$ ) als auch transiente Absorption (für $\tau>5 \mathrm{ps}$ ) detektiert werden. 


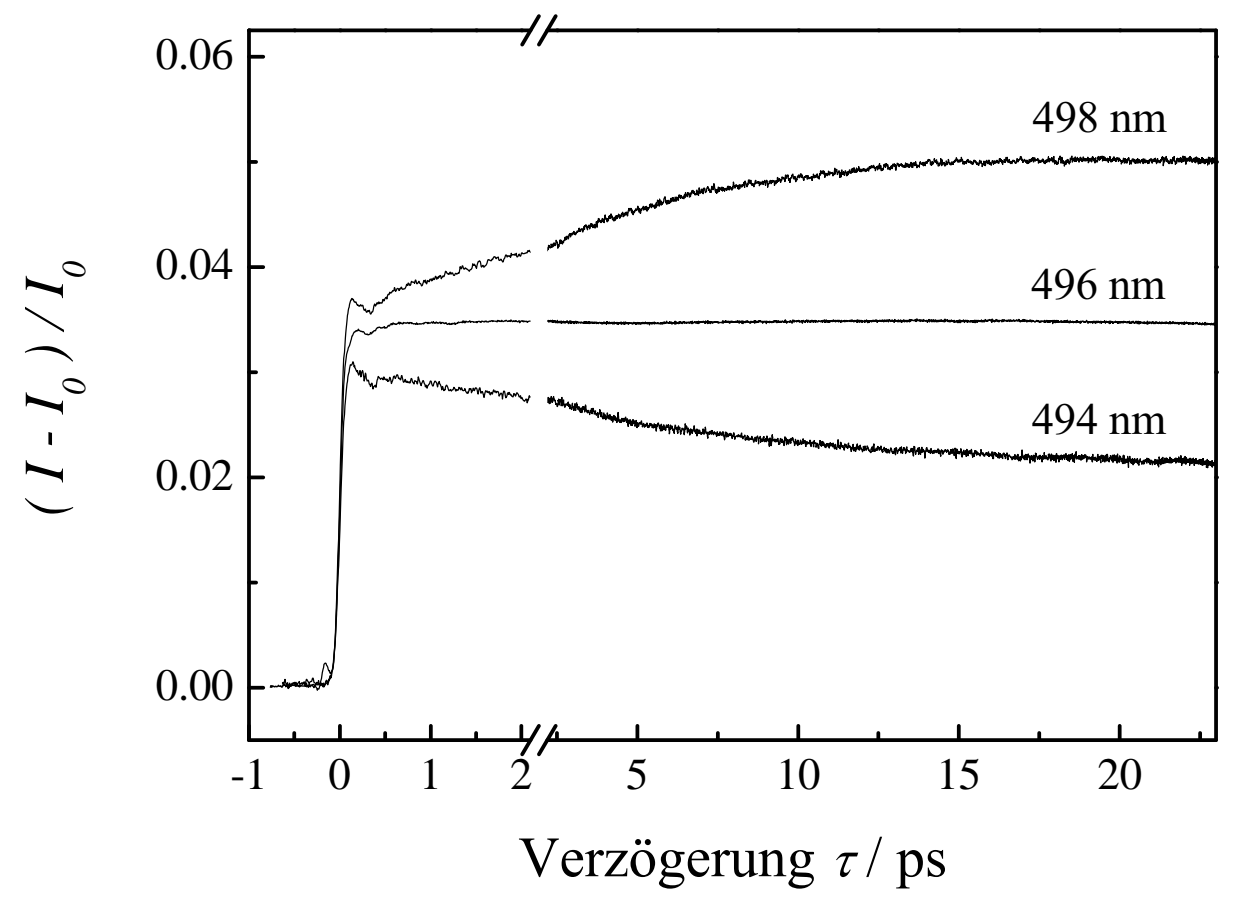

Abbildung 4.5: Repräsentative Signale für den blauen Spektralbereich des stationären Emissionsspektrums des GFP bei den Wellenlängen 494, 496 und 498 nm.

Für Nachweiswellenlängen, die größer als $630 \mathrm{~nm}$ sind, wird eine transiente Absorption beobachtet. Sie erscheint innerhalb der Zeitauflösung und klingt anschließend auf einer Zeitskala ab, die dem Anwachsen der stimulierten Emission für $496<\lambda<600 \mathrm{~nm}$ entspricht. In Abbildung 4.6 sind einige Signale, die repräsentativ für den Spektralbereich $600 \mathrm{~nm} \leq \lambda \leq 730 \mathrm{~nm}$ sind, dargestellt. In dieser Abbildung ist der Übergang von stimulierter Emission $\mathrm{zu}$ transienter Absorption durch die Signale bei $600 \mathrm{~nm}, 627 \mathrm{~nm}, 655 \mathrm{~nm}, 705 \mathrm{~nm}$ und $724 \mathrm{~nm}$ veranschaulicht. Entgegen den Beobachtungen von Lossau et al. ${ }^{32}$ konnte in diesem spektralen Bereich kein isosbestisches Verhalten mit zeitlich konstanter Signalintensität gefunden werden. 


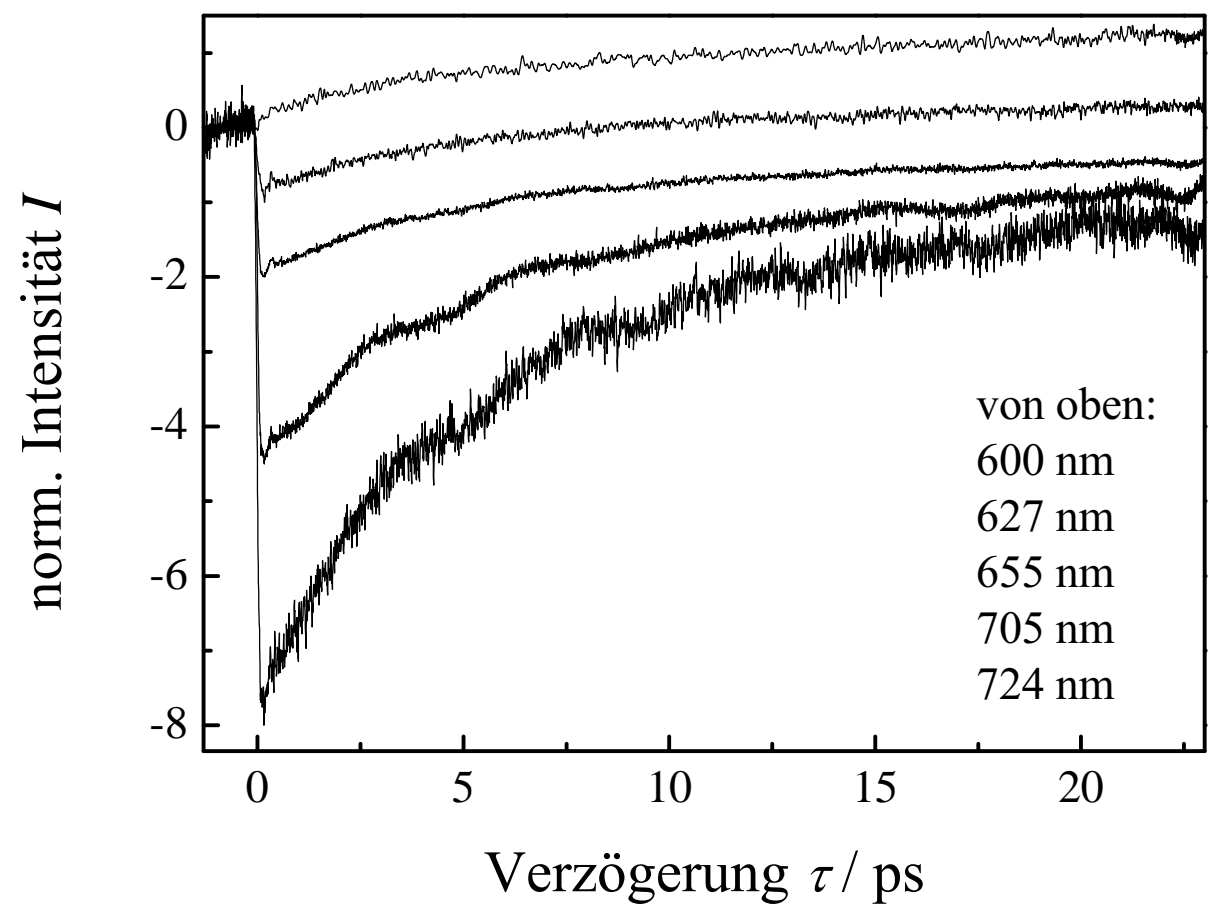

Abbildung 4.6: Repräsentative Transienten für den Spektralbereich für Wellenlängen größer als $600 \mathrm{~nm}$. Für längere Wellenlängen als $630 \mathrm{~nm}$ sind die Signale durch eine transiente Absorption gekennzeichnet. Zur Übersichtlichkeit wurden die auf das Minimum normierten Signale mit einem beliebigen Faktor multipliziert.

\subsection{Zeitabhängige differentielle Transmissions- spektren}

Zeitabhängige differentielle Transmissionsspektren wurden unter anderem aufgenommen, um zu verifizieren, ob bei $496 \mathrm{~nm}$ ein isosbestischer Punkt vorliegt. Zusätzlich dazu erlaubt die Aufnahme differentieller Transmissionsspektren die adäquate Normierung der in Abschnitt 4.1 gezeigten zeitaufgelösten Transienten. (Alle Signale aus diesem Kapitel wurden bereits normiert.) Darüberhinaus ist in diesen Experimenten die spektrale Auflösung von $2 \mathrm{~nm}$ deutlich besser, als die der zeitaufgelösten Pump-Probe-Signale aus Abschnitt 4.1 (Fehler etwa 5 - $8 \mathrm{~nm}$ ). Die Verbesserung der spektralen Auflösung hat sich als notwendig erwiesen, da sich bei Aufnahme der zeitaufgelösten Signale eine hohe Empfindlichkeit der Signale gegenüber spektralen Verschiebungen des Nachweispulses ergab. Diese Empfindlichkeit war im Bereich der isosbestischen Wellenlänge sowie im Bereich 


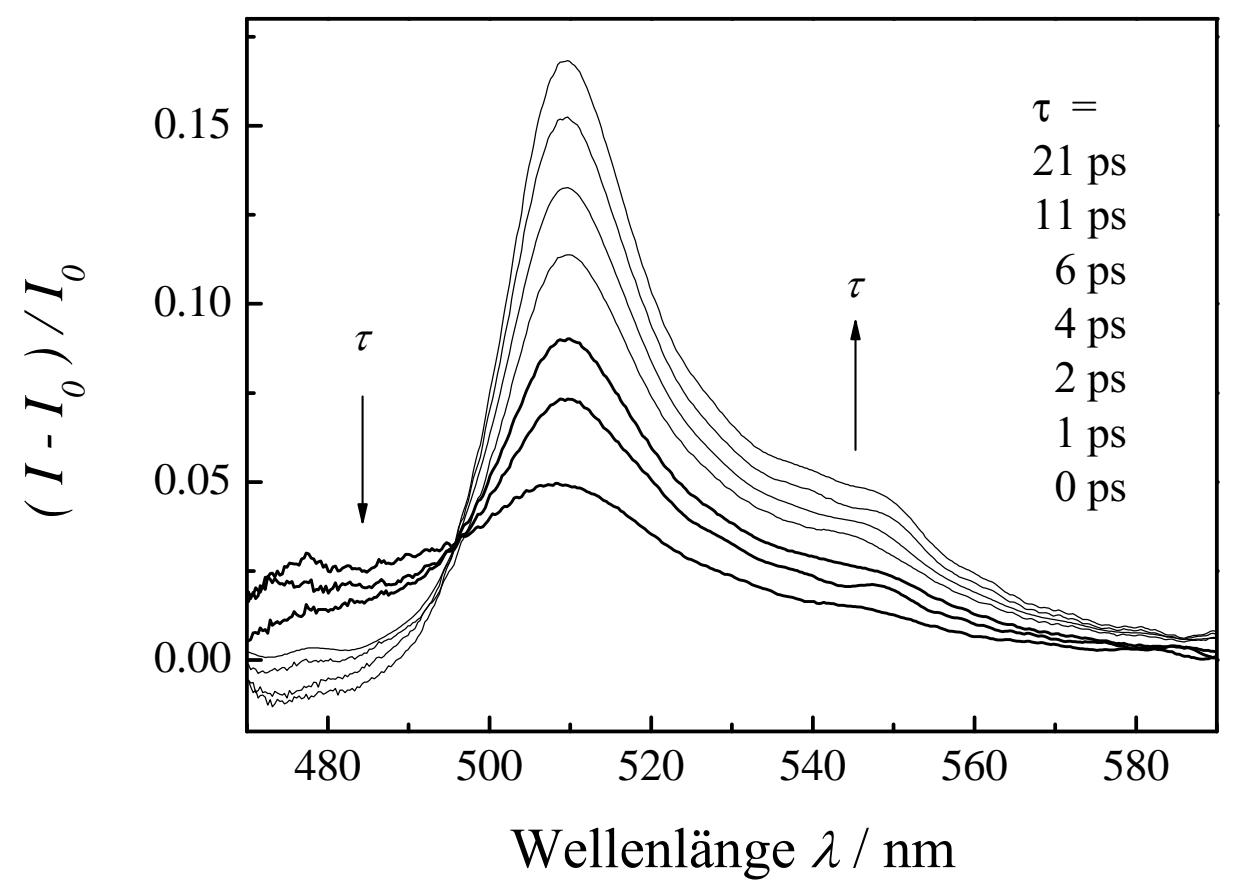

Abbildung 4.7: Transiente Spektren des GFP bei einer Anregungswellenlänge von $400 \mathrm{~nm}$ für den Bereich von 470 bis $590 \mathrm{~nm}$ bei verschiedenen Pump-ProbeVerzögerungszeiten.

des sehr schmalen Maximums des stationären Emissionsspektrums ( 508 nm) besonders ausgeprägt. Im Weiteren erlauben differentielle Transmissionsspektren bei langen Pump-Probe-Verzögerungszeiten (z. B. 100 ps) die genaue Charakterisierung der im blauen Spektralbereich $(\lambda \leq 500 \mathrm{~nm})$ beobachteten transienten Absorption. Nichtzuletzt sind differentielle Transmissionsspektren notwendig, um Aussagen über die zeitabhängige Entwicklung des Spektrums treffen zu können - im speziellen sind dies Fragen nach der Entwicklung der Form des Spektrums sowie der zeitabhängigen Verschiebung des oder der Emissionsmaxima.

Transiente Spektren nach Anregung bei $400 \mathrm{~nm}$ sind in Abbildung 4.7 für verschiedene Pump-Probe-Verzögerungszeiten dargestellt. Bei den kürzesten Verzögerungszeiten ist die stimulierte Emission wesentlich breiter als das stationäre Emissionsspektrum des GFP (siehe Abbildungen 4.7 und 4.8). Nach etwa 6 ps gleicht die rote Flanke des transienten Spektrums der des stationären Emissionsspektrums. Eine spektrale Verschiebung des Emissionsmaximums kann nicht beobachtet werden. Das Ausbleiben einer dynamischen Rotverschiebung 


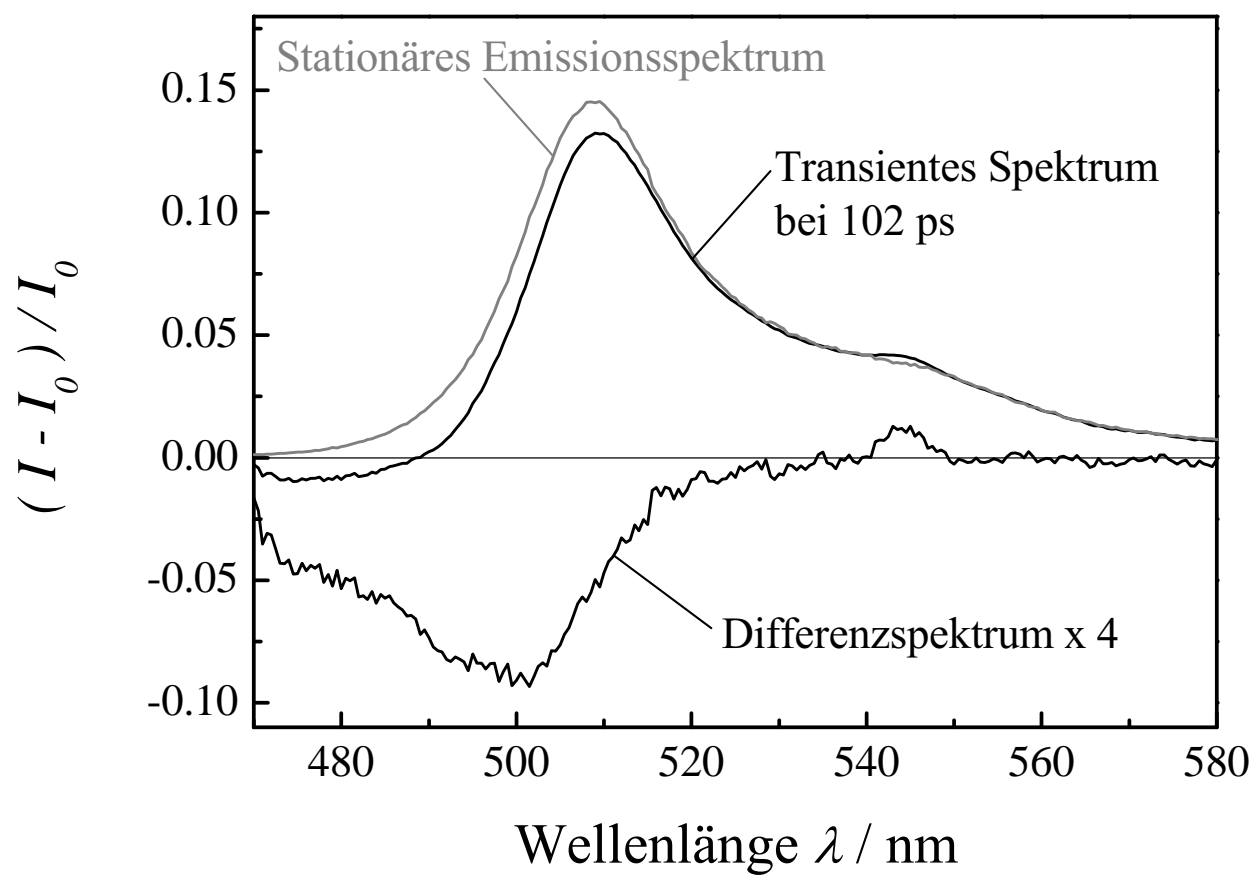

Abbildung 4.8: Bildung des Differenzspektrums aus dem stationären $\left(\lambda_{\text {exc }}=\right.$ $400 \mathrm{~nm}$ ) und dem transienten Spektrum bei 102 ps.

deutet an, dass strukturelle Reorganisierung der Umgebung des Chromophors spektral ohne Bedeutung ist. Nach etwa 6 ps bleibt das gesamte Spektrum formstabil. Die Schulter bei etwa $545 \mathrm{~nm}$, die die Schwingungsstruktur des GFP im Grundzustand widerspiegelt, ist bereits bei den kürzesten Verzögerungszeiten vorhanden. Sie erscheint jedoch bei längeren Zeiten deutlich schärfer. Bei langen Verzögerungszeiten erscheint analog zu den Beobachtungen in den zeitaufgelösten Experimenten im Bereich für kürzere Wellenlängen unterhalb $480 \mathrm{~nm}$ eine transiente Absorption.

Da die rote Flanke des transienten Spektrums bei $102 \mathrm{ps}$ mit der des stationären Emissionsspektrums von GFP quantitativ übereinstimmt, kann angenommen werden, dass bei dieser Verzögerungszeit das Spektrum der reinen stimulierten Emission der stationären Fluoreszenz des Proteins bereits gleicht. Daher ergibt sich aus der Differenz beider Spektren eine probenwellenlängenabhängige transiente Absorption, die im unteren Teil der Abbildung 4.8 dargestellt ist. Diese transiente Absorption hat ihr Maximum bei etwa $500 \mathrm{~nm}$ und eine Schulter bei $475 \mathrm{~nm}$. 


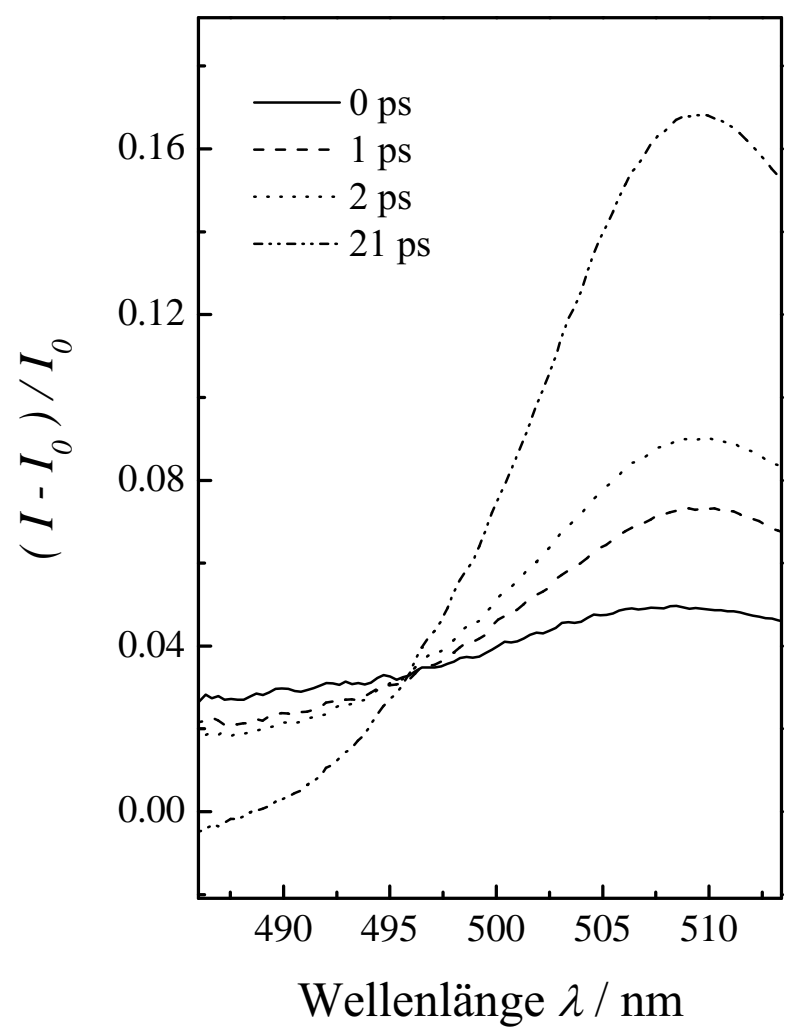

Abbildung 4.9: Darstellung des isosbestischen Punktes im zeitabhängigen transienten Spektrum des GFP bei 0, 1, 2 und 21 ps.

Wie in Abbildung 4.9 zu erkennen ist, ergibt sich in den zeitabhängigen differentiellen Transmissionsspektren bei $496 \mathrm{~nm}$ ein isosbestischer Punkt, der bereits anhand der Messungen aus Abschnitt 4.1 zu erwarten war. Gezeigt sind die Spektren bei Verzögerungszeiten von 0 ps, 1 ps, 2 ps und 21 ps. 


\subsection{Zeitkorreliertes Einzelphotonenzählen}

Zur Bestimmung des Abklingverhaltens der GFP-Emission auf einer Zeitskala von mehreren Nanosekunden wurde zeitkorreliertes Einzelphotonenzählen (TCSPC, siehe Abschnitt 3.6) durchgeführt. Dabei wurde die Kinetik des Emissionszerfalls bei $450 \mathrm{~nm}$ und $510 \mathrm{~nm}$ detektiert. Diese Wellenlängen sind für die Emissionen aus dem angeregten Zustand $A^{*}$ bzw. dem angeregten Intermediärzustand $I^{*}$ des GFP repräsentativ. Beide Kinetiken wurden im magischen Winkel $\left(54.7^{\circ}\right)$ relativ zur linearen Polarisation des Pumplichtes $(400 \mathrm{~nm})$ aufgenommen. Die maximale Verzögerungszeit betrug $50 \mathrm{~ns}$, die mit einer Auflösung von 1024 Kanälen aufgenommen wurden. Jedes Signal wurde über 60 s mit einer Zählrate von etwa $30 \mathrm{kHz}$ akkumuliert.

In Abbildung 4.10 sind jeweils die Signale, die Gerätefunktionen, die Anpassungen an die Signale sowie die Residuen aus Signal und Anpassung dargestellt. Die Gerätefunktion wurde mit Hilfe einer methanolischen Kaliumiodid/DASPILösung (DASPI-2-(p-Dimethylaminostyryl-)pyridylmethyliodid) bestimmt. Hierzu wurde die Referenzlösung bei $400 \mathrm{~nm}$ angeregt und ihre Fluoreszenzlebensdauer bei $600 \mathrm{~nm}$ gemessen. Aufgrund der Fluoreszenzlöschung durch das im Überschuss vorliegende Kaliumiodid, reduziert sich die Strahlungslebensdauer auf weniger als 50 ps. Daher sollte das gemessene Signal lediglich die Gerätefunktion wiederspiegeln. Eine Fehlerquelle bei der Bestimmung der Gerätefunktion für die Signale der GFP-Dynamik bei 450 und $510 \mathrm{~nm}$ ist ihre Wellenlängenabhängigkeit. Erwartungsgemäß sollte die Gerätefunktion bei 450 und $510 \mathrm{~nm}$ anders verlaufen als bei $600 \mathrm{~nm}$.

Die Anpassung der Signale erfolgte mit einem least-squares-Verfahren (Edinburgh Instruments Ltd. ${ }^{77}$ ). Dabei werden die Daten durch eine Faltung der Gerätefunktion $E(t)$ mit einer Antwortfunktion $R(t)$ gemäß:

$$
X(t)=\int_{0}^{t} E\left(t^{\prime}\right) R\left(t-t^{\prime}\right) d t^{\prime}
$$

simuliert. Die Antwortfunktion entspricht einer Summe aus Exponentialfunktionen:

$$
R(t)=A+B_{1} \cdot e^{-\frac{t}{\tau_{1}}}+B_{2} \cdot e^{-\frac{t}{\tau_{2}}}+B_{3} \cdot e^{-\frac{t}{\tau_{3}}}+\ldots
$$

Nach diesem least-squares-Verfahren ergeben sich für die Messungen bei 450 und $510 \mathrm{~nm}$ die in Tabelle 4.1 zusammengestellten Anpassungsparameter. 

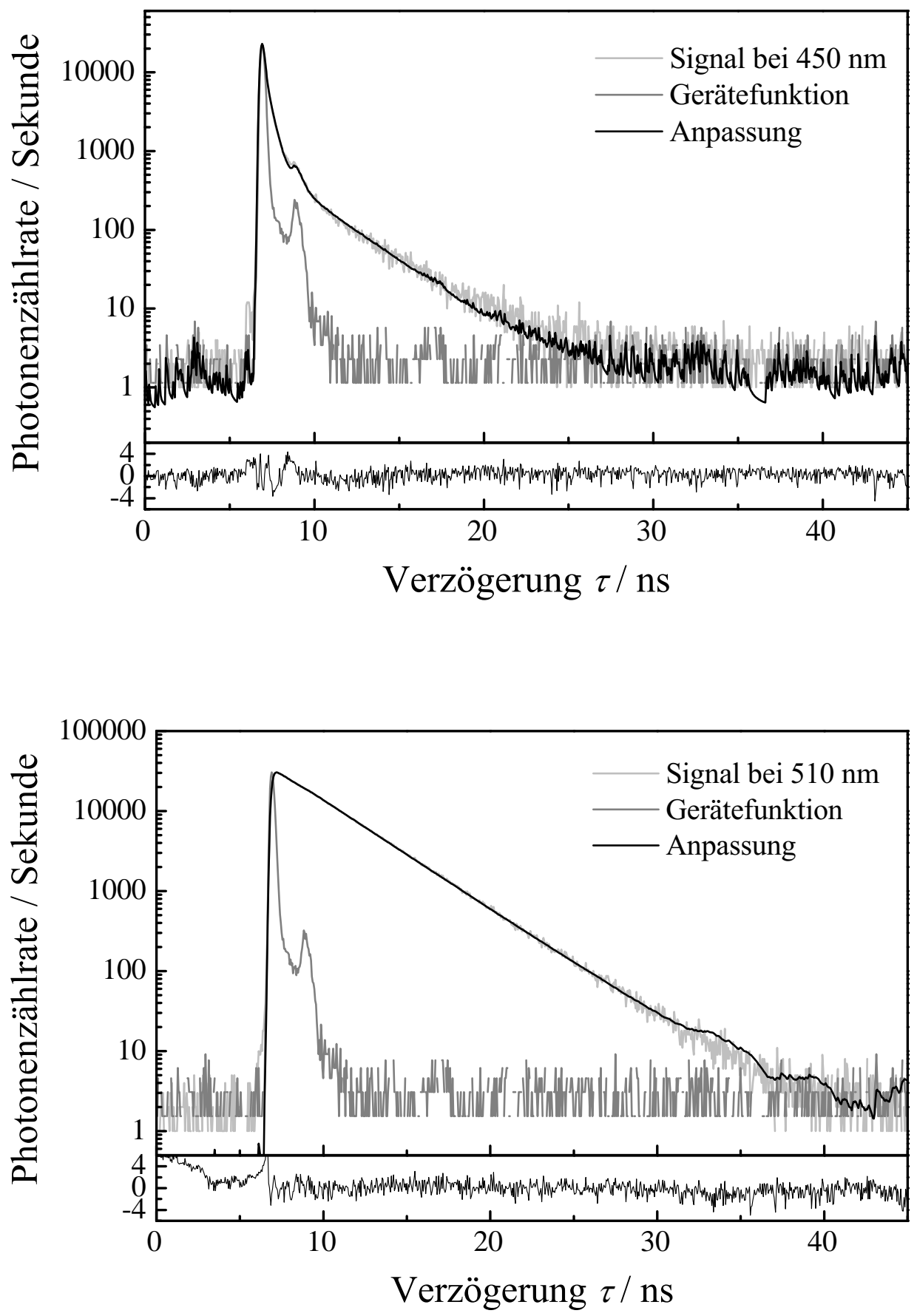

Abbildung 4.10: Emissionssignal von GFP bei einer Detektionswellenlänge von $450 \mathrm{~nm}$ (oben) und $510 \mathrm{~nm}$ (unten) aus TCSPC-Messungen. Dargestellt sind die jeweiligen Signale, die Gerätefunktionen und die Anpassungen nach Gleichung 4.3, sowie die Residuen im unteren Teil der Abbildungen. 


\begin{tabular}{c|ccccccc}
$\lambda / \mathrm{nm}$ & $\tau_{1} / \mathrm{ns}$ & $B_{1} / \%$ & $\tau_{2} / \mathrm{ns}$ & $B_{2} / \%$ & $\tau_{3} / \mathrm{ns}$ & $B_{3} / \%$ & $\mathrm{~A}$ \\
\hline 450 & 0.3477 & 46.90 & 2.922 & 15.99 & 0.0287 & 37.11 & 0.470 \\
510 & 3.179 & 100 & - & - & - & - & -6.653
\end{tabular}

Tabelle 4.1: Anpassungsparameter aus der Faltung nach Gleichung 4.2 mit der Summe der Exponentialfunktionen nach Gleichung 4.3

Das Signal bei $510 \mathrm{~nm}$ klingt monoexponentiell mit einer Zeitkonstanten von $\tau_{1}=3.2 \mathrm{~ns}$ ab. Die Dynamik des Signals bei $450 \mathrm{~nm}$ muss hingegen mit drei exponentiellen Komponenten angepasst werden. Der exponentielle Anteil mit der größten Amplitude hat dabei eine Zeitkonstante von $\tau_{1}=347.7 \mathrm{ps}$, während die Komponente mit der geringsten Amplitude mit einer Zeitkonstanten von $\tau_{2}=2.92 \mathrm{~ns}$ abklingt. Der exponentielle Anteil mit der sehr schnellen Zeitkonstanten von $\tau_{3}=28.8 \mathrm{ps}$ liegt innerhalb der Gerätefunktion und ist daher stärker fehlerbehaftet als die beiden langsameren Zeiten.

\subsection{Temperaturabhängige Messungen}

Zunächst wurde die Temperaturabhängigkeit des stationären Absorptionsspektrums gemessen. Spektren bei den Temperaturen $6{ }^{\circ} \mathrm{C}, 15^{\circ} \mathrm{C}, 25^{\circ} \mathrm{C}, 35^{\circ} \mathrm{C}, 45^{\circ} \mathrm{C}$ und $55^{\circ} \mathrm{C}$ sind in Abbildung 4.11 dargestellt. Eine weitere Ausdehnung ist unter den verwendeten Bedingungen (wässrige Phosphatpufferlösung des GFP) nicht möglich, da die Proteinlösung unter $0^{\circ} \mathrm{C}$ erstarren und bei Temperaturen über $60^{\circ} \mathrm{C}$ denaturieren. Der Temperaturbereich kann ausgedehnt werden, indem der Phosphatpufferlösung Glycerol beigefügt wird, wodurch es zu einer Gefrierpunktserniedrigung kommt. Das Beifügen von Glycerol würde jedoch das stationäre Absorptionsspektrum und damit die Versuchsbedingungen verändern. Daher wurde dies in der vorliegenden Arbeit vermieden.

Abbildung 4.11 ist zu entnehmen, dass die Absorption der Bande der anionischen Form B, die ihr Maximum bei $478 \mathrm{~nm}$ hat, mit höherer Temperatur steigt, während gleichzeitig die Absorption der neutralen Form A bei $400 \mathrm{~nm}$ sinkt. Bei einer Wellenlänge von etwa $435 \mathrm{~nm}$ schneiden sich die Kurven - ein isosbestischer Punkt erscheint. Aus der Temperaturabhängigkeit des stationären Absorptionsspektrums könnte das relative energetische Verhältnis der beiden Grundzustände sowie die zugehörige Gleichgewichtskonstante bestimmt werden.

Temperaturabhängige Messungen der pumpinduzierten Änderung der Transmission bei $510 \mathrm{~nm}$ wurden ebenfalls bei $6^{\circ} \mathrm{C}, 15^{\circ} \mathrm{C}, 25^{\circ} \mathrm{C}, 35^{\circ} \mathrm{C}, 45^{\circ} \mathrm{C}$ und $55^{\circ} \mathrm{C}$ durchgeführt. Die Temperatur der Probe, die in einer temperierbaren Glasdurchflussküvette eingebracht wurde, konnte mit Hilfe eines Thermostaten (Julabo HC, Ultratemp 2000) mit einer Genauigkeit von $1{ }^{\circ} \mathrm{C}$ eingestellt werden. 


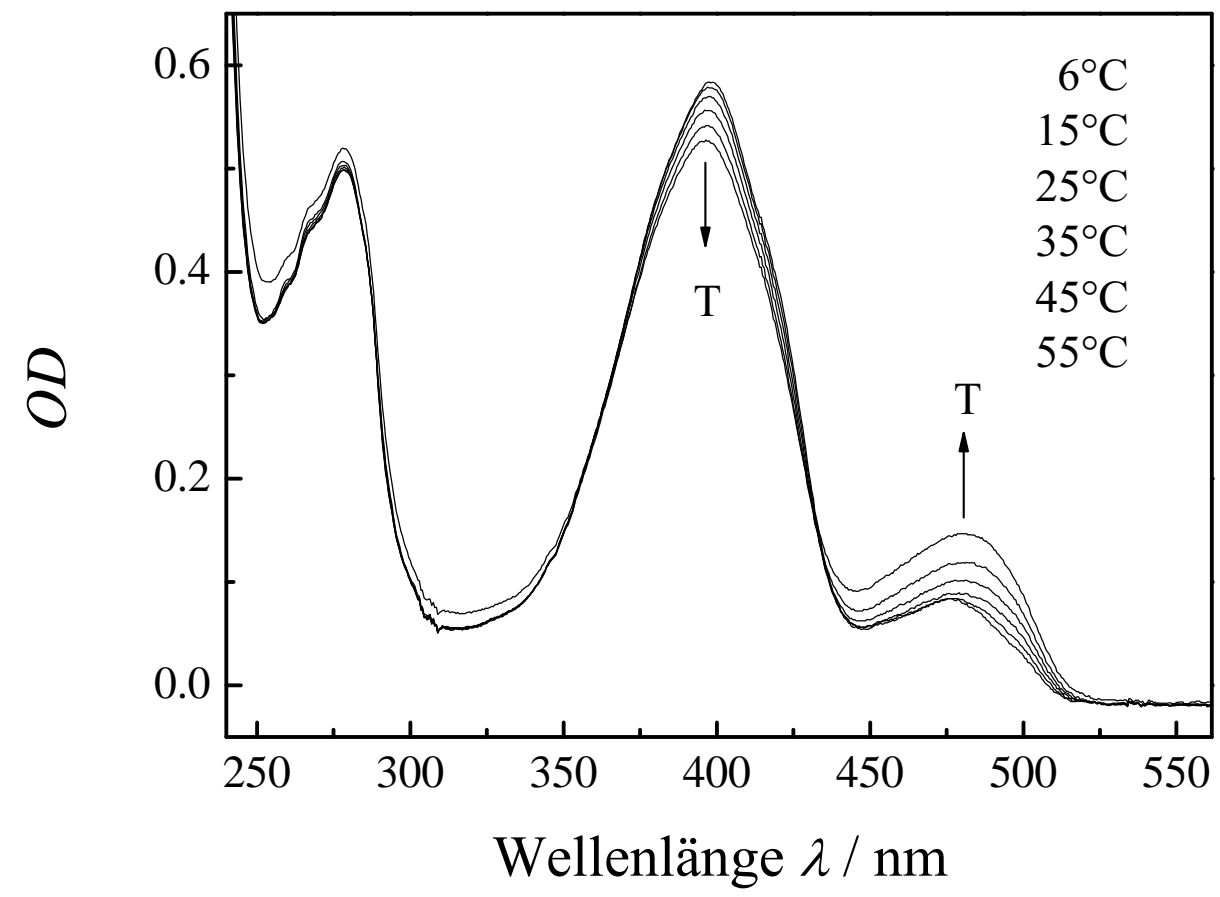

Abbildung 4.11: Temperaturabhängiges stationäres Absorptionsspektrum des GFP

Abbildung 4.12 verdeutlicht, dass sich die Änderung der Temperatur nur gering auf das Pump-Probe-Signal auswirkt. Dennoch kann ein Trend beobachtet werden - das Signal steigt mit höherer Temperatur etwas schneller an. Tabelle 4.2 verdeutlicht den Rahmen, in dem sich die Dynamik ändert. Mit der Summe zweier Exponentialfunktionen (Gleichung 4.4) wurde lediglich der verzögerte Fluoreszenzanstieg angepasst, d.h. auf eine Entfaltung der Signale wurde verzichtet:

$$
F(t)=1-\left[A_{1} \cdot e^{-\frac{t}{\tau_{1}}}+A_{2} \cdot e^{-\frac{t}{\tau_{2}}}\right]+B
$$

Dabei entspricht B der instantanen Emission. In der letzten Spalte der Tabelle ist die gewichtete, mittlere Zeitkonstante $\tau_{\text {gewichtet }}$ angegeben, die sich aus der Summe der Produkte von Amplitude und Zeitkonstante ergibt:

$$
\tau_{\text {gewichtet }}=\tau_{1} \cdot A_{1}+\tau_{2} \cdot A_{2} .
$$




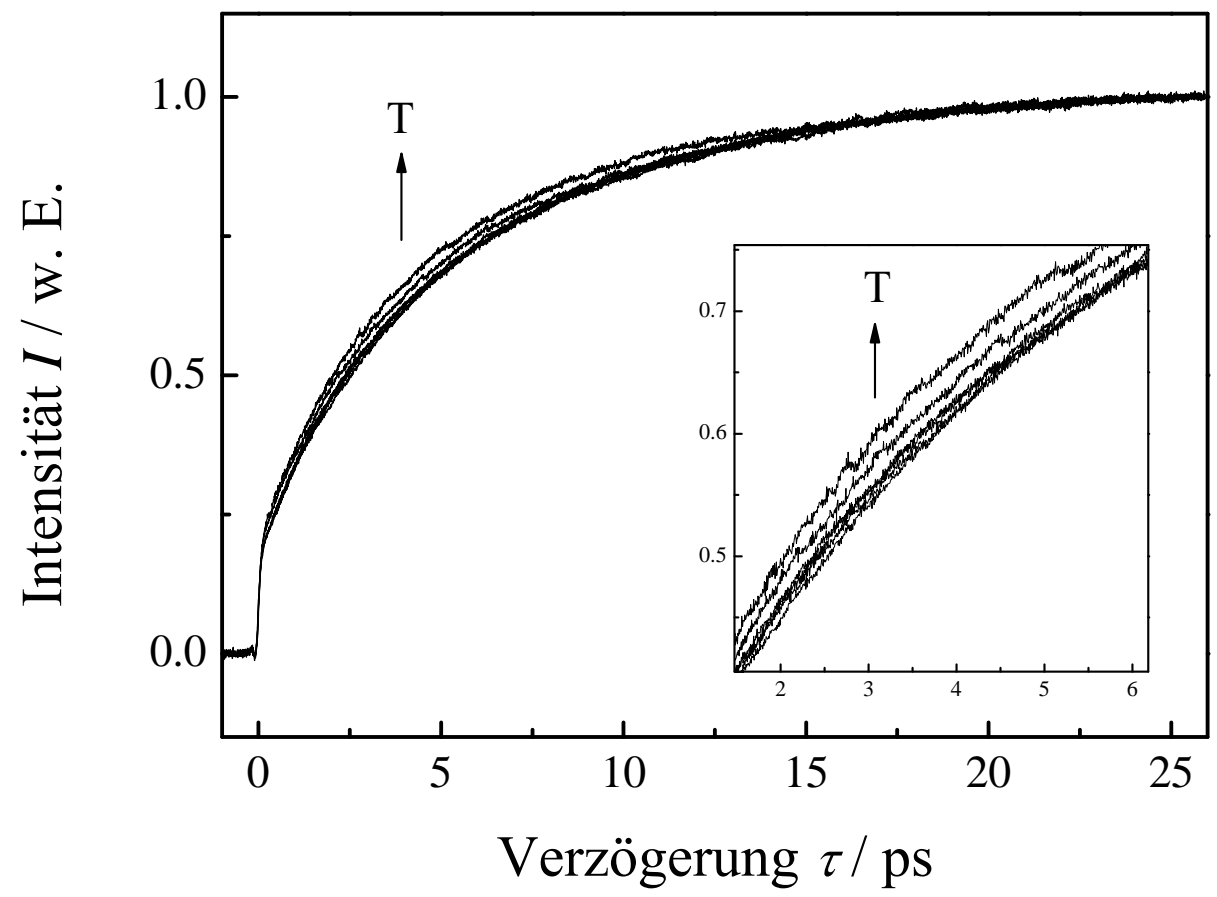

Abbildung 4.12: Temperaturabhängige Pump-Probe-Transienten von GFP bei $510 \mathrm{~nm}$. Die Transienten wurden auf den Maximalwert des Signals normiert $(I(\tau=26 \mathrm{ps}))$. In der Einblendung befindet sich die Vergrößerung von $1-7 \mathrm{ps}$.

\begin{tabular}{c|ccccc} 
Temperatur $/{ }^{\circ} \mathrm{C}$ & $\tau_{1} / \mathrm{ps}$ & $A_{1} / \%$ & $\tau_{2} / \mathrm{ps}$ & $A_{2} / \%$ & $\tau_{\text {gewichtet }} / \mathrm{ps}$ \\
\hline 6 & 7.4 & 0.61 & 2.50 & 0.23 & 5.09 \\
15 & 7.1 & 0.66 & 2.0 & 0.18 & 5.05 \\
25 & 7.2 & 0.65 & 1.8 & 0.21 & 5.05 \\
35 & 7.1 & 0.66 & 1.6 & 0.19 & 4.99 \\
45 & 7.2 & 0.61 & 1.8 & 0.23 & 4.81 \\
55 & 6.9 & 0.56 & 2.0 & 0.26 & 4.38
\end{tabular}

Tabelle 4.2: Anpassungsparameter der temperaturabhängigen Pump-ProbeTransienten nach Gleichung 4.4

Nach dem Betrag der Zeitkonstanten wird die Dynamik um so schneller, je höher die Temperatur ist. Allerdings ist die Erhöhung der Geschwindigkeitskonstanten relativ klein. 


\subsection{Messungen der Schwingungsdynamik des GFP}

Im Bereich von $496 \mathrm{~nm}$ bis $510 \mathrm{~nm}$ ist es möglich, neben dem verzögerten Fluoreszenzanstieg auch kohärente periodische Signalbeiträge zu detektieren. Zum einwandfreien Nachweis dieser Wellenpacketbeiträge sind ein optimal laufendes Lasersystem und lange Mittelung essentiell. Die Abbildung 4.13 zeigt einen Transienten bei einer Nachweiswellenlänge von $499 \mathrm{~nm}$, sowie die Schwingungsdynamik in der Einblendung. Hierin ist erkennbar, dass die kohärenten Schwingungen bereits nach zwei Pikosekunden vollständig gedämpft sind.

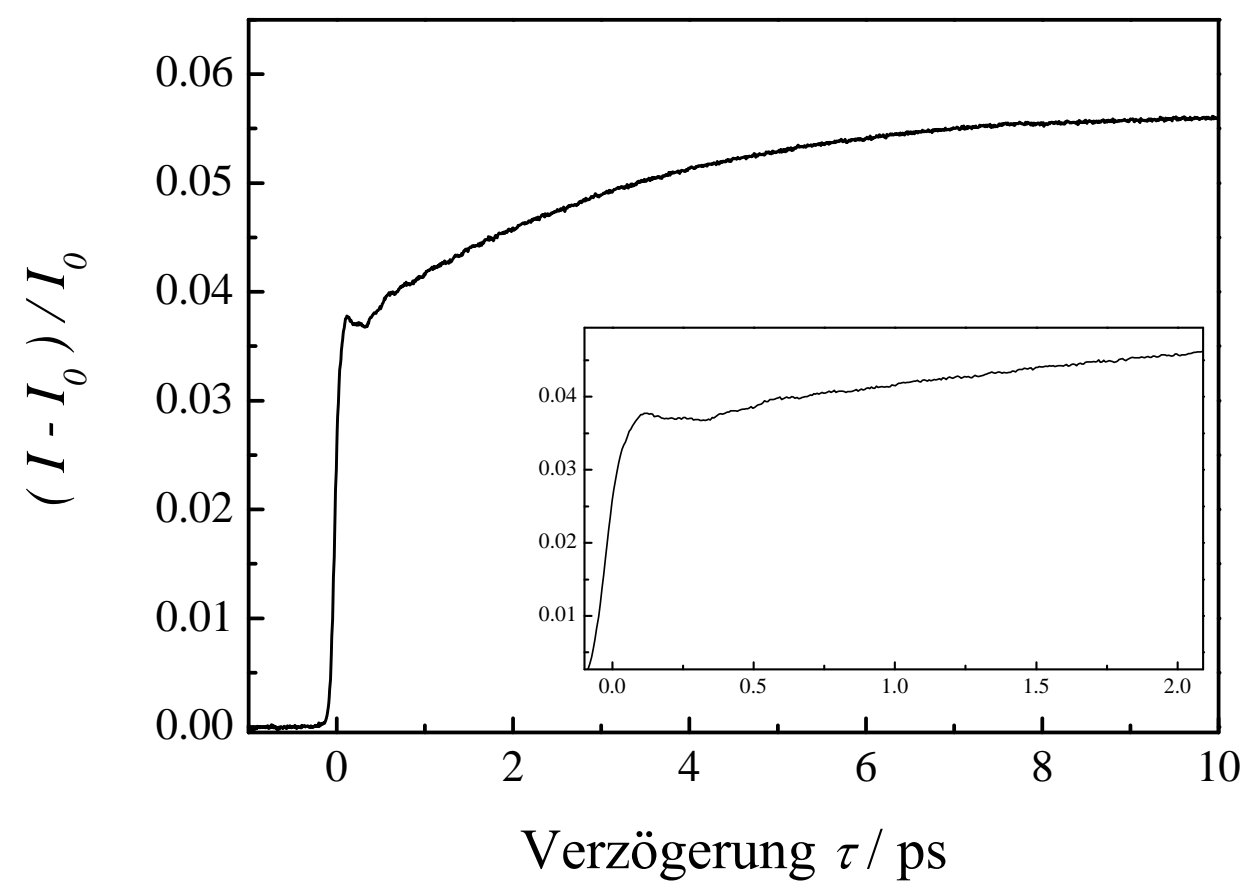

Abbildung 4.13: Pump-Probe-Signal bei einer Nachweiswellenlänge von $499 \mathrm{~nm}$ mit Schwingungsdynamik äußerst kleiner Amplitude.

Ist die spektrale Bandbreite des Pumppulses größer als die Energiedifferenz benachbarter Eigenzustände einer Schwingungsmode des Chromophors, so wird dieser Freiheitsgrad impulsiv präpariert, d.h. der Lichtimpuls erzeugt eine kohärente Überlagerung benachbarter Schwingungseigenzustände dieser Mode - also ein Wellenpacket. Diese nichtstationäre Wellenfunktion oszilliert 
mit der inversen Energiedifferenz der benachbarten Vibrationsquanten. Ist die korrespondierende anharmonische Schwingungsperiode länger als die Dauer der verwendeten Nachweisimpulse, so ist die resultierende pumpinduzierte Transmission mit der oszillatorischen Bewegung des Wellenpackets moduliert. Eine semiklassische Theorie zur dynamischen Spektroskopie von Wellenpacketen wurde von Heller und Mathies formuliert.

Zur Analyse dieses Wellenpackets wurde die Analysemethode Linear Prediction Singular Value Decomposition (LPSVD) angewandt. Das der LPSVD-Analyse zugrundeliegende mathematische Model geht davon aus, dass das Signal als eine Summe exponentiell gedämpfter Kosinusfunktionen darstellbar ist ${ }^{78}$ :

$$
I(t)=\sum_{i=1} A_{i} \cos \left(\omega_{i} t+\phi_{i}\right) \exp \left(-\frac{t}{\tau_{i}}\right)
$$

Dabei sind $\omega_{i}$ die Frequenz, $1 / \tau_{i}$ die Dämpfungskonstante, $A_{i}$ die Amplitude und $\phi_{i}$ die Phase der individuellen Komponenten $i$. Die Methode liefert einen Satz von $i$ Frequenzen, Amplituden, Phasen und Dämpfungsfaktoren. Diese Methode ist daher eine Alternative zur Bestimmung der Frequenzen durch die Fast Fourier Transformation (FFT).

Abbildung 4.14 zeigt einen Ausschnitt des Signals aus Abbildung 4.13 und die zugehörige LPSVD-Analyse. Im unteren Teil der Abbildung ist die Differenz aus Signal und LPSVD-Ergebnis gezeigt. Die für die reine Schwingsdynamik dieses Signals relevanten Parameter sind in Tabelle 4.3 aufgeführt.

\begin{tabular}{c|cccc}
$\mathrm{i}$ & $\omega_{i} / \mathrm{cm}^{-1}$ & $A_{i}$ & $\phi_{i}$ & $\tau_{i} / \mathrm{ps}$ \\
\hline 1 & 327.6 & $3.59 \cdot 10^{-5}$ & -270.1 & 0.873 \\
2 & 258.3 & $2.47 \cdot 10^{-4}$ & -54.4 & 2.863 \\
3 & 212.5 & $9.80 \cdot 10^{-4}$ & -257.0 & 1.097 \\
4 & 173.7 & $1.27 \cdot 10^{-3}$ & -11.1 & 0.621 \\
5 & 118.7 & $9.28 \cdot 10^{-4}$ & -303.6 & 0.598
\end{tabular}

Tabelle 4.3: Ergebnisse der LPSVD-Analyse des Datensatzes von Abbildung 4.14. Aufgeführt sind die Frequenzen $\omega_{k}$, Amplituden $c_{k}$, Phasen $\phi_{k}$ und Dämpfungskonstanten $b_{k}$.

Demnach hat die Komponente mit der höchsten Amplitude eine Frequenz von $174 \mathrm{~cm}^{-1}$ und eine Dämpfungskonstante von 1/621 fs. 


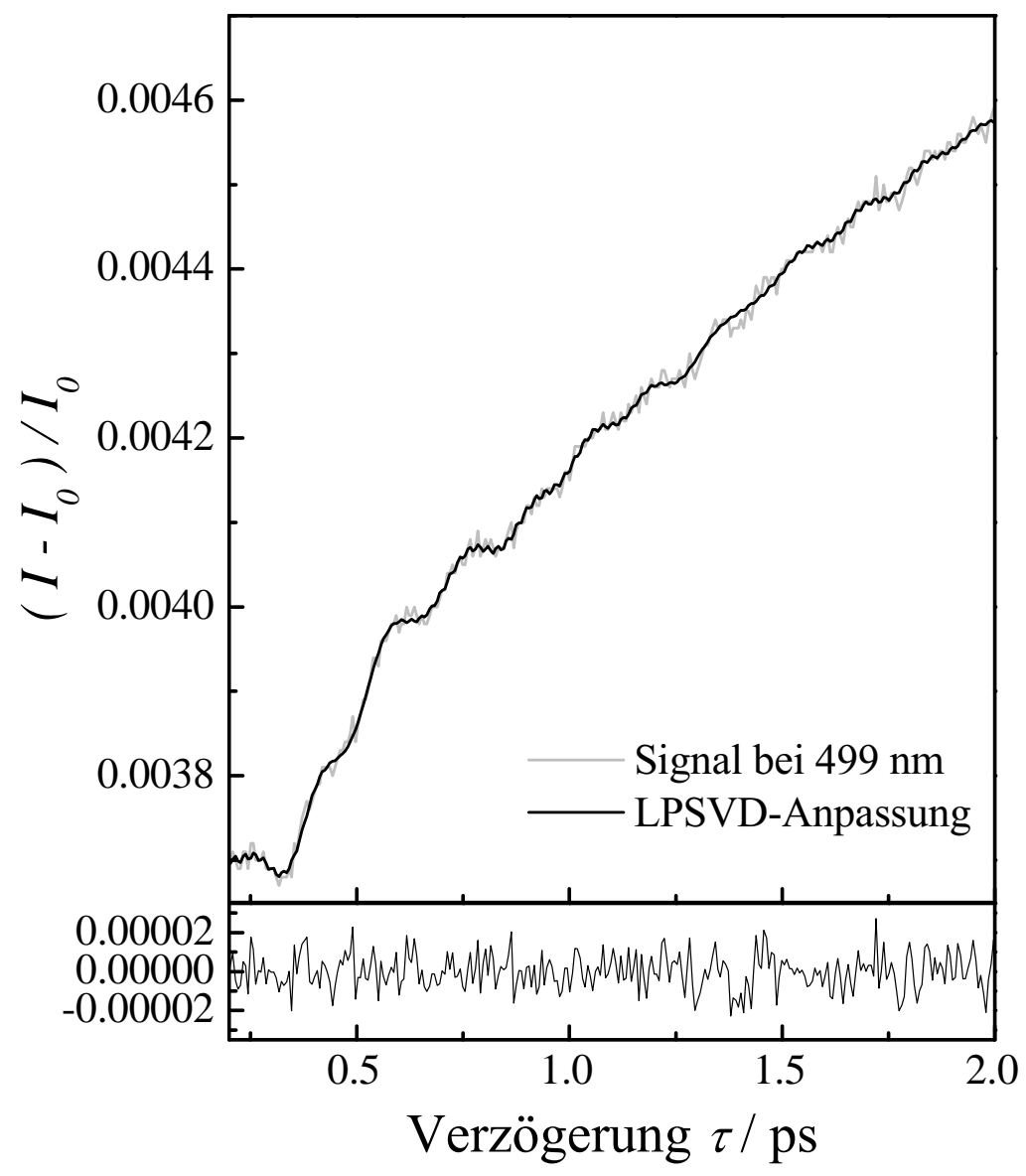

Abbildung 4.14: Pump-Probe-Signal bei einer Nachweiswellenlänge von $499 \mathrm{~nm}$ und LPSVD-Anpassung. Im unteren Teil sind auch die Residuen aus Signal und Anpassung dargestellt.

\subsection{Messungen der Anisotropie}

Dynamische Anisotropiemessungen geben Auskunft über die Rotationsdynamik eines Chromophors (Fluorophors) in seiner Umgebung. Wenn das Anregungslicht linear polarisiert ist, so ist die Wahrscheinlichkeit $P$ des Überganges zwischen zwei elektronischen Zuständen A und B proportional zu dem Skalarprodukt aus Übergangsdipolmoment $\vec{\mu}_{A \rightarrow B}$ und dem elektromagnetischen Feldvektor $\vec{E}$, d. h. $P \propto \cos ^{2} \theta_{A}$. Dabei ist $\theta_{A}$ der Winkel zwischen $\vec{E}$ und $\vec{\mu}_{A \rightarrow B}$. Diese Wahrscheinlichkeit ist maximal, wenn $\vec{E}$ parallel zu $\vec{\mu}_{A \rightarrow B}$ ausgerichtet ist, und sie wird null, wenn $\vec{E}$ und $\vec{\mu}_{A \rightarrow B}$ senkrecht zueinander stehen. Die Chromophore (Fluorophore), deren Übergangsdipolmomente entlang der Polarisationsebene des Anregungslichtes ausgerichtet sind, werden also bevorzugt angeregt, so dass sie im 
angeregten Zustand anisotrop verteilt sind. Die Emission aus diesem Zustand ist daher zunächst auch anisotrop. Für die folgenden Erklärungen wird beispielhaft die Emission aus einem angeregten Zustand betrachtet. Ursachen, die zu einer Depolarisierung der Emission führen, können nichtparallele Absorptions- und Emissionsdipolmomente sein, Torsionsschwingungen, Brown'sche Bewegungen sowie der Transfer von Anregungsenergie zu einem Molekül mit einer anderen Orientierung. Die gesamte Fluoreszenzintensität setzt sich aus den in die drei Laborkoordinaten $\mathrm{x}$, y und z polarisierten Teilintensitäten zusammen: $I=I_{x}+I_{y}+I_{z}$. Die Beträge der einzelnen Komponenten sind von der Polarisation des Anregungslichtes sowie den Depolarisationsprozessen abhängig. Ist das Anregungslicht entlang $x$ polarisiert, so gibt es eine dazu parallele Intensität $I_{x}=I_{\|}$und zwei senkrechte Intensitäten $I_{y}=I_{z}=I_{\perp}$. Die Gesamtintensität beträgt demnach $I_{\|}+2 I_{\perp}$. Werden $I_{\|}$und $I_{\perp}$ zeitabhängig gemessen, so kann daraus die zeitabhängige Anisotropie $r(t)$ der Emission:

$$
r(t)=\frac{I_{\|}(t)-I_{\perp}(t)}{I_{\|}(t)+2 \cdot I_{\perp}(t)}
$$

ermittelt werden. Aus dieser Gleichung lässt sich auch die Beziehung zwischen der Anisotropie für die Emission und der Winkelverteilung der Emissionsübergangsdipolmomente $\theta_{E}(t)$ relativ zur Achse des linear polarisierten Anregungslichtes herleiten ${ }^{79}$ :

$$
r(t)=\frac{3\left\langle\cos ^{2} \theta_{E}(t)\right\rangle-1}{2}
$$

Dabei entsprechen die eckigen Klammern einer Mittelung über die Orientierung aller Moleküle im Laborkoordinatensystem. Im Falle paralleler Absorptionsund Emissionsübergangsmomente, d. h. $\theta_{A}=\theta_{E}=\theta$, erreicht die Anisotropie $r(t)$ ihren oberen Grenzwert, die fundamentale Anisotropie $r_{0}$ von:

$$
\begin{gathered}
r_{0}=\frac{3\left\langle\cos ^{2} \theta\right\rangle-1}{2}=\frac{2}{5} \\
\left\langle\cos ^{2} \theta\right\rangle=\frac{3}{5}
\end{gathered}
$$

Im Falle nicht-paralleler Absorptions- und Emissionsübergänge, $\theta_{A} \neq \theta_{E}$, kann die fundamentale Anisotropie $r_{0}$ einen theoretischen Wert zwischen -0.2 und 0.4 annehmen.

Je nachdem, welche Rotationseigenschaften der Fluorophor innerhalb seiner 
Umgebung hat, klingt die Anisotropie nach den entsprechenden funktionalen Zusammenhängen $\mathrm{ab}^{79}$ : Beispielsweise ergibt sich für einen gedämpften sphärischen Rotor im diffusiven Grenzfall ein monoexponentielles Abklingverhalten von $r_{0}$ auf null, weil die Moleküle bei unendlichen Zeiten beliebig orientiert sind. Bei einer dedämpften Rotation auf einem Konus ist der Grenzwert bei unendlichen Zeiten $r_{\infty}$ verschieden von null.

Anisotropiemessungungen wurden zunächst im zeitaufgelösten Pump-ProbeExperiment durchgeführt. Aufgrund der Ergebnisse dieser Experimente wurde die Anisotropie weiterhin in Fluoreszenzkonversionsexperimenten und in Einzelphotonenzählexperimenten (TCSPC) gemessen.

\section{Anisotropie im Pump-Probe Experiment}

Zur Messung der Anisotropie im Pump-Probe-Experiment wurden, wie bereits in Abschnitt 3.3.3 beschrieben, zwei Experimente durchgeführt. Zunächst wurden parallele und senkrechte Komponente des Signals gleichzeitig gemessen, und zur Verbesserung des Signal zu Rausch-Verhältnisses beide Komponenten anschließend nacheinander mit Referenz gemessen. Die Ergebnisse der Experimente wurden verglichen und zeigten Übereinstimmung. Daher sind in dieser Arbeit lediglich die Ergebnisse mit dem besseren Signal zu Rausch-Verhältnis aufgeführt.

Anisotropiemessungen wurden bei den Nachweiswellenlängen $530 \mathrm{~nm}$ und $714 \mathrm{~nm}$ durchgeführt. Im oberen Teil von Abbildung 4.15 sind das parallele und das senkrechte Signale (parallel und senkrecht entsprechen der linearen Polarisationsebene des Probestrahls relativ zur linearen Polarisation des Pumpstrahls) bei $530 \mathrm{~nm}$ dargestellt. Der dynamische Verlauf beider Signale ist ähnlich, allerdings unterscheiden sie sich voneinander bezüglich ihrer Intensität. Die daraus resultierende Anisotropie, die im unteren Teil von Abbildung 4.15 gezeigt ist, wurde nach Gleichung 4.7 berechnet.

Die Anisotropie bei $530 \mathrm{~nm}$ hat bei $t=0 \mathrm{ps}$ einen Wert von 0.5 und klingt innerhalb des Zeitfensters von 25 ps exponentiell mit einer Zeitkonstanten von etwa $2.5 \mathrm{ps}$ auf einen Wert von 0.35 ab. Das anschließende Abklingen der Anisotropie auf einen Wert von null durch Rotationsdiffusion des gesamten Proteins kann offensichtlich mit dieser Methode nicht beobachtet werden. Der überraschende Wert der Anfangsanisotropie von $r_{0}=0.5$ lässt auf die Beteiligung elektronischer Kohärenzen schließen ${ }^{80}$.

Parallele und senkrechte Komponente bei einer Nachweiswellenlänge von $714 \mathrm{~nm}$ sind in Abbildung 4.16 dargestellt. Die nach Gleichung 4.7 berechnete Anisotropie bei $714 \mathrm{~nm}$ hat am Zeitnullpunkt einen Wert von 0.35 und klingt innerhalb $24 \mathrm{ps}$ auf $0.13 \mathrm{ab}$. In Abbildung 4.16 ist neben der Anisotropie bei dieser Nachweiswellenlänge die monoexponentielle Anpassung dargestellt, derzufolge die Anisotropie danach durch eine Abklingzeit von 24.5 ps charakterisiert ist. 

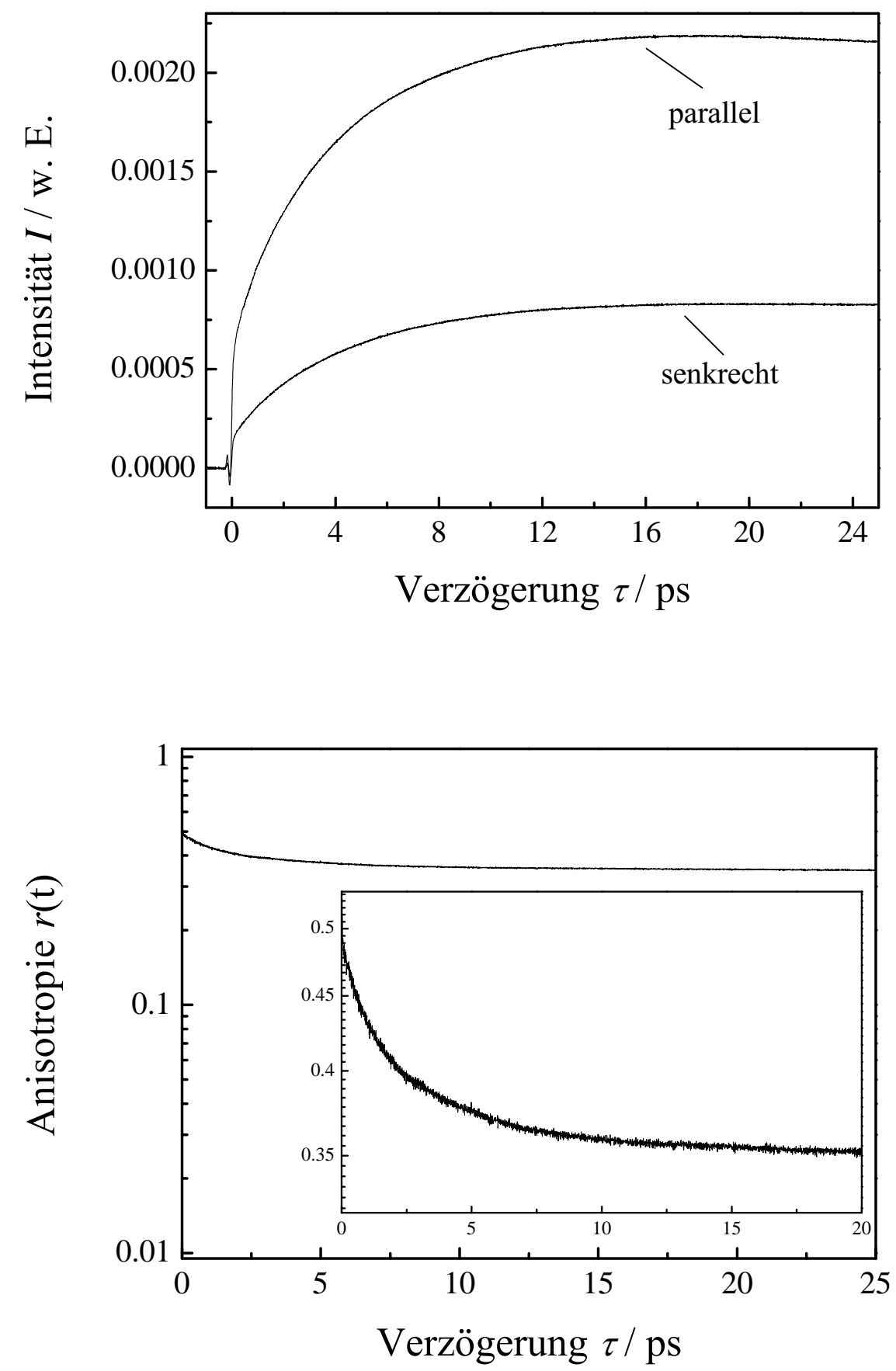

Abbildung 4.15: Oben: Pump-Probe-Signale bei einer Probewellenlänge von $530 \mathrm{~nm}$. Dargestellt sind die Signale mit paralleler bzw. senkrechter Orientierung der Polarisationsebenen von Pump- zu Probewelle. Unten: Zeitabhängige Anisotropie berechnet nach Gleichung 4.7. 

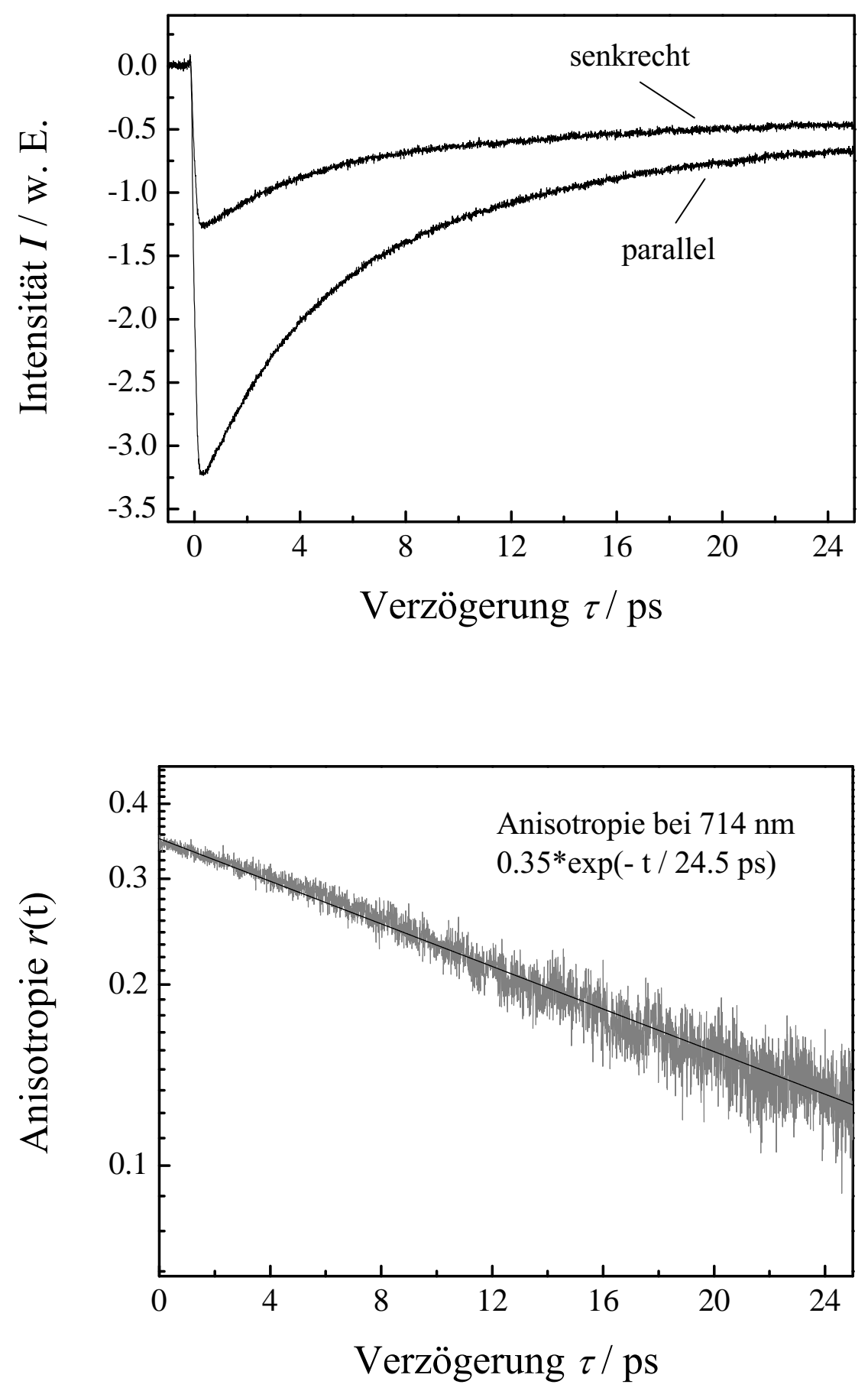

Abbildung 4.16: Pump-Probe-Signale bei einer Probewellenlänge von $714 \mathrm{~nm}$. Dargestellt sind die Signale mit paralleler bzw. senkrechter Orientierung der Polarisationsebenen von Pump- zu Probewelle. Unten: Zeitabhängige Anisotropie berechnet nach Gleichung 4.7. 


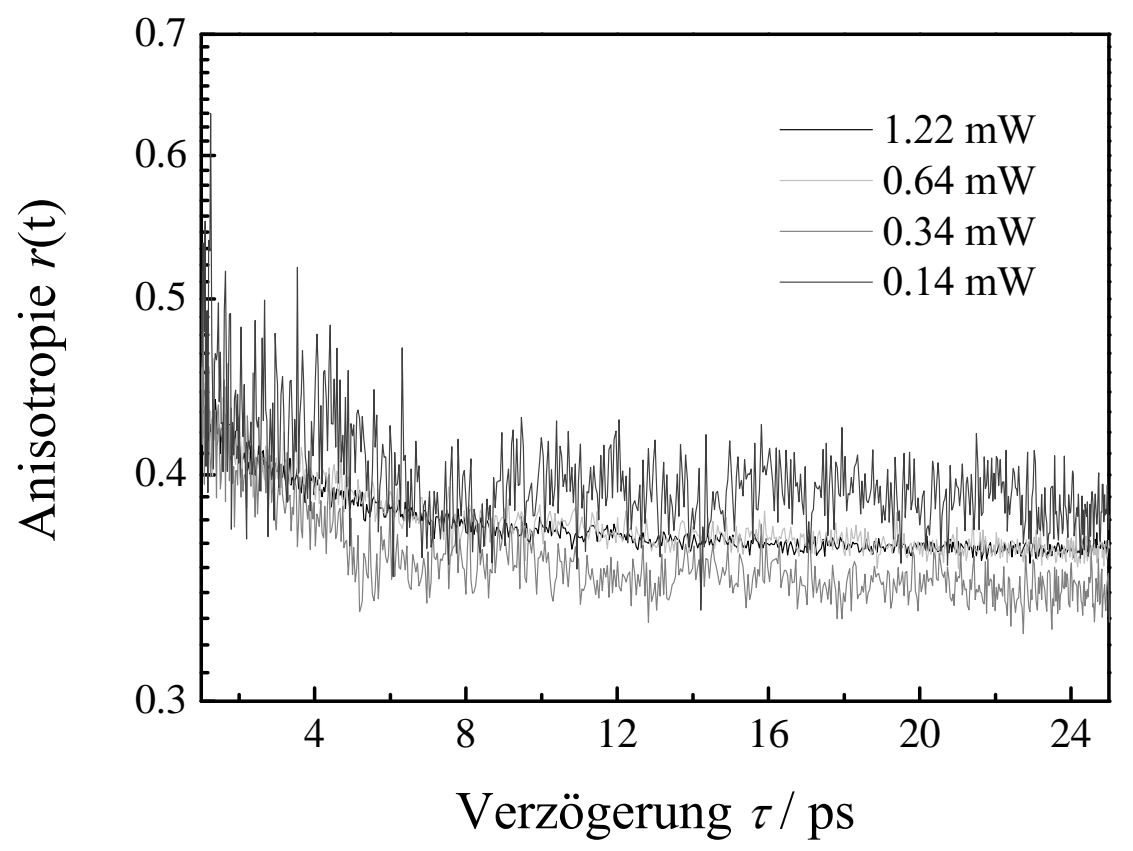

Abbildung 4.17: Pumpleistungsabhängigkeit der Anisotropie bei einer Nachweiswellenlänge von $530 \mathrm{~nm}$.

Um unerwünschte Sättigungsphänomene auszuschließen, wurde der Einfluss der Pumpleistung auf die Anisotropie untersucht. Die Pumpleistungen für die Aufnahme von parallelem und senkrechtem Signal betrugen hierbei $1.22 \mathrm{~mW}$, $0.64 \mathrm{~mW}, 0.34 \mathrm{~mW}$ und $0.14 \mathrm{~mW}$. Die Anregungsleistung von $1.22 \mathrm{~mW}$ entspricht dabei der Energie, die in allen Experimenten zur elektronischen Anregung des GFP verwendet wurde. Abbildung 4.17 verdeutlicht, dass die Anregungsleistung innerhalb des Fehlers des Experimentes keinen Einfluss auf die Anisotropie hat.

\section{Anisotropie im Fluoreszenzkonversionsexperiment}

Das Fluoreszenzkonversionsexperiment hat gegenüber dem Pump-ProbeAbsorptionsexperiment den Vorteil, dass lediglich die Emission aus den angeregten Zuständen nachgewiesen wird, während im Pump-Probe-Experiment mehrere Signalbeiträge überlappen können (z.B. stimulierte Emission und transiente Absorption). Um die Anisotropie der spontanen Emission aus den angeregten Zuständen zu untersuchen, wurden daher Fluoreszenzkonversionsexperimente bei den Nachweiswellenlängen $530 \mathrm{~nm}$ und $450 \mathrm{~nm}$ durchgeführt ${ }^{81}$. Zur kurzen Erklärung, aber ohne an dieser Stelle der Diskussion in Kapitel 6 vorzugreifen, wurde die Emission bei $530 \mathrm{~nm}$ als repräsentativ für die Emission 


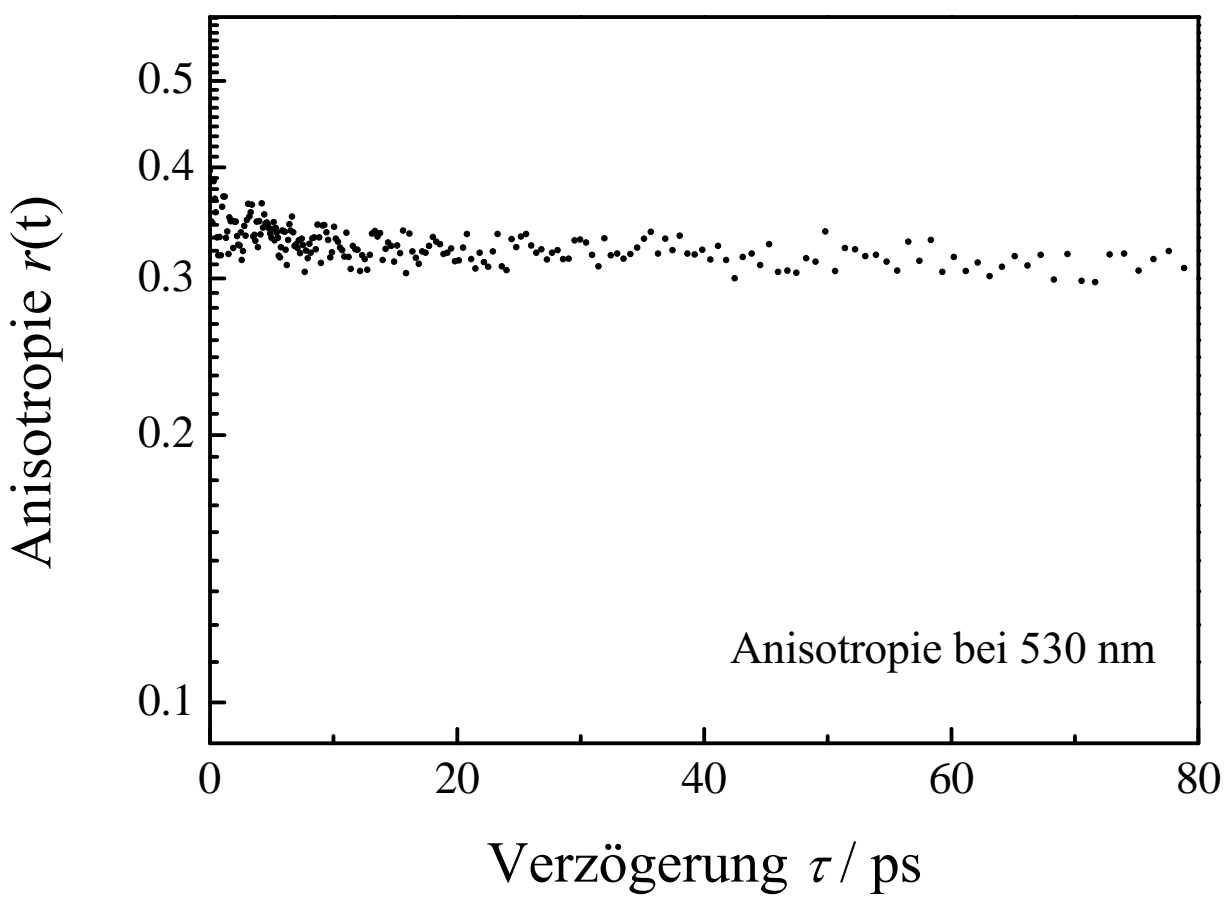

Abbildung 4.18: Verlauf der Anisotropie aus Fluoreszenzkonversionsexperimenten bei einer Nachweiswellenlänge von $530 \mathrm{~nm}$.

aus dem angeregten Intermediärzustand I*, die Emission bei $450 \mathrm{~nm}$ als repräsentativ für die Dynamiken des angeregten Zustand $\mathrm{A}^{*}$ und die Absorption bei $714 \mathrm{~nm}$ ebenfalls als charakteristisch für die Dynamiken im angeregten Zustand A* angenommen. Auf dieser Grundlage ist es schlüssig, die Anisotropien bei $530 \mathrm{~nm}$ und $714 \mathrm{~nm}$ aus den Pump-Probe-Messungen mit den Fluoreszenzkonversionsmessungen bei $530 \mathrm{~nm}$ und $450 \mathrm{~nm}$ miteinander zu vergleichen. Ergeben beide Messungen das gleiche Ergebnis, so können Signalüberlagerungen als Ursache für die im vorhergehenden beobachteten Phänomene ausgeschlossen werden.

Die Abbildungen 4.18 und 4.19 zeigen die Anisotropien bei $530 \mathrm{~nm}$ und $450 \mathrm{~nm}$ aus Fluoreszenzkonversionsexperimenten in einem Zeitintervall von etwa 100 ps. Die Anisotropie bei $530 \mathrm{~nm}$ klingt innerhalb dieser Zeit nur äußerst langsam ab. Am Zeitnullpunkt hat die Anisotropie einen Betrag von 0.35. Der Verlauf der Anisotropie bei dieser Wellenlänge unterscheidet sich damit von dem im PumpProbe-Experiment bei $530 \mathrm{~nm}$.

Die Anisotropie bei $450 \mathrm{~nm}$ klingt innerhalb des Fehlers der Messung auf einer 


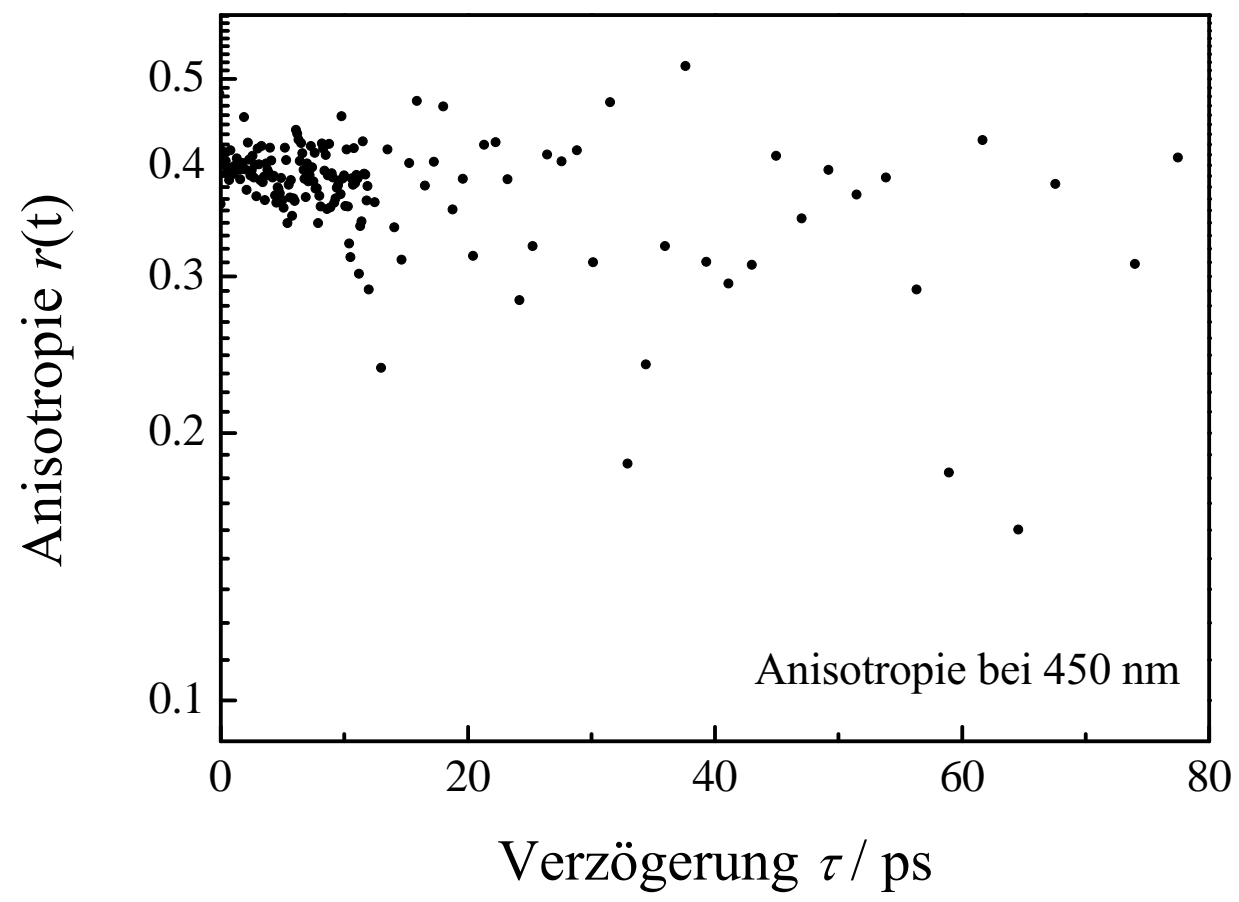

Abbildung 4.19: Verlauf der Anisotropie aus Fluoreszenzkonversionsexperimenten bei einer Nachweiswellenlänge von $450 \mathrm{~nm}$.

Zeitskala von 80 ps von $r_{0}=0.4$ nur äußerst schwach ab und unterscheidet sich daher von der im Pump-Probe-Experiment berechneten Anisotropie bei $714 \mathrm{~nm}$ fundamental.

\section{Anisotropie im TCSPC-Experiment}

Konzentrationsabhängige Anisotropiemessungen können Aufschluss darüber geben, inwiefern Dimerisierung der GFP-Moleküle einen Einfluss auf die Rotationseigenschaften des GFP und des Chromophors im GFP haben. Alle bisherigen Messungen wurden bei einer optischen Dichte von $O D=0.6$ bei $400 \mathrm{~nm}$ durchgeführt. Dies entspricht einer Konzentration von $2 \cdot 10^{-4} \mathrm{~mol} / \mathrm{l}$. Von Tsien et al. ${ }^{14}$ wurde die Dimerisierungskonstante des GFP in Lösung zu 1/100 $\mu \mathrm{mol} / \mathrm{l}$ bestimmt. Bei der verwendeten optischen Dichte ergäbe sich demnach ein Verhältnis Dimer zu Monomer von zwei zu eins. Ein Einfluss der Dimerisierung auf die Photochemie und Photophysik des Proteins wäre damit nicht ausgeschlossen. Aufgrund des größeren hydrodynamischen Volumens sollte aber die Rotationsdiffusion eines GFP-Dimers deutlich langsamer sein als die der 

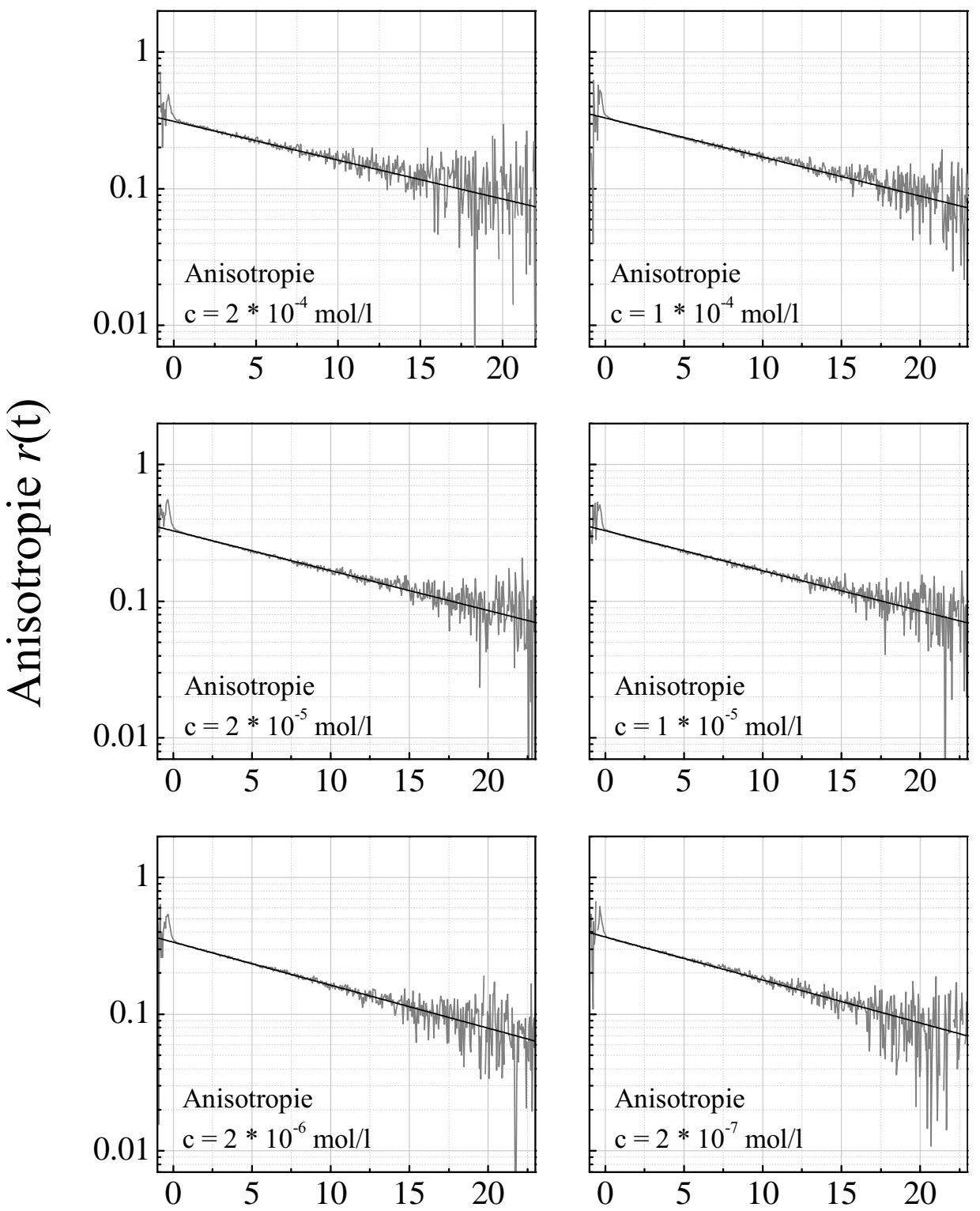

Verzögerung $\tau /$ ns

Abbildung 4.20: Verlauf der Anisotropie aus Einzelphotonenzählexperimenten bei einer Nachweiswellenlänge von $510 \mathrm{~nm}$ bei verschiedenen Konzentrationen des GFP. Dargestellt sind auch die monoexponentiellen Anpassungen nach $F(t)=$ $A \cdot \exp (-t / \tau)$. 


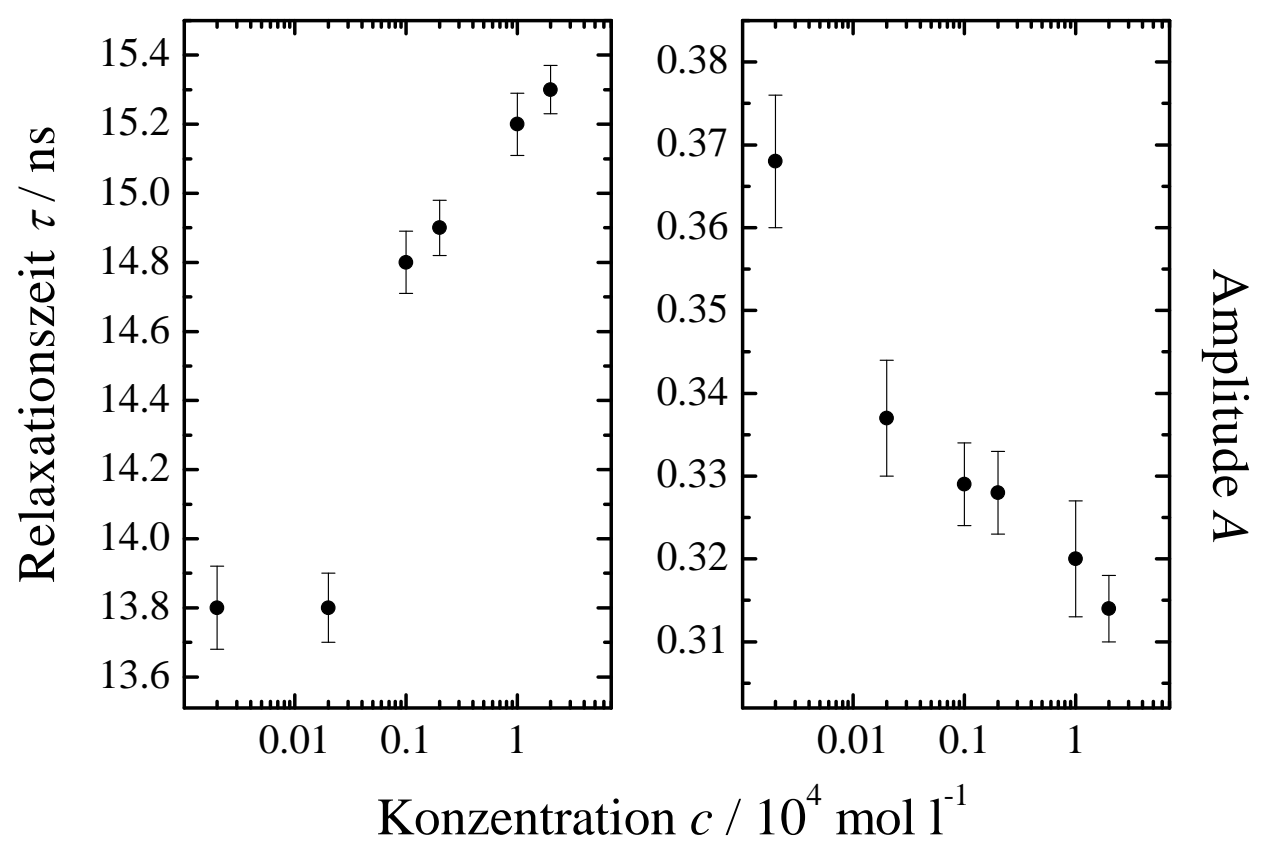

Abbildung 4.21: Graphische Auftragung der Anpassungsparameter $\tau$ und $A$ der exponentiellen Funktionen der konzentrationsabhängigen Anisotropie.

Monomeren. Durch Messung der Anisotropie als Funktion der Proteinkonzentration müsste daher die Dimerisierung als Verlangsamung der Rotationsdiffusion erkennbar werden. Änderungen der zeitabhängigen Anisotropie könnten grundsätzlich auch im Pump-Probe-Experiment nachgewiesen werden. Jedoch ist das TCSPC-Experiment deutlich empfindlicher als das Pump-Probe-Experiment, so dass hier mit deutlich kleineren Konzentrationen gearbeitet werden kann.

Die zeitabhängige Anisotropie wurde bei sechs Konzentrationen untersucht $(200 \mu \mathrm{M}, 100 \mu \mathrm{M}, 20 \mu \mathrm{M}, 10 \mu \mathrm{M}, 1 \mu \mathrm{M}, 0.1 \mu \mathrm{M})$. Die konzentrationsabhängigen Anisotropien sind in Abbildung 4.20 gezeigt. Alle Signale wurden monoexponentiell angepasst. Die Abklingzeiten und zugehörigen Amplituden sind in Abbildung 4.21 zusammengestellt. Die Abklingzeiten nehmen in der Tat mit wachsender Konzentration zu. Gleichzeitig klingen die Anfangswerte der Anisotropie am Zeitnullpunkt von 0.37 bis 0.31 ab. Obwohl die Proteinkonzentration über mehr als drei Größenordnungen variiert wurde, ändert sich die Relaxationszeit allerdings nur um etwa $10 \%$. 
Die Änderung der exponentiellen Abklingzeit, die bei vollständiger Dimerisierung erwartet würde, lässt sich folgendermaßen abschätzen: Der Zerfall der Anisotropie kann auf einer Nanosekundenzeitskala der diffusiven Reorientierung der GFP-Moleküle (Rotationsdiffusion) zugeschrieben werden. Im hydrodynamischen Grenzfall gilt für den Koeffizienten $D$ der Rotationsdiffusion eines sphärischen Rotors die Stokes-Einstein-Debye-Beziehung:

$$
D=\frac{k_{B} T}{V \eta},
$$

wobei $k_{B}$ die Boltzmann-Konstante darstellt. $T$ ist die Temperatur, $V$ das hydrodynamische Volumen des Rotors und $\eta$ der Viskositätskoeffizient des Lösungsmittels ${ }^{82}$. Die Ansitropie klingt in diesem Fall monoexponentiell gemäß:

$$
r(t)=r_{0} \cdot \exp (-6 D t),
$$

ab, wobei der Rotationsdiffusionskoeffizient $D$ in dieser Gleichung wieder auftaucht $^{82}$. Obwohl das GFP-Molekül einem Zylinder mit dem Durchmesser von 30 Åund einer Höhe von $40 \AA$ gleicht ${ }^{11}$, kann sein hydrodynamisches Volumen zu etwa $65500 \AA^{3}$ abgeschätzt werden. Dabei entspricht das hydrodynamische Volumen von Proteinen nicht dem reinen Proteinvolumen, das von Yang et al. röntgenstrukturanalytisch bestimmt wurde. Vielmehr muss die Hydratisierung des Proteins einbezogen werden, wobei das hydratisierte Volumen eines typischen Proteins etwa $1 \mathrm{~cm}^{3} \mathrm{~g}^{-1}$ beträgt ${ }^{37}$. Das Dimer sollte dann näherungsweise ein Volumen von $260000 \AA^{3}$ annehmen (sphärischer Rotor mit $\mathrm{r}=40 \AA$ ). Mit diesen Volumina und der Viskosität des Wassers von $0.891 \mathrm{~g} / \mathrm{ms}^{83}$ bei einer Temperatur von $T=298 \mathrm{~K}$ werden die folgenden Rotationsdiffusionskoeffizienten für das Monomer $D_{M}$ und das Dimer $D_{D}$ erhalten:

$$
\begin{aligned}
D_{M} & =7.055 \cdot 10^{7} \mathrm{~s}^{-1} \\
D_{D} & =1.775 \cdot 10^{7} \mathrm{~s}^{-1} .
\end{aligned}
$$

Die diffusiven Reorientierungszeiten $\tau_{M}$ und $\tau_{D}$ entsprechen den reziproken Diffusionskoeffizienten:

$$
\begin{aligned}
\tau_{M} & =14.2 \mathrm{~ns} \quad \text { und } \\
\tau_{D} & =53.3 \mathrm{~ns} .
\end{aligned}
$$

Nach diesem Modell sollte die Reorientierungszeit des Dimers fast viermal so langsam sein wie die des Monomers. Obwohl das Verhältnis von Dimer zu Monomer bei der höchsten Konzentration nur 2:1 beträgt, sollte die Anisotropie mit steigender Dimerkonzentration entweder biexponentielles Abklingverhalten aufweisen oder eine deutlichere Verlangsamung zeigen, als experimentell beobachtet wurde. Daher kann zusammengefasst werden, dass innerhalb der Genauigkeit der Messungen keine Dimerisierung festgestellt wird. 


\subsection{Photokonversionsstudien}

Die Pump-Probe-Experimente offenbarten zum Zeitpunkt $t=0$ ps eine unmittelbar auftretende stimulierte Emission (siehe Abschnitte 4.1 und 4.2). Zur Klärung der Herkunft dieser Komponente wurden Photokonversionsstudien durchgeführt. Abbildung 4.22 zeigt den Einfluss der Bestrahlung einer frischen GFP-Lösung mit ultraviolettem Licht bei $\lambda=400 \mathrm{~nm}$ auf das stationäre Absorptionsspektrum. Die optische Dichte der höherfrequenten Bande (A, $\left.\lambda_{\max }=398 \mathrm{~nm}\right)$ sinkt, während die der niederfrequenten $\left(\mathrm{B}, \lambda_{\max }=478 \mathrm{~nm}\right.$ ) gleichzeitig steigt. Bei einer Wellenlänge von $428 \mathrm{~nm}$ erscheint ein isosbestischer Punkt. Ganz offensichtlich lässt sich das Protein durch Bestrahlung von UV-Licht $(400 \mathrm{~nm})$ von der neutralen Form $\mathrm{A}$ in die deprotonierte Form B umwandeln.

In Abhängigkeit der Bestrahlungsdauer wurden nun Pump-Probe-Signale bei einer Nachweiswellenlänge von $530 \mathrm{~nm}$ aufgenommen. Zu jedem Spektrum gehört daher ein zeitaufgelöstes Pump-Probe-Signal. Diese sind in Abbildung 4.23 dargestellt, wobei sie auf die Amplitude der instantan erscheinenden

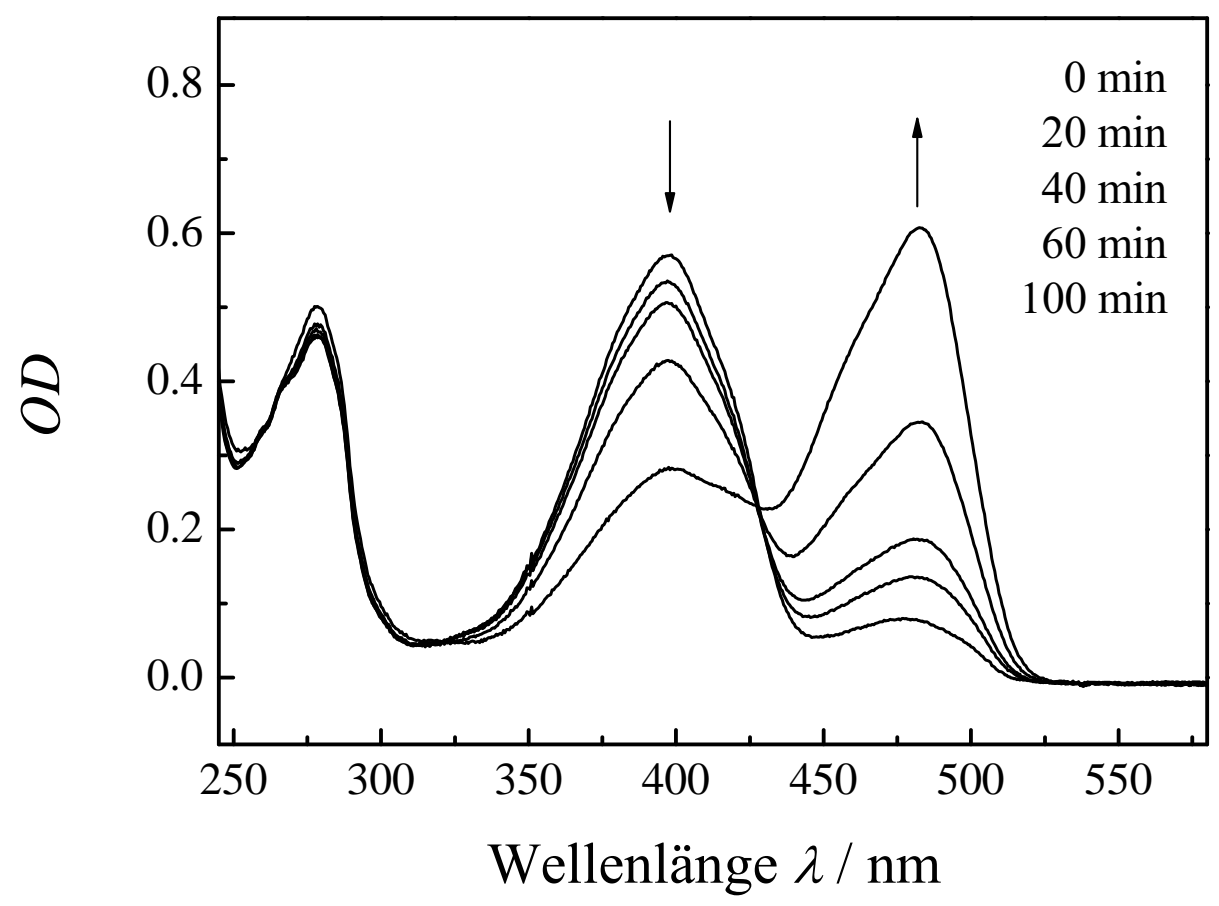

Abbildung 4.22: Stationäre Absorptionsspektren von wt-GFP in Abhängigkeit von der Bestrahlungsdauer. Die Leistung des verwendeten Lichtes bei $400 \mathrm{~nm}$ betrug $1-3 \mathrm{~mW}$. 


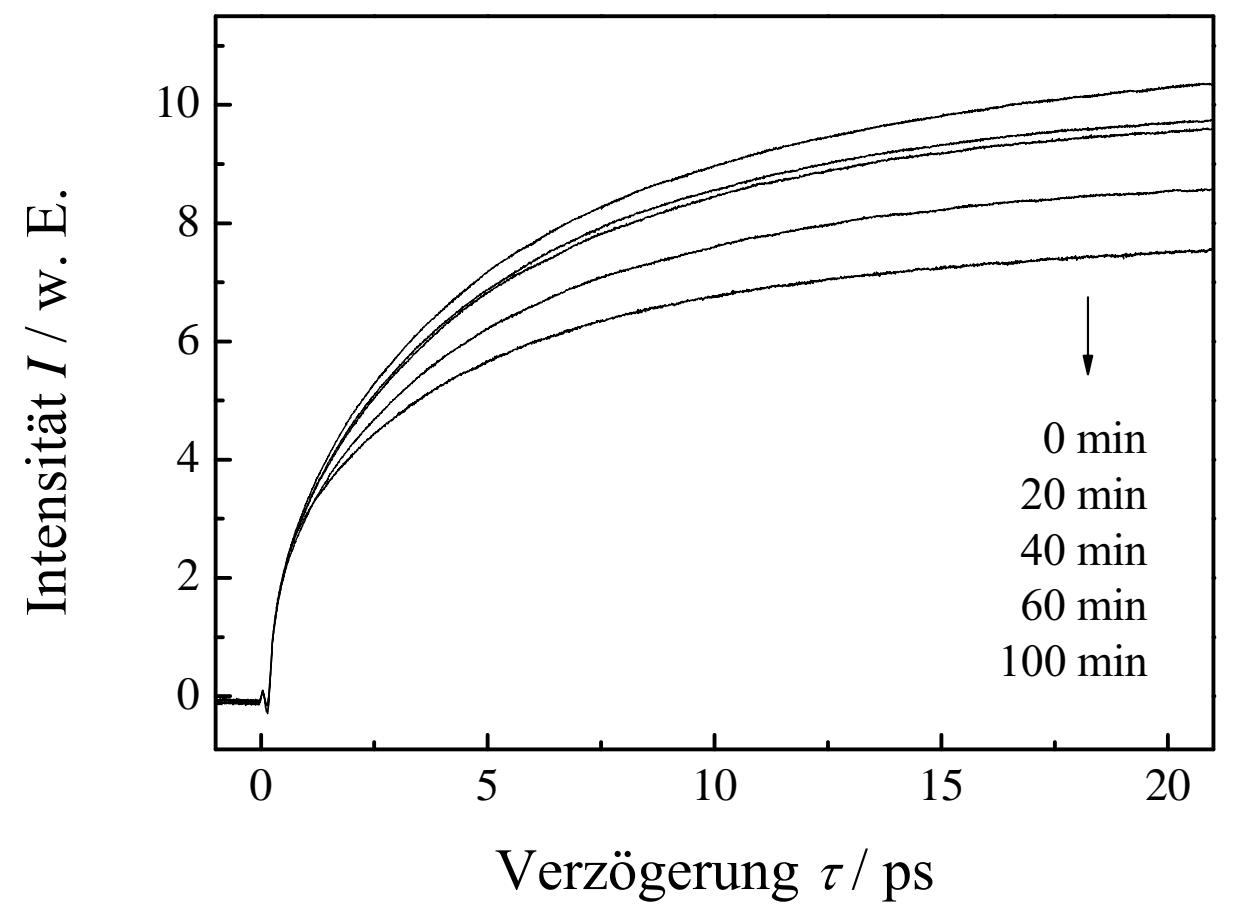

Abbildung 4.23: Pump-Probe-Signale bei einer Nachweiswellenlänge von $530 \mathrm{~nm}$ in Abhängigkeit der Bestrahlungsdauer. Die Signale wurden auf den instantan erscheinenden Teil des Signals normiert.

Signalkomponente normiert wurden. Es wird deutlich, dass die Intensität des zeitlich verzögerten Teils des Signals relativ zum instantanen Teil mit zunehmender Bestrahlungsdauer sinkt. Ein Vergleich der Abbildungen 4.22 und 4.23 verdeutlicht, dass das Amplitudenverhältnis aus instantaner und verzögerter, pumpinduzierter Emission mit wachsendem $O D_{B} / O D_{A}$ ansteigt. Dies lässt vermuten, dass der instantane Signalbeitrag zu $\triangle O D$ durch direkte Anregung von B herrührt. Eine solche direkte Anregung von B ist vorstellbar, wenn ihr Extinktionskoeffizient bei der Pumpwellenlänge von $400 \mathrm{~nm}$ nicht verschwindet. Für die Klärung dieses Problems ist der quantitative Vergleich der Verhältnisse der Banden A und B der Spektren bei der Anregungswellenlänge von $400 \mathrm{~nm}$ mit dem Verhältnis aus instantanem und verzögert erscheinendem Signalbeitrag der Pump-Probe-Signale notwendig. Bevor dies umgesetzt werden kann, müssen Gleichungen aufgestellt werden, die das Entstehen des Spektrums und des Pump-Probe-Signals beschreiben. Dafür ist es notwendig, einige dynamische Prozesse des GFP zu verstehen, die erst in der Diskussion (Kapitel 5) erläutert werden. Um der Diskussion an dieser Stelle nicht vorgreifen zu müssen, wird die 


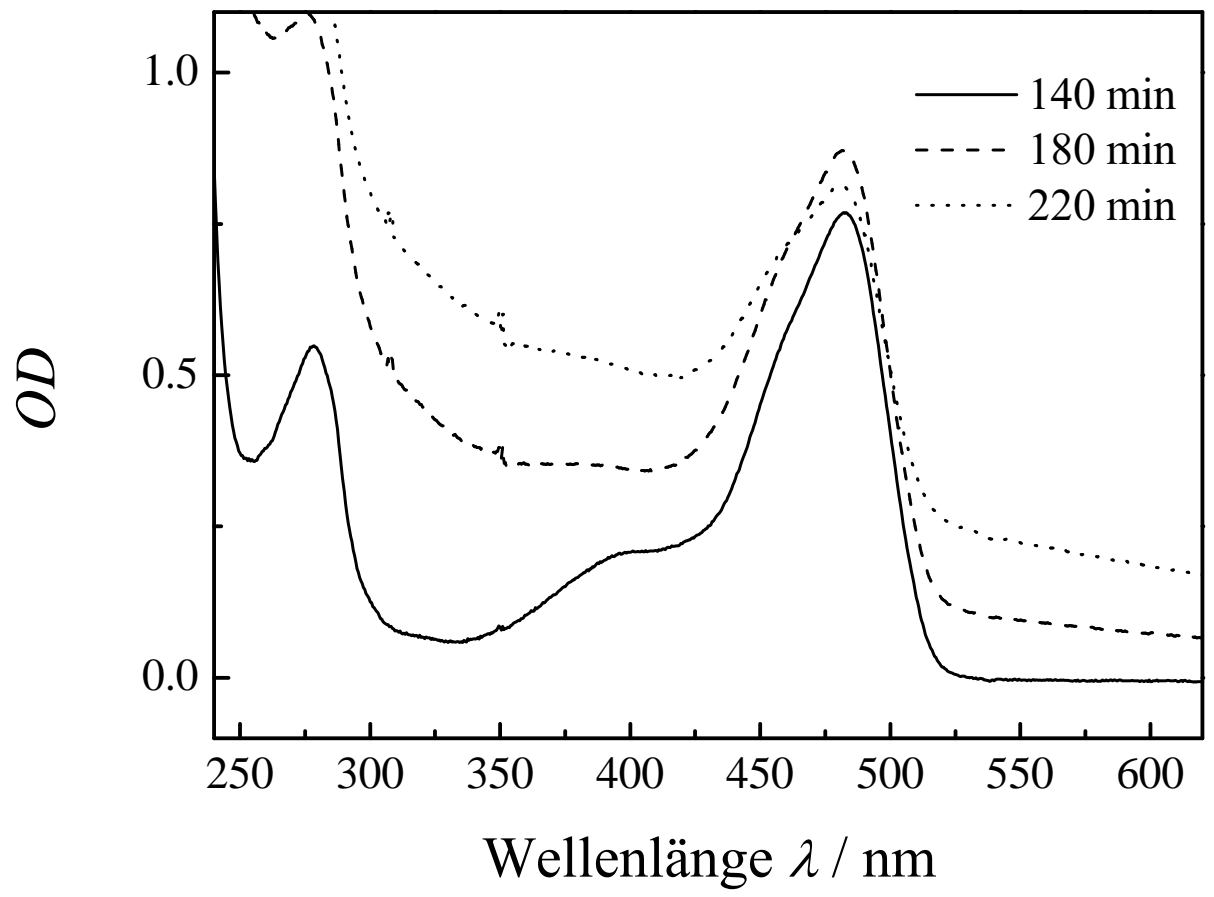

Abbildung 4.24: Stationäre Absorptionsspektren bei weiterer Bestrahlungsdauer. Die Leistung des verwendeten Lichtes bei $400 \mathrm{~nm}$ betrug $1-3 \mathrm{~mW}$.

Frage nach der Ursache der instantan ansteigenden Emission erst in Abschnitt 5.1 geklärt.

Bei weiterer Bestrahlung sinkt die Amplitude der höherfrequenten Bande weiterhin, die der niederfrequenten steigt (Abbildung 4.24). Allerdings ist dieser Trend von der stärker werdenden Zersetzung des Proteins überlagert, die zu einem starken Streulichtuntergrund führt. Es ist anzunehmen, dass bei einer Bestrahlungsdauer von 180 und 220 Minuten so gut wie keine bzw. keine Amplitude der höherfrequenten Bande vorliegt, so dass in diesem Falle fast ausschließlich in der niederfrequenten Bande angeregt wird.

Die Signale, die bei diesen Bestrahlungsdauern gemessen wurden (Abbildung 4.24), weichen zunehmend von der Dynamik ab, die beobachtet wird, wenn nicht-photokonvertierte GFP-Lösungen mit $400 \mathrm{~nm}$-Licht angeregt werden. Das Anstiegsverhalten des vollständig photokonvertierten Signals ist nahezu instantan und bleibt innerhalb der maximalen Verzögerungszeit konstant. 


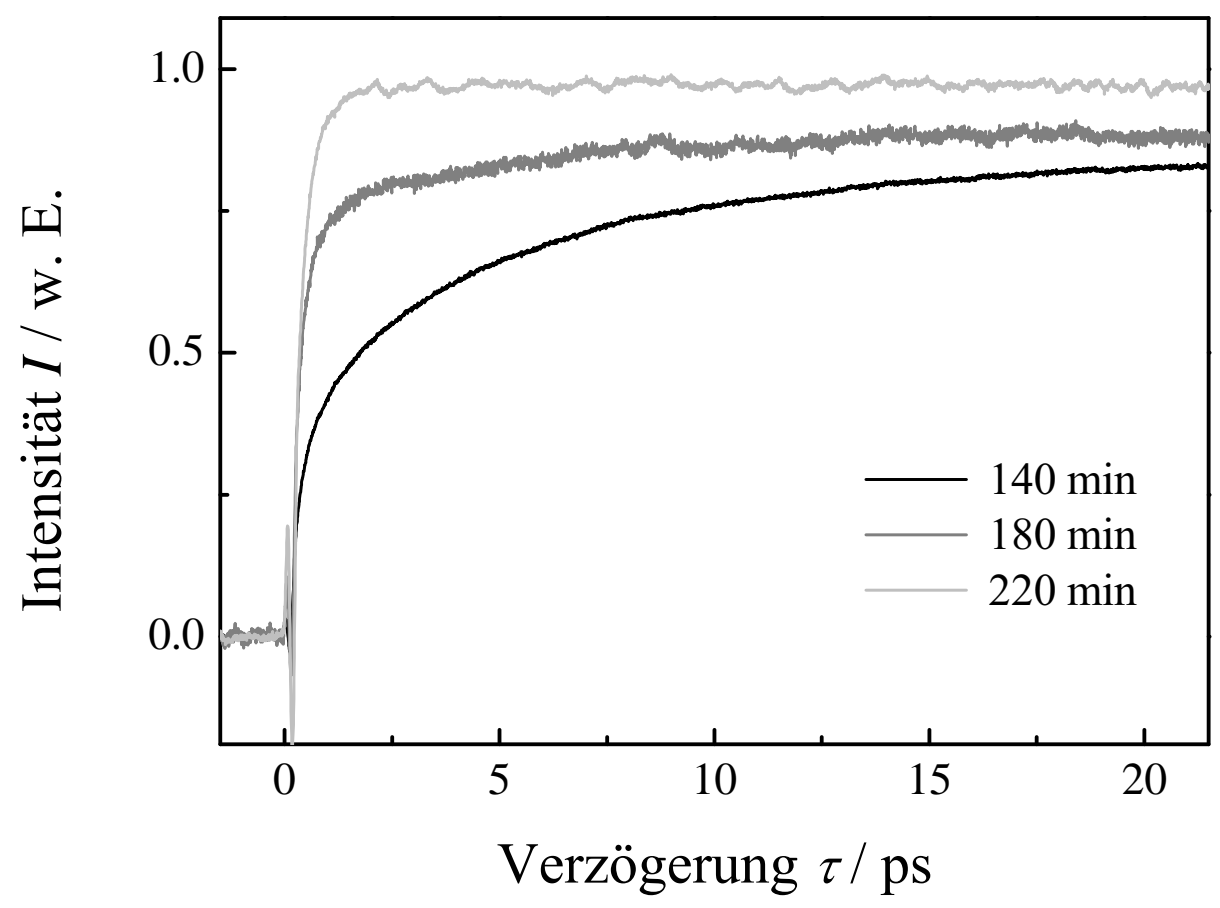

Abbildung 4.25: Pump-Probe-Signale bei einer Nachweiswellenlänge von $530 \mathrm{~nm}$ bei weiterer Bestrahlungsdauer. 


\subsection{Pumpleistungsabhängigkeit}

Um Pumpleistungseffekte auf die Dynamik des GFP ausschließen zu können, wurde sie innerhalb einer Messreihe systematisch verringert und das zugehörige Signal aufgezeichnet. Abbildung 4.26 zeigt, dass die Dynamik über den Pumpleistungsbereich von $0.14 \mathrm{~mW}$ bis $1.22 \mathrm{~mW}$ innerhalb der Genauigkeit des Experimentes nicht beeinflusst wird.

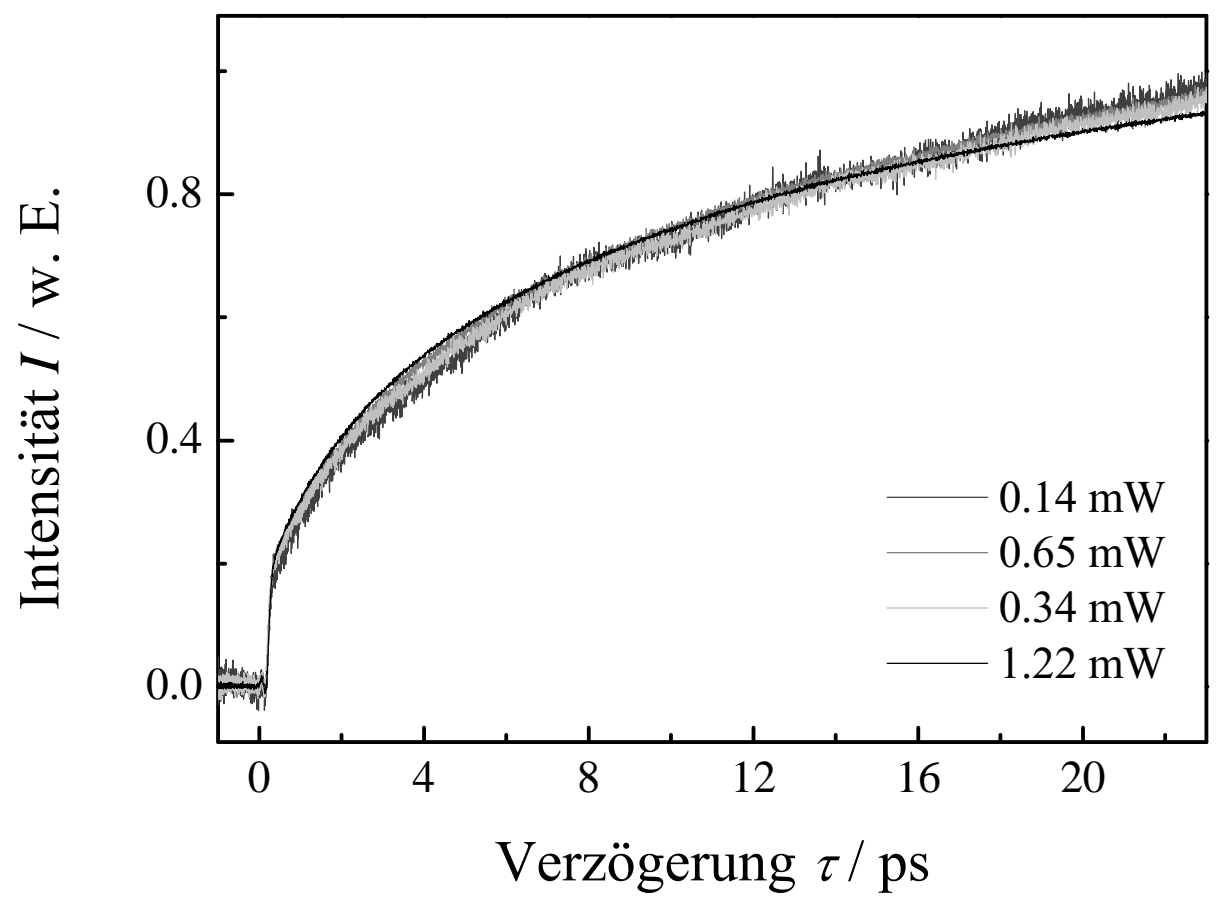

Abbildung 4.26: Pumpleistungsabhängigkeit eines Pump-Probe-Signals. Die Daten wurden auf die Intensität des instantanen Teils normiert. 


\section{Kapitel 5}

\section{Diskussion}

\subsection{Energetische Einordung der Ergebnisse}

Spektrale Lochbrennexperimente bei tiefen Temperaturen ${ }^{33}$ führten zu dem in Abschnitt 2.3.2 vorgestellten Energiediagramm. Danach ist im elektronischen Grundzustand der Chromophor in seiner neutralen Form A thermodynamisch begünstigt (Abbildung 5.1). Der vertikale 0-0-Übergang vom Grundzustand A zum angeregten Zustand A* liegt bei $23042 \mathrm{~cm}^{-1}(434 \mathrm{~nm})$. Der Grundzustand der anionischen Form B liegt energetisch etwas höher. Entsprechend der Besetzungen der Grundzustände A und B ist der Energieunterschied zwischen A und $\mathrm{B}$ nach Brejc et al. kleiner als $k_{B} T^{59}$. Der 0-0-Übergang von $\mathrm{B}^{*}$ befindet sich bei $20964 \mathrm{~cm}^{-1}(477 \mathrm{~nm})$. Hieraus ergibt sich ein Energieunterschied zwischen den angeregten Zuständen $\mathrm{A}^{*}$ und $\mathrm{B}^{*}$ von etwa $2000 \mathrm{~cm}^{-1}$. Der Grundzustand der Intermediärform I befindet sich nach Creemers et al. ${ }^{33}$ energetisch höher als A und $\mathrm{B}$ und ist bei Zimmertemperatur nur schwach populiert. Der 0-0-Übergang $\mathrm{I} \rightarrow \mathrm{I}^{*}$ wurde bei $20202 \mathrm{~cm}^{-1}(495 \mathrm{~nm})$ gefunden ${ }^{33}$. Die Barriere zwischen den angeregten Zuständen $\mathrm{B}^{*}$ und I* beträgt mindestens $2000 \mathrm{~cm}^{-1}{ }^{33}$. Die Grundzustände $\mathrm{A}$, I und $\mathrm{B}$ sind durch Barrieren getrennt, die zu einigen hundert reziproken Zentimetern abgeschätzt wurden ${ }^{33}$. Aus temperaturabhängigen Fluoreszenzmessungen von Chattoraj et al. lässt sich eine Barriere zwischen A* und I* abschätzen, deren Höhe etwa $200 \mathrm{~cm}^{-1}$ beträgt.

Die in Kapitel 4 dargestellten Ergebnisse sollen nun in dieses Energieschema (Abbildung 5.1) eingeordnet werden. Dazu sind die für die verschiedenen Spektralbereiche charakteristischen Signale noch einmal in Abbildung 5.2 übersichtlich zusammengefasst. Abbildung 5.1 repräsentiert das Energieschema, das anhand der Ergebnisse von Creemers et al. ${ }^{33}$ erstellt werden konnte. Die für die verschiedenen Spektralbereiche charakteristischen Signale (Abbildung 5.2), die in der vorliegenden Arbeit gemessen wurden, sind in diesem Energieschema durch vertikale Pfeile und nebenstehende Wellenlängen gekennzeichnet. 


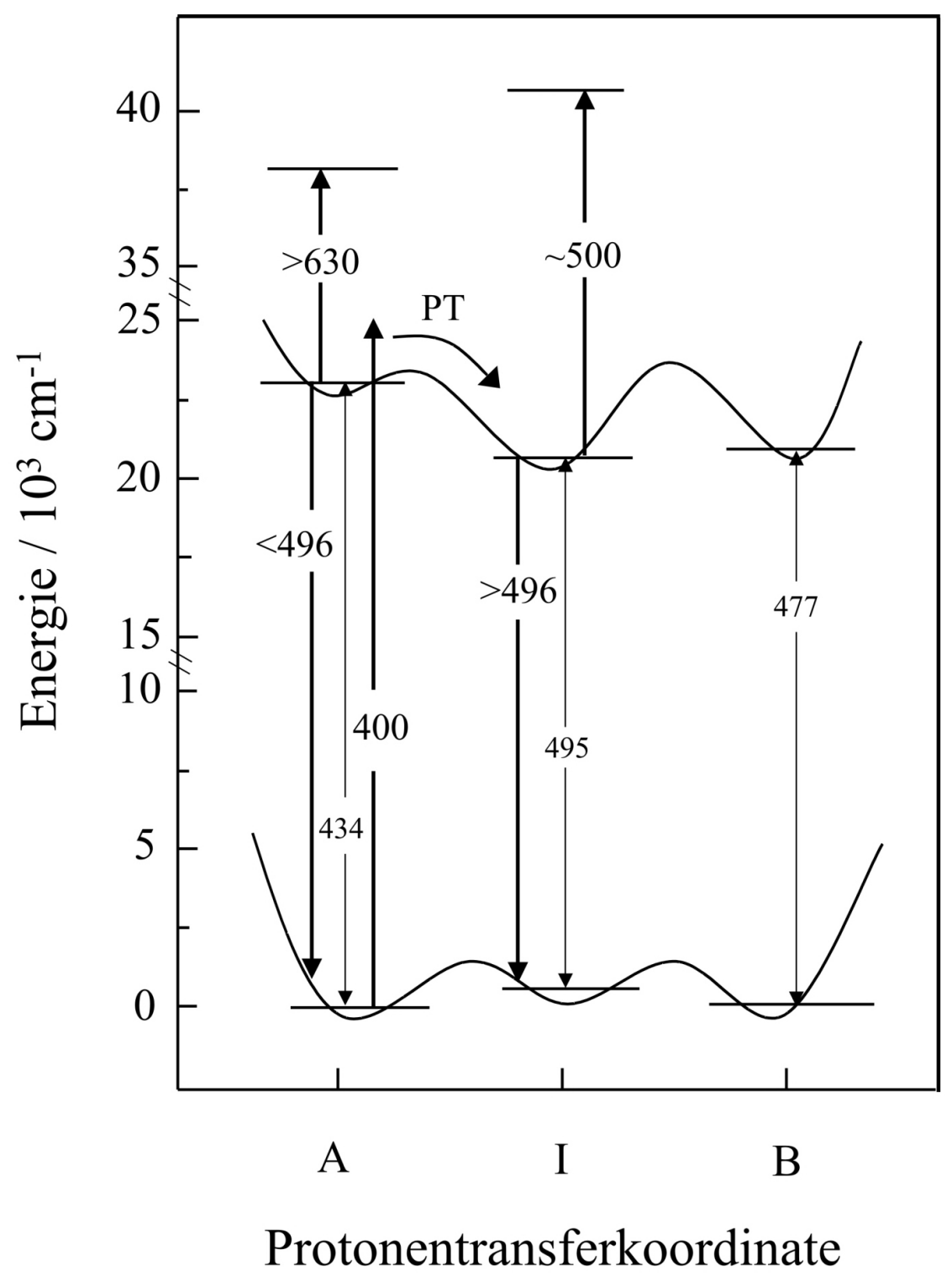

Abbildung 5.1: Energieschema mit den stimulierten Emissionen und transienten Absorptionen aus dieser Arbeit (siehe Kapitel 4). Die Wellenlänge für die 0-0Übergänge zwischen Grund- und angeregten Zuständen wurden der Arbeit von Creemers et al. entnommen ${ }^{33}$. Die Zahlen repräsentieren Wellenlängen in Nanometer und PT steht für Protonentransfer. Die dünn gargestellten Pfeile stellen die Wellenlänge der entsprechenden 0-0-Energie dar. 
Bei einer Anregungsenergie von $25000 \mathrm{~cm}^{-1}(400 \mathrm{~nm})$ wird die A-Form mit etwa $2000 \mathrm{~cm}^{-1}$ Überschussenergie angeregt - sie ist daher schwingungsangeregt. Diese Anregungsenergie liegt darüberhinaus oberhalb der Konversionsbarriere von $\mathrm{I}^{*} \rightarrow \mathrm{B}^{*}$, wodurch die direkte Photokonversion von $\mathrm{A}^{*} \mathrm{zu} \mathrm{B}^{*}$ möglich wird. Im Bereich für Nachweiswellenlängen von $\lambda>496 \mathrm{~nm}$ steigt die stimulierte Emission nach einem instantan erscheinenden Anteil langsam auf einer Zeitskala von $20 \mathrm{ps}$ an. Die differentiellen Transmissionsspektren weisen über dem Verzögerungsbereich von insgesamt $102 \mathrm{ps}$ keine Verschiebung des Emissionsmaximums auf, und das Spektrum bleibt formstabil. Darüberhinaus stimmt die rote Flanke der differentiellen Transmissionsspektren bereits nach kurzer Zeit (6ps) mit der des stationären Emissionsspektrums quantitativ überein. Die beobachtete Emission kann daher in diesem Bereich primär der Emission aus dem angeregten Intermediärzustand I* zugeordnet werden. Diese Zuordnung ist im Einklang mit der aus fluoreszenzspektroskopischen Studien am GFP und dessen deuterierten Lösungen ${ }^{31}$. Eine ausgeprägte Verlangsamung der Fluoreszenz durch Isotopenaustausch belegt zweifelsfrei, dass die Bildung von I* durch Protonentransfer erfolgt $t^{31}$.

Für Wellenlängen $\lambda<496 \mathrm{~nm}$ erscheint die stimulierte Emission instantan und klingt auf der gleichen Zeitskala ab, wie sie bei längeren Wellenlängen ansteigt. Sie wird der Emission aus dem direkt angeregten $\mathrm{A}^{*}$-Zustand zugeordnet und stimmt mit früheren Studien von Chattoraj et al. überein. Diese Emission zeigt ebenfalls einen deutlichen Isotopeneffekt, wenn deuteriertes GFP untersucht wird. Die Zustände $\mathrm{A}^{*}$ und $\mathrm{I}^{*}$ sind daher beide mit der Protonenbewegung verbunden und deshalb miteinander verknüpft.

Abbildung 5.2 zeigt nochmals differentielle Transmissionsspektren für repräsentative Anregungs-Abtastzeiten. Darüberhinaus ist das gemäß Abbildung 5.2 berechnete Differenzspektrum als gestrichelte Kurve wiedergegeben. Letzteres entspricht einer Absorption, die um $500 \mathrm{~nm}$ maximal ist. Da diese bei großen Verzögerungen (102 ps) nachgewiesen werden kann, muss sie zwangsläufig dem Produktzustand - also I* - zugeordnet werden (siehe Abbildung 5.1). Die Absorption von Licht aus dem Intermediärzustand I* führt also zu höheren elektronisch angeregten Zuständen $I_{n}$ des Intermediats.

Die transiente Absorption im langwelligen Spektralbereich $\lambda>630 \mathrm{~nm}$ steigt instantan innerhalb der Zeitauflösung an und klingt auf einer Zeitskala von einigen $10 \mathrm{ps}$ ab. Die resultierenden Zeitkonstanten finden sich im Anstieg der stimulierten Emission für $\lambda \leq 600 \mathrm{~nm}$ wieder. Die transiente Absorption entspricht dem elektronischen Übergang von $A^{*}$ zu einem höheren elektronischen Niveau $A_{n}$. 

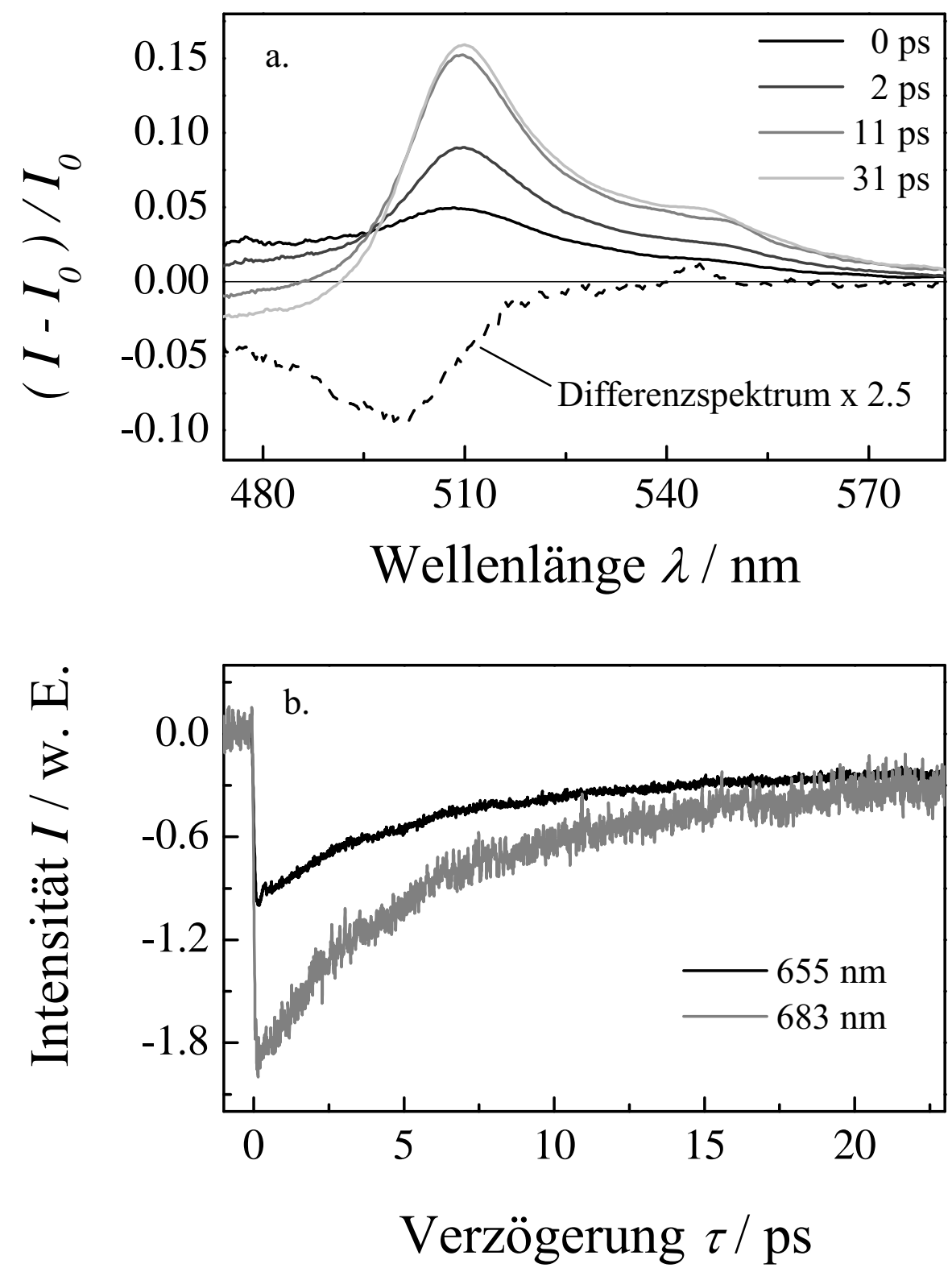

Abbildung 5.2: Zusammenfassende Darstellung der Signale, die für die verschiedenen Spektralbereiche charakteristisch sind. a. Charakteristische Signale im Spektralbereich $470<\lambda<590 \mathrm{~nm}$, b. Charakteristische Signale im Spektralbereich $600<\lambda<720 \mathrm{~nm}$ 


\section{Ursprung der instantanen Emission}

Wie bereits in Abschnitt 4.1 (Abbildung 4.4) gezeigt wurde, steigt die stimulierte Emission innerhalb der experimentellen Zeitauflösung an und ist anschließend durch einen langsamen Anstieg auf einer Zeitskala von mehr als 20 ps gekennzeichnet. Das differentielle Transmissionsspektrum ist bereits zum zeitlichen Nullpunkt bei 507 - $508 \mathrm{~nm}$ maximal. Der Ursprung dieser „prompten“ Emission soll im Folgenden diskutiert werden. In ihren Experimenten zur Dynamik der Fluoreszenz des GFP beobachteten Chattoraj et al. ${ }^{31}$ zusätzlich zum langsam ansteigenden Signal einen mit in der vorliegenden Arbeit angestellten Beobachtungen vergleichbaren instantanen Anteil der Fluoreszenz bei Detektionswellenlängen um $508 \mathrm{~nm}$. Da die A- und B-Bande bei der Anregungswellenlänge überlappen könnten, vermuteten Chattoraj et al., dass eine direkte Anregung der B-Form für die sofortige Emission verantwortlich ist. Da es zunächst nicht möglich ist, das alleinige Absorptionsspektrum der B-Form einwandfrei zu ermitteln, kann über die optische Dichte der B-Bande bei $400 \mathrm{~nm}$ nur spekuliert werden. Um abzuschätzen, ob die optische Dichte dieser Bande bei $400 \mathrm{~nm}$ zu dem beobachteten instantanen Signalbeitrag relativ zum verzögerten führen könnte, wurde zunächst die höherenergetische Flanke der B-Bande eines photokonvertierten Spektrums zu kürzeren Wellenlängen extrapoliert. Dazu wurde dieser Teil der Bande mit einer Lognormalverteilung angepasst:

$$
G(\lambda)=A \cdot \exp \left[-\ln (2) \cdot\left[\frac{\ln \left(1+2 b \cdot \frac{\left(\lambda-\lambda_{0}\right)}{\Delta}\right)}{b}\right]^{2}\right] \cdot \Phi\left[-\lambda+\lambda_{0}-\frac{\Delta}{2 b}\right]
$$

wobei $\Phi$ die Heavyside-Sprungfunktion beschreibt. Die Mittenwellenlänge $\lambda_{0}$ beträgt $464.5 \mathrm{~nm}$, der Asymmetriefaktor $b=-1.1$ und der Verbreiterungsparameter $\Delta$ nimmt einen Wert von $31 \mathrm{~nm}$ an. Die Amplitude $A$ beträgt 1.69. In Abbildung 5.3 (a.) sind ein photokonvertiertes Spektrum und die Anpassung nach Gleichung 5.1 für den relevanten Bereich dargestellt. Die A-Bande wurde bei $400 \mathrm{~nm}$ auf eins normiert.

Mit Hilfe dieser Anpassung lassen sich die Anteile $A_{A}$ und $A_{B}$ der Absorptionen der A- und B-Form bei $400 \mathrm{~nm}$ bestimmen. Das dem Spektrum korrespondierende Pump-Probe-Signal wurde bei der maximalen Verzögerungszeit normiert. In Abbildung 5.3 sind die entsprechenden Anteile $S_{A}$ des verzögerten Signalbeitrags und $S_{B}$ des instantanen dargestellt. Damit ein Vergleich beider Verhältnisse möglich ist, müssen Gleichungen gefunden werden, die die Entstehung der Spektren und der Transienten beschreiben können. 


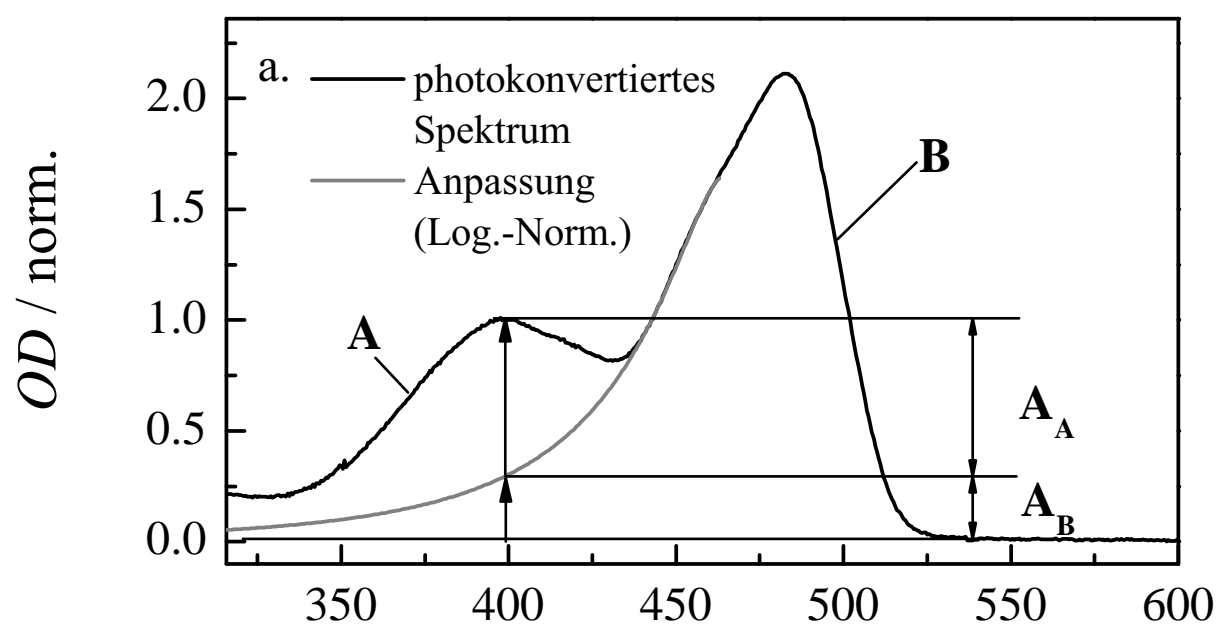

Wellenlänge $\lambda / \mathrm{nm}$

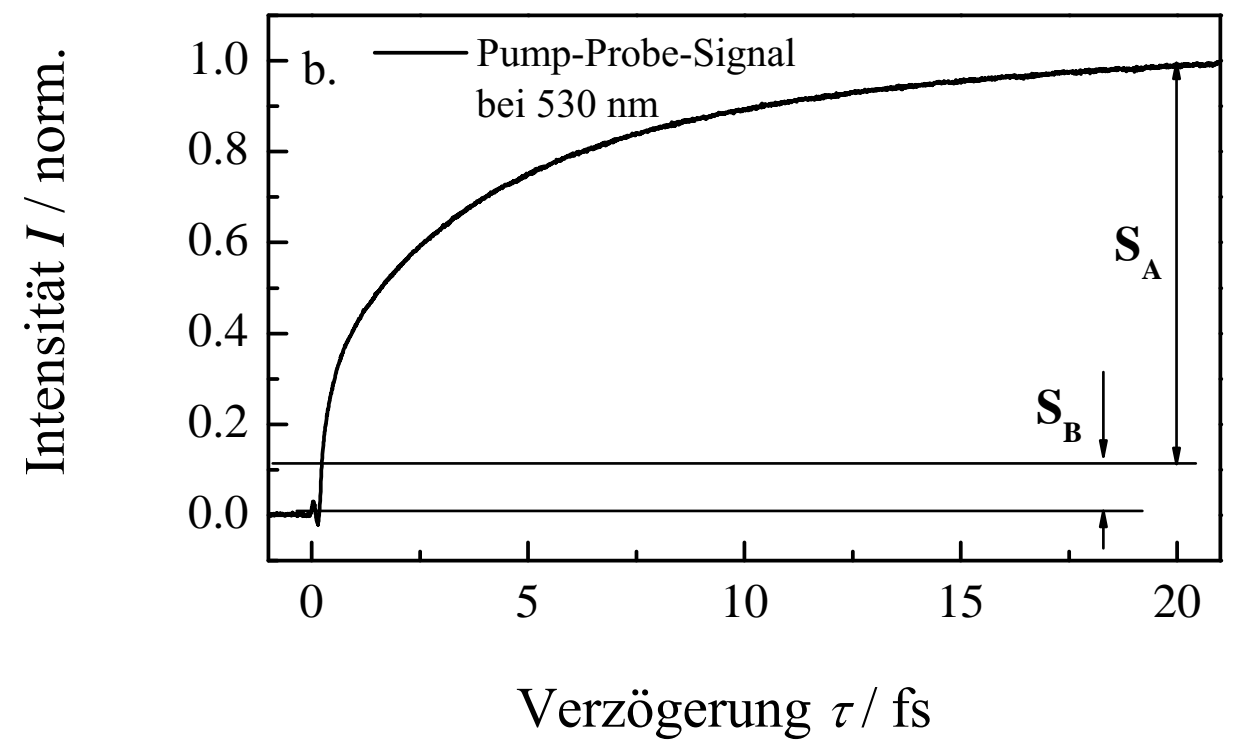

Abbildung 5.3: a. Photokonvertiertes Spektrum des GFP (bei $400 \mathrm{~nm}$ normiert) und Anpassung mit einer Lognormalfunktion. b. zugehöriges Pump-Probe-Signal bei $530 \mathrm{~nm}$. Die Anteile $A_{A}$ und $A_{B}$ bzw. $S_{A}$ und $S_{B}$ sind ebenfalls dargestellt. 
Für das Verhältnis $\mathrm{A}_{A}: \mathrm{A}_{B}$ der Spektren ergeben sich die Proportionalitäten:

$$
\frac{A_{A}}{A_{B}} \propto \frac{N_{A}}{1-N_{A}} \cdot \frac{\sigma_{A, 400}^{a b s}}{\sigma_{B, 400}^{a b s}}
$$

wobei $\sigma_{X, 400}^{a b s}$ der Absorptionsquerschnitt der jeweiligen Komponente X bei $400 \mathrm{~nm}$ ist und $N_{X}$ die Teilchenzahl im Grundzustand darstellt. Dabei wird die Bevölkerung von I im Grundzustand vernachlässigt, so dass $N_{B}=1-N_{A}$ ist. Unter der Annahme, dass die prompte Emission durch direkte Anregung von von B herrührt, ist das Verhältnis $S_{A}: S_{B}$ bei $530 \mathrm{~nm}$ proportional zum Produkt der Absorptions- $\left(\sigma_{X, 400}^{a b s}\right)$ und Emissionsquerschnitte $\left(\sigma_{X, 530}^{\text {sem }}\right)$ :

$$
\frac{S_{A}}{S_{B}} \propto \frac{N_{A}}{1-N_{A}} \cdot \frac{\sigma_{A, 400}^{a b s}}{\sigma_{B, 400}^{a b s}} \cdot \frac{\sigma_{I, 530}^{s e m}}{\sigma_{B, 530}^{s e m}} \cdot \Phi .
$$

Das verzögert ansteigende Signal muss zudem mit der Fluoreszenzquantenausbeute $\Phi$ multipliziert werden, weil nicht die gesamte induzierte Population aus $\mathrm{A}^{*}$ zum Zustand I* transferriert wird ${ }^{36}$. Aus den Gleichungen 5.2 und 5.3 ergibt sich die Beziehung für $A_{A} / A_{B}$ unter Annahme der instantanen Emission von B* zu:

$$
\frac{A_{A}}{A_{B}}=\left[\frac{S_{A}}{S_{B}} \cdot \Phi^{-1} \cdot \frac{\sigma_{B, 530}^{s e m}}{\sigma_{I, 530}^{s e m}}\right] .
$$

Da das Absorptionsspektrum bei $400 \mathrm{~nm}$ normiert wurde, gilt $A_{B}=1-A_{A}$, so dass sich Gleichung 5.4 vereinfachen lässt zu:

$$
A_{A}=\left[\frac{S_{B}}{S_{A}} \cdot \Phi \cdot \frac{\sigma_{I, 530}^{s e m}}{\sigma_{B, 530}^{s e m}}+1\right]^{-1} .
$$

Bei einem Verhältnis $S_{A}: S_{B}$ von 7.52, kann nach Gleichung 5.5 ein Wert von $A_{b e r, A}=89.9 \%$ berechnet werden. Aus den Spektren ergibt sich ein $A_{A}$ von $71.4 \%$. Die beiden Werte differieren daher um 18.5\%. Zwei unbekannte Terme in Gleichung 5.5 sind die Emissionsquerschnitte $\sigma_{I, 530}^{\text {sem }}$ sowie $\sigma_{B, 530}^{\text {sem }}$, die diese Differenz kompensieren könnten. Der Unterschied von $18.5 \%$ zwischen berechnetem und ermitteltem $A_{A}$ verschwindet, wenn der Emissionsquerschnitt von I um einen Faktor 3.5 größer wäre als der von B. Über den Vergleich der Strahlungslebensdauern der beiden Zustände kann geschlossen werden, ob dieser Unterschied realistisch wäre. Die Fluoreszenzlebensdauer $1 / \tau_{f}$, die z. B. im TCSPC-Experiment 
gemessen werden kann, ist die Summe der Geschwindigkeitskonstanten aller strahlenden und nicht-strahlenden Desaktivierungskanäle $i$ :

$$
\frac{1}{\tau_{f}}=\frac{1}{\tau_{r}}+\sum_{i} \frac{1}{\tau_{i}} .
$$

Dabei ist $\tau_{r}$ die sogenannte Strahlungslebensdauer für den Übergang $S_{1} \longrightarrow S_{0}$ unter Emission eines Photons. Die Summe berücksichtigt dabei nicht-adiabatische Übergänge wie innere Konversion und Intersystem Crossing, sowie strahlungslose Desaktivierungsprozesse wie z. B. Protonentransfer. Von der Struktur des Chromophors im GFP ist bekannt, dass die Fluoreszenzlebensdauer deshalb so gross ist, weil Löschung der Fluoreszenz (quenching) infolge von Stößen mit anderen Molekülen aufgrund der Abschirmung des Chromophors durch das Proteingerüst vernachlässigbar ist. Auffallend ist die zwischen I und B exakte Übereinstimmung der in Fluoreszenzexperimenten bestimmten Fluoreszenzlebensdauer von 3.3 ns und das sehr ähnliche Emissionsspektrum von I und B. Hinzu kommt die Beobachtung einer Fluoreszenzquantenausbeute von nahezu $100 \%^{36}$, wenn die Form B elektronisch angeregt wird. Die Desaktivierung von B scheint daher lediglich durch Emission zu erfolgen. Die Tatsache, dass die Fluoreszenzlebensdauer die gleiche Größe hat wie die von B, deutet darauf hin, dass auch I* hauptsächlich infolge von Strahlung desaktiviert wird. Wenn alle aufgeführten Desaktivierungsprozesse zu vernachlässigen sind, so dass die angeregten Zustände I* und $\mathrm{B}^{*}$ nur noch durch Emission relaxieren, sollte die gemessene Lebensdauer von 3.3 ns lediglich von den intrinsischen Eigenschaften der Zustände I/I* und $\mathrm{B} / \mathrm{B}^{*}$ abhängen, die über die Emissionsquerschitte $\sigma_{I, 530}^{\text {sem }}$ bzw. $\sigma_{B, 530}^{\text {sem }}$ definiert sind. Da die Lebensdauern jedoch gleich sind, sollten aus diesem Grund auch die Emissionsquerschnitte gleich bzw. sehr ähnlich sein. Sie werden nicht exakt gleich sein, weil die Fluoreszenzspektren von $I^{*}$ und $B^{*}$ um etwa $4 \mathrm{~nm}$ verschoben sind. Dennoch ist ein Faktor 3.5 für den Unterschied der Emissionsquerschnitte deutlich zu hoch.

Unter der Annahme gleicher Emissionsquerschnitte, muss der instantane Anteil im Pump-Probe-Signal $S_{B}$ nach Gleichung 5.5 etwa 3.5 mal größer sein als tatsächlich beobachtet wird. Aus diesem Grund kann diese Komponente nicht ausschließlich auf die Direktanregung von B bei einer Pumpwellenlänge von $400 \mathrm{~nm}$ zurückzuführen sein. Das Sinken des Verhältnisses $S_{A}: S_{B}$ mit fortschreitender Photokonversion spricht jedoch dafür, dass die Anregung von B und folglich die detektierte stimulierte Emission partiell eine Rolle spielt.

Eine weitere mögliche Quelle der instantanen Emission ist der niederenergetische Bereich der Emission von A*. Wie das differentielle Transmissionsspektrum bei 0 ps zeigt, müsste das Emissionsspektrum von $A^{*}$ in diesem Fall bei etwa $508 \mathrm{~nm}$ maximal und extrem breit sein, d. h. es würde sich über einen Wellenlängenbereich von $400 \mathrm{~nm}$ bis $600 \mathrm{~nm}$ erstrecken. Dies entspräche einer spektralen 
Breite der Fluoreszenz aus $\mathrm{A}^{*}$ von über $8000 \mathrm{~cm}^{-1}$, was im Vergleich zur Breite des Absorptionsspektrums von nur $3800 \mathrm{~cm}^{-1}$ als unrealistisch groß erscheint. Zudem müsste die Fluoreszenz aus A* zu frühen Zeiten ebenfalls um $508 \mathrm{~nm}$ ein lokales Maximum besitzen.

Aus diesen Gründen ist die instantane Emission wahrscheinlich eine Mischung der Emissionen von $\mathrm{A}^{*}, \mathrm{I}^{*}$ und $\mathrm{B}^{*}$. Für Wellenlängen, die kleiner als die isosbestische Wellenlänge bei $496 \mathrm{~nm}$ sind, wird primär Emission aus $\mathrm{A}^{*}$ beobachtet, während die Emission im langwelligen Bereich $(496 \mathrm{~nm}<\lambda<600 \mathrm{~nm})$ von $\mathrm{I}^{*}$ und $B^{*}$ herrührt. Die instantane Emission aus I* setzt voraus, dass dieser Zustand entweder direkt angeregt $\left(\mathrm{I} \rightarrow \mathrm{I}^{*}\right)$ oder über einen nicht-vertikalen Übergang vom Grundzustand $\mathrm{A}\left(\mathrm{A} \rightarrow \mathrm{I}^{*}\right)$ populiert wird (non-vertical cross-well excitation). Da der Intermediärgrundzustand I bei kryostatischen Bedingungen nicht und bei Zimmertemperatur nur schwach populiert ist, kann eine Direktanregung $\left(\mathrm{I} \rightarrow \mathrm{I}^{*}\right)$ ausgeschlossen werden. Demnach wird die instantane Emission anteilig durch nicht-vertikale Anregung $\left(\mathrm{A} \rightarrow \mathrm{I}^{*}\right)$ hervorgerufen. Diese Anregungen sind möglich, wenn die Franck-Condon-Faktoren zwischen den Schwingungseigenfunktionen des Grundzustandes A und denen des angeregten Zustandes I* nicht verschwinden. Nicht-vertikale Übergänge wurden bereits in früheren experimentellen ${ }^{84}$ und theoretischen ${ }^{85}$ Arbeiten zum Protonentransfer in kleineren Systemen untersucht.

\subsection{Dynamisches Modell}

Nachdem die individuellen Komponenten des differentiellen Transmissionsspektrums zu frühen und langen Zeiten den Zuständen ihres Ursprungs zugeordnet wurden, wird im Folgenden ein Modell entwickelt, das die kinetischen Prozesse im angeregten Zustand beschreibt.

\subsubsection{2-Niveau-Interkonversionsmodell}

\section{Isosbestischer Punkt}

Die Ähnlichkeit der Kinetiken von A* und I*, d.h. das Abklingen der stimulierten Emission aus $\mathrm{A}^{*}(\lambda<496 \mathrm{~nm})$, das Abklingen der transienten Absorption aus $A^{*}$ im roten Spektralbereich $(\lambda>630 \mathrm{~nm})$ sowie der Anstieg der stimulierten Emission aus I* $(496 \mathrm{~nm}<\lambda<630 \mathrm{~nm})$, weist auf eine direkte Korrelation der Zustände $\mathrm{A}^{*}$ und $\mathrm{I}^{*}$ hin. Der isosbestische Punkt, der in den zeitabhängigen differentiellen Transmissionsspektren bei $\lambda=496 \mathrm{~nm}$ erscheint und das Spektrum der stimulierten Emission in den Bereich abklingender und ansteigender stimulierter Emission unterteilt (siehe Abbildungen 4.7 und 4.9) ist ein weiterer Beleg für diese Annahme. Die Existenz eines isosbestischen Punktes ist ein Indiz dafür, dass zwei Spezies oder in diesem Fall zwei Zustände vorliegen, die durch eine Barriere voneinander getrennt sind und zwischen denen ein Konzentrationsfluss bzw. Populationsfluss stattfindet. Werden zwei Spezies 
A $^{*}$ und I* betrachtet, so ist die Geschwindigkeit des Flusses $d[A *] / d t$ gleich der von $d[I *] / d t$, d. h. die Population, die aus $\mathrm{A}^{*}$ verschwindet, sammelt sich mit einer Geschwindigkeitskonstanten $k$ in $\mathrm{I}^{*}$ an $\left(\mathrm{A}^{*} \stackrel{k}{\longrightarrow} \mathrm{I}^{*}\right)$. Für eine derartige unimolekulare Reaktion würde sowohl die Abnahme der Population von $\mathrm{A}^{*}$ als auch die Zunahme von I* monoexponentiell erfolgen.

Darauf basierend kann für die Dynamik im angeregten Zustand des GFP das folgende Modell entwickelt werden: Der Zustand A* wird mit einer Überschussenergie von etwa $2000 \mathrm{~cm}^{-1}$ elektronisch angeregt. Da der Chromophor aus mindestens 20 Atomen aufgebaut ist, ergeben sich mindestens 54 Schwingungsfreiheitsgrade (3N-6) des Chromophors. Abbildung 5.1 stellt eine Potentialhyperfläche als Funktion der Protonentransferkoordinate dar und spiegelt aufgrunddessen nur einen Ausschnitt der gesamten Prozesse wieder. Aufgrund der hohen Anzahl der Schwingungsfreiheitsgrade ist der Abbau der Überschussenergie durch intramolekulare Schwingungsenergieumverteilung (IVR) und Schwingungsenergietransfer (VET) möglich. Der Reaktand A* könnte demnach schwingungsmäßig äquilibriert sein, noch bevor der Protonentransfer stattgefunden hat. Schnelle intramolekulare Schwingungsumverteilung kann also effizient von den wenigen Franck-Condon-aktiven Schwingungsmoden zu den Moden erfolgen, deren Franck-Condon-Faktoren vernachlässigbar sind. Hochfrequente Schwingungen, wie NH- oder $\mathrm{OH}-$ Streckschwingungen, die mit hoher Wahrscheinlichkeit an die Reaktionskoordinate koppeln, können bereits relaxiert sein, noch bevor der Protonentransfer erfolgt. Wenn daher die Schwingungsrelaxationsprozesse in den an die Reaktionskoordinate stark koppelnden Moden vollständig abgeschlossen sind, kann davon ausgegangen werden, dass der Chromophor im Zustand A* entlang der Reaktionskoordinate (Abbildung 5.1) tatsächlich thermalisiert ist. Wenn zudem diese Schwingungsmoden die entscheidenden Franck-Condon-Moden sind, wird die Emission aus A* von dem Betrag der Überschussenergie unabhängig.

Nach dieser Schwingungsthermalisierung erfolgt der Protonentransfer mit einem temperaturabhängigen Geschwindigkeitskoeffizienten, die der Theorie unimolekularer Reaktionen folgend als kanonischer Mittelwert über die energieabhängigen Geschwindigkeitskonstanten $k(E)$ zu verstehen ist ${ }^{86}$ (Abbildung 5.4):

$$
k(T)=\int_{0}^{\infty} k(E) \cdot f(E, T) d E .
$$

Dabei ist $f(E, T)$ die thermische Schwingungsenergieverteilung bei der Temperatur $T$. Dieses Modell erklärt zwar den isosbestischen Punkt, bei der Beschreibung des beobachteten multiexponetiellen zeitlichen Verhaltens versagt es jedoch. 


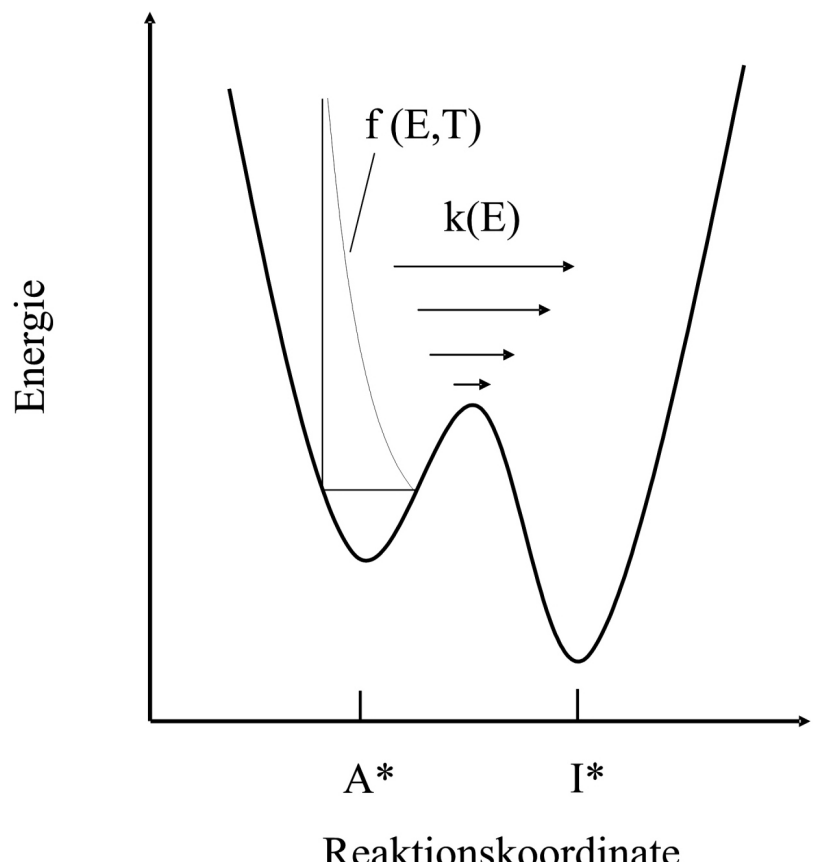

Abbildung 5.4: Zweiniveausystem, innerhalb dessen die Konversion $\mathrm{A}^{*} \stackrel{k}{\longrightarrow} \mathrm{I}^{*}$ ausgehend von einer kanonischen Verteilung im Potential A* stattfindet.

\section{Emissionsdynamik auf einer Nanosekundenzeitskala}

Bei Betrachtung der gesamten Emission, die auf einer Zeitskala von mehreren Nanosekunden abläuft, wird deutlich, dass dieses einfache Modell versagt. Die ausgeprägte Multiexponentialität der Emission auf einer Zeitskala von mehreren Pikosekunden kann auch auf Nanosekundenzeitskalen wiedergefunden werden. Bereits Chattoraj et al. ${ }^{31}$ sowie Lossau et al. ${ }^{32}$ beobachteten ein multiexponentielles Verhalten, die mit den in Abschnitt 2.5 (Tabellen 2.1 und 2.2) aufgeführten Zeitkonstanten angepasst wurden. Aus diesen Experimenten und denen der vorliegenden Arbeit ergibt sich zusammenfassend das folgende Bild für die Emissionen aus A* und I*: Die Emission aus I* steigt mit $\tau_{1} \approx 2$ ps und $\tau_{2} \approx 8$ ps biexponentiell an. Diese Zeiten können im Emissionsabklingverhalten von $A^{*}$ wiedergefunden werden. Die Emission von I* klingt dann mit $\tau_{4} \approx 3.2 \mathrm{~ns}$ monoexponetiell ab. Wird nun die Emission von $\mathrm{A}^{*}$ bei $450 \mathrm{~nm}$ betrachtet, so beobachtet man zusätzlich zu den schnellen Abklingzeiten eine dritte, die in dieser Arbeit zu $\tau_{3} \approx 347 \mathrm{ps}$ bestimmt wurde. Lossau et al. und Chattoraj et al. fanden mit ihren Anpassungsmethoden für diese Komponente Zeitkonstanten von 227 ps bzw. 120 ps. Auch wenn diese Werte differieren, zeigte sich in beiden Arbeiten, dass diese Zeitkon- 
stante von der Deuterierung unbeeinflusst bleibt, während die schnellen Zeiten einen deutlichen Isotopeneffekt aufweisen ${ }^{31,32}$. Diese mittlere Komponente (100$300 \mathrm{ps}$ ) taucht nicht in der Emissionsdynamik von I* auf. Wie bereits in Abschnitt 2.5 beschrieben wurde, führen Lossau et al. das gesamte multiexponentielle Verhalten auf strukturelle Heterogenitäten des Chromophors zurück. Wären für dieses Verhalten allein strukturelle Heterogenitäten verantwortlich, so müssten die Emissionen aus $\mathrm{A}^{*}$ und I* in einem einfachen 2-Niveau-Interkonversionsmodell direkt miteinander korreliert sein, d. h. das Zeitverhalten von A* müsste in I* wiederzufinden sein. Diese Korrelationslücke spricht daher gegen die strukturellen Heterogenitäten als alleinige Ursache für das multiexponentielle Verhalten.

Auch die Tatsache, dass die dritte Exponentialzeit $\left(\tau_{3}=100-300 \mathrm{ps}\right)$ von der Deuterierung unbeeinflusst bleibt, ist ein weiterer Indiz dafür, dass das einfache Interkonversionsmodell nicht die Gesamtheit der Dynamik wiedergeben kann. Vielmehr scheinen weitere Desaktivierungskanäle relevant zu sein, die nicht mit dem Protonentransfer verknüpft sind. Da die Fluoreszenzquantenausbeute nach Anregung von $\mathrm{A}^{*}$ nur $80-85 \%$ beträgt $^{36}$, existieren auch strahlungslose Desaktivierungskanäle, z. B. innere Konversion, die nicht zur Emission eines Photons führen.

In mehreren Arbeiten untersuchten Kummer et al. ${ }^{40,39,36,38}$ die innere Konversion des Chromophors im wt-GFP, in verschiedenen Mutanten des GFP sowie eines Modellchromophors in Lösungsmitteln. Die Mutanten des GFP unterscheiden sich vom Wildtyp in der Struktur des Chromophors oder in dessen Verankerung im Protein. Eine gezielte Mutation, die die chemische Konstitution des Fluorophors ändert, z. B. Y66H/Y145F $\mathrm{F}^{87}$ oder $\mathrm{S} 65 \mathrm{~T}^{88}$, modifiziert neben den linearspektroskopischen Eigenschaften des Proteins auch die Säure-Base-Eigenschaften im elektronisch angeregten Zustand. Demgegenüber führt eine Mutation, die den Chromophor unbeeinflusst lässt, zu einer strukturellen Modifikation der nanoskopischen Umgebung desselben. Die Umgebung beeinflusst ihrerseits die Dynamik im angeregten Zustand des Luminophors, beispielsweise durch Ausübung einer sterischen Hinderung molekularer Bewegungen. In Abschnitt 2.5 wurde ausführlich gezeigt, dass die Quantenausbeute und die Emissionseigenschaften stark von diesen Faktoren abhängen. Aus diesem Grund kann innere Konversion des Chromophors im GFP entlang einer Torsionskoordinate erfolgen. Diese Annahme wurde durch den Vergleich der Struktur und der elektronischen Anordnung des Chromophors im GFP mit ähnlichen Molekülen, bei denen innere Konversion über Torsion experimentell beobachtet wurde, unterstützt ${ }^{89,90,91,92,93}$. Weiterhin zeigen theoretische Studien an einem Modellchromophor, dass Torsion innerhalb dieses Moleküls möglich ist ${ }^{48}$.

Wie im folgenden noch ausgeführt wird, repräsentieren die schnellen Zeitkonstanten (im Bereich von 2-4 ps und 8-12 ps) der Emission bei $450 \mathrm{~nm}$ den Protonentransfer unter Bildung von I*, während die mittlere Exponentialzeit um 300 ps die Zeitkonstante für innere Konversion darstellt. 


\subsubsection{Erweitertes dynamisches Modell}

Das Interkonversionsmodell lässt sich jedoch verfeinern, wenn man berücksichtigt, dass die Schwingungsrelaxationen (IVR,VET) auf ähnlichen Zeitskalen stattfinden kann wie der Protonentransfer. Dies hat zur Folge, dass der Geschwindigkeitskoeffizient $k(T)$ für Protonentransfer zeitabhängig wird. Die Anregung mit $400 \mathrm{~nm}, 30 \mathrm{fs}$ Lichtimpulsen präpariert eine mikrokanonische Verteilung $f(E, t=0)$, die sich zunächst oberhalb der Barriere für Protonentransfer befindet. Die Schwingungsrelaxation sorgt dafür, dass $f(E, t=0)$ in eine Verteilung $f(E, t=\infty)=f(T)$ überführt wird, deren Maximum sich unterhalb der Barriere befindet. Abbildung 5.5 veranschaulicht schematisch einen derartigen Prozess. Der Geschwindigkeitskoeffizient ist demzufolge zeitabhängig und errechnet sich formal als momentaner Mittelwert energiespezifischer Geschwindigkeitskonstanten $k(E)$ :

$$
k(T, t)=\int_{0}^{\infty} k(E) \cdot f(E, T, t) d E .
$$

Der zeitabhängige Geschwindigkeitskoeffizient $k(T, t)$ spiegelt somit prinzipiell die dynamische Entwicklung der Verteilungsfunktion $f(E, T, t)$ wider. Dies liegt daran, dass $k(E)$ in der Regel mit zunehmender Energie wächst. Obwohl die spezifischen Geschwindigkeitskonstanten in kondensierter Phase prinzipiell nicht bestimmt werden können, wird in diesem Kapitel ein vereinfachtes Modell vorgeschlagen, welche eine Abschätzung der Zeitskala für Schwingungsenergierelaxationen ermöglicht.

Zu frühen Zeiten, bevor die Äquilibrierung im Potentialtopf A* vollständig ist, ist der Protonentransfer der dominierende Desaktivierungskanal. Mit fortschreitender Schwingungsrelaxation (IVR, VET) wird den reaktiven Moden Energie entzogen. Infolgedessen wird der Protonentransfer zunehmend langsamer und die innere Konversion über Torsionsfreiheitsgrade gewinnt an Bedeutung. Befindet sich A* energetisch unterhalb der Barriere zum Protonentransfer, so ist lediglich die innere Konversion für die Desaktivierung von $A^{*}$ verantwortlich.

Nach dieser Vorstellung wird deutlich, warum die Fluoreszenzkinetik von A* und $I^{*}$ bei frühen Zeiten miteinander korrelieren. Der isosbestische Punkt, der bis zu 30 ps in den zeitabhängigen differentiellen Transmissionsspektren existiert, ist ebenfalls zu verstehen. Zu späteren Zeiten verschwindet jedoch die Korrelation, da $A^{*}$ nur durch die innere Konversion zerfällt. Dieses Modell erklärt des Weiteren den Isotopeneffekt, der nur bezüglich der schnellen Zeitkonstanten beobachtet $\operatorname{wird}^{32}$. 


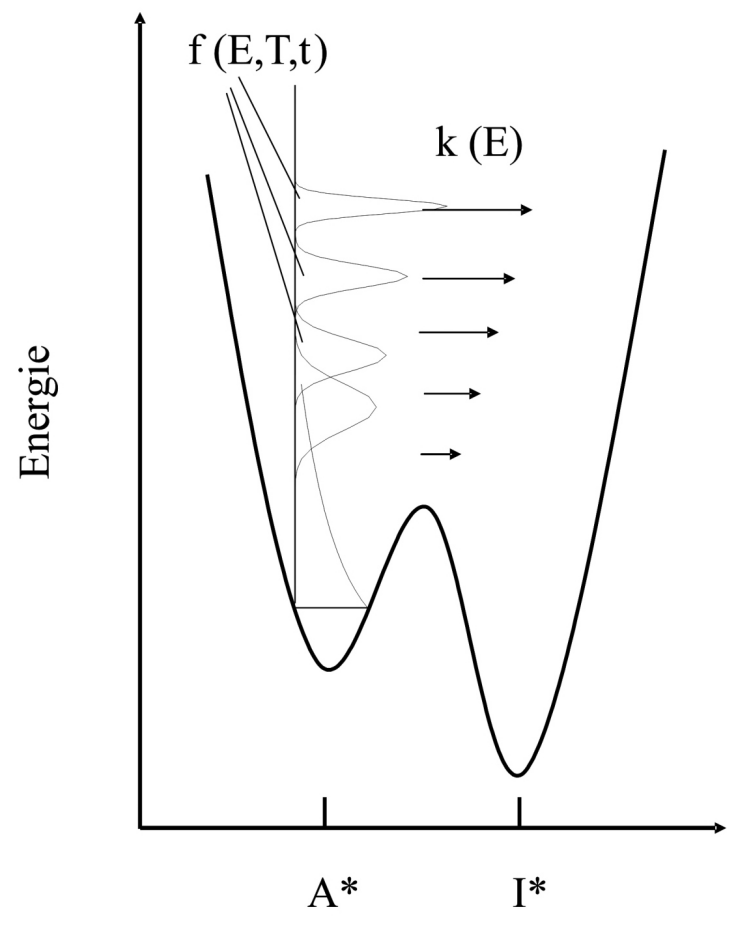

Reaktionskoordinate

Abbildung 5.5: Zweiniveausystem, innerhalb dessen die Konversion $\mathrm{A}^{*} \stackrel{k}{\longrightarrow} \mathrm{I}^{*}$ ausgehend von einer mikrokanonischen Verteilung im Potential A* stattfindet. Die resultierende Geschwindigkeitskonstante ist zeitabhängig.

\section{Darstellung des Konzeptes}

Diese Vorstellungen werden im folgenden Modell umgesetzt. Abbildung 5.6 zeigt einen Ausschnitt einer schematischen Potentialfä̈che des angeregten Zustandes des GFP. In diesem Modell wird die Energieabhängigkeit des Protonentransfers durch Aufteilung des Potentials $A^{*}$ in drei energetisch verschiedene Zustände $\mathrm{A}_{\mathrm{h}}^{*}, \mathrm{~A}_{\mathrm{p}}^{*}$ und $\mathrm{A}_{\mathrm{c}}^{*}$ unterteilt. Dabei beschreibt $\mathrm{A}_{\mathrm{h}}^{*}$ schwingungsangeregte, heisse Moleküle $(\mathrm{h}-\mathrm{hot}), \mathrm{A}_{\mathrm{p}}^{*}$ teilweise relaxierte Moleküle ( $\mathrm{p}$-partially relaxed) und $\mathrm{A}_{\mathrm{c}}^{*}$ schwingungskalte Moleküle (c-cold). Von den Zuständen $\mathrm{A}_{\mathrm{h}}^{*}$ und $\mathrm{A}_{\mathrm{p}}^{*}$ kann Protonentransfer erfolgen, der zur Bildung des Zustandes I* führt. Diese Kanäle konkurrieren mit der inneren Konversion, die entlang der Torsionskoordinate verläuft und mit der Geschwindigkeitskonstanten $k_{T}$ beschrieben wird. Sind die Chromophormoleküle in Abbildung 5.6 einmal äqulibriert, so befinden sie sich primär unterhalb der Barriere im Zustand $\mathrm{A}_{\mathrm{c}}^{*}$, von dem aus Protonentransfer nicht mehr stattfinden kann. Als einziger, noch offener Kanal verbleibt die Torsion mit nach- 


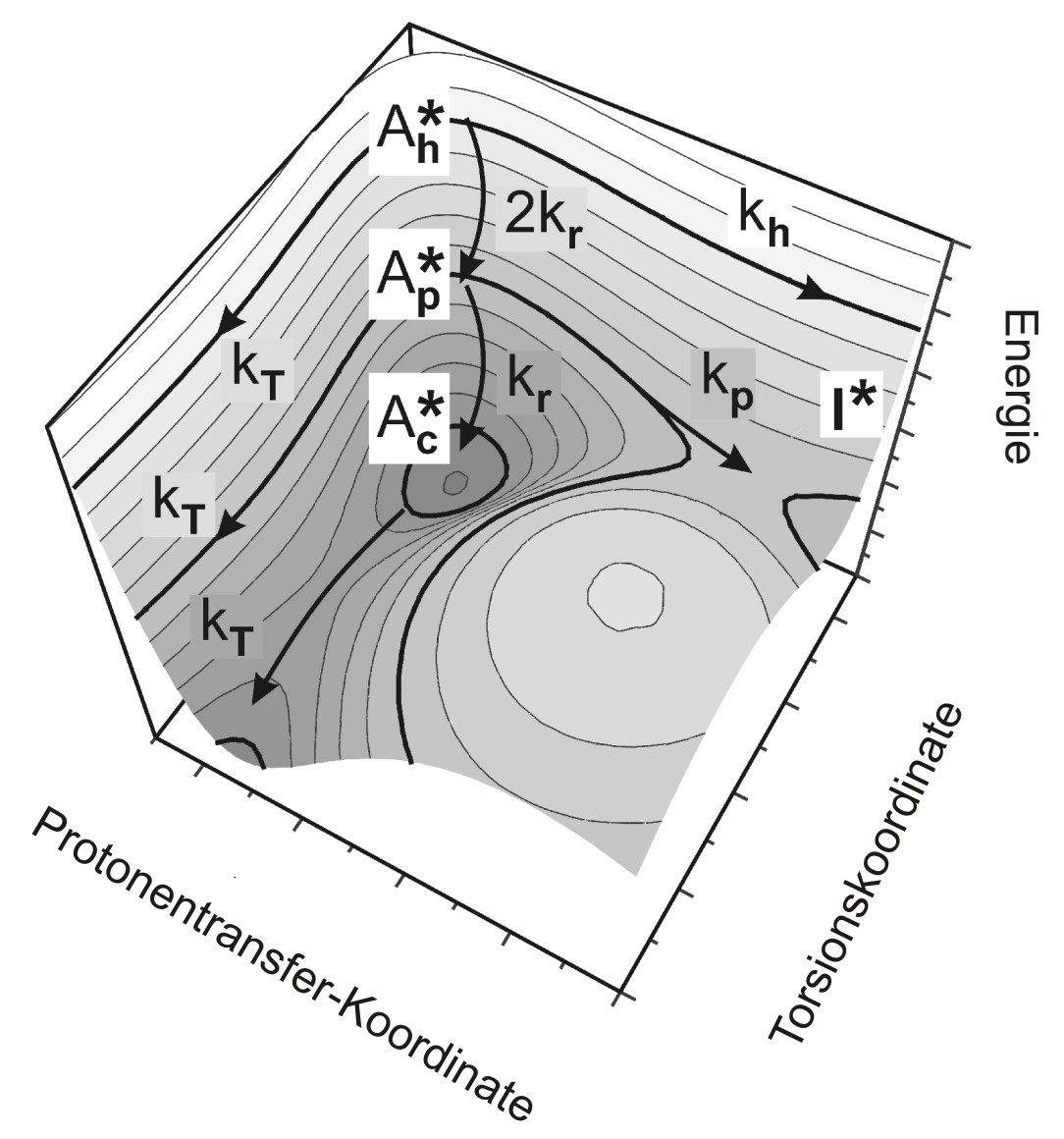

Abbildung 5.6: Dynamisches Modell auf einer schematischen Potentialfläche entlang der Protonentransfer- und der Torsionskoordinate.

folgender innerer Konversion. Zur Vereinfachung wird diese als energieunabhängig angenommen.

Die Energierelaxation wird mit dem Geschwindigkeitskoeffizienten $\mathrm{k}_{r}$ beschrieben. Unter Annahme eines harmonischen Potentialtopfes von $A^{*}{ }^{94}$ erfolgt der Übergang $A_{\mathrm{h}}^{*} \stackrel{2 k_{r}}{\longrightarrow} A_{\mathrm{p}}^{*}$ doppelt so schnell der Übergang $A_{\mathrm{p}}^{*} \stackrel{k_{r}}{\longrightarrow} A_{\mathrm{c}}^{*}$. Da die anfängliche Überschussenergie bezüglich des Schwingungsgrundzustands in $\mathrm{A}^{*}$ $2000 \mathrm{~cm}^{-1}$ beträgt, entsprechen die Zustände $A_{\mathrm{p}}^{*}, A_{\mathrm{h}}^{*}$ und $A_{\mathrm{c}}^{*}$ einem bzw. zwei Quanten einer fiktiven Schwingungsmode von $1000 \mathrm{~cm}^{-1}$. Natürlich spiegelt diese 
energetische Aufspaltung nicht die realistische Schwingungsstruktur des Potentials wider. Eine feinere Energieunterteilung wäre vermutlich angebracht, allerdings wäre die Lösung der daraus resultierenden kinetischen Differentialgleichungen erschwert.

\section{Differentialgleichungssystem}

Der Übersichtlichkeit wegen ist das Energieschema mit den dynamischen Annahmen des Modells noch einmal in Abbildung 5.7 zweidimensional dargestellt. Darin finden sich auch die Energien der 0-0-Übergänge zwischen Grund- und angeregtem Zustand der einzelnen Spezies, die Anregungsenergie von $25000 \mathrm{~cm}^{-1}$, sowie die Fluoreszenz aus dem Zustand I* mit der inversen Strahlungslebensdauer $k_{I}$. Die Lebensdauer für Emission aus $\mathrm{A}^{*}$ kann vernachlässigt werden, da sie wesentlich kleiner als $k_{r}, k_{h}, k_{p}$ und $k_{T}$ ist. Wie das stationäre Fluoreszenzspektrum beweist (siehe 2.3) ist darüberhinaus die Emissionsquantenausbeute

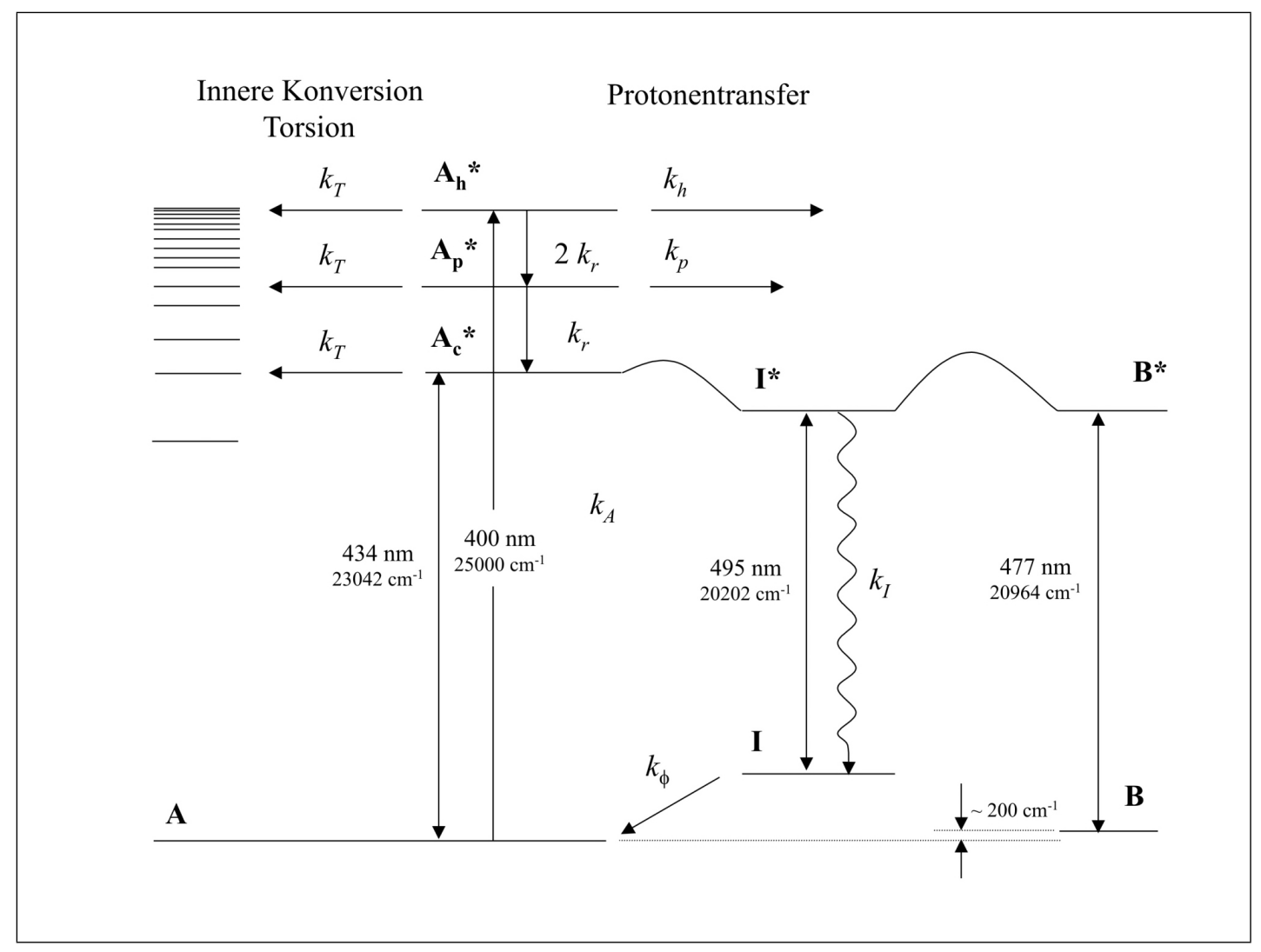

Abbildung 5.7: Dynamisches Modell anhand eines schematischen Energieniveaudiagramms (Energetische Niveaus und Barrieren entsprechen nicht den tatsächlichen Werten. Diese Darstellung soll lediglich der Verdeutlichung des Modells dienen.). 
von $A^{*}$ äußerst gering. Sie beträgt schätzungsweise bei Zimmertemperatur weniger als $1 \%$. A* wird hauptsächlich über den Protonentransfer und innere Konversion desaktiviert. Die Konversion vom Grundzustand I zu A erfolgt mit der Geschwindigkeitskonstanten $k_{\phi}$. Die Photokonversion zu B* und schließlich $\mathrm{B}$ wird nicht betrachtet, da sie deutlich langsamer als alle betrachteten Prozesse und daher für das Modell irrelevant ist.

Für jeden Zustand wird eine Differentialgleichung formuliert, die die Änderung seiner Population beschreibt. Für die Schwingungszustände $A_{h}^{*}, A_{\mathrm{p}}^{*}$ und $A_{c}^{*}$ ergeben sich folgende Zeitgesetze:

$$
\begin{gathered}
\frac{d\left[A_{h}^{*}\right]}{d t}=-k_{\gamma}\left[A_{h}^{*}\right] \quad \text { mit } \quad k_{\gamma}=k_{T}+2 \cdot k_{r}+k_{h}, \\
\frac{d\left[A_{p}^{*}\right]}{d t}=-k_{\alpha}\left[A_{p}^{*}\right]+2 \cdot k_{r}\left[A_{h}^{*}\right] \quad \text { mit } \quad k_{\alpha}=k_{T}+k_{r}+k_{p},
\end{gathered}
$$

sowie

$$
\frac{d\left[A_{c}^{*}\right]}{d t}=-k_{T}\left[A_{c}^{*}\right]+k_{r}\left[A_{p}^{*}\right] .
$$

Für die Populationsänderung von I* und I finden sich die Ausdrücke:

$$
\begin{gathered}
\frac{d\left[I^{*}\right]}{d t}=k_{h}\left[A_{h}^{*}\right]+k_{p}\left[A_{p}^{*}\right]-k_{I}\left[I^{*}\right], \\
\frac{d[I]}{d t}=k_{I}\left[I^{*}\right]-k_{\phi}[I] .
\end{gathered}
$$

Aus diesem Satz gekoppelter Differentialgleichungen ergeben sich die folgenden Beziehungen für den zeitabhängigen Populationsfluss jeder Spezies. Dabei wurde angenommen, dass die Zustände $\mathrm{A}_{p}^{*}$ und $\mathrm{A}_{c}^{*}$ zum Zeitpunkt $t=0$ ps nicht besetzt sind.

$$
\frac{\left[A_{h}^{*}(t)\right]}{\left[A_{h}^{*}(0)\right]}=e^{-k_{\gamma} t},
$$




$$
\begin{aligned}
\frac{\left[A_{p}^{*}(t)\right]}{\left[A_{h}^{*}(0)\right]}= & \frac{2 k_{r}}{k_{\beta}}\left(e^{-k_{\gamma} t}-e^{-k_{\alpha} t}\right) \quad \text { mit } \quad k_{\beta}=k_{p}-k_{r}-k_{h}, \\
\frac{\left[A_{c}^{*}(t)\right]}{\left[A_{h}^{*}(0)\right]}= & 2 k_{r}^{2}\left(\frac{1}{k_{\beta}\left(k_{r}+k_{p}\right)} e^{-k_{\alpha} t}\right. \\
& \left.+\frac{1}{\left(2 k_{r}+k_{h}\right)\left(k_{r}+k_{p}\right)} e^{-k_{T} t}-\frac{1}{k_{\beta}\left(2 k_{r}+k_{h}\right)} e^{-k_{\gamma} t}\right) \\
\frac{\left[I^{*}(t)\right]}{\left[A_{h}^{*}(0)\right]}= & \frac{k_{h} k_{\beta}+2 k_{r} k_{p}}{k_{\beta}\left(k_{I}-k_{\gamma}\right)} e^{-k_{\gamma} t} \\
& +\left(\frac{2 k_{r} k_{p}-k_{h}\left(k_{I}-k_{\alpha}\right)}{\left(k_{I}-k_{\alpha}\right)\left(k_{I}-k_{\gamma}\right)}+\frac{\left[I^{*}(0)\right]}{\left[A_{h}^{*}(0)\right]}\right) e^{-k_{I} t} \\
& -\frac{2 k_{r} k_{p}}{k_{\beta}\left(k_{I}-k_{\alpha}\right)} e^{-k_{\alpha} t} .
\end{aligned}
$$

\subsubsection{Dynamische Simulationen}

Für alle Simulationen wurden basierend auf dem vorgestellten Differentialgleichungssystem die folgenden Annahmen gemacht. Die Desaktivierung von A* erfolgt lediglich strahlungslos über den Protonentransfer und innere Konversion (Torsion), d. h. $k_{A} \ll k_{T}, k_{r}, k_{h}, k_{p}$. Die Geschwindigkeitskonstante für die Torsion wird zu $k_{T}=1 / 0.3 \mathrm{~ns}$ festgelegt. Dies ist das Ergebnis verschiedener Messungen zur Fluoreszenzlebensdauer ${ }^{32,46,95,48,37}$ und den in dieser Arbeit vorgestellten TCSPC-Experimenten. $k_{I}$ entspricht der inversen Strahlungslebensdauer von I* - sie beträgt in allen Simulationen $k_{I}=1 / 3.3$ ns. Der Anteil der instantanen Emission über nicht-vertikale Anregung $\mathrm{A} \rightarrow \mathrm{I}^{*}$ und durch Direktanregung von $\mathrm{B}^{*}$ wurde aus Fluoreszenzkonversionsexperimenten ${ }^{31}$ abgeschätzt. Das Verhältnis $\left[I^{*}(0)\right] /\left[A^{*}(0)\right]$ beträgt demnach 0.74 . Bei $t=0$ ps gilt $\left[I^{*}(0)\right]=1-\left[A^{*}(0)\right]$. Es sollte weiterhin beachtet werden, dass das Experiment nicht auf die einzelnen Schwingungszustände $A_{\mathrm{h}}^{*}, A_{\mathrm{p}}^{*}$ und $A_{\mathrm{c}}^{*}$ sensitiv ist. Stattdessen wird die Emission von $\mathrm{A}^{*}$ grundsätzlich als die Summe von $A_{\mathrm{h}}^{*}, A_{\mathrm{p}}^{*}$ und $A_{\mathrm{c}}^{*}$ detektiert.

Für die Simulationen verbleiben lediglich $k_{r}, k_{h}$ und $k_{p}$ als anpassbare Parameter, 
um die Transienten und die differentiellen Transmissionsspektren zu reproduzieren. Das Modell sollte außerdem sowohl die Fluoreszenzlebensdauer-Messungen von I* und A* reproduzieren als auch die Daten aus Fluoreszenzkonversionsexperimenten von Chattoraj et al..$^{31}$ wiedergeben.

\section{Simulation der zeitabhängigen Signale}

Für die Simulation wurden Signale bei Wellenlängen gewählt, die selektiv nur einen Zustand nachweisen. Für die Dynamik von I* wurde ein Signal bei $530 \mathrm{~nm}$ gewählt, die von A* wird durch die transiente Absorption bei $669 \mathrm{~nm}$ wiedergegeben. Die Wahl der Probewellenlänge zu $530 \mathrm{~nm}$ garantiert, dass die stimulierte Emission ausschließlich von I* stammt. Sie umgeht die Beimischung der transienten Absorption bei Wellenlängen von $\lambda>630 \mathrm{~nm}$, sowie die Beiträge der transienten Absorption von I* $(\sim 500 \mathrm{~nm})$ und der stimulierten Emission von $\mathrm{A}^{*}$ $(<496 \mathrm{~nm})$. Die Wahl der Transienten bei $669 \mathrm{~nm}$ ist aus den gleichen Gründen für die Dynamik von A* geeigneter als eine Nachweiswellenlänge von $480 \mathrm{~nm}$, da bei letzterer Wellenlänge die transiente Absorption von I* die stimulierte Emission von $A^{*}$ überlagert.

Abbildung 5.8 zeigt die ausgewählten Signale mit ihren jeweiligen Simulationen nach dem vorgestellten Modell. Das Signal bei $530 \mathrm{~nm}$ konnte dabei mit den Zeitkonstanten für den Protonentransfer $1 / k_{h}=5.0 \mathrm{ps}$ und $1 / k_{p}=13 \mathrm{ps}$ simuliert werden, für die Schwingungsrelaxation ergab sich $1 / k_{r}=23$ ps. Für die Dynamik von $\mathrm{A}^{*}$, die durch das Signal bei $669 \mathrm{~nm}$ repräsentiert ist, ergeben sich sehr ähnliche Zeitkonstanten: $1 / k_{h}=6.5 \mathrm{ps}, 1 / k_{p}=13 \mathrm{ps}$ sowie $1 / k_{r}=23 \mathrm{ps}$. Abbildung 5.8 belegt die sehr gute Übereinstimmung zwischen Experiment und Simulation. Die Daten aus fluoreszenzspektroskopischen Untersuchungen von Chattoraj et al. sind ebenfalls als dünne Linien dargestellt. Sie geben das in der vorliegenden Arbeit beobachtete dynamische Verhalten gut wieder. Die Abweichungen, die in Abbildung 5.8 erkennbar sind, lassen sich darauf zurückführen, dass sie bei anderen Wellenlängen (508 $\mathrm{nm}$ und $460 \mathrm{~nm}$ ) detektiert wurden als die Pump-ProbeSignale. Die Übereinstimmung zwischen dem Pump-Probe-Signal bei $669 \mathrm{~nm}$ und dem Fluoreszenzsignal von Chattoraj et al. bei $460 \mathrm{~nm}$ belegt sehr deutlich die korrekte Zuweisung der transienten Absorption zum Zustand A*.

Die Simulation des Fluoreszenzabklingverhaltens auf einer Piko- bis Nanosekundenzeitskala ist in Abbildung 5.9 dargestellt. Gezeigt sind die Simulationen für $\mathrm{A}^{*}$ und I*, die nach den Gleichungen 5.14 bis 5.17 berechnet wurden. Erwartungsgemäß sagt das Modell das richtige Abklingverhalten von I* mit $k_{I}=1 / 3.3 \mathrm{~ns}$ sowie von $\mathrm{A}^{*} k_{T}=1 / 0.3 \mathrm{~ns}$ voraus. Dieses Ergebnis zeigt, dass das Modell das in verschiedenen Experimenten ${ }^{32,36,40}$ beobachtete Verhalten der Dynamik gegenüber Deuterierung richtig wiedergibt. Die Konstanten $k_{I}$ und $k_{T}$, die den Langzeitbereich dominieren, können von einem Isotopenaustausch nicht beeinflusst werden, da sie nicht mit der Protonenbewegung verbunden sind. 


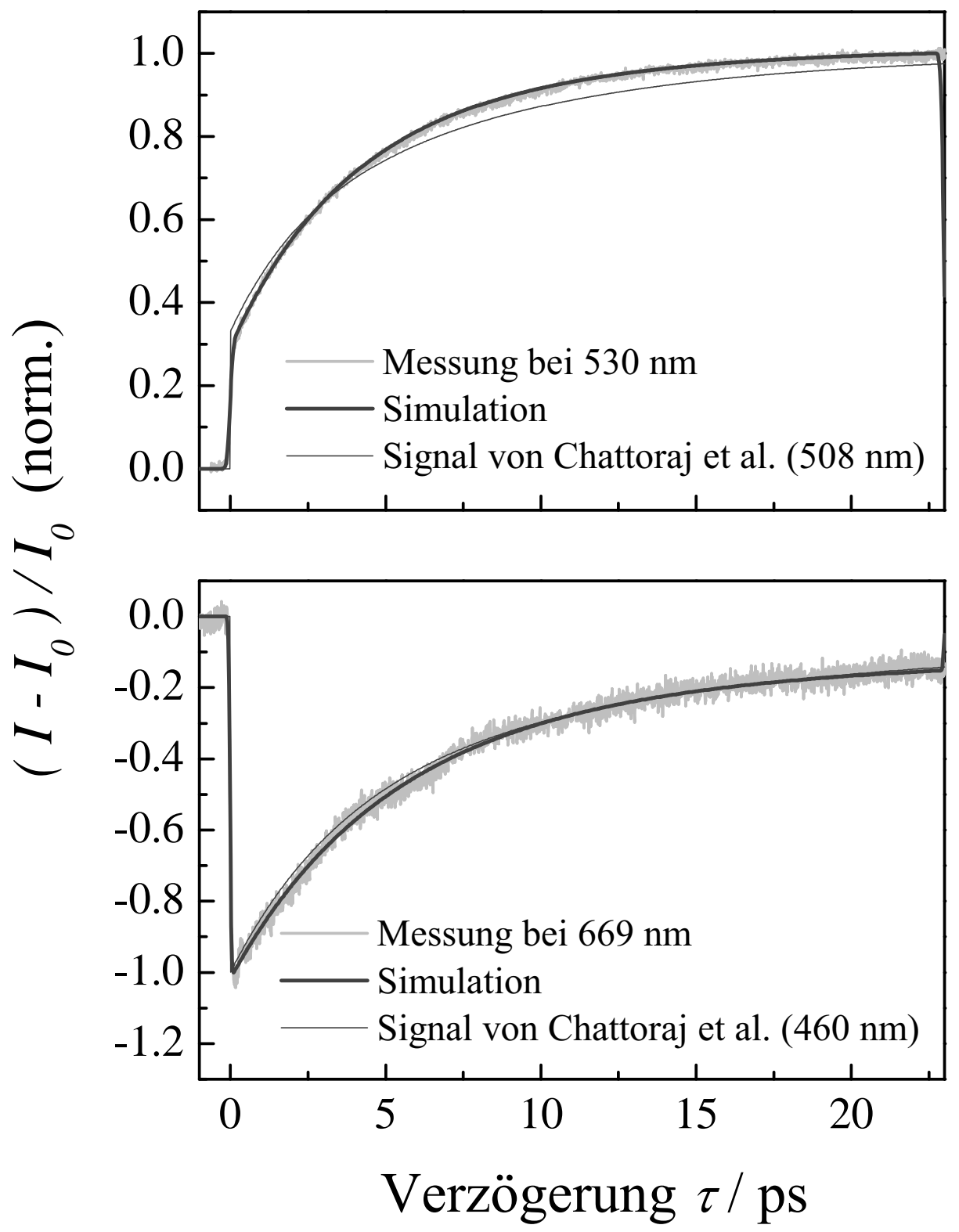

Abbildung 5.8: Pump-Probe-Signale bei Nachweiswellenlängen von $530 \mathrm{~nm}$ und $669 \mathrm{~nm}$ sowie die Simulationen nach dem vorgestellten Modell. Desweiteren sind Signale aus Fluoreszenzkonversionsexperimenten von Chattoraj et al. ${ }^{31}$ bei $508 \mathrm{~nm}$ und $460 \mathrm{~nm}$ dargestellt. 


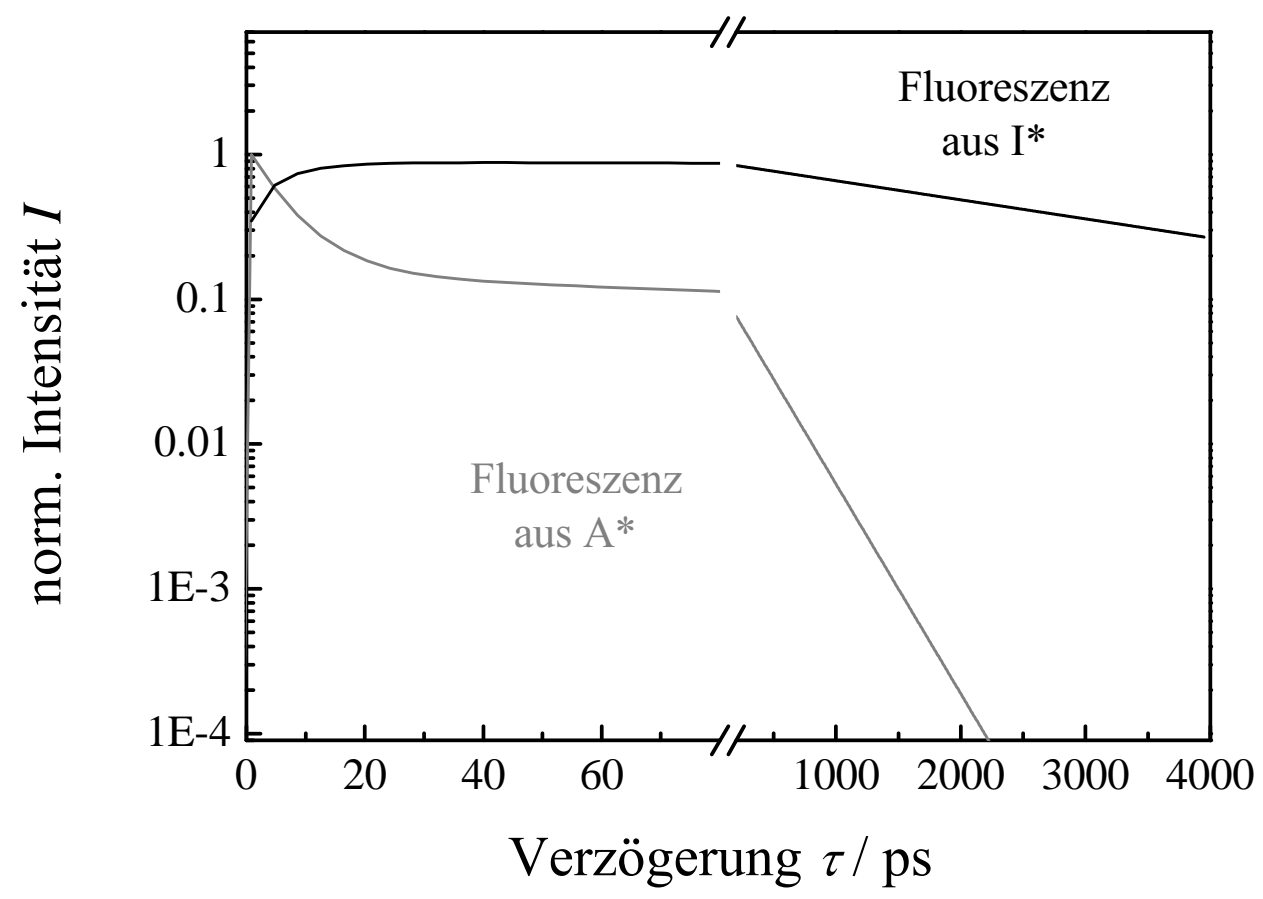

Abbildung 5.9: Simulationen der Fluoreszenzabklingkurven auf einer Nanosekundenzeitskala der Emissionen von A* und I*

\section{Simulationen der transienten Spektren}

Die differentiellen Transmissionsspektren können simuliert werden, indem die zeitabhängigen Populationen der Zustände $i$ mit ihren Spektren $\varepsilon_{i}$ multipliziert werden:

$$
\varepsilon(t, \lambda)=\left\{\varepsilon_{E}(\lambda)+\varepsilon_{T A}(\lambda)\right\} \cdot\left[I^{*}(t)\right]+\varepsilon_{A}(\lambda) \cdot\left[A^{*}(t)\right] .
$$

Dabei entsprechen $\varepsilon_{E}$ der Wellenlängenabhängigkeit der stimulierten Emission, $\varepsilon_{T A}$ der transienten Absorption aus I* und $\varepsilon_{A}$ dem stimulierten Emissionsspektrum aus A*. Dieser Simulation liegt die Annahme zugrunde, dass die Spektren zeitlich fomstabil sind und sich nicht zu längeren oder kürzeren Wellenlängen verschieben. Das Spektrum der stimulierten Fluoreszenz aus I* wird durch das stationäre Emissionsspektrum nach Anregung bei $400 \mathrm{~nm}$ approximiert. Letzteres kann unabhängig in den Experimenten ermittelt werden und in numerischer Form nach Kubo's Linienformanalyse ${ }^{96,97}$ : 


$$
\begin{aligned}
\varepsilon(\omega)= & \int_{-\infty}^{\infty} d t e^{i \omega t} \sum_{i} \varepsilon_{i}\left(\frac{\Delta^{2}}{\gamma}\left(1-e^{-\gamma t}\right) \cos \left(\Omega_{i} t\right)+\Omega_{i} \sin \left(\Omega_{i} t\right)\right) \\
& \cdot \exp \left(-\frac{\Delta^{2}}{\gamma^{2}}\left(e^{-\gamma t}+\gamma t-1\right)\right)
\end{aligned}
$$

dargestellt werden. Hierbei ist $\omega=2 \pi c / \lambda$ und $c$ die Lichtgeschwindigkeit. Die Amplituden $\varepsilon_{i}$ der individuellen Kubo-Terme ergeben sich hierbei zu 0.89, $0.15,0.12,0.17$ und 0.05. Die entsprechenden Mittenwellenlängen $\lambda_{i}=2 \pi c / \Omega_{i}$ betragen 508.9, 523.2, 533.9, 547.6 und $570 \mathrm{~nm}$. Jede Komponente ist gemäß $\Delta=$ $\gamma=490 \mathrm{~cm}^{-1}$ verbreitert. Die Summierung über mehrere Kubo-Terme ist nötig, um die für GFP typische Franck-Condon-Struktur des Fluoreszenzspektrums zu reproduzieren. Abbildung 5.10 zeigt das stationäre Emissionsspektrum und seine Anpassung nach Gleichung 5.19.

Das Spektrum der transienten Absorption von I*, das sich aus der Differenz von stationärem Emissionsspektrum und differentiellem Transmissionsspektrum bei 102 ps ergibt, ist ebenfalls in Abbildung 5.10 dargestellt. Zur Anpassung dieses Spektrums wurde die Summe zweier Gaußfunktionen gewählt:

$$
\varepsilon_{T A}(\lambda)=-\sum_{i} \varepsilon_{i} \cdot \exp \left(-4 \ln (2) \frac{\left(\lambda-\lambda_{i}\right)^{2}}{\sigma_{i}}\right) .
$$

Die Mittenwellenlängen $\lambda_{i}$ sind hierbei $499 \mathrm{~nm}$ und $479 \mathrm{~nm}$ mit den entsprechenden Amplituden $\varepsilon_{i}$ von 1 bzw. 0.55. Beide Komponenten besitzen eine Halbwertsbreite von $\sigma_{i}=20 \mathrm{~nm}$.

Das Emissionsspektrum von A* ist schwieriger zu ermitteln, da deren Fluoreszenz durch das Emissionsspektrum von I* überlagert wird. Es ist allerdings noch als schwache Schulter auf der hochfrequenten Seite des linearen Fluoreszenzspektrums des wt-GFP zu erkennen. Aus diesem Grund wurde die GFP-Mutante P4-3 zur Hilfe genommen, deren Chromophor lediglich in der neutralen Form vorliegt. Der Protonentransfer ist daher in dieser Mutante unterbunden. Wie Abbildung 5.11 zeigt, ist das Emissionsspektrum dieser Mutante bei $449 \mathrm{~nm}$ maximal und besitzt eine Halbwertsbreite von etwa $3800 \mathrm{~cm}^{-1}$. Zur Darstellung der Fluoreszenz von $\mathrm{A}^{*}$ wurde dieses Spektrum um etwa $1000 \mathrm{~cm}^{-1}$ zu niedrigeren Wellenzahlen verschoben, so dass es die oben genannte Schulter im Wildtyp-Spektrum bei $440 \mathrm{~nm}$ reproduziert. Abbildung 5.11 zeigt alle Spektren sowie die Anpassung mit einer Summe aus Lognormalverteilungen nach Gleichung 5.21: 


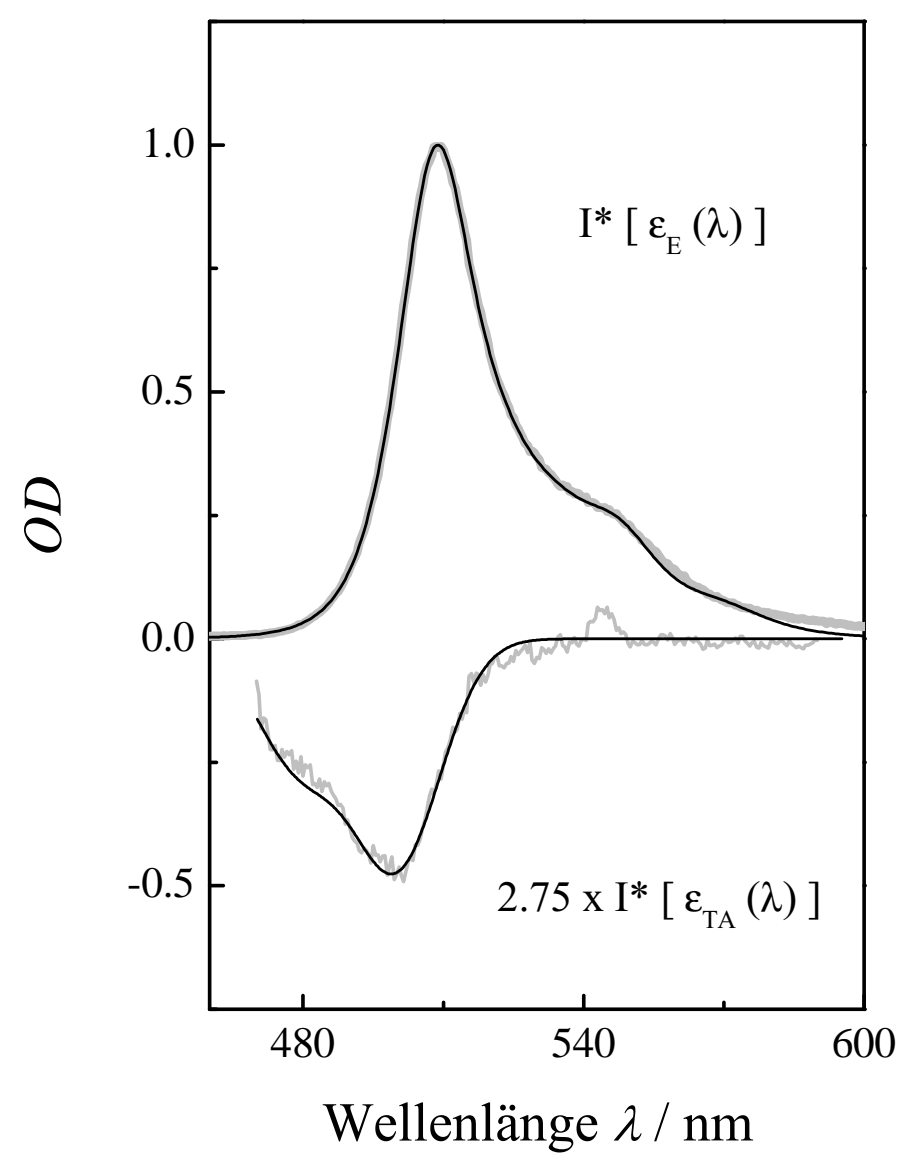

Abbildung 5.10: Stationäres Fluoreszenzspektrum und Anpassung nach Kubo's Linienformanalyse sowie Spektrum der transienten Absorption, das die Differenz von stationärem Fluoreszenzspektrum und transientem Spektrum bei 102 ps darstellt sowie seine Anpassung mit einer Summe mehrerer Gauß-Funktionen

$$
\begin{aligned}
\varepsilon_{A}(\nu)= & \sum_{i} \varepsilon_{i}^{0} \Theta\left[\left(\nu_{i}-\frac{\Delta_{i}}{2 b_{i}}\right)-\nu\right] \\
& \cdot \exp \left[-\ln (2)\left[\frac{\ln \left(1+2 b_{i}\left(\nu-\nu_{i}\right) / \Delta_{i}\right)}{b_{i}}\right]^{2}\right],
\end{aligned}
$$

mit $\nu=1 / \lambda$ und $\Theta(\nu)$ der Heavyside-Sprungfunktion. Die Schwingungsstruktur der Bande wurde mit vier logarithmischen Normalverteilungen angepasst, wobei die Mittenwellenlängen 1/ $\nu$ dieser Funktionen 442.5, 472.6, 506.8 und 540.5 
nm betragen. Die zugehörigen Amplituden $\varepsilon_{i}$ sind 45.6, 36.8, 14.6 und 2.9\%. Der Verbreiterungsparameter $\Delta_{i}$ beträgt dabei $1850 \mathrm{~cm}^{-1}$, während der Asymmetriefaktor $b_{i}$ einen Wert von -0.49 annimmt.

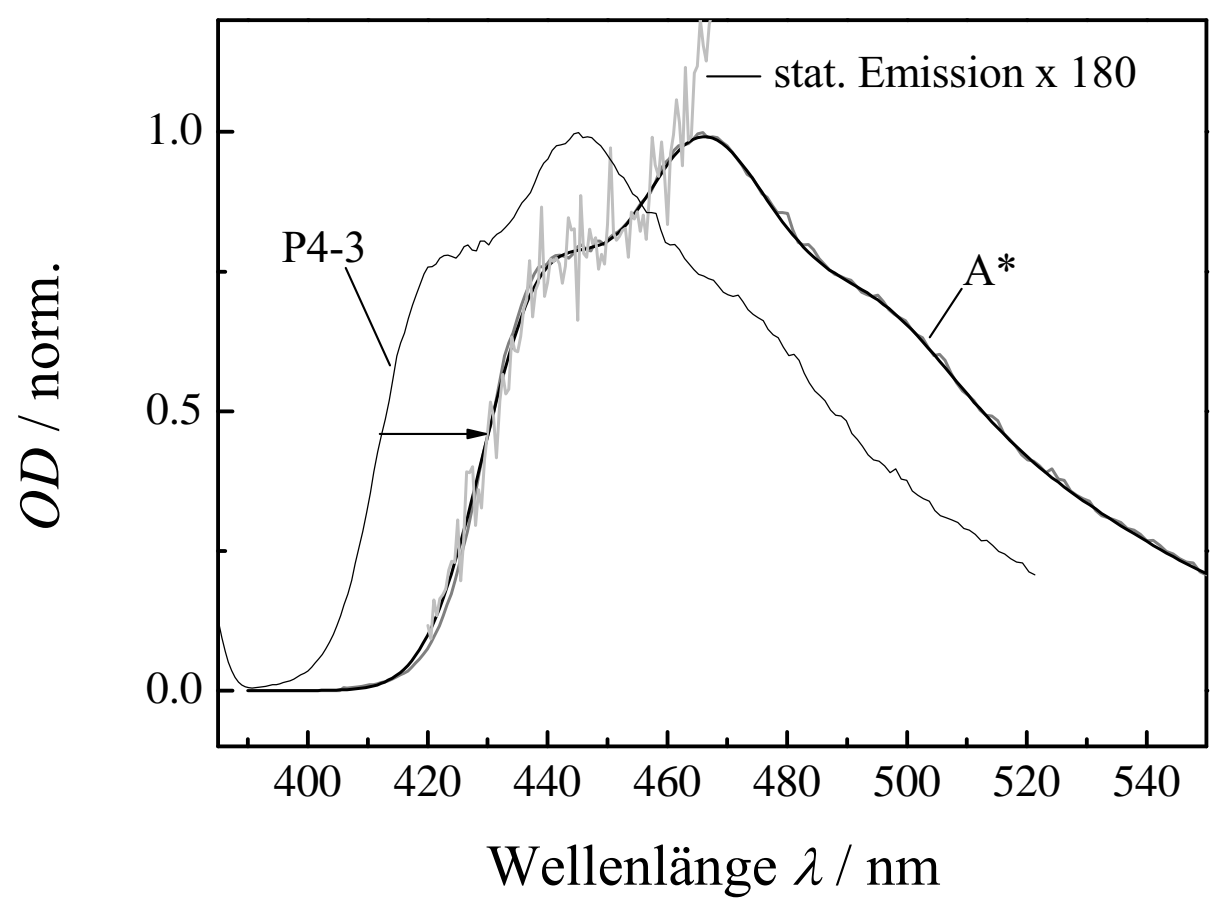

Abbildung 5.11: Stationäres Fluoreszenzspektrum stark vergrößert, Spektrum der blauen Mutante P4-3, das um $1000 \mathrm{~cm}^{-1}$ zu längeren Wellenzahlen verschoben ist sowie Anpassung des Spektrums nach Gleichung 5.21

Mit diesen Spektren und den Beziehungen 5.14 bis 5.17 können die Spektren nach Gleichung 5.18 simuliert werden, wobei wiederum die folgenden Geschwindigkeitskonstanten verwendet wurden:

$$
\begin{aligned}
k_{h} & =5.8 p s \\
k_{p} & =13 p s \\
k_{r} & =23 p s \\
k_{T} & =300 p s \\
k_{I} & =3300 \mathrm{ps} .
\end{aligned}
$$


Differentielle Transmissionsspektren für verschiedene Verzögerungszeiten sind in Abbildung 5.12 der entsprechenden Simulation gegenübergestellt. Die Übereinstimmung zwischen Experiment und Simulation ist sehr gut. Abweichungen bei kurzen Wellenlängen und frühen Zeiten $(\tau=0 \mathrm{ps})$ sind auf die Gruppengeschwindigkeitsdispersion des Weißlichtkontinuums zurückzuführen.

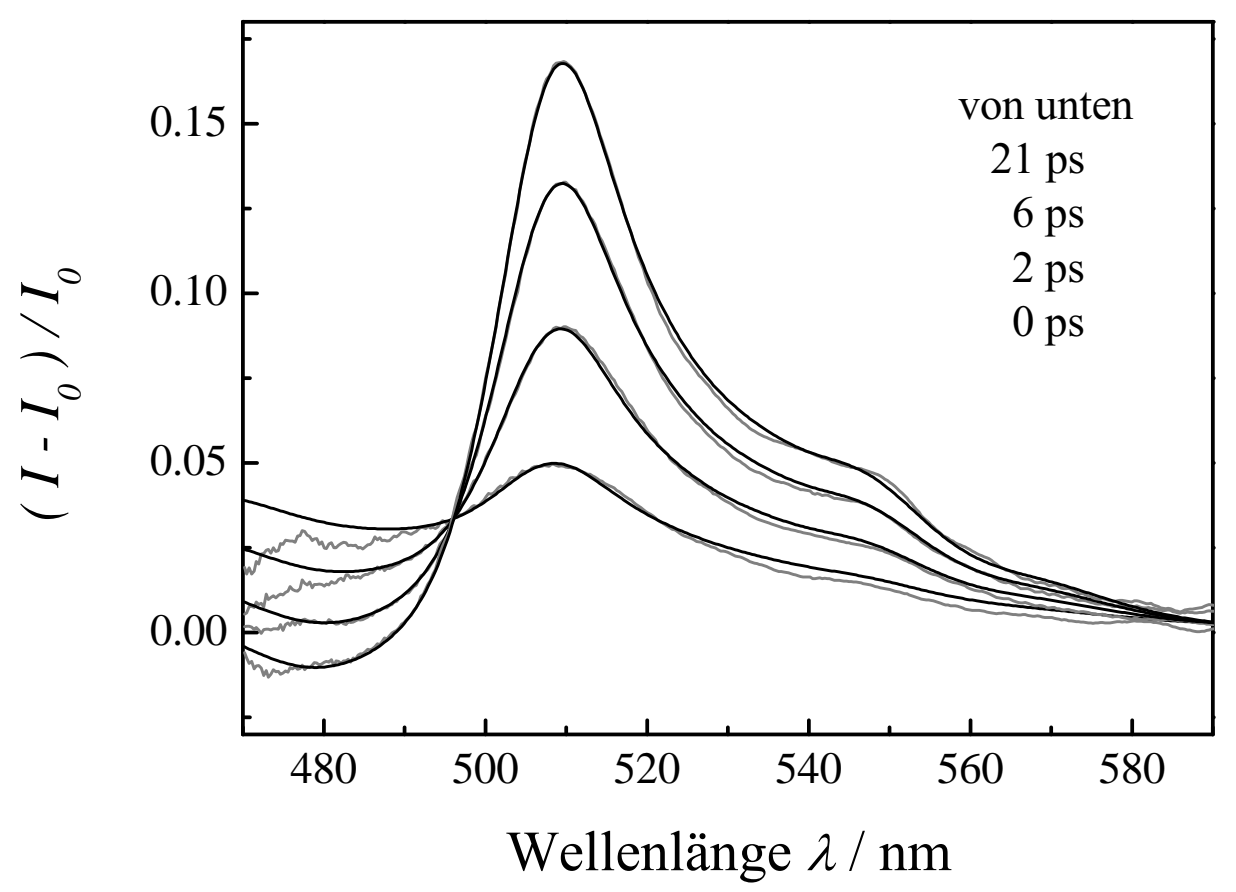

Abbildung 5.12: Differentielle Transmissionsspektren bei ausgesuchten Verzögerungszeiten mit den jeweiligen Simulationen

Abschließend wurde die Fluoreszenzquantenausbeute aus den oben aufgestellten Gleichungen (Gleichungen 5.14 bis 5.17) berechnet. Diese ergibt sich zu:

$$
\Phi_{f}=1-\left[A_{h}^{*}(0)\right]\left[1-\frac{2 k_{r} k_{p}-k_{h}\left(k_{I}-k_{\alpha}\right)}{\left(k_{I}-k_{\alpha}\right)\left(k_{I}-k_{\gamma}\right)}\right] .
$$

Nach dieser Gleichung wird eine Fluoreszenquantenausbeute von $89 \%$ ermittelt, die mit dem von Kummer et al..$^{36}$ angegebenen Wert von etwa $85 \%$ gut übereinstimmt. 
Um die Ergebnisse dieses Kapitels noch einmal zusammenzufassen, sei erwähnt, dass das hier vorgestellte Modell die in dieser Arbeit gewonnenen zeitaufgelösten Pump-Probe-Daten, die zeitabhängigen differentiellen Transmissionsspektren, die Dynamik auf Nanosekundenzeitskala, das Verhalten der Dynamik bei Deuterierung sowie die Fluoreszenzquantenausbeute richtig wiedergibt. Die hervorragende Übereinstimmung mit dieser Vielzahl experimenteller Ergebnisse unterstützt die Annahme, dass der Protonentransfer von nicht-reaktivem, interund intramolekularem Schwingungsenergietransfer begleitet wird. Ein weiterer Desaktivierungskanal von $A^{*}$ ist die innere Konversion, die im Rahmen des verfeinerten Modells einer Torsionsbewegung des Chromophors folgt ${ }^{1}$.

\subsubsection{Vibrationsdynamiken in Proteinumgebungen}

Das erweiterte Modell aus Abschnitt 5.2.2 bringt eine inter- und intramolekulare Schwingungsenergieverteilung hervor, die mit 23 ps mehr als doppelt so langsam ist wie der simultan beobachtete Protonentransfer. Die Anregung von GFP mit $25000 \mathrm{~cm}^{-1}$ präpariert einen Zustand $A^{*}$, dessen Population mit $2000 \mathrm{~cm}^{-1}$ Überschussenergie oberhalb der Barriere für den Protonentransfer liegt. Der langsame Energietransfer resultiert in multiexponentieller Kinetik. Eine schnellere Schwingungsenergierelaxation würde die Chromophore in kurzer Zeit primär unterhalb der Schwelle befördern und die Effizienz des Protonentransfers deutlich verringern. Der primäre Desaktivierungskanal wäre dann die innere Konversion über Torsion. Für einen effizienten Protonentransfer ist daher die langsame Schwingungsenergierelaxation essentiell. Dies wird durch die relativ feste aber wenig dichte Proteinumgebung gewährleistet, in der der Chromophor über kovalente und Wasserstoffbrückenbindungen fixiert ist. Wie Untersuchungen an Mutanten des GFP $^{36}$ und dem Chromophor in Lösung ${ }^{39}$ gezeigt haben, nimmt die Effizienz des Protonentransfers mit Öffnung dieses Netzwerkes im Protein ab. Die Desaktivierung erfolgt dann durch innere Konversion und infolge Löschung der Fluoreszenz (quenching). Die Fluoreszenz eines Modellchromophors des GFP (Ethyl-4-(4Hydroxyphenyl)methylidene-2-methyl-5-oxo-1-imidazolazetat) in flüssiger Phase ist stark vom Lösungsmittel abhängig und zeigt in sehr nieder viskosen Flüssigkeiten kaum Floreszenz ${ }^{39}$. Dieses Verhalten wird im photoactive yellow protein (PYP), dessen Chromophor ( $p$-Coumarinsäure) dem GFP-Chromophor sehr ähnlich ist, ebenfalls beobachtet. Die Desaktivierung des elektronisch angeregten Zustandes verläuft im PYP hauptsächlich über cis-trans-Isomerisierung ${ }^{89,90,91}$.

Schwingungsenergietransfer bzw. -relaxation innerhalb zylinderförmiger Proteine mit einer ähnlichen Sekundärstruktur ( $\beta$-sheet) wurde bislang weder experimentell noch theoretisch untersucht. Daher lässt sich die Relaxationskonstante von 23 ps nicht in frühere Studien einordnen. Untersucht wurde demgegenüber die Schwingungsrelaxation nach Infrarotanregung der Amid-I-Bande kleiner Peptide 98. Der Energietransfer von der Amid-I-Mode auf andere Schwingungsfreiheitsgrade des Peptids wurde zu 1.2 ps bestimmt. Diese Befunde sind jedoch mit de- 
nen am GFP nicht vergleichbar. Repräsentativer sind Experimente, bei denen die Schwingungsenergie durch optische Anregung eines Kofaktors in das Protein eingebracht wird. Lian et al. haben beispielsweise die Geschwindigkeit der Aufheizung der wässrigen Umgebung des Myoglobins untersucht, nachdem die Hämgruppe elektronisch angeregt wurde. Dabei wurde die Überschussenergie in 15 ps von der Hämgruppe zunächst zum Protein und schließlich auf das Wasser übertragen ${ }^{99}$. Kürzlich untersuchten Xie et al. die Schwingungsrelaxationszeiten von Proteinen in Abhängigkeit von der Sekundärstruktur. Sie konnten zeigen, dass die Proteine, die eine langsame Relaxationszeit aufweisen (15ps), aus $\alpha$ Helices bestehen ${ }^{100}$. Dieses Ergebnis legt nahe, dass diese langen Relaxationszeiten nur bei Proteinen mit einer $\alpha$-helikalen Struktur, nicht aber bei Proteinen mit $\beta$-Faltblättern, zu finden sind. Im PYP wurde tatsächlich eine Lebensdauer der Amid-I-Bande ermittelt, die eine Größenordnung kleiner war als die bei Proteinen mit $\alpha$-Helices. Demgegenüber deuten molekulardynamische Simulationen aus jüngerer Vergangenheit darauf, dass der Schwingungsenergietransfer in Proteinen stark modenspezifisch sein kann, d. h. die Energie wird von einer Mode zu wenigen ausgewählten Freiheitsgraden transferriert ${ }^{101}$. Es ist durchaus möglich, dass eine solche Modenspezifität im GFP ebenfalls eine Rolle spielt, da der Chromophor, wie beschrieben, im Protein stark isoliert ist. Dieses Phänomen führt zu der beobachteten langsamen Schwingungsrelaxation ${ }^{1}$. 



\section{Kapitel 6}

\section{Ausblick}

\subsection{Anisotropie}

Messungen der Anisotropie durch Pump-Probe-Experimente, Fluoreszenzkonversionsexperimente sowie Einzelphotonenzählen (TCSPC) wurden in Abschnitt 4.6 vorgestellt. Die Pump-Probe-Experimente bei $714 \mathrm{~nm}$ und $530 \mathrm{~nm}$ repräsentieren die Kinetik von $A^{*}$ bzw. I*. Im Fluoreszenzkonversionsexperiment wurde diese bei den Wellenlängen $450 \mathrm{~nm}$ und $530 \mathrm{~nm}$ nachgewiesen. TCSPC-Experimente wurden konzentrationsabhängig bei $530 \mathrm{~nm}$ durchgeführt. Das Abklingverhalten der Anisotropie hängt stark von der Nachweiswellenlänge ab. Bei $714 \mathrm{~nm}$ hat sie einen Startwert von 0.35 und klingt innerhalb 24 ps auf 0.13 ab. Demgegenüber klingt die Anisotropie bei $530 \mathrm{~nm}$ innerhalb des zeitlichen Detektionsfensters von 25 ps nur sehr wenig ab. Auffallend bei dieser Wellenlänge ist die ungewöhnlich hohe Anfangsanisotropie von $r(0 \mathrm{ps})=0.5$. Die Ergebnisse der Pump-Probe-Experimente und der Fluoreszenzkonversionsmessungen sind zur Zusammenfassung in Abbildung 6.1 zusammengestellt.

\section{Verlauf der Anisotropie bei 530 nm}

Die Anisotropie bei einer Nachweiswellenlänge von $530 \mathrm{~nm}$ ist bei Messung der Fluoreszenz (Fluoreszenzkonversionsexperiment) über einen Zeitbereich von 100 ps bei etwa $r=0.35$ nahezu konstant. Ein sehr ähnliches Verhalten wird auch im Pump-Probe-Experiment bei dieser Wellenlänge festgestellt $(r(25 \mathrm{ps})=0.37)$. Dieses Ergebnis impliziert, dass der Chromophor im Zustand I* auf dieser Zeitskala nicht rotieren kann. Auffällig ist jedoch die Anfangsanisotropie im Pump-Probe-Experiment von $r(0 \mathrm{ps})=0.5$, die innerhalb $5 \mathrm{ps}$ auf einen Wert von 0.37 abklingt. Um dieses Verhalten zu erklären, wurde zunächst der Einfluss der Pumpleistung im Pump-Probe-Experiment, sowie der Einfluss der Proteinkonzentration im TCSPC-Experiment untersucht. Wie Abschnitt 4.6 zeigt, kann keine Abhängigkeit der Anisotropie von der Pumpleistung festgestellt werden. 


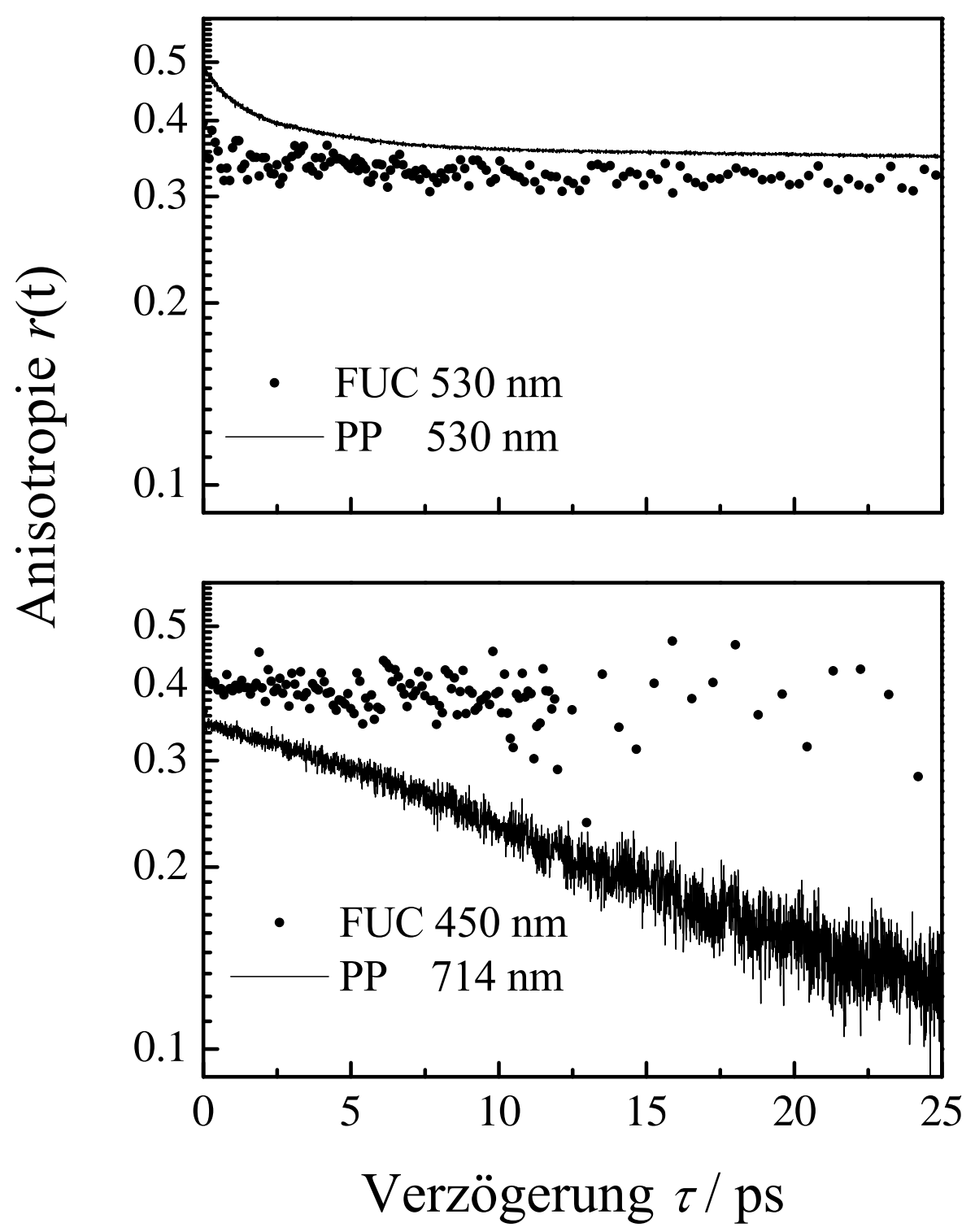

Abbildung 6.1: Zusammenfassung der Anisotropiemessungen im Fluoreszenzkonversionsexperiment (FUC) und im Pump-Probe-Experiment (PP) bei den eingezeichneten Nachweiswellenlängen.

Unerwünschte Sättigungsphänomene können daher ausgeschlossen werden. Die Konzentrationsabhängigkeit der Anisotropie im TCSPC-Experiment wurde gemessen, um zu erfahren, ob die ungewöhnlich hohe Anisotropie von 0.5 
möglicherweise in der Dimerisierung der GFP-Moleküle ihre Ursache hat. Infolge der Dimerisierung kann eine Entartung der elektronischen Zustände erfolgen, die einen größeren Wert der Anisotropie als 0.4 hervorbringt. Die Erhöhung der Anfangsanisotropie infolge der Wechselwirkung entarteter Zustände wurde in verschiedenen experimentellen und theoretischen Untersuchungen gezeigt ${ }^{80,102,103}$ und wird im Folgenden noch ausführlicher diskutiert.

Die monoexponentielle Abklingzeit der Anisotropie beträgt etwa 15 ns. Die konzentrationsabhängigen Messungen in Abbildung 4.20 und Abbildung 4.21 zeigen jedoch nur geringfügige Änderung des dynamischen Verhaltens der Anisotropie, die auf Verdünnungseffekte zurückzuführen sein sollte. Wäre Dimerisierung tatsächlich von Bedeutung, so wäre ein deutlicherer Effekt zu erwarten. Dies wurde bereits in Abschnitt 4.6 ausgeführt.

Bereits in resonanten Raman-Experimenten wurden Anisotropien bestimmt, die Werte in einem Bereich von -0.5 bis 1 annehmen konnten. Diese Werte waren davon abhängig, welche Symmetrie der Endzustand bei dem RamanÜbergang hatte ${ }^{102}$. In femtosekundenzeitaufgelösten Pump-Probe-Experimenten wurden ähnliche Anisotropien beobachtet ${ }^{104,105,103}$, die mit Systemen verbunden wurden, in denen entartete Zustände vorliegen. Theoretisch wurden diese Phänomene u. a. von Wynne et al. ${ }^{102,80}$ behandelt. Danach wird in einem System bestehend aus einem nicht-entarteten Grundzustand, zwei entarteten ersten angeregten Zuständen und einem nicht-entarteten zweiten angeregten Zustand durch einen kurzen Pumppuls eine elektronische Kohärenz zwischen den beiden entarteten Zuständen erzeugt. Ihre Übergangsdipolmomente sind dabei orthogonal zueinander. Der Probepuls koppelt diese elektronisch kohärente Superposition (Interferenz) zu einem gemeinsamen Endzustand, beispielsweise durch den Übergang in den zweiten elektronisch angeregten Zustand. Bei verschiedenen Reaktionen in Lösung klingt diese Kohärenz innerhalb mehrerer zehn Femtosekunden durch Wechselwirkung mit seiner Umgebung ab. Nach Wynne et al. ${ }^{80}$ kann die resultierende Anisotropie durch die Summe eines inkohärenten Beitrages durch Bevölkerung der entarteten Zustände und eines kohärenten Beitrages infolge der Interferenz der beiden entarteten Zustände dargestellt werde:

$$
r(t)=\frac{1}{10}\left[4+3 \exp \left(-t / T_{2}\right) \cos \Delta t\right] .
$$

Der erste Beitrag erscheint dabei durch die Anfangsanisotropie von 0.4, während der kohärente Beitrag am Anfang und bei vollständiger Entartung der Zustände 0.3 beträgt. Die Energieaufspaltung $\Delta$ zwischen den beiden Zuständen ist bei vollständiger Entartung null. Wird die Entartung teilweise oder ganz aufgehoben, sinkt bzw. verschwindet dieser Term und die Anisotropie nähert sich der fundamentalen Anisotropie $r_{0}=0.4$ an. Der Faktor $T_{2}$ entspricht der 
elektronischen Dephasierungszeit. Mit diesem Anisotropieexperiment ist es daher möglich, in einem System entarteter Zustände die elektronische Dephasierung zu messen, was im Falle nicht-entarteter Zustände mit Photon-Echo-Techniken durchgeführt wird $106,107,108,109,110$.

Da der Verlauf der Anisotropie in Abbildung 6.1 an beobachtete Phänomene entarteter Zustände erinnert, ist es durchaus denkbar, dass die Anisotropie des GFP im Pump-Probe-Experiment bei $530 \mathrm{~nm}$ auf ein solches Phänomen zurückzuführen ist. Beispielsweise kann eine Kopplung der beiden Zustände I* und $\mathrm{B}^{*}$ stattfinden, die wie Abbildung 5.1 zeigt, energetisch sehr ähnlich sind. Diese Kohärenz klingt mit einer Zeit von etwa 2.5 ps auf $r(t)=0.35 \mathrm{ab}$, was im Vergleich zu den Abklingzeiten der elektronischen Kohärenz von Reaktionen in Lösung ${ }^{104,103}$ relativ langsam ist. Da die Umgebung des Chromophors im Protein erwartungsgemäß deutlich weniger dicht ist als die eines vergleichbaren Chromophors in Lösung, ist eine Verlangsamung der elektronischen Dephasierungszeit gegenüber Reaktionen oder Dynamiken in Lösung nicht überraschend. Die Wechselwirkung mit der Umgebung ist im Protein weniger stark ausgeprägt, was mit der im vorgestellten dynamischen Modell (Abschnitt 5.2.2) getroffenen Annahme eines relativ langsamen Schwingungsenergietransfers zwischen Chromophor und Umgebung übereinstimmt.

In der zeitabhängigen Anisotropie der Fluoreszenzkonversionsmessung bei $530 \mathrm{~nm}$ wird kein vergleichbares Verhalten beobachtet. Die Anfangsanisotropie am Zeitnullpunkt beträgt hier bereits 0.35 und klingt sehr langsam ab (Abbildung 6.1. Das Fehlen eines kohärenten Probepulses in diesen Messungen könnte als Ursache für das Verschwinden des kohärenten Beitrages zur Anisotropie in der Fluoreszenzkonversionsmessung gewertet werden.

\section{Verlauf der Anisotropie bei $714 \mathrm{~nm}$ und $450 \mathrm{~nm}$}

Da die Populationen der Zustände $\mathrm{A}^{*}$ und $\mathrm{I}^{*}$ miteinander korrelieren, sollte bei dem Nachweis der Anisotropie von $A^{*}$ ein sehr ähnliches Verhalten in dem betrachteten Zeitfenster von 25 ps beobachtet werden. Tatsächlich kann in Fluoreszenzkonversionsexperimenten bei einer Nachweiswellenlänge von $450 \mathrm{~nm}$ eine nahezu konstante Anisotropie bei $r=0.4$ festgestellt werden. Das Pump-ProbeExperiment zeigt demgegenüber ein davon verschiedenes Verhalten - die Anisotropie hat hier einen Anfangswert von 0.35 und klingt innerhalb 25 ps auf 0.13 ab. Es gibt verschiedene Ursachen für eine erniedrigte Anfangsanisotropie, die theoretisch einen Wert von 0.4 annehmen sollte. Zum einen können die Ursachen instrumenteller Art sein. Dazu gehört die Depolarisation von Pump- und Probestrahl aufgrund der statischen Doppelbrechung und der verwendeten Optiken ${ }^{79}$. Darüberhinaus können bei hohen Anregungs- und Abtastfeldstärken die elektro-

nischen Übergänge gesättigt werden. Die Pumpleistungsabhängigkeit der Aniso- 
tropie in Abschnitt 4.6 zeigte jedoch, dass letztere Fehlerquelle ausgeschlossen werden kann. Können instrumentelle Artefakte vernachlässigt werden, kann die Differenz zwischen experimentell gemessener Anisotropie und theoretischem Wert auf die physikalischen Eigenschaften des Chromophors zurückgeführt werden. Beispielsweise können Signalüberlagerungen im Pump-Probe-Experiment für die Erniedrigung der Anisotropie gegenüber dem theoretischen sowie dem in Fluoreszenzkonversionsmessungen ermittelten Wert von $r=0.4$ führen. In diesem Zusammenhang ist auch der weitere Verlauf der Anisotropie im Pump-ProbeExperiment gegenüber dem aus Fluoreszenzmessungen von Bedeutung (Abbildung 6.1). Obwohl in beiden Messungen die Anisotropie des Zustandes A* nachgewiesen werden soll, klingt sie im Pump-Probe-Experiment ab, während sie im Fluoreszenzexperiment konstant bleibt. Fluoreszenzkonversionsexperimente haben den Vorteil, dass Signalüberlagerungen ausgeschlossen werden können, da lediglich die Emission aus dem angeregten Zustand detektiert wird. Diese Aussage muss eingeschränkt werden, wenn verschiedene Zustände mit unterschiedlich ausgerichteten Emissionübergangsdipolmomenten angeregt werden, die alle emittieren. Obwohl die zeitabhängige Anisotropie im Fluoreszenzexperiment über die Korrelationsfunktion des Übergangsdipolmomentes $\mu(0)$ zur Zeit null und des Übergangsdipolmomentes $\gamma(t)$ der Fluoreszenz zur Zeit $t$ nach Gleichung $6.2^{82}$ bestimmt wird und damit von der Messung der transienten Absorption verschieden ist (Korrelation zwischen $\mu(0)$ und dem Übergangsdipolmoment der transienten Absorption), wird in beiden Experimenten die gleiche Dynamik nachgewiesen, wenn nur ein einziger Zustand angeregt wird:

$$
r(t, \gamma)=\frac{2}{5}\left\langle P_{2}(\mu(0) \cdot \gamma(t))\right\rangle .
$$

Dies ist darauf zurückzuführen, dass in diesen Experimenten nur die dynamischen Kanäle (Rotation, Torsion etc.) des ersten angeregten Zustandes für die Änderung des Übergangsdipolmomentes relativ zum E-Feldvektor des Pumppulses relevant sind, aber nicht die dynamischen Kanäle des Grund- und des zweiten angeregten Zustandes. Aus diesem Grund wird ausgeschlossen, dass das schnelle Abklingen der Anisotropie im Pump-Probe-Experiment auf Torsionen bzw. Rotationen des Chromophors im angeregten Zustand zurückzuführen ist, da die Anisotropie aus Fluoreszenzkonversionsexperimenten in diesem Falle auch abklingen sollte. Darüberhinaus sollte die Torsionsbewegung nach dem vorgestellten dynamischen Modell eine Zeitkonstante um $300 \mathrm{ps}$ annehmen. Die beobachtete Zeitkonstante der Anisotropie ist demgegenüber einen Faktor zehn kleiner. Das Abklingverhalten der Anisotropie der transienten Absorption des GFP resultiert daher von Überlagerungen verschiedener Signalbeiträge. Demnach regt der Pumppuls nicht ausschließlich die Form A $\left(A \longrightarrow A^{*}\right)$, sondern möglicherweise einen weiteren angeregten Zustand an, von dem eine 
transiente Absorption in höhere Energiezustände erfolgen kann. Dieser Zustand fluoresziert bei $450 \mathrm{~nm}$ nicht, da er sonst im Fluoreszenzkonversionsexperiment durch ein ähnliches Anisotropieverhalten sichtbar würde. Die Auswirkungen der Überlagerung von verschiedenen Signalbeiträgen wurde bereits in früheren Arbeiten studiert, diese haben beispielsweise zur Ausbildung von Singularitäten im Zeitverlauf der Anisotropie geführt ${ }^{103}$.

Aufgrund der Photokonversionsergebnisse wäre es möglich, dass B zu einem geringen Teil elektronisch angeregt wird, von dessen angeregtem Zustand aus die transiente Absorption stattfindet. Das schnelle Abklingen der Anisotropie ausgehend von dieser Annahme könnte auf eine Torsion oder Rotation des Chromophors zurückzuführen sein. Der Chromophor in $B^{*}$ könnte zu einem geringen Teil über innere Konversion in den Grundzustand I übergehen. Dies würde erklären, warum Creemers et al. bei Ausbleichen von B die Bildung des Grundzustandes I beobachteten, ohne gleichzeitig die Emission von I* zu detektieren ${ }^{33}$.

\section{Abschließende Betrachtungen zur Anisotropie}

Die Kohärenz zwischen $\mathrm{B}^{*}$ und $\mathrm{I}^{*}$ als Ursache für die hohe, schnell abklingende Anfangsanisotropie $(\mathrm{r}(0)=0.5$, siehe vorletzter Abschnitt) steht jedoch in starkem Widerspruch zur partiellen Zuweisung der im Pump-Probe-Experiment bei $714 \mathrm{~nm}$ gemessenen Anisotropie zu B*. Wenn nach dieser Annahme beide Anisotropien (bei 530 und $714 \mathrm{~nm}$ ) mit B* verknüpft wären, müsste auch im Anisotropieverlauf bei $530 \mathrm{~nm}$ eine Komponente mit einer Abklingzeit von etwa 24 ps auftauchen. Daher kann unter Annahme dieser vereinfachten Zustände festgestellt werden, dass die Ursache beider Anisotropieverläufe nicht ausschliesslich im Zustand B* liegen kann. Rein hypothetisch wäre es auch möglich, dass die Form I in ihrem angeregten Zustand Entartungen aufweist, die zu der beobachteten Anisotropie bei $530 \mathrm{~nm}$ führt. Es ist nicht auszuschließen, dass die energetische Struktur des Chromophors jedoch mehr als nur drei Grund- und drei angeregte Zustände umfasst, die möglicherweise nicht an die Protonentransferkoordinate gekoppelt sind. Aus diesem Grund wäre die Möglichkeit auch nicht auszuschließen, dass der Verlauf der Anisotropie bei $714 \mathrm{~nm}$ im Pump-Probe-Experiment nicht auf Überlagerungen von $A^{*}$ und $B^{*}$, sondern möglicherweise auf die von $A^{*}$ und einem hypothetischen Zustand $\mathrm{X}^{*}$ zurückzuführen wäre. 


\subsection{Temperaturabhängigkeit}

Wie in Abschnitt 4.4 gezeigt wurde, ist die Temperaturabhängigkeit der Kinetik des Protonentransfers bei einer Nachweiswellenlänge von $530 \mathrm{~nm}$ sehr gering. Die Barriere zwischen $\mathrm{A}^{*}$ und $\mathrm{I}^{*}$ sollte daher relativ klein sein, d.h. sie wird wahrscheinlich im Bereich des Wertes für thermische Aktivierung von $207 \mathrm{~cm}^{-1}$ liegen.

Chattoraj et al. haben die Kinetik der Emission aus $A^{*}$ über einen deutlich ausgedehnteren Temperaturbereich gemessen: Sie beobachteten bei $298 \mathrm{~K}$ das Abklingen der Emission mit einer Zeitkonstanten von etwa 10 ps, während sie bei einer Temperatur von $120 \mathrm{~K}$ nur noch mit etwa 300 ps abklingt. Der Verlauf des Signals bei $85 \mathrm{~K}$ zeigte demgegenüber innerhalb des zeitlichen Beobachtungsfensters von 30 ps lediglich einen Anstieg des Signals. Vermutlich klingt dieses Signal mit einer Zeit von etwa 3 ns ab. Mit diesen Werten könnte prinzipiell die Barrierenhöhe für den Protonentransfer nach dem Arrhenius-Gesetz abgeschätzt werden, wenn davon ausgegangen würde, dass die temperaturabhängigen Signale lediglich den Protonentransfer reflektieren. Nach dem im vorherigen Kapitel diskutierten erweiterten dynamischen Modell erfolgt die Desaktivierung von A* jedoch nicht ausschließlich durch Protonentransfer, sondern zu einem nicht

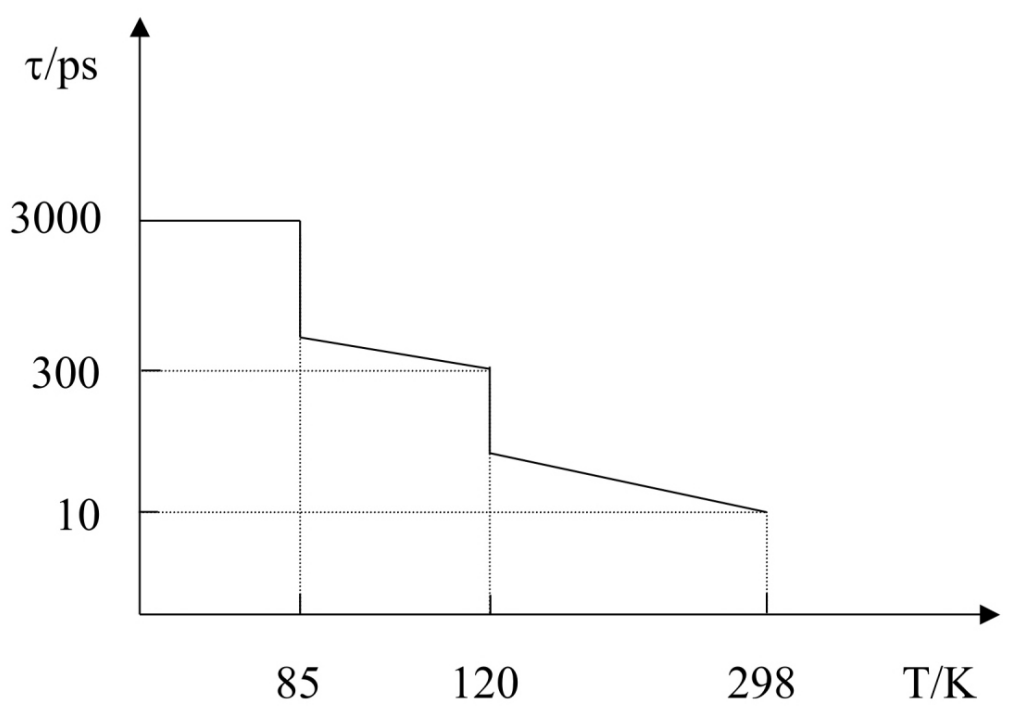

Abbildung 6.2: Verdeutlichung der Barrierenhöhen für den Protonentransfer und die Torsion und die Auswirkungungen auf das Zeitverhalten der Emission von $\mathrm{A}^{*}$. 
unwesentlichen Teil durch Torsion und folgender innerer Konversion. Zudem fällt bei näherem Betrachten der temperaturabhängigen Zeitkonstanten von Chattoraj et al. auf, dass sie bei $120 \mathrm{~K}$ etwa 300 ps entspricht. Diese liegt somit in der Größenordnung der aus TCSPC-Messungen bestimmten Zeitkonstanten $\tau_{3} \approx 300 \mathrm{ps}$, die innerhalb des vorgestellten erweiterten Modells bei Zimmertemperatur der Torsion zugeschrieben wurde (siehe Abschnitt 5.2.2). Nach dieser Annahme wäre es also denkbar, dass sich die Chromophore in $\mathrm{A}^{*}$ bei $T=120 \mathrm{~K}$ bereits unterhalb der Barriere zum Protonentransfer befinden, so dass die Desaktivierung hauptsächlich über die innere Konversion mit vorheriger Torsion des Chromophors stattfindet. Die Barriere für die Torsion wäre dann nach $k_{B} T / h c^{1}$ kleiner als $83 \mathrm{~cm}^{-1}$. Bei der Temperatur von $85 \mathrm{~K}$ zeigt sich eine weitere Verlangsamung der Kinetik von $A^{*}$, die vermutlich mit 3 ns exponentiell abklingt. Bei dieser Temperatur wäre es möglich, dass sich die Chromophormoleküle nun unterhalb sowohl der Protonentransferbarriere als auch der Torsionsbarriere befinden, so dass beide Prozesse unterdrückt werden und die Desaktivierung nun durch Strahlung erfolgt. Wenn dies der Fall wäre, könnte man ein unteres Limit für die Barrierenhöhe der Torsion zu $60 \mathrm{~cm}^{-1}$ ermitteln. Diese Ausführungen sind noch einmal in Abbildung 6.2 zusammengestellt.

Diese Annahmen bedürfen allerdings sorgfältiger experimenteller Überprüfung. Dafür ist es notwendig, dass die temperaturabhängige Kinetik über ein deutlich längeres Beobachtungsfenster als nur 30 ps gemessen wird. Darüberhinaus müssen die Experimente mit deuteriertem GFP wiederholt werden. Der Austausch der aziden Protonen mit Deuterium sollte zur Verlangsamung aller Vorgänge führen, die mit einer Protonenbewegung verknüpft sind. Es sollte keine Auswirkung auf das zeitliche Verhalten der Torsion und der strahlenden Desaktivierung haben. Würde man einen Isotopeneffekt bei $298 \mathrm{~K}$ beobachten, der jedoch bei $120 \mathrm{~K}$ und $85 \mathrm{~K}$ verschwindet, so wäre das oben angestellte Gedankenexperiment richtig.

\subsection{Photokonversion}

Obwohl die in Abschnitt 5.1 dargestellte Auswertung der Photokonversion eine akzeptable Methode zur Erforschung der Ursache der instantan ansteigenden Emission ist, bedarf die Photokonversionsstudie selbst höherer Genauigkeit. Wie in Abschnitt 4.7 gezeigt, unterliegt die lange Photokonversion mit leistungsstarken Femtosekundenpulsen der vermehrten Zersetzung des Proteins, was im Absorptionsspektrum als starker Untergrund erscheint. In verbesserten Photokon-

\footnotetext{
${ }^{1} k_{B}$-Boltzmann-Konstante, $\quad h$-Plancksche Konstante, $\quad c$-Lichtgeschwindigkeit, $\quad T-$ Temperatur
} 
versionsstudien muss diese Zersetzung entweder durch Abschwächen der Laserlichtleistung oder durch Verwenden einer Lampe unterbunden werden. Die Photokonversion muss dann vollständig erfolgen, um in zukünftigen Messungen das reine Absorptionsspektrum der B-Form zu erhalten und so den genauen Wert für die Absorption von B bei $400 \mathrm{~nm}$ ermitteln zu können. Im Anschluss daran muss die Dynamik der B-Form bei Anregung mit etwa $480 \mathrm{~nm}$ einer nichtphotokonvertierten Lösung untersucht werden. Für die Frage nach der Ursache der instantanen Emission ist die Messung des transienten Spektrums insbesondere am Zeitnullpunkt wichtig, da mit diesem das transiente Spektrum bei Anregung mit $400 \mathrm{~nm}$ bei $\tau=0 \mathrm{ps}$ verglichen und simuliert werden kann.

\subsection{Multiexponentielle Dynamik}

Pump-Probe-Experimente unter Variation der Pumpwellenlänge innerhalb der höherenergetischen Absorptionsbande A sind erforderlich, um die Annahmen des erweiterten dynamischen Modells zu überprüfen. Wie bereits beschrieben, steht der Annahme der Energieabhängigkeit der Geschwindigkeitskonstanten für den Protonentransfer infolge der langsamen Schwingungsenergierelaxation die Erklärung der Multiexponentialität durch strukturelle Heterogenitäten des Chromophors gegenüber. Würde eine Beschleunigung bei Erhöhung der Anregungsenergie erfolgen, wäre dies ein Indiz für die Richtigkeit des vorgestellten Modells. Die Frage, ob strukturelle Heterogenitäten die Multiexponentialität bewirken, kann unabhängig davon durch einzelmolekülspektroskopische Methoden aufgeklärt werden. Sind die Chromophormoleküle strukturell und energetisch verteilt, so muss für jedes einzelne Molekül ein etwas anderes dynamisches Verhalten beobachtet werden.

\subsection{Energietransfer}

Der Energietransfer von Aminosäureresten im GFP auf den Chromophor kann durch Anregung der hochfrequenten Absorptionsbande des GFP bei $\lambda_{\max }=$ $278 \mathrm{~nm}$ untersucht werden. Diese Bande setzt sich hauptsächlich durch elektronische Resonanzen aromatischer Aminosäuren, wie Tyrosin, Phenylalanin und Tryptophan, zusammen, die primär innerhalb des Zylinder lokalisiert sind. $\mathrm{Zu}$ dieser Thematik wurden bereits Messungen in der vorliegenden Arbeit durchgeführt. Eine dieser Messungen ist in Abbildung 6.3 dargestellt. Das Problem bei der Analyse dieser Daten ist die Eigenschaft des Chromophors, in diesem Bereich ebenfalls schwache Absorptionsbanden aufzuweisen, so dass bislang unklar ist, ob 


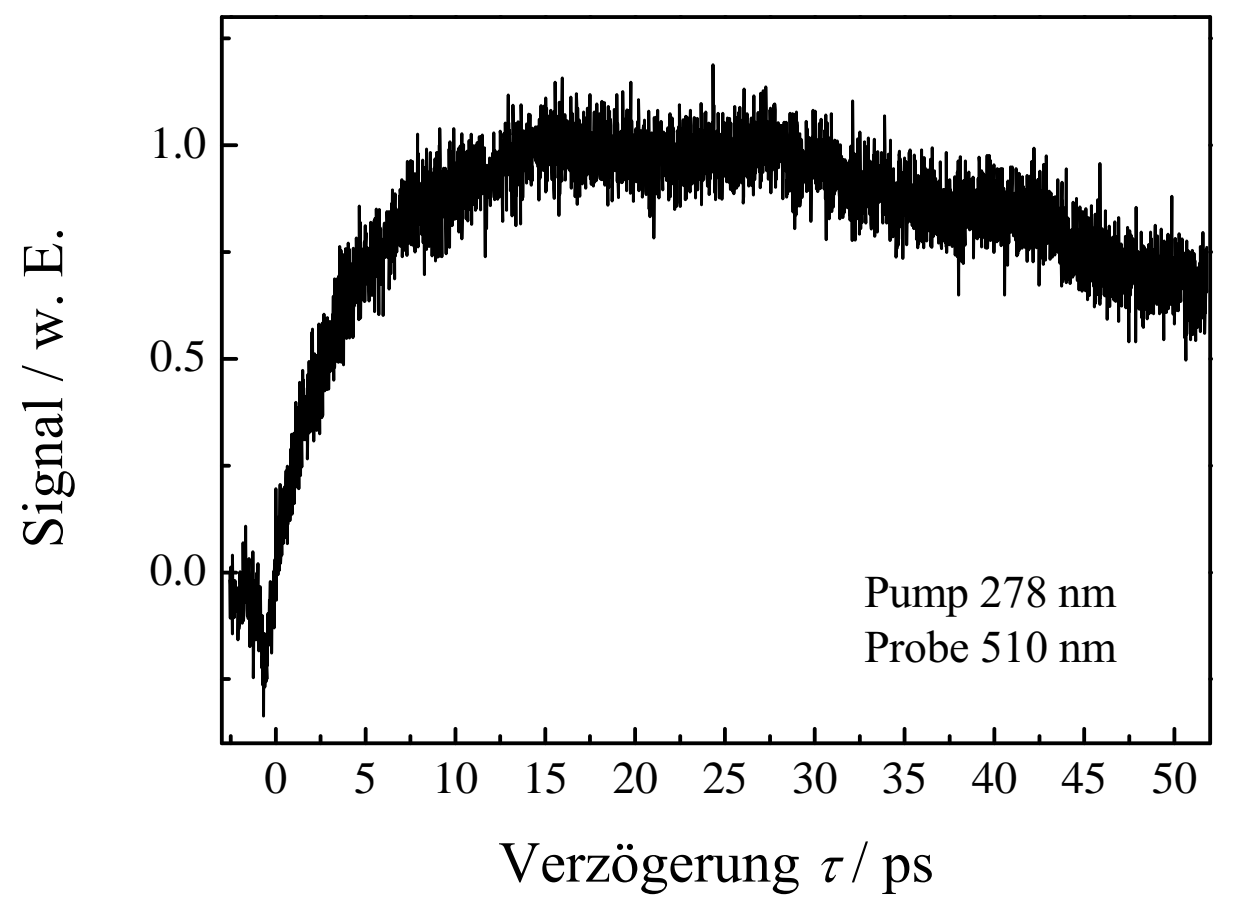

Abbildung 6.3: Pump-Probe-Signal bei einer Anregungswellenlänge von $256 \mathrm{~nm}$ und einer Nachweiswellenlänge von $510 \mathrm{~nm}$.

die dargestellten Signale tatsächlich den Energietransfer beschreiben, oder aber auf Resonanzen des Chromophors zurückzuführen sind. Der Frage zum Energietransfer des GFP bedarf es daher detailliertere Untersuchungen.

\section{Abschließende Bemerkungen}

Wie die Ausführungen zeigen, gibt es noch immer ein großes Forschungspotential zu den ultraschnellen Primärprozessen im elektronisch angeregten Zustand des GFP. Die Diskussion zur Anisotropie und Energieabhängigkeit implizieren ein hochdiffizieles molekulares System, welches mit weiteren sensitiven experimentellen Methoden studiert werden sollte. Dabei stellt die Überlagerung der Absorptionsbanden und der verschiedenen Signalbeiträge große Herausforderungen an die Experimente dar. Die Erforschung des Protonentransfer und des Energietransfers in biologischen Systemen sind dabei zwei äußerst relevante Prozesse. 


\section{Literaturverzeichnis}

[1] K. Winkler, J. Lindner, V. Subramaniam, T. M. Jovin, P. Vöhringer. Ultrafast dynamics in the excited state of green fluorescent protein (wt) studied by frequency-resolved femtosecond pump-probe spectroscopy. Physical Chemistry Chemical Physics, 4, (2002), 1072-1081.

[2] M. Chalfie, S. Kain. GFP - Green Fluorescent Protein - Properties, Applications, and Protocols (Wiley-Liss, 1998).

[3] O. Shimomura, F. H. Johnson, Y. Saiga. Extraction, purification and properties of aequorin, a bioluminescent protein from luminous hydromedusan Aequorea. J. Cell. Comp. Physiol., 59, (1962), 223-239.

[4] O. Shimomura. A short story of Aequorin. Biol. Bull., 189, (1995), 1-5.

[5] W. W. Ward, M. J. Cormier. An energy transfer protein in coelenterate bioluminescence. Characterization of the Renilla green fluorescent protein.. J. Biol. Chem., 254, (1979), 781-788.

[6] W. W. Ward, C. W. Cody, R. C. Hart, M. J. Cormier. Spectrophotometric Identity of the Energy-Transfer Chromophores in Renilla and Aequorea Green-Fluorescent Proteins. Photochem. Photobiol., 31(6), (1980), 611-615.

[7] H. Morise, O. Shimomura, F. H. Johnson, J. Winant. Intermolecular Energy Transfer in the bioluminescent system of Aequorea. Biochemistry, 13, (1974), 2656-2662.

[8] D. C. Prasher, V. K. Eckenrode, W. W. Ward, F. G. Prendergast, M. J. Cormier. Primary structure of the Aequorea victoria green-fluorescent protein. Gene, 111, (1992), 229-233.

[9] M. Chalfie, Y. Tu, G. Euskirchen, W. W. Ward, D. C. Prasher. Greenfluorescent Protein as a marker for gene expression. Science, 263, (1994), 502-805.

[10] M. Ormö, A. B. Cubitt, K. Kallio, L. A. Gross, R. Y. Tsien, S. J. Remington. Crystal structure of the Aequorea victoria green fluorescent protein. Science, 273(5280), (1996), 1392-1395. 
[11] F. Yang, L. G. Moss, G. N. Phillips. The molecular structure of green fluorescent protein. Nat. Biotechnol., 14(10), (1996), 1246-1251.

[12] M. Zimmer. Green Fluorescent Protein (GFP): Applications, Structure, and Related Photophysical Behavior. Chem. Rev., 102, (2002), 759-781.

[13] A. B. Cubitt, R. Heim, S. R. Adams, A. E. Boyd, L. A. Gross, R. Y. Tsien. Understanding, Improving and Using Green Fluorescent Proteins. Trends Biochem. Sci., 20(11), (1995), 448-455.

[14] R. Y. Tsien. The Green Fluorescent Protein. Annu. Rev. Biochem., 67, (1998), 509-544.

[15] J. M. Kendall, M. N. Badminton. TIBTECH, 16, (1998), 216-224.

[16] P. I. H. Batsiaens, R. Pepperkok. Observing proteins in their natural habitat: the living cell. Trends Biochem. Sci., 25, (2000), 631-637.

[17] K. K. Jensen, L. Martini, T. W. Schwartz. Enhanced Fluorescence Resonance Energy Transfer between Spectral Variants of Green Fluorescent Protein through Zinc-Site Engineering. Biochemistry, 40(4), (2001), 938945.

[18] T. Pozzan. Protein-protein interactions: Calcium turns turquoise into gold. Nature, 388, (1997), 834-835.

[19] K. Truong, M. Ikura. The use of FRET imaging microscopy to detect protein-protein interactions and protein conformational changes in vivo. Current Opinion in Structural Biology, 11, (2001), 573-578.

[20] R. Brock, G. Vamosi, G. Vereb, T. M. Jovin. Rapid characterization of green fluorescent protein fusion proteins on the molecular and cellular level by fluorescence correlation microscopy. Proc. Natl. Acad. Sci. U. S. A., 96(18), (1999), 10123-10128.

[21] A. S. Belmont. Visualizing chromosome dynamics with GFP. Trends Cell Biol., 11(6), (2001), 250-257.

[22] J. White, E. Stelzer. Photobleaching GFP reveals protein dynamics inside live cells. Trends Cell Biol., 9(2), (1999), 61-65.

[23] E. A. Reits, J. J. Neefjes. From fixed to FRAP: measuring protein mobility and activity in living cells. Nat. Cell Biol., 3, (2001), E145-E147.

[24] C. J. Bardeen, V. V. Yakovlev, J. A. Squier, K. R. Wilson. Quantum Control of Population Transfer in Green Fluorescent Protein by Using Chirped Femtosecond Pulses. J. Am. Chem. Soc., 120, (1998), 13023-13027. 
[25] Y. Li, A. Arawal, J. Sakon, R. R. Beitle. Characterization of metal affinity of green fluorescent protein and its purification through salt promoted, immobilized metal affinity chromatography. J. Chromatogr., 909(2), (2001), 183-190.

[26] T. Richmond, T. Takahashi, R. Shimkada, J. Bernsdorf. Engineered Metal Binding Sites on Green Fluorescence Protein. Biochem. Biophys. Res. Commun., 268(2), (2000), 462-465.

[27] R. A. G. Cinelli, V. Pellegrini, A. Ferrari, P. Faraci, R. Nifosi, M. Tyagi, M. Giacca, F. Beltram. Green fluorescent proteins as optically controllable elements in bioelectronics. Appl. Phys. Lett., 79(20), (2001), 3353-3355.

[28] W. W. Ward, H. J. Prentice, A. F. Roth, C. W. Cody, S. C. Reeves. Spectral Perturbations of the Aequorea Green-Fluorescent Protein. Photochem. Photobiol., 35(6), (1982), 803-808.

[29] S. B. Nielsen, A. Lapierre, J. U. Andersen, U. V. Pedersen, S. Tomita, L. H. Anderson. Absorption spectrum of the green fluorescent protein chromophore anion in vacuo. Phys. Rev. Lett., 8722(22), (2001), art.-228102.

[30] K. Mauring, A. Suisalu, J. Kikas. Laser-induced phototransformation in green fluorescent protein at low temperature. J. Lumines., 87-89, (2000), 812-814.

[31] M. Chattoraj, B. A. King, G. U. Bublitz, S. G. Boxer. Ultra-fast excited state dynamics in green fluorescent protein: Multiple states and proton transfer. Proc. Natl. Acad. Sci. U. S. A., 93(16), (1996), 8362-8367.

[32] H. Lossau, A. Kummer, R. Heinecke, F. PollingerDammer, C. Kompa, G. Bieser, T. Jonsson, C. M. Silva, M. M. Yang, D. C. Youvan, M. E. MichelBeyerle. Time-resolved spectroscopy of wild-type and mutant Green Fluorescent Proteins reveals excited state deprotonation consistent with fluorophore-protein interactions. Chem. Phys., 213(1-3), (1996), 1-16.

[33] T. M. H. Creemers, A. J. Lock, V. Subramaniam, T. M. Jovin, S. Völker. Three photoconvertible forms of green fluorescent protein identified by spectral hole-burning. Nature Structural Biology, 6(6), (1999), 557-560.

[34] J. J. van Thor, A. J. Pierik, I. Nugteren-Roodzant, A. Xie, K. J. Hellingwerf. Characterization of the Photoconversion of Green Fluorescent Protein with FTIR Spectroscopy. Biochemistry, 37, (1998), 16915-16921.

[35] J. J. van Thor, T. Gensch, K. Hellingwerf, L. N. Johnson. Phototransformation of green fluorescent protein with $U V$ and visible light leads to decarboxylation of glutamate222. Nature Structural Biology, 9(1), (2002), $37-41$. 
[36] A. D. Kummer, C. Kompa, H. Lossau, F. Pollinger-Dammer, M. E. MichelBeyerle, C. M. Silva, E. J. Bylina, W. J. Coleman, M. M. Yang, D. C. Youvan. Dramatic reduction in fluorescence quantum yield in mutants of Green Fluorescent Protein due to fast internal conversion. Chem. Phys., 237(1-2), (1998), 183-193.

[37] A. Volkmer, V. Subramaniam, D. J. S. Birch, T. M. Jovin. One- and TwoPhoton Excited Fluorescence Lifetimes and Anisotropy Decays of Green Fluorescent Proteins. Biophysical Journal, 78, (2000), 1589-1598.

[38] A. D. Kummer, J. Wiehler, T. A. Schüttrigkeit, B. W. Berger, B. Steipe, M. E. Michel-Beyerle. Picosecond Time-Resolved Fluorescence from BlueEmitting Chromophore Variants Y66F and Y66H of the Green Fluorescent Protein. ChemBioChem, 3(7), (2002), 659-663.

[39] A. D. Kummer, C. Kompa, H. Niwa, T. Hirano, S. Kojima, M. E. MichelBeyerle. Viscosity-Dependent Fluorescence Decay of the GFP Chromophore in Solution Due to Fast Internal Conversion. J. Phys. Chem. B, 106, (2002), 7554-7559.

[40] A. D. Kummer, J. Wiehler, H. Rehaber, C. Kompa, B. Steipe, M. E. MichelBeyerle. Effects of threonine 203 replacements on excited-state dynamics and fluorescence properties of the green fluorescent protein (GFP). J. Phys. Chem. B, 104(19), (2000), 4791-4798.

[41] U. Haupts, S. Maiti, P. Schwille, W. W. Webb. Dynamics of fluorescence fluctuations in green fluorescent protein observed by fluorescence correlation spectroscopy. Proc. Natl. Acad. Sci. U. S. A., 95(23), (1998), 13573-13578.

[42] S. M. Kirkpatrick, R. R. Naik, M. O. Stone. Nonlinear saturation and determination of the two-photon absorption cross section of green fluorescent protein. J. Phys. Chem. B, 105(14), (2001), 2867-2873.

[43] M. H. Seifert, D. Ksiazek, M. K. Azim, P. Smialowski, N. Budisa, T. A. Holak. Slow exchange in the chromophore of a green fluorescent protein variant. J. Am. Chem. Soc., 124(27), (2002), 7932-7942.

[44] M. Cotlet, J. Hofkens, M. Maus, T. Gensch, M. V. der Auweraer, J. Michiels, G. Dirix, M. VanGuyse, J. Vanderleyden, A. J. W. Visser, G. DeSchryver, F. C. Excited-state dynamics in the enhanced green fluorescent protein mutant probed by picosecond time-resolved single photon counting spectroscopy. J. Phys. Chem. B, 105(21), (2001), 4999-5006.

[45] A. A. Heikal, S. T. Hess, W. W. Webb. Multiphoton molecular spectroscopy and excited-state dynamics of enhanced green fluorescent protein (EGFP): acid-base specificity. Chem. Phys., 274(1), (2001), 37-55. 
[46] A. A. Voityuk, M. E. MichelBeyerle, N. Rosch. Protonation effects on the chromophore of green fluorescent protein. Quantum chemical study of the absorption spectrum. Chem. Phys. Lett., 272(3-4), (1997), 162-167.

[47] A. A. Voityuk, M. E. Michel-Beyerle, N. Rosch. Quantum chemical modeling of structure and absorption spectra of the chromophore in green fluorescent proteins. Chem. Phys., 231(1), (1998), 13-25.

[48] A. A. Voityuk, M. E. Michel-Beyerle, N. Rosch. Structure and rotation barriers for ground and excited states of the isolated chromophore of the green fluorescent protein. Chem. Phys. Lett., 296(3-4), (1998), 269-276.

[49] M. C. Chen, C. R. Lambert, J. D. Urgitis, M. Zimmer. Photoisomerization of green fluorescent protein and the dimensions of the chromophore cavity. Chem. Phys., 270(1), (2001), 157-164.

[50] W. Weber, V. Helms, J. A. McCammon, P. W. Langhoff. Shedding light on the dark and weakly fluorescent states of green fluorescent proteins. Proc. Natl. Acad. Sci. U. S. A., 96(11), (1999), 6177-6182.

[51] V. Helms. Electronic excitations of biomolecules studied by quantum chemistry. Current Opinion in Structural Biology, 12, (2002), 169-175.

[52] M. A. Lill, V. Helms. Proton shuttle in green fluorescent protein studied by dynamic simulations. Proc. Natl. Acad. Sci. U. S. A., 99(5), (2002), $2778-2781$.

[53] N. Reuter, R. Lin, W. Thiel. Green fluorescent proteins: Empirical force field for the neutral and deprotonated forms of the chromophore. Molecular dynamics simulation's of the wild type and S65T mutant. J. Phys. Chem. B, 106(24), (2002), 6310-6321.

[54] H. Y. Yoo, J. A. Boatz, V. Helms, J. A. McCammon, P. W. Langhoff. Chromophore protonation states and the proton shuttle mechanism in green fluorescent protein: Inferences drawn from ab initio theoretical studies of chemical structures and vibrational spectra. J. Phys. Chem. B, 105(14), (2001), 2850-2857.

[55] V. Helms, C. Winstead, P. W. Langhoff. Low-lying electronic excitations of the green fluorescent protein chromophore. Journal of Molecular Structure (Theochem), 506, (2000), 179-189.

[56] H. Lossau. Dynamik der Fluoreszenz aus photosynthetischen Reaktionszentren und Grün Fluoreszierendem Protein (GFP). Untersuchungen ultraschneller Energie-, Elektronen- und Protonentransferprozesse. Dissertation, Technische Universität München (1998). 
[57] G. N. P. Jr. Structure and dynamics of green fluorescent protein. Curr. Opin. Struct. Biol., 7, (1997), 821-827.

[58] Ich danke Dr. Matthias Müller für die Erstellung dieses sehr schönen Bildes.

[59] K. Brejc, T. K. Sixma, P. A. Kitts, S. R. Kain, R. Y. Tsien, M. Ormo, S. J. Remington. Structural basis for dual excitation and photoisomerization of the Aequorea victoria green fluorescent protein. Proc. Natl. Acad. Sci. U. S. A., 94(6), (1997), 2306-2311.

[60] J. Jortner, S. A. Rice, R. M. Hochstrasser. Radiationless Transition in Photochemistry. Advances of Photochemistry, 7, (1969), 16915-16921.

[61] N. J. Turro. Modern Molecular Photochemistry (Benjamin/Cummings, Menlo Park, 1978).

[62] M. Klessinger, J. Michl. Excited States and Photochemistry of Organic Molecules (VCH, Weinheim, 1995).

[63] K. Winkler. Ultraschneller Optischer Kerr-Effekt von Wasser und schwerem Wasser. Diplomarbeit, Universität Göttingen (2000).

[64] Mira Seed Laser Operator's Manual (1996).

[65] RegA Model 9000 Laser Operator's Manual (1994).

[66] C. Kappel. Stoßwellenuntersuchungen zur Kinetik und Druckabhängigkeit der Wasserstoffperoxidpyrolyse mittels Laser-Absorptions-Spektroskopie. Dissertation, Universität Göttingen (2002).

[67] Operator's Manual; The Coherent Innova Sabre TM Series Ion Laser (1997).

[68] Y. R. Shen. The Principles of Nonlinear Optics (John Wiley \& Sons, Inc, 1984).

[69] K. Ekvall, P. van der Meulen, C. Dhollande, L.-E. Berg, S. Pommeret, R. Naskrecki, J.-C. Mialocq. Cross phase modulation artifact in liquid phase transient absorption spectroscopy. Journal of Applied Physics, 87(5), (2000), 2340-2352.

[70] M. J. Feldstein, P. Vöhringer, N. F. Scherer. Rapid-scan pump-probe spectroscopy with high time and wave-number resolution: optical-Kerr-effect measurements of neat liquids. J. Opt. Soc. Am. B, 12(8), (1995), 15001510. 
[71] K. Winkler, J. Lindner, H. Bürsing, P. Vöhringer. Ultrafast Raman-induced Kerr-effect of water. Single molecule versus collective motions. Chem. Phys., 113(11), (2000), 4674-4682.

[72] Operator's Manual; The Coherent Model 9400 Optical Amplifier (OPA) (1994).

[73] M. T. Seidel. Unpublizierter Experimenteller Aufbau.

[74] H. Mahr, M. D. Hirsch. An Optical Up-Conversion Light Gate with Picosecond Resolution. Optics Communications, 13(2), (1975), 96-99.

[75] J. Jethwa, P. Vöhringer. Unpublizierter Experimenteller Aufbau.

[76] persönl. Mitteilung von Dr. Vinod Subramaniam..

[77] Edinburgh Instruments Ltd. TCC 900; Computer Module for Time Correlated Single Photon Counting (2001).

[78] H. Barkhuijsen, R. de Beer, W. M. M. J. Bovée, D. van Ormondt. Retrieval of Frequencies, Amplitudes, Damping Factors, and Phases from TimeDomain Signals Using a Linear Least-Squares Procedure. Journal of Magnetic Resonance, 61, (1985), 465-481.

[79] B. Valeur. Molecular Fluorescence - Principles and Applications (WileyVCH, 2002).

[80] K. Wynne, R. M. Hochstrasser. Anisotropy as an ultrafast Probe of Electronic Coherence in Degenerate Systems Exhibiting Raman Scattering, Fluorescence, Transient Absorption and Chemical Reactions. Journal of Raman Spectroscopy, 26, (1983), 561-569.

[81] Ich danke Marco T. Seidel für die Durchführung der Fluoreszenzkonversionsexperimente.

[82] G. R. Fleming. Chemical Applications of Ultrafast Spectroscopy (Oxford University Press, 1986).

[83] P. W. Atkins. Physikalische Chemie (VCH, 1990).

[84] J. Jethwa, D. Ouw, K. Winkler, N. Hartmann, P. Vöhringer. Ultrafast Proton-Transfer and Coherent Wavepacket Motion of Electronically Wxcited 1,8-Dihydroxyanthraquinone in Liquid Benzyl Alcohol Solution. Zeitschrift für Physikalische Chemie, 214(10), (2000), 1367-1381. 
[85] A. L. Sobolewski, W. Domcke. Ab initio potential-energy functions for excited state intramolecular proton transfer: a comparative study of ohydroxybenzaldehyde, salicylic acid and 7-hydroxy-1-indanone. PCCP Phys. Chem. Chem. Phys., 1(13), (1999), 3065-3072.

[86] R. G. Gilbert, S. C. Smith. Theory of Unimolecular and Recombination Reactions (Blackwell Scientific Publications, 1990).

[87] R. M. Wachter, B. A. King, R. Heim, K. Kallio, R. Y. Tsien, S. G. Boxer, S. J. Remington. Crystal structure and photodynamic behavior of the blue emission variant $Y 66 \mathrm{H} / \mathrm{Y} 145 \mathrm{~F}$ of green fluorescent protein. Biochemistry, 36(32), (1997), 9759-9765.

[88] M. A. Elsliger, R. M. Wachter, G. T. Hanson, K. Kallio, S. J. Remington. Structural and spectral response of green fluorescent protein variants to changes in pH. Biochemistry, 38(17), (1999), 5296-5301.

[89] W. D. Hoff, I. H. M. V. Stokkum, H. J. van Ramesdonk, M. E. van Brederode, A. M. Brouwer, J. C. Fitch, T. E. Meyer, R. V. Grondelle, K. J. Hellingwerf. Measurement and Global Analysis of the Absorbance Changes in the Photocycle of the Photoactive Yellow Protein from EctothiorhodospiraHalophila. Biophys. J., 67(4), (1994), 1691-1705.

[90] H. Chosrowjan, N. Mataga, N. Nakashima, Y. Imamoto, F. Tokunaga. Femtosecond-picosecond fluorescence studies on excited state dynamics of photoactive yellow protein from Ectothiorhodospira halophila. Chem. Phys. Lett., 270(3-4), (1997), 267-272.

[91] H. Chosrowjan, N. Mataga, Y. Shibata, Y. Imamoto, F. Tokunaga. Environmental effects on the femtosecond-picosecond fluorescence dynamics of photoactive yellow protein: Chromophores in aqueous solutions and in protein nanospaces modified by site-directed mutagenesis. J. Phys. Chem. B, 102(40), (1998), 7695-7698.

[92] D. H. Waldeck. Photoisomerization dynamics of stilbenes. Chem. Rev., 91, (1991), 415-436.

[93] J. E. Gano, P. A. Garry, P. Sekher, J. Schliesser, Y. W. Kim. Double stereochemical labeling in stilbene photochemistry: Tracing phenyl rotation reveals stereochemically distinct reaction pathways for formation of the $E$ photoproducts. J. Am. Chem. Soc., 119(16), (1997), 3826-3827.

[94] T. Kühne, P. Vöhringer. Vibrational relaxation and geminate recombination in the femtosecond-photodissociation of triiodide in solution. Journal of Chemical Physics, 105(24), (1996), 10788-10802. 
[95] G. Striker, V. Subramaniam, C. A. M. Seidel, A. Volkmer. Photochromicity and fluorescence lifetimes of green fluorescent protein. J. Phys. Chem. B, 103(40), (1999), 8612-8617.

[96] R. Kubo, M. Toda, N. Hashitsume. Nonequilibrium Statistical Mechanics (Springer Verlag, Berlin, 1978).

[97] R. Kubo. Adv. Chem. Phys., 15, (1969), 101.

[98] P. Hamm, M.-H. Lim, R. M. Hochstrasser. Structure of the Amide I Band of Peptides Measured by Femtosecond Nonlinear-Infrared Spectroscopy. J. Phys. Chem. B, 102, (1998), 6123-6138.

[99] T. Lian, B. Locke, Y. Kholodenko, , R. M. Hochstrasser. Energy Flow from Solute to Solvent Probed by Femtosecond IR Spectroscopy: Malachite Green and Heme Protein Solutions. J. Phys. Chem., 98, (1994), 11648-11656.

[100] A. H. Xie, L. vanderMeer, W. Hoff, R. H. Austin. Long-lived amide I vibrational modes in myoglobin. Phys. Rev. Lett., 84(23), (2000), 54355438.

[101] K. Moritsugu, O. Miyashita, A. Kidera. Vibrational energy transfer in a protein molecule. Phys. Rev. Lett., 85(18), (2000), 3970-3973.

[102] K. Wynne, R. M. Hochstrasser. Coherence effects in the anisotropy of optical experiments. Chemical Physics, 171, (1993), 179-188.

[103] S. Hess, H. Bürsing, P. Vöhringer. Dynamics of fragment recoil in the femtosecond photodissociation of triiodide ions in liquid solution. Journal of Chemical Physics, 111(12), (1999), 5461-5473.

[104] C. Galli, K. Wynne, S. M. LeCours, M. J. Therien, R. M. Hochstrasser. Direct measurement of electronic dephasing using anisotropy. Chemical Physics Letters, 206(5,6), (1993), 493-499.

[105] K. Wynne, S. M. Lecours, C. Galli, M. J. Therien, R. M. Hochstrasser. Porphyrin-Quinone Electron Transfer Revisited. The Role of Excited-State Degeneracy in Ultrafast Charge Transfer Reactions. J. Am. Chem. Soc., 117, (1995), 3749-3753.

[106] M. Cho, G. R. Fleming. Photon echo measurements in liquids: Numerical calculations with model systems. J. Chem. Phys., 98(4), (1993), 2848-2859.

[107] W. P. de Boeij, M. S. Pshenichnikov, D. A. Wiersma. System-Bath Correlation Function Probed by Conventional and Time-Gated Stimulated Photon Echo. J. Phys. Chem., 100, (1996), 11806-11823. 
[108] P. Vöhringer, D. C. Arnett, R. A. Westervelt, M. J. Feldstein, N. F. Scherer. Optical dephasing on femtosecond time scales: Direct measurement and calculation from solvent spectral densities. J. Chem. Phys., 102(10), (1995), 4027-4036.

[109] T.-S. Yang, P. Vöhringer, D. C. Arnett, N. F. Scherer. The solvent spectral density and vibrational multimode approach to optical dephasing: Two-pulse photon echo response. J. Chem. Phys., 103(19), (1995), 8346-8359.

[110] P. Vöhringer, D. C. Arnett, T.-S. Yang, N. F. Scherer. Time-gated photonecho spectroscopy in liquids. Chemical Physics Letters, 237, (1995), 387398. 


\section{Abbildungsverzeichnis}

1.1 Qualle Aequorea aequorea .................. 4

2.1 Kristallstruktur des GFP . . . . . . . . . . . . . . . 8

2.2 Chromophor des GFP . . . . . . . . . . . . . . . . . 8

2.3 Absorptions- und Fluoreszenzspektrum des GFP . . . . . . . . 10

2.4 Energieniveauschema nach Chattoraj et al. . . . . . . . . . . . 12

2.5 Energieniveauschema nach Creemers et al. . . . . . . . . . . . . 14

2.6 Prinzip des Protonentransfers anhand kristallographischer Untersuchungen . . . . . . . . . . . . . . . . 16

2.7 Modellchromophor . . . . . . . . . . . . . . . . . . . . . . . 21

2.8 Anionischer Modelchromophor für theoretische Studien von Voityuk et al. . . . . . . . . . . . . . . . . . . 22

2.9 Schema einer Chromophorgeometrie . . . . . . . . . . . . . 23

3.1 Oszillator und Strecker . . . . . . . . . . . . . . . . . 26

3.2 Regenerativer Verstärker und Kompressor . . . . . . . . . . . 28

3.3 Optischer Parametrischer Verstärker . . . . . . . . . . . . . 32

3.4 Autokorrelationen bei verschiedenen Wellenlängen . . . . . . . . . 33

3.5 Spektren der im OPA generierten und verstärkten Femtosekunden-

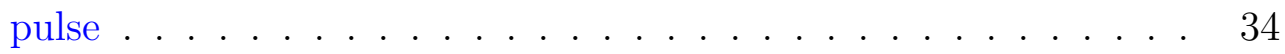

3.6 Vorexperimenteller Aufbau . . . . . . . . . . . . . . . . . . 36

3.7 Pump-Probe-Absorptionssignal von 1,8-Dihydroxyanthrachinon . 37

3.8 Zellhalterung mit Kugellager . . . . . . . . . . . . . . . . . . . . 39

3.9 Referenztechnik . . . . . . . . . . . . . . . . . . . . . . . 41

3.10 Vergleich verschiedener Detektionstechniken . . . . . . . . . 42

3.11 Verbesserte Referenztechnik . . . . . . . . . . . . . . . . 43

3.12 Vergleich der Referenztechniken . . . . . . . . . . . . . . 44

3.13 Rapid-Scan Vorrichtung . . . . . . . . . . . . . . . 46

3.14 Experimenteller Aufbau . . . . . . . . . . . . . . . . . 48

3.15 Kreuzkorrelationen . . . . . . . . . . . . . . . . . . . 49

3.16 Schematische Darstellung des Einzelphotonenzählexperimentes . . 53 
4.1 Zeitaufgelöste Pump-Probe-Signale im spektralen Bereich des stationären Emissionsspektrums . . . . . . . . . . . . 57

4.2 Pump-Probe-Signale als Konturdarstellung . . . . . . . . . . . . . 58

4.3 Repräsentative Transienten für verschiedene Spektralbereiche . . . 59

4.4 Instantane und verzögerte stimulierte Emission . . . . . . . . . . . 60

4.5 Repräsentative Signale bei der isosbestischen Wellenlänge . . . . . 61

4.6 Repräsentative Transienten für Wellenlängen größer als $600 \mathrm{~nm}$. . 62

4.7 Transiente Spektren des GFP . . . . . . . . . . . . . . . . . . 63

4.8 Differenzspektrum aus stationärem und transientem Spektrum bei $102 \mathrm{ps} \ldots \ldots \ldots \ldots$. . . . . . . . . . . . . . 64

4.9 Isosbestischer Punkt im zeitabhängigen transienten Spektrum . . 65

4.10 Signale des GFP aus TCSPC-Experimenten . . . . . . . . . . . . 67

4.11 Temperaturabhängiges stationäres Absorptionsspektrum des GFP 69

4.12 Temperaturabhängige Pump-Probe-Transienten des GFP . . . . . 70

4.13 Schwingungsdynamik im Pump-Probe-Experiment . . . . . . . . . 71

4.14 Pump-Probe-Signal und LPSVD-Anpassung . . . . . . . . . . . . 73

4.15 Polarisationsabhängige Messung bei $530 \mathrm{~nm}$. . . . . . . . . . . . 76

4.16 Polarisationsabhängige Messung bei $714 \mathrm{~nm}$. . . . . . . . . . . . 77

4.17 Pumpleistungsabhängigkeit der Anisotropie . . . . . . . . . . . . . 78

4.18 Anisotropie aus Fluoreszenzkonversionsexperimenten bei $530 \mathrm{~nm}$. 79

4.19 Anisotropie aus Fluoreszenzkonversionsexperimenten bei $450 \mathrm{~nm}$. 80

4.20 Anisotropie aus TCSPC-Experimenten bei $510 \mathrm{~nm}$. . . . . . . . . 81

4.21 Graphische Auftragung der Anpassungsparameter an die Anisotropiesignale . . . . . . . . . . . . . . . . . . . . 82

4.22 Stationäre Absorptionsspektren von wt-GFP in Abhängigkeit von der Bestrahlungsdauer . . . . . . . . . . . . . . . . 84

4.23 Pump-Probe-Signale in Abhängigkeit der Bestrahlungsdauer . . . 85

4.24 Stationäre Absorptionsspektren bei weiterer Bestrahlungsdauer . . 86

4.25 Pump-Probe-Signale bei weiterer Bestrahlungsdauer . . . . . . . . 87

4.26 Pumpleistungsabhängigkeit eines Pump-Probe-Signals . . . . . . . 88

5.1 Energieschema mit den stimulierten Emissionen und transienten Absorptionen aus dieser Arbeit . . . . . . . . . . . . . . . . . . 90

5.2 Zusammenfassende Darstellung der Signale, die für die verschiedenen Spektralbereiche charakteristisch sind . . . . . . . . . . . 92

5.3 Photokonvertiertes Spektrum des GFP und zugehöriges PumpProbe-Signal bei $530 \mathrm{~nm}$. . . . . . . . . . . . . . . . . . .

5.4 Darstellung der Interkonversion zwischen $\mathrm{A}^{*}$ und I* mit zeitunabhängiger Geschwindigkeitskonstante . . . . . . . . . . . . . .

5.5 Darstellung der Interkonversion zwischen $\mathrm{A}^{*}$ und $\mathrm{I}^{*}$ mit zeitabhängiger Geschwindigkeitskonstante . . . . . . . . . . . . . . . . . 102

5.6 Dynamisches Modell auf einer schematischen Potentialfläche entlang der Protonentransfer- und der Torsionskoordinate. . . . . . . 103 
5.7 Dynamisches Modell anhand eines schematischen Energieniveaudiagramms . . . . . . . . . . . . . . . . . . . . . 104

5.8 Zeitaufgelöste Pump-Probe-Signale und Simulationen . . . . . . . 108

5.9 Simulationen der Fluoreszenzabklingkurven auf einer Nanosekundenzeitskala . . . . . . . . . . . . . . . . . . . . . . . 109

5.10 Stationäres Fluoreszenzspektrum und Spektrum der transienten Absorption . . . . . . . . . . . . . . . . . . . . . 111

5.11 Spektrum der Emission aus A* . . . . . . . . . . . . . . 112

5.12 Differentielle Transmissionsspektren und Simulationen . . . . . . . 113

6.1 Zusammenfassung verschiedener Anisotropiemessungen . . . . . . 118

6.2 Verdeutlichung der Barrierenhöhen für den Protonentransfer und die Torsion . . . . . . . . . . . . . . . . . . . . . . . . . . . 123

6.3 Pump-Probe-Signal bei einer Anregungswellenlänge von $256 \mathrm{~nm}$ und einer Nachweiswellenlänge von $510 \mathrm{~nm}$. . . . . . . . . . . 126 



\section{Tabellenverzeichnis}

2.1 Zeitkonstanten aus exponentiellen Anpassungen an die Fluoreszenzsignale aus Arbeiten von Chattoraj et al. . . . . . . . . . . . 19

2.2 Zeitkonstanten aus exponentiellen Anpassungen an die Fluoreszenzsignale aus Arbeiten von Lossau et al . . . . . . . . . . . . . . 20

4.1 Exponentielle Anpassungszeiten an die Signale aus TCSPCExperimenten . . . . . . . . . . . . . . . 68

4.2 Anpassungsparameter der temperaturabhängigen Pump-ProbeSignale . . . . . . . . . . . . . . . . . . 70 70

4.3 Ergebnisse der LPSVD-Analyse . . . . . . . . . . . . . . . . . . 72 



\section{Danksagung}

Diese Arbeit wurde am Max-Planck-Institut für biophysikalische Chemie in der Arbeitsgruppe Biomolekulare und Chemische Dynamik durchgeführt unter der Anleitung von Priv.-Doz. Dr. Peter Vöhringer. An erster Stelle möchte ich Priv.-Doz. Dr. Peter Vöhringer für die Themenstellung, die stete Unterstützung und hilfreiche Betreuung dieser Arbeit danken. Die hervorragenden experimentellen Bedingungen in seiner Arbeitsgruppe trugen maßgeblich zum Erfolg dieser Arbeit bei.

Ein herzlicher Dank gilt Prof. Dr. Jürgen Troe für die Übernahme des Referates. Für die Übernahme des Korreferates bedanke ich mich nicht weniger bei Prof. Dr. Jörg Schroeder.

Der gesamten Arbeitsgruppe danke ich für die zahlreichen Hilfestellungen jedes einzelnen sowie für die gute Arbeitsatmosphäre. Insbesondere möchte ich Jaydev Jethwa hier aufführen, der bei der Lösung aller elektronischen Fragestellungen unentbehrlich war. Hervorzuheben sei an dieser Stelle auch Eveline Heinemann, die mit ihrem ausgesprochenen Organisationstalent das soziale Leben in der Arbeitsgruppe gestaltet hat.

Den Mitgliedern aller Werkstätten sei außerordentlich gedankt, denn ohne ihre Mithilfe wäre die Lösung vieler Probleme deutlich schwieriger gewesen. Im speziellen danke ich hierbei Wolfgang Sauermann und seinen Mitarbeitern, die immer schnelle und hervorragende Lösungen für optische Probleme hatten, sowie Manfred Schmidt und seinen Mitarbeitern für ihre konzeptionelle, qualitativ wertvolle und zügige Arbeit.

Für die vielen interessanten, wissenschaftlichen Diskussionen gilt großer Dank auch Dr. Wolfgang Winkler und Dr. Christoph Kappel sowie Marco T. Seidel, dessen Präsenz nicht nur hilfreich war, sondern auch für ausgesprochen gute Laune sorgte. Nicht zuletzt danke ich meiner Familie und meinen Freunden für ihre vielfältige Unterstützung. 



\section{Lebenslauf}

Am 27.03.1975 wurde ich, Kathrin Winkler, als Tochter von Doris Winkler, geb. Schulz, und Dr. Wolfgang Winkler in Greifswald geboren. Nach dem Besuch der Polytechnischen Oberschulen Georg Handke und Otto Grothewohl in Berlin von 1981 bis 1989 wechselte ich auf das Ratsgymnasium Stadthagen, auf dem ich im Mai 1994 die allgemeine Hochschulreife erlangte. Im Wintersemester 1994/95 immatrikulierte ich mich an der Georg-August-Universität Göttingen, an der ich im Oktober 1996 die Diplomvorprüfung bestand. Im Rahmen eines Stipendiums innerhalb des Educational Abroad Program des Kalifornischen Studienzentrums Göttingen studierte ich 1997 ein Jahr an der University of California, Santa Barbara. Ab Januar 1998 setzte ich das Chemiestudium an der Georg-AugustUniversität Göttingen fort. Ab April 1999 begann ich mit meiner Diplomarbeit am Max-Planck-Institut für biophysikalische Chemie Göttingen unter Anleitung von Priv.-Doz. Dr. Peter Vöhringer mit dem Thema „Ultraschneller Optischer Kerr-Effekt von Wasser und schwerem Wasser“. Im Februar 2000 erwarb ich das Diplom der Fakultät für Chemie Göttingen. Von März 2000 bis Februar 2002 war ich als wissenschaftliche Mitarbeiterin innerhalb des Forschungsvorhabens der Deutschen Forschungsgemeinschaft (DFG) „Transiente Anisotropie zur Dynamik der Übergangszustände und der Fragmente in impulsiv induzierten Bindungsbruchreaktionen in Flüssigkeiten" in der Arbeitsgruppe für Biomolekulare und Chemische Dynamik von Priv.-Doz. Dr. Peter Vöhringer beschäftigt. Seit Februar 2002 bin ich am Max-Planck-Institut für biophysikalische Chemie angestellt. In der Arbeitsgruppe Biomolekulare und Chemische Dynamik beschäftigte ich mich mit Untersuchungen zur ultraschnellen Dynamik des Grün Fluoreszierenden Proteins. 



\section{Publikationen}

- Kathrin Winkler, Jörg Lindner, Helge Bürsing and Peter Vöhringer, Ultrafast Raman-induced Kerr-effect of water: Single molecule versus collective motions, Journal of Chemical Physics, 2000, 113(11), 4674-4682

- Kathrin Winkler, Jörg Lindner, and Peter Vöhringer, Ultrafast depolarized Raman-response of water, OSA Trends in Optics and Photonics. 12th Int. Conf. Ultrafast Phenomena 2000, 43, pp. 513-515

- Jaydev Jethwa, Donald Ouw, Kathrin Winkler, Nicole Hartmann and Peter Vöhringer, Ultrafast proton-transfer and coherent wavepacket motion of electronically excited 1,8-dihydroxyanthraquinone in liquid benzyl alcohol solution, Zeitschrift fur Physikalische Chemie-International Journal of Research in Physical Chemistry \& Chemical Physics, 2000, 214 (Part 10), $1367-1381$

- Kathrin Winkler, Jörg Lindner, Vinod Subramaniam, Thomas M. Jovin and Peter Vöhringer, Ultrafast dynamics in the excited state of green fluorescent protein (wt) studied by frequency-resolved femtosecond pump-probe spectroscopy, Physical Chemistry Chemical Physics, 2002, 4 (6), 1072-1081

- Kathrin Winkler, Jörg Lindner and Peter Vöhringer, Low-frequency depolarized Raman-spectral density of liquid water from femtosecond optical Kerreffect measurements: Lineshape analysis of restricted translational modes, Physical Chemistry Chemical Physics, 2002, 4 (11), 2144-2155

- Kathrin Winkler, Marco Seidel, and Peter Vöhringer, Ultrafast Elementary Events in the Excited State of Wild-Type Green-Fluorescent Protein, Chemical Physics - Ultrafast Phenomena XIII, Editors: R. D. Miller, M. M. Murnane, N.F. Scherer, A. M. Weiner, Springer-Verlag Berlin Heidelberg 2003, pp. 611-613 